\author{
UNIVERSIDADE DE SÃO PAULO \\ ESCOLA DE ENGENHARIA DE SÃO CARLOS \\ INSTITUTO DE FÍSICA DE SÃO CARLOS \\ INSTITUTO DE QUÍMICA DE SÃO CARLOS
}

\title{
RELAXAÇÃO DIPOLAR ELÉTRICA FOTOINDUZIDA EM ALEXANDRITAS SINTÉTICA E NATURAL.
}

\section{USP/IFSC/SBI}

Rosa Maria Fernandes Scalvi

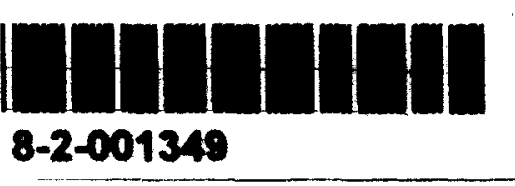

Tese apresentada à Área Interunidades do EESC, IFSC, IQSC, como parte dos requisitos para a obtenção do grau de "Doutor em Ciência e Engenharia de Materiais".

Orientador: Prof. Dr. Máximo Siu Li 
UNIVERSIDADE DE SÃO PAULO

Ciência e Engenharia de Materiais

Caixa Postal 369 - CEP 13560-970 - São Carlos-SP - Brasil Tel: (0xx16) 2739589/ Fax: (Oxx16) 2739777

E-mail: erica@if.sc.usp.br

MEMBROS DA COMISSÃO JULGADORA DA TESE DE DOUTORADO DE ROSA MARIA FERNANDES SCALVI, APRESENTADA A ÁREA INTERUNIDADES EM CIÊNCIA E ENGENHARIA DE MATERIAIS, DA EESCIFSC-IQSC, UNIVERSIDADE DE SÃO PAULO, EM O9/03/200O.

COMISSÃO JULGADORA:

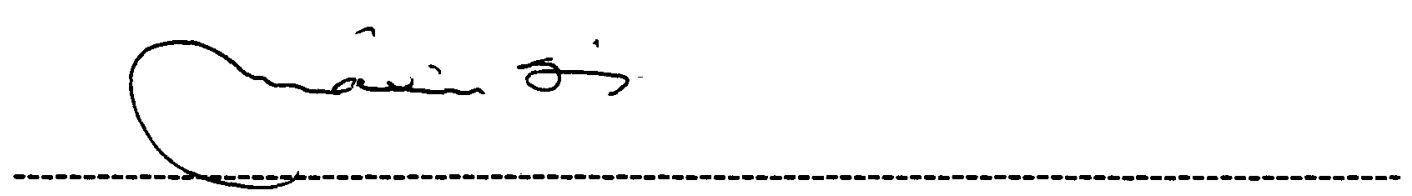

Prof. Dr. MÁXIMO SIU LI-Orientador (IFSC/USP)

PbArOsamion

Profa. Dra. REGINA HELENA PORTO FRANCISCO (IQSC/USP)

Trey Caturs

Prof. Dr. TOMAZ CATUNDA (IFSC/USP)

(mese

PROF. Dr. MARIO ERNESTO GIROLDO VALERIO (UFS)

Sor Eemas Lla Ala boy

PGOF. Dr. JOSÉ FERNANDO DIAIZZ CHUBACI (IF/USP)

IFSC-USP SERVICO DE BIBLIOTECA 


\section{Scalvi, Rosa Maria Fernandes}

Relaxação Dipolar Elétrica Fotoinduzida em Alexandrita Sintética e Natural, 2000

$154 p$

Tese ( doutorado )-Instituto de Física de São Carlos, 2000.

Orientador: Prof. Dr. Máximo Siu Li

1.Alexandrita. 2. Relaxação Dipolar 3. Fenômenos Fotoinduzidos I. Título 
Ao meu filho Marcelo, cuja paciência e compreensão durante esses anos foram fundamentais para a realização deste trabalho. 


\section{AGRADECIMENTOS:}

Ao Prof. Dr. Máximo Siu Li, pela orientação desse trabalho e pela compreensão e amizade

Ao Prof. Dr. Tomáz Catunda, pela gentileza no empréstimo da amostra sintética de alexandrita.

A Profa. Dra. Regina Porto Francisco e ao Prof. Dr. José Alberto Giacometti, pela contribuição dada durante o Exame de Qualificação.

A Profa. Dra. Lígia de Oliveira Ruggiero, pela ajuda desde as primeiras medidas no laboratório, pelas sugestões e discussões.

Ao Klaus Petersen Junior do Instituto de Geociências da USP, pelas sugestões e por ceder-me amostras naturais de alexandrita oriundas do estado de Goiás.

A Profa. Dra. Ana Regina Blak, pelas poucas, porém muito proveitosas discussões e sugestões.

Aos colegas do Laboratório: Antônio Carlos Castro, Fábio Simões de Vicente, Luis Humberto C. Andrade, Claúdia Cândido, Cristina Tereza Ribeiro e Sandra Messadeq, pela boa vontade e disposição em ajudar uns aos outros, dividindo além de equipamentos, seus conhecimentos.

Aos colegas Frederico Ayres de Oliveira Neto, do IFUSP, e Diógenes Reyes Ardila, do grupo de Crescimento de Cristais do IFSC, pela atenção e boa vontade em ajudar-me.

Aos funcionários: (técnicos) José Heraldo Gallo, Cássio, João Frigo, Augusto, (bibliotecárias) Mara, Cibele, Neusa e Betânia; (secretárias) Isabel Sartori, Érica Signini e Wladerez Caiado; e aos funcionários das oficinas mecânica $e$ de criogenia, pela atenção e boa vontade com que sempre fui recebida. E, aos técnicos Marcelo Francisco e Clever Chinaglia do CCDM-UFSCar.

Aos colegas do Departamento de Física Unesp- Bauru, pelo apoio e pelos afastamentos concedidos.

A CAPES e PRONEX pelo auxilio financeiro.

Ao CNPq, FINEP e FAPESP.

E, de forma muito especial, agradeço a Elisabete Aparecida Andrello Rubo, pelo apoio, sugestões, discussões e principalmente pela sua amizade incondicional; ao Luis Vicente de Andrade Scalvi, pela sua paciência, ajuda e, acima de tudo, sua compreensão e, a todos os meus familiares, pelo apoio e incentivo ao longo de minha vida, em especial minha mãe Irene, minha irmã Lydia Maria e minha sobrinha Mariana, que ajudaram a "segurar as pontas" nos momentos em que estive ausente. 
ÍNDICE:

I - ÍNDICE DE FIGURAS .................................................................................... III

II - ÍNDICE DE TABELAS......................................................................... VII

III - RESUMO ............................................................................................................................ IX

IV - ABSTRACT .................................................................................................................. X

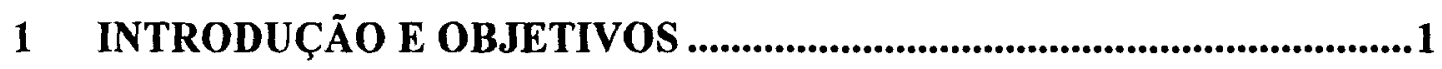

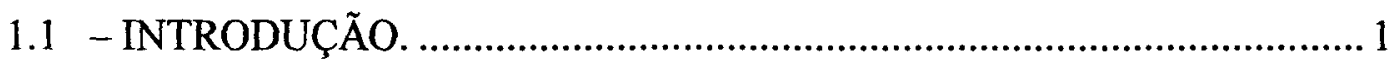

1.2 - OBJETIVOS DESTE TRABALHO ................................................. 9

2 CARACTERÍSTICAS DA ALEXANDRITA ............................................10

2.1 - O "EFEITO ALEXANDRITA"........................................................... 10

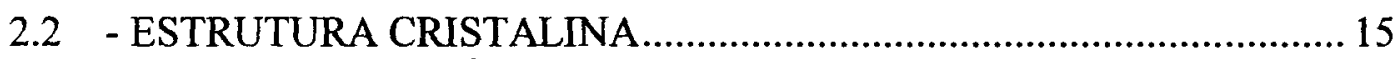

2.3 - PROPRIEDADES FÍSICAS E O LASER DE ALEXANDRITA.............. 18

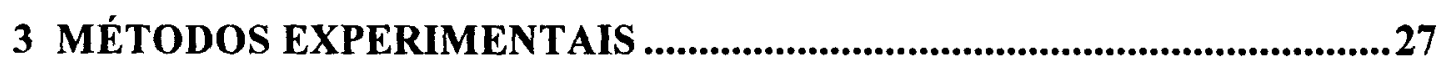

3.1 - PREPARAÇÃO DAS AMOSTRAS, MICROANÁLISE E ANÁLISE

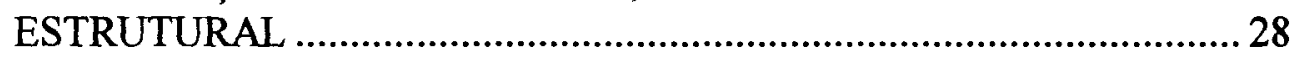

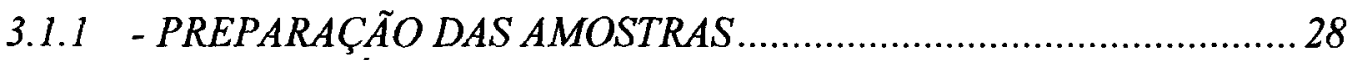

3.1.2 - MICROANÁLISE POR EDX/WDX ..................................................

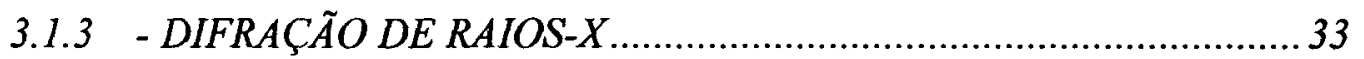

3.2 - TÉCNICAS EXPERIMENTAIS UTILIZADAS NA DETERMINAÇÃO DOS PARÂMETROS ESPECTROSCÓPICOS. ...................................... 34

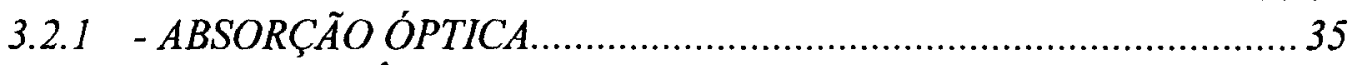

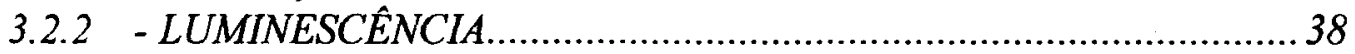

3.3 - CORRENTE DE DESPOLARIZAÇÃO TERMICAMENTE ESTIMULADA - CDTE .................................................................... 40

3.3 .1 - PRINCÍPIOS BÁSICOS .......................................................... 41

3.3.2 - CDTE FOTOINDUZIDA..........................................................

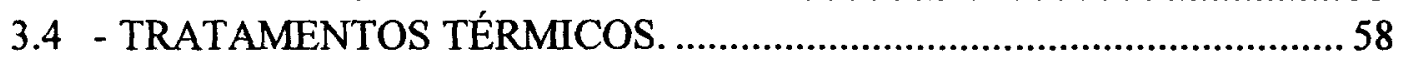

4 RESULTADOS EXPERIMENTAIS............................................................61

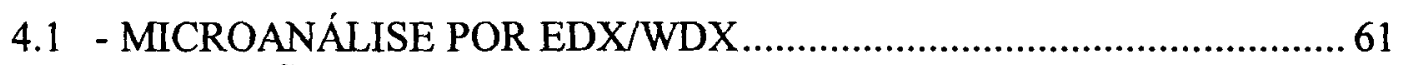

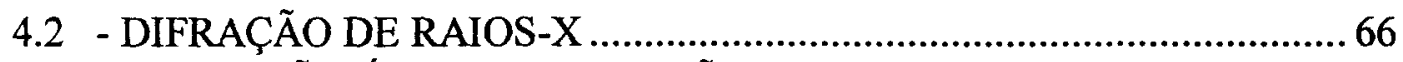

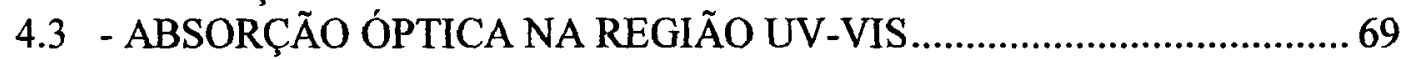

4.4 - ABSORÇÃO ÓPTICA NO INFRAVERMELHO ……………………..... 76

4.5 - LUMINESCÊNCIA ....................................................................... 78

4.6 - CORRENTE DE DESPOLARIZAÇÃO TERMICAMENTE
ESTIMULADA

4.6.1 - COMPORTAMENTO DAS BANDAS DE CDTE PARA AS AMOSTRAS

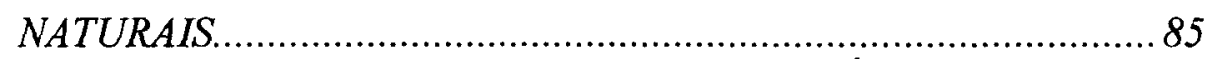

4.6.2 - MEDIDAS DE CDTE PARA A AMOSTRA SINTÉTICA..................95

4.7 - EFEITO DOS TRATAMENTOS TÉRMICOS ……………………….... 98

4.7.1 - CDTE APÓS OS TRATAMENTOS TÉRMICOS. ………………...... 99 
4.7.2 - ABSORÇÃO ÓPTICA APÓS TRATAMENTOS TÉRMICOS ........... 108

4.7.3 - LUMINESCENCIA APÓS TRATAMENTOS TÉRMICOS...............113

4.7.4 - DIFRAÇÃO DE RAIOS X EM FUNÇÃO DE TRATAMENTOS

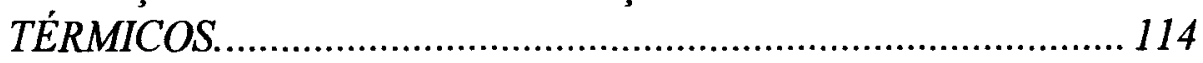

4.8 - CDTE FOTOINDUZIDA ………………………………………....... 117

4.8.1 - CDTEFI PARA A AMOSTRA SINTÉTICA …………................... 121

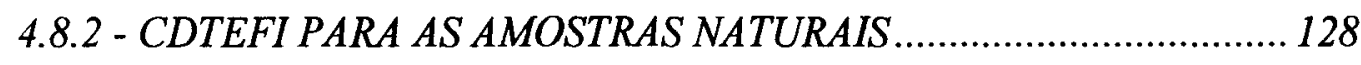

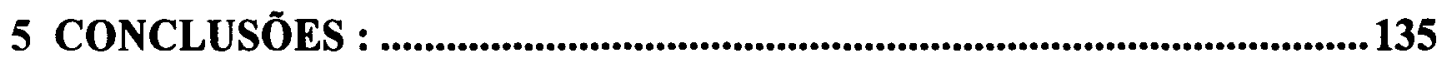

5.1 - IDENTIFICAÇÃO DAS AMOSTRAS................................................. 135

5.1.1 - COMPOSIÇÃO QUÍMICA E CARACTERIZAÇÃO ESTRUTURAL 135

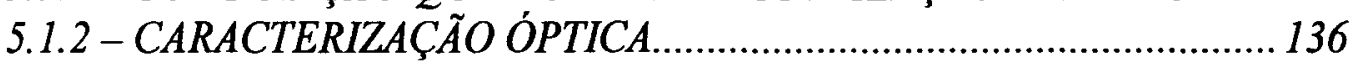

5.2 - CORRENTE DE DESPOLARIZAÇÃO TERMICAMENTE ESTIMULADA

5.3 - EFEITOS DOS TRATAMENTOS TÉRMICOS ……………………........ 139

5.4 - MEDIDAS DE CDTEFI ………………………………………...... 140

6 TRABALHOS FUTUROS..........................................................................142

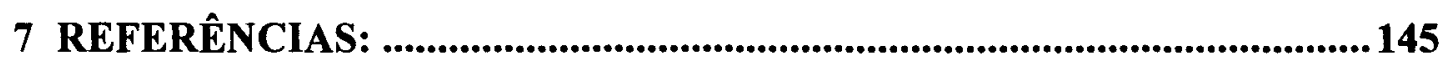


4.7.2 - ABSORÇÃO ÓPTICA APÓS TRATAMENTOS TÉRMICOS...........108

4.7.3 - LUMINESCÊNCIA APÓS TRATAMENTOS TÉRMICOS................113

4.7.4 - DIFRAÇÃO DE RAIOS X EM FUNÇÃO DE TRATAMENTOS TÉRMICOS.

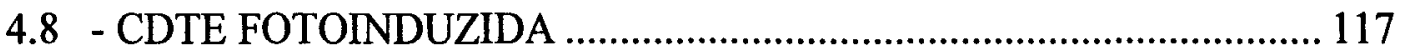

4.8.1 - CDTEFI PARA A AMOSTRA SINTÉTICA ………………….......... 121

4.8.2 - CDTEFI PARA AS AMOSTRAS NATURAIS ................................. 128

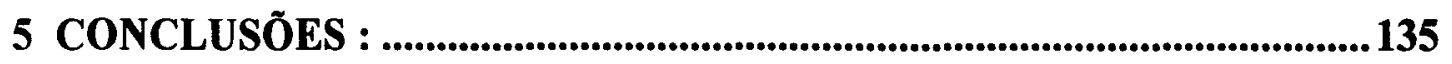

5.1 - IDENTIFICAÇÃO DAS AMOSTRAS.................................................. 135

5.1.1 - COMPOSIÇÃO QUIMICA E CARACTERIZAÇÃO ESTRUTURAL 135

5.1 .2 - CARACTERIZACẼO ÓPTICA .................................................. 136

5.2 - CORRENTE DE DESPOLARIZAÇÃO TERMICAMENTE ESTIMULADA

5.3 - EFEITOS DOS TRATAMENTOS TÉRMICOS

5.4 - MEDIDAS DE CDTEFI ............................................................... 140

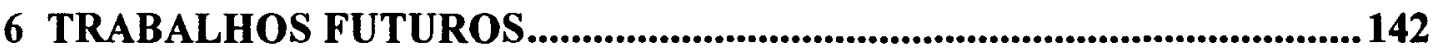

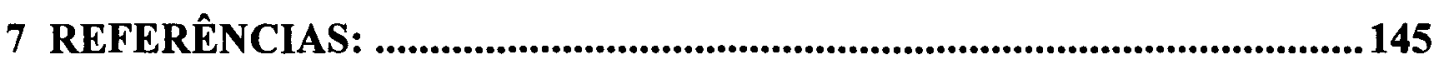




\section{$\underline{\underline{I}-\text { INDICE DE FIGURAS }}$}

FigURA 1 - ILUSTRAÇ̃̃o DO “EFEITO ALEXANDRITA" PARA UM CRISTAL NATURAL LAPIDADO. 12

FIGURA 2 - (A) ESTRUTURA DO CRISOBERILO COM A INDICAÇÃO DOS EIXOS A, B E C . (B)ESTRUTURA DO CRISOBERILO PROJETADA SOBRE (001), ADAPTADA DA REFERÊNCIA [8]. 16

FIGURA 3- ESPECTRO DE ABSORÇÃO DE ALEXANDRITA À TEMPERATURA AMBIENTE. PARA E $\|$ B, E $\|C, E\|$ A. ADAPTADO DA REFERÊNCIA [27]. .23

FIGURA 4- ESPECTRO DE LUMINESCÊNCIA DA ALEXANDRITA À TEMPERATURA AMBIENTE MOSTRANDO AS LINHAS $S_{1} E S_{2}$ E $R_{1} E R_{2}$. ADAPTADO DA REFERÊNCIA [28]. .23

FIGURA 5 - DIAGRAMA DE NÍVEIS DE ENERGIA PARA ÍONS $\mathrm{CR}^{3+}$ LOCALIZADOS SOBRE UM PLANO DE REFLEXÃO DE ALEXANDRITA. ADAPTADO DA REFERÊNCIA [5]. ..24

FIGURA 6- DIAGRAMA ESQUEMÁTICO DO SISTEMA DE MEDIDAS DE LUMINESCÊNCIA. EXTRAÍDO DA REFERÊNCIA [69].

FIGURA 7 - GRÁFICO DA FUNÇÃO DE LANGEVIN L(X) .43

FIGURA 8- (A) REPRESENTAÇÃo ESQUEMÁTICA DO EXPERIMENTO DE CDTE, MOSTRANDO OS PARÂMETROS CAMPO ELÉTRICO (E), TEMPERATURA (T) E CORRENTE (I) , EM FUNÇÃO DO TEMPO. (B) ESQUEMA DO MOVIMENTO DOS DIPOLOS NA AMOSTRA, CORRESPONDENDO A SITUAÇÃO FÍSICA DESCRITA EM (A). FIGURA ADAPTADA DA REFERÊNCIA [78].

FIGURA 9- ESQUEMA DE MEDIDAS DE CDTEFI. (I) INCIDÊNCIA DE LUZ QUANDO O SISTEMA DE DIPOLOS ESTÁ PREVIAMENTE POLARIZADO $\left(\mathrm{T}_{\mathrm{P}}=300 \mathrm{~K}\right)$ E CONGELADO, (II) INCIDÊNCIA DE LUZ QUANDO O SISTEMA DE DIPOLOS ESTÁ PREVIAMENTE NÃO POLARIZADO E CONGELADO $\left(\mathrm{T}_{\mathrm{P}}=77 \mathrm{~K}\right)$.

FIGURA 10- ESQUEMA INDICANDO AS DIREÇÕES DA INCIDÊNCIA DE LUZ E APLICAÇÃO DO CAMPO ELÉTRICO NA AMOSTRA.

FIGURA 11- MICROGRAFIA DA AMOSTRA DE ALEXANDRITA NATURAL (AN4) MOSTRANDO FASES DISTINTAS: (A) MATRIZ, (B) QUARTZO E (C) MICA

Figura 12- (A) Difratograma de RaIOS-X PARA A AMOSTRA NATURAL AN4 E REPRESENTAÇÃO DAS TRÊS LINHAS MAIS INTENSAS PARA UMA AMOSTRA NATURAL E UMA AMOSTRA SINTÉTICA OBTIDAS NOS FICHÁRIOS JCPDS [88]. (B) DIFRATOGRAMA DE RAIOS X PARA UMA AMOSTRA SINTÉTICA OBTIDO A PARTIR DO PROGRAMA "POWDER CELL". 
FIGURA 13 - ESPECTROS DE ABSORÇÃo ÓPTICA DAS AMOSTRAS SINTÉTICAS (AS1), NATURAL (AN3) E DA REFERÊNCIA [27] A 300K E 77K. AS INSERÇõES MOSTRAM AS LINHAS VIBRÔNICAS LATERAIS DA BANDA A DE FORMA AMPLIADA

FIGURA 14 - ESPECTROS DE ABSORÇÃO ÓPTICA NO INFRAVERMELHO PARA AS1 E AN5, A $300 \mathrm{~K}$ .77

FIGURA 15 - ESPECTROS DE EMISSÃO DAS AMOSTRAS DE ALEXANDRITA NATURAL (AN3) E SINTÉTICA (AS1), OBTIDOS À TEMPERATURA AMBIENTE, ATRAVÉS DE EXCITAÇÃO COM MLUV DO LASER DE KR ${ }^{+}$ .79

FIGURA 16 - ESQUEMA DA FORMAÇÃO DE DIPOLOS NA ALEXANDRITA: (A) DETALHES DE UM SÍtTo $\mathrm{AL}_{2}$ (LOCALIZADO NUM PLANO DE REFLEXÃO). (B) SÍtTO $\mathrm{AL}_{1}$ (LOCALIZADO SOBRE UM CENTRO DE INVERSÃO). ADAPTADO DA REFERÊNCIA [8].

Figura 17- MEDIDAS DE CDTE PARA amostra AN1. PARA CURVA EM VERMELHO, $T_{P}=297 \mathrm{~K}$ E PARA CURVA EM PRETO, $T_{\mathrm{p}}=170 \mathrm{~K}$. $E_{\mathrm{P}}=4,6 \mathrm{KV} / \mathrm{CM}$ PARA AMBAS AS CURVAS.

FIGURA 18 - COMPORTAMENTO DA ÁREA SOB A BANDA DE CDTE EM FUNÇÃo DO CAMPO ELÉTRICO DE POLARIZAÇÃO PARA A AMOSTRA NATURAL AN2

FIGURA 19 - MEDIDAS DE CDTE PARA A AMOSTRA AN3 . (A) CURVA EXPERIMENTAL PARA $T_{P}=278 \mathrm{~K}$. (B) CURVA EXPERIMENTAL PARA $T_{P}=189 \mathrm{~K}$. AS CURVAS EM VERMELHO E AZUL REPRESENTAM O AJUSTE TEÓRICO PELO MÉTODO DE HAVRILIAK-NEGAMI. .90

FIGURA $20-$ CDTE PARA A AMOSTRA AN3 COM $T_{\mathrm{p}}=189 \mathrm{~K}, \mathrm{E}_{\mathrm{p}}=6,9 \mathrm{KV} / \mathrm{CM}$ E ELETRODOS DE OURO.

FIGURA 21- CDTE PARA A AMOSTRA AS1 .(A) CURVA EXPERIMENTAL PARA $T_{\mathrm{p}}=285 \mathrm{~K}$. (B)CURVA EXPERIMENTAL PARA $T_{\mathrm{P}}=167 \mathrm{~K}$. PARA AMBAS $\mathrm{E}_{\mathrm{P}}=6,9 \mathrm{KV} / \mathrm{CM}$. As CURVAS VERMELHA E AZUL REPRESENTAM O AJUSTE TEÓRICO PELO MÉTODO DE HAVRILIAK-NEGAMI. .96

FIGURA 22- MEDIDAS DE CDTE PARA A AMOSTRA AN5 SEM TRATAMENTO TÉRMICO E APós TT1 $\left(700{ }^{\circ} \mathrm{C}-5 \mathrm{MIN}\right)$, TT2 $\left(800{ }^{\circ} \mathrm{C}-5 \mathrm{MIN}\right)$, TT3 $\left(900{ }^{\circ} \mathrm{C}-5 \mathrm{MIN}\right)$, TT4 $\left(1000{ }^{\circ} \mathrm{C}-5 \mathrm{MIN}\right)$ E TT5 $\left(1000^{\circ} \mathrm{C}-5\right.$ HORAS $)$. EM TODAS AS MEDIDAS $\mathrm{T}_{\mathrm{P}} \cong 185 \mathrm{~K}$ 101

Figura 23 - MEdidAs de CDTE PaRa a AMOSTRA AN5 APós TT3 $\left(900{ }^{\circ} \mathrm{C}-5 \mathrm{MIN}\right)$, TT4 $\left(1000{ }^{\circ} \mathrm{C}-5 \mathrm{MIN}\right)$ E TT5 $\left(1000{ }^{\circ} \mathrm{C}-5\right.$ HORAS $)$. EM TODAS AS MEDIDAS $\mathrm{T}_{\mathrm{p}} \cong$ $175 \mathrm{~K}$ 101 
FIGURA 24 - MEDIDAS DE CDTE PARA AN5 SEM TRATAMENTO TÉRMICO. As CURVAS EM VERMELHO E AZUL REPRESENTAM AS DISTRIBUIÇÕES DOS PARÂMETROS DE RELAXAÇÃO OBTIDAS A PARTIR DO MÉTODO DE NAVRILIAK-NEGAMI. 103

FiguRa 25 - CDTE PARA A AMOSTRA AN5 APÓS TT1 (700 $\left.{ }^{\circ} \mathrm{C}-5 \mathrm{MIN}\right)$. A CURVA EM VERMELHO REPRESENTA A DISTRIBUIÇÃO OBTIDA ATRAVÉS DO MÉTODO DE HAVRILIAK-NEGAMI. 104

FIgURA 26 - CDTE PARA A AMOSTRA AN5 APÓS TT3 ( $\left.900{ }^{\circ} \mathrm{C}-5 \mathrm{MIN}\right)$. AS CURVAS EM VERMELHO E AZUL REPRESENTAM A DISTRIBUIÇÃO OBTIDA ATRAVÉS DO MÉTODO DE HAVRILIAK-NEGAMI. 104

FIgURA 27 - CDTE PARA A AMOSTRA AN5 APÓS TT4 (1000 $\left.{ }^{\circ} \mathrm{C}-5 \mathrm{MIN}\right)$. As CURVAS EM VERMELHO E AZUL REPRESENTAM A DISTRIBUIÇÃO OBTIDA ATRAVÉS DO MÉTODO DE HAVRILIAK-NEGAMI. 105

Figura 28 - CDTE PARA A AMOSTRA AN5 APÓS TT5 (1000 $\left.{ }^{\circ} \mathrm{C}-5 \mathrm{H}\right)$. AS CURVAS EM VERMELHO E AZUL REPRESENTAM A DISTRIBUIÇÃO OBTIDA ATRAVÉS DO MÉTODO DE HAVRILIAK-NEGAMI. 105

FIGURA 29 - ESPECTROS DE ABSORÇÃO ÓPTICA NO UV-VIS PARA AN5 SEM TRATAMENTO TÉRMICO E APÓS TT1, TT2, TT3, TT4 E TT5. 108

Figura 30 - ESPECTROS DE ABSORÇÃo ÓPTICA, À TEMPERATURA AMBIENTE, PARA A AMOSTRA NATURAL AN5 APÓS OS TRATAMENTOS TÉRMICOS TT1, TT2, TT3, TT4 E TT5 E SEM TRATAMENTO TÉRMICO .112

FIGURA 31 - ESPECTROS DE LUMINESCÊNCIA, À TEMPERATURA AMBIENTE, PARA AN5 SUBMETIDA AOS TRATAMENTOS TÉRMICOS TT1, TT2, TT3, TT4, TT5 E SEM TRATAMENTO TÉRMICO. .113

Figura 32 - Difratogramas de RaIOS X PARA A AMOSTRA NATURAl AN4. (A) ANTES DOS TRATAMENTOS TÉRMICO, (B) APÓS TT1 $=700{ }^{\circ} \mathrm{C}$ POR 15 MINUTOS E (C) APÓS TT5' $=1000^{\circ} \mathrm{C}$ POR 5 HORAS. 115

FIGURA 33- FotOGRAFIAS DAS AMOSTRAS DE ALEXANDRITA NATURAL E SINTÉTICA ILUMINADAS COM LUZ DE LÂMPADA FLUORESCENTE E COM LASER DE KR SINTONIZADO NO MULTILINHAS ULTRAVIOLETA 118

FIGURA 34 - ESPECTRO DE ABSORÇÃo ÓPTICA DA AMOSTRA SINTÉTICA DE ALEXANDRITA MOSTRANDO AS FAIXAS DE COMPRIMENTOS DE ONDA UTILIZADOS NAS MEDIDAS DE CDTEFI. 120

FIGURA 35 - CDTEFI PARA A AMOSTRA AS1 $\operatorname{COM} T_{\mathrm{P}}=297 \mathrm{~K}, E_{\mathrm{p}}=7,0 \mathrm{KV} / \mathrm{CM}$ E $\mathrm{B}=0,08$ $\mathrm{K} / \mathrm{s}$, INCIDINDO LUZ MLUV À TNL 122

FIGURA 36- CDTEFI PARA A AMOSTRA AS1, COM E $E_{\mathrm{p}}=7,0 \mathrm{KV} / \mathrm{CM}$ E LUZ MLUV POR 2, 5 E 10 MINUTOS EM $T_{P}=77 \mathrm{~K}, B=0,08-0,12 \mathrm{~K} / \mathrm{s}$. 124 
FIGURA 37 - CDTEFI PARA A AMOSTRA AS1, COM E $\mathrm{P}_{\mathrm{P}}=7,0 \mathrm{KV} / \mathrm{CM}$ E LUZ MLVI POR 2, 5 E 15 MINUTOS EM $T_{P}=77 \mathrm{~K}, B=0,08 \mathrm{~K} / \mathrm{S}$. 124

FIGURA 38 - CDTEFI PARA A AMOSTRA AS1, COM E $\mathrm{E}_{\mathrm{P}}=7,0 \mathrm{KV} / \mathrm{CM}$ E MLBG POR 2, 10 E 15 MINUTOS EM $T_{P}=77 \mathrm{~K}, B=0,08-0,09 \mathrm{~K} / \mathrm{s}$.

FIGURA 39 - CDTEFI PARA A AMOSTRA AS1, COM $\mathrm{E}_{\mathrm{p}}=7,0 \mathrm{KV} / \mathrm{CM}$ E MLRD POR 2, 5 E 15 MINUTOS EM $T_{P}=77 \mathrm{~K}, B=0,06-0,08 \mathrm{~K} / \mathrm{s}$. .125

FIguRA 40 - Posições das BANDAS DE CDTE REFERENTES AO PROCESSO DE FORMAÇÃO DAS BANDAS COM IRRADIAÇÃO POR 5 MINUTOS, NO MLUV, MLVI, MLBG E MLRD.

Figura 41 - CDTEFI PARA AMOSTRA AN3 COM $T_{\mathrm{P}}=280 \mathrm{~K}, \mathrm{E}_{\mathrm{p}}=6,9 \mathrm{KV} / \mathrm{CM}$ E $\mathrm{B}=0,08 \mathrm{~K} / \mathrm{S}$, COM LUZ MLUV (PROCESSO I). 130

FIGURA 42 - CDTEFI PARA A AMOSTRA AN3 $\operatorname{com} \mathrm{T}_{\mathrm{P}}=83 \mathrm{~K}, \mathrm{E}_{\mathrm{P}}=6,9 \mathrm{KV} / \mathrm{CM} \mathrm{E}$ $\mathrm{B}=0,08 \mathrm{~K} / \mathrm{S}$ (PROCESSO II). 130

FIGURA 43 - CDTE FOTOINDUZIDA PARA AN3 COM ELETRODOS DE OURO, COM $\mathrm{T}_{\mathrm{P}}=190 \mathrm{~K}, \mathrm{E}_{\mathrm{P}}=6,9 \mathrm{KV} / \mathrm{CM}$ E B $=0,09 \mathrm{~K} / \mathrm{S}$ (PROCESSO I). 131

FIGURA 44 - CDTE FOTOINDUZIDA PARA AN3 COM ELETRODOS DE OURO, COM $\mathrm{T}_{\mathrm{P}}=83 \mathrm{~K}, \mathrm{E}_{\mathrm{P}}=6,9 \mathrm{KV} / \mathrm{CM} \mathrm{E} \mathrm{B}=0,08 \mathrm{~K} / \mathrm{S}$ (PROCESSO II) 132

FIGURA 45 - CDTE FOTOINDUZIDA PARA AN5 COM ELETRODOS DE TINTA PRATA, $\mathrm{T}_{\mathrm{P}}=186 \mathrm{~K} \mathrm{E} \mathrm{B}=0,08 \mathrm{~K} / \mathrm{S}$ (PROCESSO I). 133 


\section{II - ÍNDICE DE TABELAS}

TABELA 1 - ALGUNS RESULTADOS OBTIDOS COM MEDIDAS DE EPR RELACIONANDO A MUDANÇA DE COR COM A CONCENTAÇÃO DE $\mathrm{CR}^{3+}$ E A TAXA RELATIVA DE $\mathrm{CR}^{3+}$ NOS SÍTIOS $\mathrm{AL}_{2}$ (LOCALIZADOS NUM PLANO DE REFLEXÃO) E AL NUM CENTRO DE INVERSÃO). EXTRAÍDO DA REFERÊNCIA [13].

TABELA 2 - POSIÇÕES OCUPADAS PELOS ÁTOMOS NA ESTRUTURA DO CRISOBERILO EXTRAÍDO DA REFERÊNCIA [37]................................................................... 17

TABELA 3- PROPRIEDADES FíSICAS DA ALEXANDRITA OBTIDAS NA LITERATURA. .......19

TABELA 4 - PROPRIEDADES DO LASER DE ALEXANDRITA COMPARADAS A OUTROS LASERES. $\Delta \lambda$ : LARGURA DA BANDA A MEIA ALTURA DA EMISSÃO; $\sigma_{\mathrm{E}}$ SEÇÃO DE CHOQUE DA EMISSÃO ESTIMULADA; N: ÍNDICE DE REFRAÇ̃̃O (PARA $\lambda=250 \mathrm{NM}$ ); $\varepsilon$ : PERDA POR ESPALHAMENTO; $\sigma$ : TEMPO DE VIDA DA EMISSÃO ESPONTÂNEA........20

TABELA 5- CARACTERÍSTICAS MACROSCÓPICAS DAS AMOSTRAS UTLLIZADAS E TÉCNICAS EXPERIMENTAIS A QUE FORAM SUBMETIDAS. "AN" REFERE-SE AS AMOSTRAS NATURAIS E “AS” A AMOSTRA SINTÉTICA..........................................30

TABELA 6- VÁRIOS TERMOS USADOS PARA ABSORÇãO. EXTRAÍDO DA REFERÊNCIA [39]. .37

TABELA 7 - COMPOSIÇÃo QUímicA PARCIAL DAS AMOSTRAS DE ALEXANDRITAS NATURAIS E SINTÉTICA OBTIDA ATRAVÉS DAS MICROANÁLISES POR EDX E WDX. A PARTIR DE 5 ÁREAS DIFERENTES DA MATRIZ DE ALEXANDRITA (REGIÃO A NA FIGURA 11). A CONCENTRAÇÃO DOS ELEMENTOS FOI MEDIDA EM PORCENTAGEM EM ÁTOMOS $(A T . \%)$ .64

TABELA 8- RESUlTADOS DAS MEDIDAS DE ABSORÇÃo ÓPTICA, NO VISIVEL, OBTIDOS À TEMPERATURA AMBIENTE. $\lambda$ INDICA AS POSIÇÕES DE MÁXIMOS DE ABSORÇÃO, $\alpha$ É O COEFICIENTE DE ABSORÇÃO CALCULADO A PARTIR DA EQUAÇÃO (5) E $\Delta \lambda$ É A LARGURA A MEIA ALTURA DA BANDA DE ABSORÇÃO. .74

TABela 9 - Posições daS liNHAS R NOS Sítios localizados NUM PLANO DE REFLEXÃO $\left(R_{1} E R_{2}\right)$ E DAS LINHAS $S$ NOS SÍTIOS LOCALIZADOS NO CENTRO DE INVERSÃO $\left(\mathrm{S}_{1}\right.$ E $\left.\mathrm{S}_{2}\right)$ PARA AS AMOSTRAS AS1, AN3 E DA REFERÊNCIA [28].......80

TABELA 10- PARÂMETROS DE RELAXAÇÃo OBTIDOS PARA AS1 E AN3 ATRAVÉS DO AJUSTE POR HAVRILIAKI-NEGAMIN. $T_{M}$ É A TEMPERATURA MÁXIMA DE CADA UMA DAS DISTRIBUIÇÕES EM [K]; E É É A ENERGIA DE ATIVAÇÃO EM [EV]; $\tau_{0}$ É O TEMPO DE RELAXAÇÃO $\left(\times 10^{-14}\right)$ EM [s] E Q É A CARGA TOTAL DE POLARIZAÇÃO $\left(\mathrm{X} 10^{-10}\right)$ EM $\left[\mathrm{C}^{-1}\right]$. .97 
TABela 11 - Resultados obTidos a PaRTIR DAS MEDIDAS DE CDTE PARA A AMOSTRA AN5 ANTES E APÓS OS TRATAMENTOS TÉRMICOS. 102

TABELA 12 - PARÂMETROS DE RELAXAÇÃo OBTIDOS PARA AN5, ANTES E APÓS OS TRATAMENTOS TÉRMICOS, ATRAVÉS DO AJUSTE POR HN. $T_{M} E$ É TEMPERATURA MÁXIMA DE CADA UMA DAS DISTRIBUIÇÕES EM [K]; $E_{A}$ É A ENERGIA DE ATIVAÇÃO EM [EV]; $\tau_{0}$ É O TEMPO DE RELAXAÇÃO $\left(X 10^{-14}\right)$ EM [S] . 106

TABELA 13 - RESULTADOS DAS MEDIDAS DE ABSORÇÃO ÓPTICA (UV-VIS) OBTIDOS À TEMPERATURA AMBIENTE, APÓS OS TRATAMENTOS TÉRMICOS DE AN5. $\lambda$ SIGNIFICA AS POSIÇÕES DE MÁXIMOS DE ABSORÇÃO, $\alpha$ O COEFICIENTE DE ABSORÇÃO ÓPTICA E $\Delta \lambda$ É A LARGURA A MEIA ALTURA DA BANDA DE ABSORÇ̃̃o 109 


\section{III - RESUMO}

Realizamos a caracterização elétrica de alexandrita $\left(\mathrm{BeAl}_{2} \mathrm{O}_{4}: \mathrm{Cr}^{3+}\right)$, nas formas sintética e natural, através de medidas de Corrente de Despolarização Termicamente Estimulada (CDTE). Obtivemos evidências conclusivas do fenômeno de relaxação dipolar em ambos os tipos de amostra, e que as curvas experimentais devem ser ajustadas por uma distribuição contínua dos parâmetros de relaxação. Para a amostra sintética a banda de CDTE está centralizada em torno de $179 \mathrm{~K}$ e para as naturais em 187 à 195K. Utilizando o método de Havriliak-Negami são necessárias duas distribuições continuas de $\mathrm{E}_{\mathrm{a}}$ e $\tau_{0}$ para ajustar as curvas experimentais, sendo que uma delas, em torno de $177 \mathrm{~K}$, com $E_{a} \cong 0,56 \mathrm{eV}$ e $\tau_{0} \cong 1,2 \times 10^{-14} \mathrm{~s}$ está presente em ambos os tipos de amostras. As bandas de CDTE são atribuídas a dipolos do tipo impureza-vacância de oxigênio ou a deformação local da estrutura causada pela diferença de raio iônico entre os íons $\mathrm{Cr}^{3+}(0,615 \AA)$ e $\mathrm{Al}^{3+}(0,535 \AA)$.

Também realizamos medidas de CDTE fotoinduzidas, onde as amostras são irradiadas com um laser sintonizado em comprimentos de onda entre 337,5 e $676,4 \mathrm{~nm}$. Verificamos que as bandas de CDTE podem ser "destruídas" ou "criadas" com a incidência de luz com diferentes condições iniciais de polarização.

Para ajudar a interpretação dos resultados de CDTE nós usamos outras técnicas de caracterização, tais como Absorção Óptica, Luminescência, Difração de Raios X e microanálises de EDX e WDX. Todas estas técnicas foram também aplicadas às amostras naturais após tratamentos térmicos consecutivos. 


\section{IV - ABSTRACT}

We have done electrical characterization of natural and synthetic alexandrite $\left(\mathrm{BeAl}_{2} \mathrm{O}_{4}: \mathrm{Cr}^{3+}\right)$, using the thermally stimulated depolarization current (TSDC) technique. We have obtained conclusive evidences of dipole relaxation in both kinds of samples. Besides, the experimental data must be fitted by a continuous distribution of relaxation parameters. For the synthetic sample, TSDC band has a peak about $179 \mathrm{~K}$ and for natural samples, TSDC bands have peaks about $187 \mathrm{~K}$ at $195 \mathrm{~K}$. Using Havriliak-Negami method, we need two continuous distributions of activation energy $\left(E_{a}\right)$ and relaxation time constant $\left(\tau_{0}\right)$ to fit experimental data. One of these two curves, centered at $177 \mathrm{~K}$, is present for both kinds of samples and has $\mathrm{E}_{\mathrm{a}} \cong 0.56 \mathrm{eV}$ and $\tau_{0} \cong 1.2 \times 10^{-14} \mathrm{~s}$. TSDC bands are attributed to impurity-oxygen vacancy dipoles or local structure deformation caused by the difference between ionic radius of $\mathrm{Cr}^{3+}(0.615 \AA)$ and $\mathrm{Al}^{3+}(0.535 \AA)$ ions.

We have also carried out photo-induced TSDC, where samples are irradiated with a tunable laser with wavelength from $337.5 \mathrm{~nm}$ to $676.5 \mathrm{~nm}$. We have observed that TSDC bands may be destroyed or created with illumination from different polarization conditions.

To help the interpretation of TSDC results we have used other techniques of characterization such as optical absorption, luminescence, X-ray diffraction, besides EDX and WDX microanalyses. All of these techniques were also applied to natural samples after consecutive annealing. 


\section{INTRODUCÃ̃O E OBJETIVOS}

\section{1 - INTRODUÇÃO.}

Alexandrita, nome comum usado para o crisoberilo dopado com cromo $\left(\mathrm{BeAl}_{2} \mathrm{O}_{4}: \mathrm{Cr}^{3+}\right)$, é uma gema rara e preciosa que apresenta propriedades peculiares, sendo a mais atraente delas a sua capacidade em mudar de cor, passando do verde na luz do dia ao vermelho quando incidimos luz artificial. Esse fenômeno é descrito na literatura como "efeito alexandrita" e nas últimas décadas tem sido muito estudado $[1,2,3]$. A alexandrita tornou-se tecnologicamente importante a partir de 1974, quando foi possível obtê-la na forma sintética, crescida pelo método de Czochralsky, como um material ativo para laser com caracteristicas muito superiores a outros tipos de materiais, conforme descrito na literatura [4,5]. Um outro fator interessante no estudo desse material é o fato do Brasil ser, atualmente, um dos maiores fornecedores de crisoberilo e alexandrita, juntamente com o Sri Lanka, sendo que o Brasil apresenta produções mais promissoras com lavras, principalmente, nos estados de Minas Gerais, Bahia e Espírito Santo [6,7].

Esse material pertence ao sistema cristalino ortorrômbico e ao grupo espacial Pnma $\left(D_{2 h}{ }^{16}\right)$. Sua estrutura cristalina foi determinada pela primeira vez em 1926 por BRAGG \& BROWN e refinada por FARREL em 1963 [8]. A estrutura do crisoberilo é hexagonal com empacotamento compacto $(h c p)$, porém distorcida, de íns de oxigênio, com íons $\mathrm{Al}^{3+}$ e $\mathrm{Be}^{2+}$ ocupando sítios octaédricos e tetraédricos respectivamente. As distorções de uma estrutura $h c p$ exata de íons de oxigênio 
deslocados em relação ao eixo c causam o aparecimento de dois sítios coordenados octaedricamente: $\mathrm{Al}_{1}$, situado num centro de inversão e $\mathrm{Al}_{2}$, localizado num plano de reflexão. Sabe-se que $\mathrm{Al}_{2}$, por ser maior, é preferencialmente ocupado pelos íons $\mathrm{Cr}^{3+}$ e é o principal responsável pelas propriedades ópticas da alexandrita. Os espectros de emissão e absorção óptica têm sido investigados em diferentes condições, com ou sem polarização ao longo dos eixos cristalográficos e ainda em função de variações de pressão e temperatura, por exemplo $[9,10,11]$.

Entretanto, a forma exata como ocorre a distribuição dos íons $\mathrm{Cr}^{3+}$ nos dois sítios distintos, $\mathrm{Al}_{1}$ e $\mathrm{Al}_{2}$, é desconhecida. Outras técnicas, além de absorção e emissão óptica, têm sido utilizadas no estudo de alexandritas, como Ressonância Paramagnética Eletrônica (EPR) [12,13,14] e Ressonância Magnética Nuclear (NMR) [15,16,17,18]. Medidas de EPR reportadas recentemente por RAGER et al[13] indicam que a distribuição de $\mathrm{Cr}^{3+}$ nos dois sítios de simetrias diferentes depende das concentrações desse íon na matriz de crisoberilo e também que essa distribuição, influencie na intensidade de mudança de cor, ou seja, no "efeito alexandrita". No trabalho de RAGER et al [13] são mencionados alguns resultados a respeito da taxa de concentrações relativas de $\mathrm{Cr}^{3+}$ nos sítios $\mathrm{Al}_{1}$ e $\mathrm{Al}_{2}$ reportados por diversos outros autores, como por exemplo, os resultados de BUKIN et al [19] indicando que para um aumento da concentração de $0,01 \%$ para $0,25 \%$ em peso de $\mathrm{Cr}_{2} \mathrm{O}_{3}$, a fração de $\mathrm{Cr}^{3+}$ nos sítios $\mathrm{Al}_{2}$ diminui de $76 \%$ para $65 \%$, no caso de alexandritas sintéticas e, em alexandritas naturais, com 0,15 e $0,5 \%$ em peso de $\mathrm{Cr}_{2} \mathrm{O}_{3}$, BUKIN et al [19]determinaram a fração de $\mathrm{Cr}^{3+}$ em $\mathrm{Al}_{2}$ como $81 \%$ e $79 \%$, respectivamente. Entretanto, de acordo com RAGER et al [13], a diminuição de $\mathrm{Cr}^{3+}$ em $\mathrm{Al}_{2}$ com o aumento de $\mathrm{Cr}_{2} \mathrm{O}_{3}$ observada por BUKNN et al não é consistente com os dados de 
FORBES et al [14] que deduziram, a partir de medidas de EPR, uma fração constante em torno de $78 \%$ de $\mathrm{Cr}^{3+}$ nos sítios $\mathrm{Al}_{2}$ para duas amostras de alexandritas crescidas pelo método de Czochralsky contendo 0,15 e $0,44 \%$ em peso de $\mathrm{Cr}_{2} \mathrm{O}_{3}$. Ainda de acordo com RAGER [13], PESTRYAKOV et al [20] observaram uma fração aproximadamente constante de $79-80 \%$ de $\mathrm{Cr}^{3+}$ nos sítios $\mathrm{Al}_{2}$ para diferentes amostras de alexandrita crescidas pelo método de Czochralsky. Além disso, muitas questões continuam sendo levantadas e investigadas a respeito das propriedades e características da alexandrita e muitos trabalhos têm sido apresentados, baseados principalmente na investigação de suas propriedades ópticas, magnéticas e termomecânicas mas, sem fazer nenhuma alusão às propriedades elétricas desse material.

Diante disso, apresentamos neste trabalho evidências conclusivas da ocorrência do fenômeno de relaxação dipolar elétrica que pode ser detectado através da técnica de Corrente de Despolarização Termicamente Estimulada- CDTE $[21,22,23,24]$. Essa técnica tem sido utilizada no estudo de muitos materiais, tanto dielétricos, como cristais iônicos e polímeros, havendo até trabalhos que reportam a utilização de CDTE em semicondutores. Nos processos de polarização e despolarização desses materiais, diversos tipos de fenômenos podem estar envolvidos como, por exemplo, orientação e desorientação de defeitos dipolares, distribuição não uniforme de portadores de carga iônica ou eletrônica, deslocamento de defeitos iônicos (vacâncias ou intersticiais) sobre distâncias macroscópicas e injeção de elétrons a partir dos eletrodos para dentro da amostra [25]. Outro tipo de fenômeno que pode estar envolvido nesses processos é a relaxação dipolar fotoinduzida, com a aplicação simultânea de um campo elétrico e irradiação da amostra. De forma geral, o estudo de fenômenos dipolares em sólidos envolve três pontos básicos: 
1) a origem da formação de dipolos no material:

Alguns sistemas dipolares podem ser, por exemplo, os dipolos formados pelas próprias impurezas presentes no material, como os defeitos moleculares substitucional $\left(\mathrm{OH}, \mathrm{CN}^{-}\right)$; defeitos atômicos substitucional (como $\mathrm{Li}^{+}, \mathrm{Cu}^{+}$em $\mathrm{KCl}, \mathrm{KBr}$ e $\mathrm{KI}$, por exemplo) ocupando posições fora de centro; dipolos formados pelo deslocamento local dos vizinhos mais próximos devido a substituição de um íon da rede por uma impureza de maior tamanho e ainda, a presença de vacâncias como compensadoras de carga na estrutura cristalina do material que podem estar associadas a impurezas aliovalentes formando um dipolo do tipo impureza-vacância (I-V), típica nos haletos alcalinos dopados com metais divalentes.

2) os mecanismos de relaxação que podem estar presentes:

Esses mecanismos podem ser classificados basicamente, em dois tipos: os dipolos relaxam por ativação térmica ou os dipolos relaxam por tunelamento quantomecânico. No primeiro caso temos o deslocamento de uma posição de equilíbrio para outra entre dois poços de potencial $i$ e $j$, ou seja, o íon, inicialmente numa posição de equilibrio $i$, adquire energia térmica suficiente para vencer a barreira de potencial, passando para outra posição de equilíbrio $j$. O segundo caso envolve o tunelamento através da barreira de potencial.

3) a forma com que as curvas características da relaxação dipolar se apresentam:

Uma curva de CDTE pode ser singular e descrita por um uma distribuição discreta dos parâmetros de relaxação mas, geralmente sua forma é mais complexa e muitas vezes é composta por uma série de picos caracterizando uma sucessão de 
relaxações na amostra estudada descrevendo uma distribuição contínua ou discreta dos parâmetros de relaxação envolvidos.

No caso da alexandrita, sabe-se que os íons $\mathrm{Cr}^{3+}$ ocupam duas posições com simetrias diferentes, citadas anteriormente, $\mathrm{Al}_{1}$ e $\mathrm{Al}_{2}$, e estão ligados à íons de oxigênio ocupando três posições diferentes na rede, designadas $\mathrm{O}_{1}, \mathrm{O}_{2}$ e $\mathrm{O}_{3}$ na estrutura cristalina, conforme é apresentado no capítulo 2 desse trabalho. Assim, a presença de vacâncias intrínsecas na estrutura cristalina desse mineral, tais como vacâncias de oxigênio, pode dar origem a formação de entidades dipolares do tipo impureza-vacância distribuídas aleatoriamente na alexandrita. Também podemos

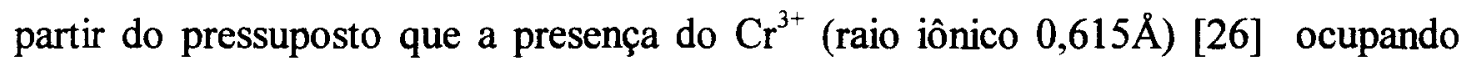
sítios usualmente preenchidos pelos íons $\mathrm{Al}^{3+}$ (raio iônico 0,535 $\AA$ ) causam distorções da estrutura na vizinhança o que pode, em primeira análise, favorecer a formação de dipolos, fazendo desse material um interessante candidato a uma investigação do fenômeno de relaxação dipolar através da técnica de CDTE.

Assim, neste trabalho estudamos cristais de alexandrita sob as formas sintética e natural, e verificamos que ocorre uma distribuição de bandas de CDTE centralizadas em torno de $179 \mathrm{~K}$, no caso da amostra sintética e 188 à $196 \mathrm{~K}$ no caso de amostras naturais.

A excelente qualidade óptica da amostra sintética utilizada nesse trabalho somada ao conhecimento de uma participação ativa dos ions $\mathrm{Cr}^{3+}$ nos sítios $\mathrm{Al}_{2}$ nas propriedades ópticas da alexandrita, nos levou também a investigar o fenômeno da relaxação dipolar através de um experimento de CDTE modificado, cujo procedimento básico foi iluminar as amostras a baixa temperatura com condições iniciais diferentes de polarização. Numa primeira condição os dipolos existentes se 
encontram orientados numa direção preferencial devido a aplicação do campo elétrico externo, e numa segunda condição, sem polarização inicial, os dipolos encontram-se orientados aleatoriamente e nessa situação são congelados abaixando-se a temperatura na amostra até $77 \mathrm{~K}$, onde somente com a aplicação do campo elétrico não seria possível sua reorientação.

Assim, com essas medidas foi possível verificar também o fenômeno de relaxação dipolar fotoinduzida e considerar a possibilidade de que as bandas de CDTE devem ser atribuídas a uma distribuição contínua dos parâmetros envolvidos no processo de relaxação, ou seja, energia de ativação e tempo de relaxação, conforme é apresentado no capítulo 4 deste trabalho.

O cristal de alexandrita na forma sintética foi crescido pelo método de Czochralsky nos E.U.A. (Allied Signal Inc.). Resultados das Microanálises de Espectroscopia por Dispersão de Energia de Raios X (EDX) e Espectroscopia por Dispersão de Comprimentos de Onda de Raios X (WDX) realizadas, indicaram apenas traços de inclusões de irídio e uma concentração desprezivel de Fe na matriz hospedeira. Assim, é possivel utilizá-la como referência na análise dos resultados obtidos com as medidas de CDTE para as amostras naturais, as quais são oriundas do Estado de Minas Gerais e, cujas microanálises através das técnicas de EDX/WDX mostraram uma alta concentração de $\mathrm{Fe}$ e outras impurezas na matriz hospedeira, além do $\mathrm{Cr}^{3+}$.

No presente trabalho, paralelo ao estudo das propriedades elétricas das alexandritas, contamos com o auxilio de investigações de suas propriedades ópticas, através de medidas de absorção óptica e luminescência, as quais puderam também dar garantia da qualidade das amostras naturais utilizadas. Os espectros obtidos de 
absorção óptica na região do ultravioleta e visivel, e emissão óptica, foram plenamente coincidentes com a literatura [27,28]. A análise estrutural das amostras naturais, através da técnica de Difração de Raios $X$, confirmou sua estrutura ortorrômbica e os parâmetros de rede foram determinados e coincidentes com a literatura [29].

Por outro lado, as bandas de CDTE foram também investigadas em função de tratamentos térmicos variando-se a temperatura e o tempo de tratamento para as amostras naturais pois, conforme mencionado, somente essas apresentam quantidades significativas de outras impurezas em sua estrutura, com a presença de inclusões sólidas (mica e quartzo) e líquidas (detectadas no espectro de absorção óptica na região do infravermelho), que poderiam influenciar na investigação de suas propriedades elétricas. Foi observado que os tratamentos térmicos provocam uma alteração na forma e posição das bandas de CDTE, deslocando a banda para temperaturas diferentes dependendo da temperatura utilizada no tratamento térmico e dando origem a uma banda larga centralizada em torno de $178 \mathrm{~K}$, ou seja, mais próxima da banda de CDTE obtida para a amostra sintética.

Assim, em resumo, podemos dizer que a metodologia experimental utilizada nesse trabalho basicamente compreende três etapas: i) preparação das amostras, adequando-as à cada uma das técnicas experimentais utilizadas, com posterior identificação dos elementos presentes e obtenção de informações cristalográficas de interesse; ii) caracterização óptica das amostras com a determinação de parâmetros espectroscópicos e comparação com os apresentados na literatura e iii) caracterização elétrica das amostras com a determinação dos parâmetros de relaxação dipolar elétrica desse material, através da técnica de CDTE. 
No capítulo 2 é apresentado um resumo das informações a respeito do material estudado, descrevendo o "efeito alexandrita", sua estrutura cristalina, algumas propriedades fisicas e características do laser de alexandrita e informações a respeito das propriedades ópticas desse material. No capítulo 3 descrevemos as técnicas experimentais utilizadas: Espectroscopia por Dispersão de Energia de Raios X e Espectroscopia por Dispersão de Comprimentos de Onda de Raios X (EDX e WDX), Difração de Raios X, Absorção Óptica na região espectral do ultravioleta, visivel e infravermelho, medidas de Luminescência e principalmente, Corrente de Despolarização Termicamente Estimulada (CDTE) e CDTE fotoinduzida. No capítulo 4 são apresentadas as composições químicas relativas das amostras estudadas, obtidas por análises de EDX e WDX, e ainda os resultados obtidos na caracterização estrutural das amostras naturais, com a verificação de sua estrutura cristalina ortorrômbica e parâmetros de rede, obtidos pela técnica de Difração de Raios X. Também são apresentados os resultados das medidas de Absorção e Emissão Óptica para ambos os tipos de amostras à temperatura ambiente e a $77 \mathrm{~K}$. O capítulo 4 se refere também as medidas de CDTE, descrevendo o comportamento das bandas, as quais são bem ajustadas quando levamos em conta a ocorrência de uma distribuição contínua de energia de ativação e tempo de relaxação, com as curvas teóricas calculadas pelo método proposto por HAVRILIAK e NEGAMI [30]. Nesse capítulo também são apresentados os resultados das medidas de CDTE em função dos tratamentos térmicos realizados para as amostras naturais e os resultados obtidos através das medidas de CDTE fotoinduzidas, as quais reforçam a ocorrência de uma distribuição contínua dos parâmetros de relaxação. 
No capítulo 5 são apresentadas as conclusões a respeito da investigação das propriedades elétricas da alexandrita e, assim, com este trabalho pretendemos contribuir significativamente para uma maior compreensão das propriedades elétricas desse material que possui amplo potencial para aplicações científicas e tecnológicas.

\section{2 - OBJETIVOS DESTE TRABALHO.}

O principal objetivo que norteou este trabalho foi a utilização da técnica de Corrente de Despolarização Termicamente Estimulada (CDTE) para uma investigação sistemática da ocorrência da formação de dipolos em cristais de alexandrita $\left(\mathrm{BeAl}_{2} \mathrm{O}_{4}: \mathrm{Cr}^{3+}\right)$ nas formas sintética e natural. A técnica de $\mathrm{CDTE}$, até então não utilizada na caracterização de alexandritas, permite determinar os parâmetros envolvidos no processo de relaxação dipolar que ocorre nesse material, ou seja, energia de ativação $\left(E_{a}\right)$ e tempo de relaxação $\left(\tau_{0}\right)$. Com os resultados obtidos é proposto um modelo que descreve a origem do fenômeno de relaxação dipolar em alexandritas. Além disso, diante do conhecimento prévio das características ópticas desse material, com os espectros de absorção óptica e luminescência bastante conhecidos na literatura, tivemos como objetivo a utilização de um método de medidas de CDTE modificado, o qual chamamos de medidas de CDTE fotoinduzidas, com o qual pudemos observar a "destruição" e a "formação" das bandas de CDTE quando as amostras são fotoexcitadas com um laser de $\mathrm{Kr}^{+}$sintonizado em comprimentos de onda localizados sobre as bandas de absorção desse material. 


\section{CARACTERISTICAS DA ALEXANDRITA}

Neste capítulo apresentamos algumas propriedades e características da alexandrita, as quais tem sido reportadas nas últimas décadas e que também nos motivaram a estudar esse material. Também são apresentadas as características do laser de alexandrita, cuja utilização e performance possuem uma vasta quantidade de trabalhos relevantes apresentados na literatura.

\section{1 - O "EFEITO ALEXANDRITA".}

O crisoberilo $\left(\mathrm{BeAl}_{2} \mathrm{O}_{4}\right)$ [31] é um mineral relativamente comum e sua cor pode apresentar vários tons de verde ou amarelo. Seu nome, em grego [32], significa "berilo dourado" e no Brasil explora-se o crisoberilo desde o século XVIII, especialmente na região de Minas Gerais. A alexandrita é a variedade de crisoberilo

contendo $\mathrm{Cr}^{3+}\left(\mathrm{BeAl}_{2} \mathrm{O}_{4}: \mathrm{Cr}^{3+}\right)$ e é uma gema extremamente rara e de alto valor comercial. As descobertas das primeiras jazidas de alexandrita ocorreram na Rússia em 1830 [1] e, de acordo com PETERSEN [33], dados atuais apontam Brasil e Sri Lanka como os maiores fornecedores dessa gema, com jazidas ocorrendo principalmente nos estados de Minas Gerais, Bahia e Espírito Santo. Dados de 1993 [6], indicam a mais rica concentração de alexandrita do mundo na mina de Hematita, próxima da cidade de Itabira, MG.

As alexandritas naturais ocorrem quando soluções ricas em $\mathrm{Be}$, provenientes de corpos graníticos, pegmatíticos ou outras manifestações hidrotermais percolam 
rochas ultramáficas que atuam como fonte de $\mathrm{Cr}$ [11]. Gemas naturais de alexandrita podem exibir faces (100) e (001) e raramente, faces menores (010) [1].

Uma das mais atraentes características da alexandrita ${ }^{1}$ é sua capacidade em mudar de cor, passando do verde na luz natural para vermelho sob luz artificial. De acordo com SCHMETZER et al [2] como a cor representa uma superposição de todas as regiões do espectro não absorvidas sob a luz do dia, as cores de um mineral são geralmente determinadas pela posição do mínimo de absorção entre 508 e 476 $\mathrm{nm}$, dependendo se ele é verde, azul esverdeado ou azul na região visível. No caso da exposição da alexandrita à luz de lâmpada incandescente e, portanto, rica em comprimentos de onda no vermelho, ocorre o seguinte: sendo a transmissão na região do vermelho $(666 \mathrm{~nm})$ maior do que na região do azul-verde, a cor vermelha no visível será mais pronunciada. Ao expor a alexandrita à luz natural (solar ou lâmpadas fluorescentes "luz do dia"), a parcela na região do vermelho muito menor nesse tipo de transmissão, permite a dominância da cor verde-azul visível [33]. Essa mudança de cor é um fator muito importante na avaliação comercial dessas gemas, sendo que para ser chamada alexandrita é preciso que essa mudança situe-se em torno de $30 \% \mathrm{e}$ alcance um máximo de $90 \%$ [7]. O fenômeno da mudança de cor é conhecido na literatura como "efeito alexandrita" [5] e inúmeros trabalhos têm sido apresentados nas últimas décadas investigando esse fenômeno, tanto para a alexandrita quanto para outros minerais que apresentam o efeito de mudança de cor [33,34]. SCHMETZER et al [2] apresentam um estudo sobre a causa da mudança de cor em diversos minerais, através dos espectros de absorção óptica polarizados e apresentam características comuns do espectro de absorção dos sólidos do tipo alexandrita

\footnotetext{
${ }^{1} \mathrm{O}$ nome alexandrita foi dado em homenagem ao Czar Alexandre II da Rússia.
} 
investigados. O "efeito alexandrita" é ilustrado na Figura 1 para um cristal natural lapidado disponível comercialmente.

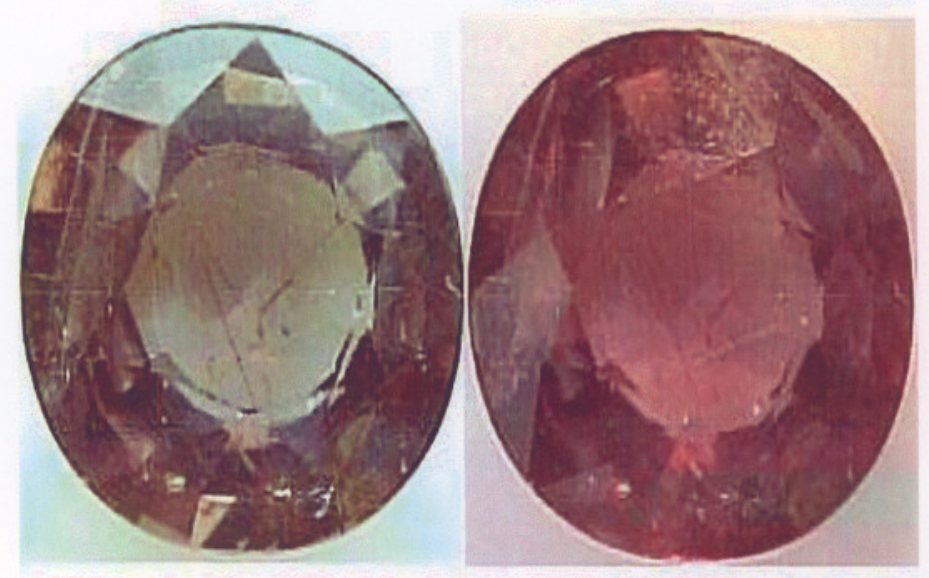

Figura 1 - Ilustração do "Efeito alexandrita" para um cristal natural lapidado disponível comercialmente, extraído da referência [35].

$\mathrm{Na}$ literatura, a maioria dos autores atribuem esse efeito às concentrações relativas de $\mathrm{Cr}^{3+}$ nos dois sítios com simetrias diferentes presentes nesse mineral ("espelho" e "centro de inversão"), conforme é descrito por RAGER et al[13] e mencionado no capítulo 1 deste trabalho. Na Tabela 1 são apresentados alguns resultados obtidos por RAGER et al [13] os quais indicam que há uma dependência da mudança de cor com a concentração de $\mathrm{Cr}^{3+}$ e com a taxa relativa de $\mathrm{Cr}^{3+}$ nos sítios $\mathrm{Al}_{1}$ e $\mathrm{Al}_{2}$, determinada a partir de medidas de Ressonância Paramagnética Eletrônica (EPR). 
Tabela 1 - Alguns resultados obtidos com medidas de EPR relacionando a mudança de cor com a concentração de $\mathrm{Cr}^{3+}$ e a taxa relativa de $\mathrm{Cr}^{3+}$ nos sítios $\mathrm{Al}_{2}$ (localizados num plano de reflexão) e $\mathrm{Al}_{1}$ (localizados num centro de inversão). Extraído da referência [13].

\begin{tabular}{|c|c|c|c|c|c|}
\hline Amostra & $\begin{array}{c}\text { Obtenção } \\
\text { /localização }\end{array}$ & $\begin{array}{c}\text { Cor sob luz } \\
\text { natural }\end{array}$ & $\begin{array}{l}\text { Mudança de } \\
\text { cor }\end{array}$ & $\begin{array}{l}\text { Microanálises } \\
\text { (\% em peso) }\end{array}$ & $\begin{array}{l}\mathrm{I}\left(\mathrm{Cr}^{3+}\left(\mathrm{Al}_{2}\right)\right): \\
\mathrm{I}\left(\mathrm{Cr}^{3+}\left(\mathrm{Al}_{1}\right)\right)\end{array}$ \\
\hline 1 & $\begin{array}{l}\text { Czochralski } \\
\text { (Allied } \\
\text { Corporation) } \\
\text { EUA }\end{array}$ & Verde & $\begin{array}{l}\text { Moderada à } \\
\text { intensa }\end{array}$ & $\begin{array}{l}\mathrm{Fe}_{2} \mathrm{O}_{3}: 0.01 \\
\mathrm{Cr}_{2} \mathrm{O}_{3}: 0.25\end{array}$ & $\begin{array}{l}73 \\
27\end{array}$ \\
\hline 2 & $\begin{array}{c}\text { Czochralski } \\
\text { (Inst. Geol. } \\
\& \text { \& } \\
\text { Geophysics), } \\
\text { Rússia }\end{array}$ & $\begin{array}{l}\text { Verde } \\
\text { brilhante }\end{array}$ & $\begin{array}{l}\text { Fraca à } \\
\text { moderada }\end{array}$ & $\begin{array}{l}\mathrm{Fe}_{2} \mathrm{O}_{3}: 0.12 \\
\mathrm{Cr}_{2} \mathrm{O}_{3}: 0.16\end{array}$ & $\begin{array}{l}72 \\
28\end{array}$ \\
\hline 3 & $\begin{array}{c}\text { Cres. Fluxo } \\
\text { (Inst. Geol. } \\
\& \\
\text { Geophysics), } \\
\text { Rússia }\end{array}$ & Verde & moderada & $\begin{array}{l}\mathrm{Fe}_{2} \mathrm{O}_{3}: 0.60 \\
\mathrm{Cr}_{2} \mathrm{O}_{3}: 0.23\end{array}$ & $\begin{array}{l}65 \\
35\end{array}$ \\
\hline 4 & Orissa, Índia & $\begin{array}{l}\text { Verde } \\
\text { intensa }\end{array}$ & intensa & $\begin{array}{l}\mathrm{Fe}_{2} \mathrm{O}_{3}: 1.34 \\
\mathrm{Cr}_{2} \mathrm{O}_{3}: 0.71\end{array}$ & $\begin{array}{c}\text { Não } \\
\text { determinada }\end{array}$ \\
\hline 5 & $\begin{array}{c}\text { Lake } \\
\text { Manyara, } \\
\text { Tanzania }\end{array}$ & Verde & moderada & $\begin{array}{c}\mathrm{Fe}_{2} \mathrm{O}_{3}: 0.93 \\
\mathrm{Cr}_{2} \mathrm{O}_{3}: 0.21\end{array}$ & $\begin{array}{c}\text { Não } \\
\text { determinada }\end{array}$ \\
\hline 6 & $\begin{array}{c}\text { Hematita, } \\
\text { Minas } \\
\text { Gerais, Brasil }\end{array}$ & $\begin{array}{c}\text { Verde } \\
\text { muito } \\
\text { brilhante }\end{array}$ & $\begin{array}{c}\text { Não } \\
\text { observada }\end{array}$ & $\begin{array}{l}\mathrm{Fe}_{2} \mathrm{O}_{3}: 1.31 \\
\mathrm{Cr}_{2} \mathrm{O}_{3}: 0.06\end{array}$ & $\begin{array}{c}\text { Não } \\
\text { determinada }\end{array}$ \\
\hline 7 & $\begin{array}{c}\text { Hematita, } \\
\text { Minas } \\
\text { Gerais, Brasil }\end{array}$ & Verde & moderada & $\begin{array}{l}\mathrm{Fe}_{2} \mathrm{O}_{3}: 1.04 \\
\mathrm{Cr}_{2} \mathrm{O}_{3}: 0.32\end{array}$ & $\begin{array}{c}\text { Não } \\
\text { determinada }\end{array}$ \\
\hline 8 & $\begin{array}{c}\text { Hematita, } \\
\text { Minas } \\
\text { Gerais, Brasil }\end{array}$ & $\begin{array}{l}\text { Verde } \\
\text { intensa }\end{array}$ & Intensa & $\begin{array}{l}\mathrm{Fe}_{2} \mathrm{O}_{3}: 1.22 \\
\mathrm{Cr}_{2} \mathrm{O}_{3}: 0.45\end{array}$ & $\begin{array}{c}\text { Não } \\
\text { determinada }\end{array}$ \\
\hline
\end{tabular}


No estudo feito por RAGER et al [13] o efeito alexandrita para os cristais naturais examinados, não pode ser correlacionado com as quantidades de $\mathrm{Cr}^{3+}$ nos sítios $\mathrm{Al}_{1}$ e $\mathrm{Al}_{2}$, através de medidas de $\mathrm{EPR}$, em razão de uma forte superposição das linhas de $\mathrm{Fe}^{3+}$ com as linhas de $\mathrm{Cr}^{3+}\left(\mathrm{Al}_{1}\right)$ nos espectros obtidos. RAGER et al apresentam apenas uma estimativa de que a taxa de $\mathrm{Cr}^{3+}\left(\mathrm{Al}_{2}\right): \mathrm{Cr}^{3+}\left(\mathrm{Al}_{1}\right)$, muito provavelmente, aumenta com o aumento de concentração de $\mathrm{Cr}$ nos cristais naturais estudados. A única correlação com a intensidade de mudança de cor observada visualmente e a composição química das amostras naturais é a quantidade absoluta de cromo dos cristais. Esses autores também observaram que, para 18 amostras de alexandrita naturais oriundas da mina de Hematita ${ }^{2}$, no estado de Minas Gerais, Brasil, um aumento da intensidade da mudança de cor é correlacionado diretamente com a quantidade de $\mathrm{Cr}_{2} \mathrm{O}_{3}$, quando essa aumenta de 0.03 para $0.64 \%$ em peso nesses 18 cristais. Em alexandritas, principalmente as naturais, pode ocorrer também a presença de $\mathrm{Fe}^{3+}$ substituindo os ions de $\mathrm{Cr}^{3+}$ e, de acordo com a literatura, embora a concentração de Fe possa ter um certo efeito sobre a intensidade da mudança de cor, a quantidade total de Fe parece ser de menor influência sobre o efeito comparado com a concentração absoluta de cromo do cristal [13]. Alguns autores atribuem o fenômeno da mudança de cor à um efeito psico-físico do olho humano e cérebro ao invés de qualquer mudança abrupta nas propriedades do material [36].

\footnotetext{
${ }^{2}$ Dados de 1993 apontam a mina de Hematita (também chamada Nova Era e Itabira), localizada a 20Km da cidade de Itabira, Minas Gerais, tendo a mais rica concentração de alexandrita do mundo [6].
} 


\section{2 - ESTRUTURA CRISTALINA}

A Figura 2(a) mostra a estrutura do crisoberilo em três dimensões e a Figura 2(b) mostra sua estrutura projetada sobre o plano bc. $O$ crisoberilo pertence ao sistema cristalino ortorrômbico e ao grupo espacial Pnma com parâmetros de rede $a=9,407 \AA, b=5,4781 \AA$ e $c=4,4285 \AA$ para $\mathrm{BeAl}_{2} \mathrm{O}_{4}$ dopado com $0,3 \%$ em átomos de $\mathrm{Cr}^{3+}$ (alexandrita) e a=9,3929 $\AA, b=5,4735 \AA$ e $c=4,419 \AA$ para $\mathrm{BeAl}_{2} \mathrm{O}_{4}$ (crisoberilo) [29]. Sua estrutura cristalina foi determinada pela primeira vez em 1926, por BRAGG \& BROWN, e refinada por FARREL [8] em 1963 e pode ser visualizada como sendo, aproximadamente, hexagonal com empacotamento compacto (hcp), com célula unitária constituída por quatro moléculas, com oito íons de $\mathrm{Al}^{3+}(0,535 \AA)$ ocupando sítios octaédricos distorcidos e quatro íons de $\mathrm{Be}^{2+}$ (raio iônico $0,45 \AA$ ) ocupando sítios tetraédricos distorcidos, formados com os íons de oxigênio localizados em planos perpendiculares ao eixo c $[14,15,16,31]$. As distorções de uma estrutura $h c p$ exata de íons oxigênio dão origem ao aparecimento de dois sítios de simetria diferentes, onde os íons $\mathrm{Al}^{3+}$ são substituídos por $\mathrm{Cr}^{3+}(0,615 \AA)$ : um sítio, $\mathrm{Al}_{1}$, situado num centro de inversão (simetria $\mathrm{C}_{\mathrm{i}}$ ) e um sítio, $\mathrm{Al}_{2}$, localizado num plano de reflexão (simetria $C_{s}$ ) $[4,14,16,29,31]$. Na Tabela 2 são apresentadas as coordenadas das posições equivalentes dos íons presentes na estrutura do crisoberilo e também as posições em termos da notação de Wyckoff [37]. 

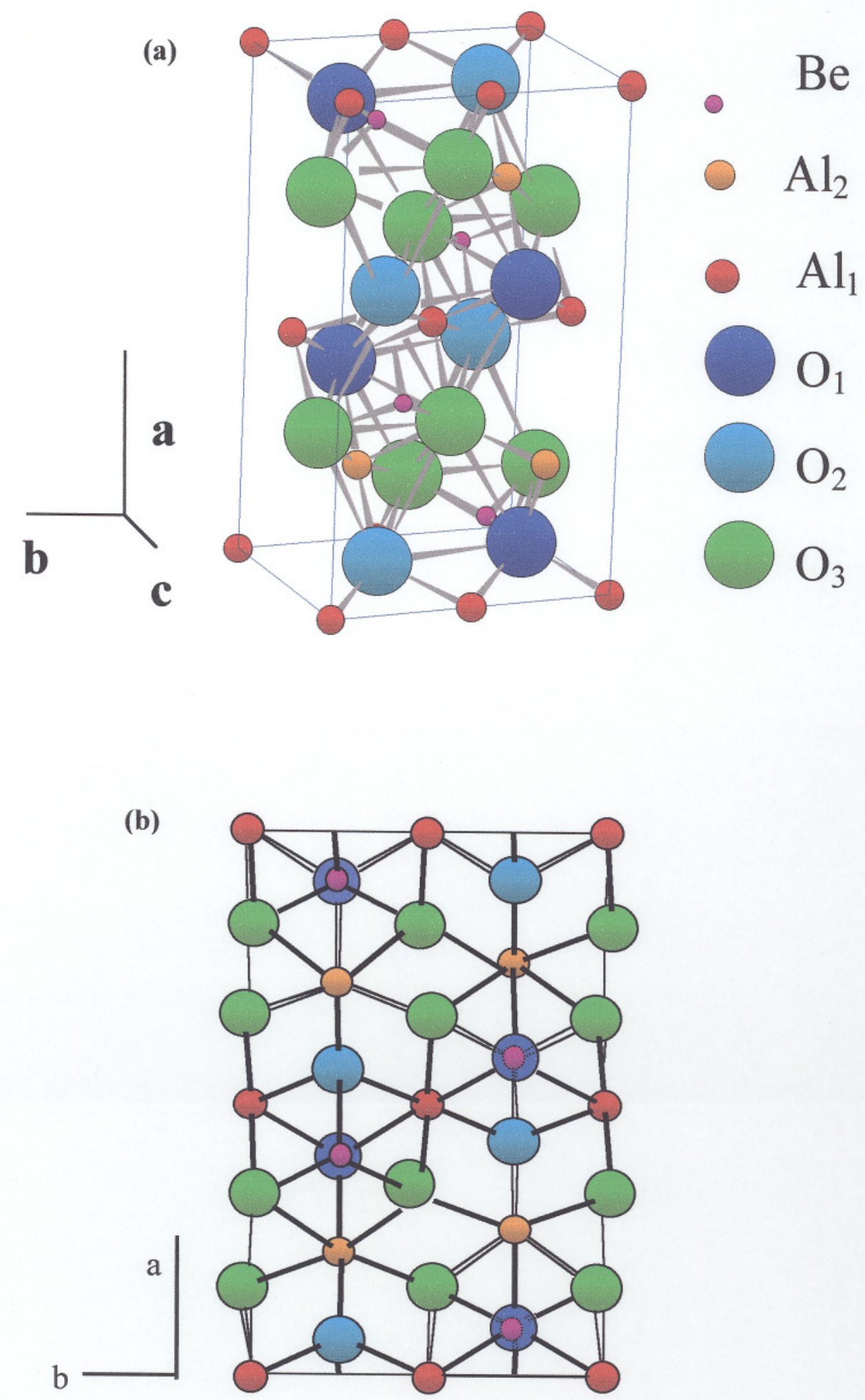

Figura 2 - (a) Estrutura do crisoberilo com a indicação dos eixos a, b e c . (b)Estrutura do crisoberilo projetada sobre (001), adaptada da referência [8]. 
Tabela 2 - Posições ocupadas pelos átomos na estrutura do crisoberilo [37]

\begin{tabular}{cccccc}
\hline átomo & $\begin{array}{c}\text { Posição de } \\
\text { Wyckoff }\end{array}$ & \multicolumn{4}{c}{ Posições equivalentes } \\
\hline $\mathrm{Al}_{1}$ & $4 \mathrm{a}$ & $0,0,0 ;$ & $0,1 / 2,0 ;$ & $1 / 2,0,1 / 2 ;$ & $1 / 2,1 / 2,1 / 2$. \\
& & & & & \\
$\mathrm{Al}_{2}, \mathrm{Be}$, & $4 \mathrm{c}$ & $\mathrm{x}, 1 / 4, \mathrm{z} ;$ & $\mathrm{x}, 3 / 4, \mathrm{z} ;$ & $1 / 2-\mathrm{x}, 3 / 4,1 / 2+\mathrm{z} ;$ & $1 / 2+\mathrm{x}, 1 / 4,1 / 2-\mathrm{z}$ \\
$\mathrm{O}_{1}, \mathrm{O}_{2}$ & & & & & \\
& & & & & \\
$\mathrm{O}_{3}$ & $8 \mathrm{~d}$ & $\mathrm{x}, \mathrm{y}, \mathrm{z} ;$ & $1 / 2+\mathrm{x}, 1 / 2-\mathrm{y}, 1 / 2-\mathrm{z} ;$ & $\mathrm{x}, 1 / 2+\mathrm{y}, \mathrm{z} ;$ & $1 / 2-\mathrm{x}, \mathrm{y}, 1 / 2+\mathrm{z} ;$ \\
& $\mathrm{x}, \mathrm{y}, \mathrm{z} ;$ & $1 / 2-\mathrm{x}, 1 / 2+\mathrm{y}, 1 / 2+\mathrm{z} ;$ & $\mathrm{x}, 1 / 2-\mathrm{y}, \mathrm{z} ;$ & $1 / 2+\mathrm{x}, \mathrm{y}, 1 / 2-\mathrm{z}$. \\
\hline
\end{tabular}

As distâncias interatômicas na estrutura do crisoberilo foram determinadas por FARREL [8] e os valores médios das distâncias entre os vizinhos mais próximos são (considerando $\mathrm{O}_{1}, \mathrm{O}_{2}$ e $\mathrm{O}_{3}$ ) $\mathrm{Al}(1)-\mathrm{O}=1,890 \AA$ (simetria $\mathrm{C}_{\mathrm{i}}$ ) e $\mathrm{Al}(2)-\mathrm{O}=1,934 \AA$ (simetria $\mathrm{C}_{\mathrm{s}}$ ) $[2,14,36]$. Uma característica de interesse é o fato do octaedro $\mathrm{Al}_{2}$ ser preferencialmente ocupado pelos íons $\mathrm{Cr}^{3+}$, por ser maior do que $\mathrm{Al}_{1}$. Entretanto, isso não impede que íons $\mathrm{Cr}^{3+}$ sejam incorporados na rede hospedeira também em $\mathrm{Al}_{1}$. Assim, desde que o íon $\mathrm{Cr}^{3+}(\mathrm{r}=0,615 \AA)$ ocupa um sítio usualmente preenchido pelos íons $\mathrm{Al}^{3+}(\mathrm{r}=0,535 \AA)$, este entra em um sítio que é, portanto, $16 \%$ menor [38]. A presença do íon $\mathrm{Cr}^{3+}$ em tal sítio causaria uma espécie de compressão da estrutura na vizinhança e afetaria a intensidade do parâmetro de desdobramento do campo cristalino, $\Delta$. De acordo com HASSAN [36], tem-se a expressão:

$$
\Delta=Q\left(r^{4}\right) / R^{5}
$$

onde $\mathrm{Q}$ é a carga nos ligantes, $\mathrm{r}$ é o valor médio dos raios dos orbitais $\mathrm{d}$ e $\mathrm{R}$ é a distância interatômica metal-ligante, a qual mostra que a divisão do campo cristalino é inversamente proporcional às distâncias interatômicas elevadas a quinta. Quanto menor a distância metal-ligante, maior o valor de $\Delta[39]$. 
$\mathrm{Na}$ literatura são encontrados diversos trabalhos a respeito das propriedades estruturais do crisoberilo como, por exemplo, o trabalho de HAZEN [40], onde cristais de crisoberilo natural oriundos de Colatina no Espírito Santo são utilizados em métodos de medidas cristalográficas à altas pressões, documentando as mudanças estruturais que resultam em compressão anisotrópica.

Em alexandritas, como foi mencionado anteriormente, pode-se ter também, $\mathrm{Fe}^{3+}(0,645 \AA)$ substituindo os íons $\mathrm{Al}^{3+}$, localizados num plano de reflexão [10,31].

\section{3 - PROPRIEDADES FÍSICAS E O ILASER DE ALEXANDRITA.}

Outras características importantes da alexandrita é o fato de possuir alta resistência mecânica e ser quimicamente estável [4]. Desde 1974, quando se tornou possível obter cristais sintéticos de alexandrita de bom tamanho e de boa qualidade óptica crescidos pelo método de Czochralski $[41,42,43,44]$, a alexandrita tornou-se tecnologicamente importante como um meio ativo para laser de estado sólido sintonizável [4]. No crescimento pelo método de Czochralki, cadinhos de Ir, fornos cerâmicos de zircônia e atmosferas $\mathrm{N}_{2}-\mathrm{O}_{2}$ são utilizados e os defeitos ópticos identificados nesses cristais são eficientemente eliminados ou controlados. propriedades físicas da alexandrita são amplamente apresentadas na literatura e algumas delas estão resumidas na Tabela 3. 
Tabela 3- Propriedades físicas da alexandrita obtidas na literatura.

\begin{tabular}{ccc}
\hline Propriedade & Valor & referências \\
\hline Ponto de fusão & $1870^{0} \mathrm{C}$ & {$[4,6,31,45]$} \\
Densidade & $3,68-3,70 \mathrm{~g} / \mathrm{cm}^{3}$ & {$[4,6,31,45,46]$} \\
Dureza & $8,5 \mathrm{Mohs}$ & {$[6,47]$} \\
Módulo de Young & $0,469 \times 10^{12} \mathrm{~Pa}$ & {$[4]$} \\
Condutividade Térmica & $23 \mathrm{~W} / \mathrm{m}^{0} \mathrm{C}$ & {$[4,45,48,49]$} \\
Coef. de expansão térmica & $7,07 \times 10^{-6} \mathrm{~K}$ & {$[4,45]$} \\
Calor específico & $0,83 \mathrm{~J} / \mathrm{gK}$ & {$[45]$} \\
& 1,74 & {$[45,49]$} \\
Índices de refração: linear & $2,0 \times 10^{-20} \mathrm{~m}^{2} / \mathrm{W}$ & {$[45,49]$} \\
\hline
\end{tabular}

A alexandrita é o terceiro material dopado com $\mathrm{Cr}^{3+}$, depois do Rubi e YAG:Cr, onde foi observada a ação laser. Entretanto, na alexandrita a ação laser ocorre não apenas nas linhas $\mathrm{R}$, como nos dois primeiros, mas também na banda vibrônica onde o laser funciona como um sistema de 4 níveis e é sintonizável de 700 à $800 \mathrm{~nm}$. Portanto, um dos méritos de alexandrita é o de ser usada como meio ativo de laser sintonizável contínuo, centralizado em 750nm e largura de $100 \mathrm{~nm}$, com um baixo limiar de excitação para operar em sistema de 4 níveis à temperatura ambiente. Resumidamente, dentre outras características desse laser, tem-se operação com chaveamento Q ("Q-switch") de alta potência, excelentes propriedades físicas, e total simplicidade de operação, as quais combinam para fazer da alexandrita um laser de estado sólido sintonizável superior a outros tipos de laseres [5,48]. 
Algumas propriedades do laser de alexandrita em comparação a outros laseres são apresentadas na Tabela 4, e uma comparação mais detalhada, levando-se em conta também outros tipos de laseres além dos contidos nessa tabela, é feita por FABENI [5]. No trabalho reportado por PAYNE [50] é apresentada uma relação de 22 materiais hospedeiros dopados com $\mathrm{Cr}^{3+}$ utilizados para operação laser de estado sólido, sendo que a melhor performance é atribuída ao laser de alexandrita. Portanto, desde que ocorreu a primeira operação do laser de alexandrita em 1974, com o $1^{\circ}$ laser sendo patenteado pôr R.C.MORRIS e C.F.CLINE em 14/12/1976 [49], suas características e performance tem sido bastante investigadas e muitos esforços foram feitos para melhorá-lo, conforme é descrito por FABENI [5].

Tabela 4 - Propriedades do laser de alexandrita comparadas a outros laseres. $\Delta \boldsymbol{\lambda}$ : largura da banda a meia altura da emissão; $\sigma_{\mathbf{e}}$ seção de choque da emissão estimulada; $n$ : índice de refração (para $\lambda=250 \mathrm{~nm}$ ); $\varepsilon$ : perda por espalhamento; $\sigma$ : tempo de vida da emissão espontânea.

\begin{tabular}{clllll}
\hline Hospedeiro laser & Alexandria & $\mathrm{Al}_{2} \mathrm{O}_{3}: \mathrm{Ti}$ & $\mathrm{LiSAF}: \mathrm{Cr}$ & Vidro:Nd & YAG:Nd \\
\hline $\begin{array}{c}\lambda \text { central fundamental do } \\
\text { laser }(\mathrm{nm})\end{array}$ & 755 & 835 & 852 & 1053 & 1064 \\
$\Delta \lambda(\mathrm{nm})$ & 160 & 20 & 220 & 22 & 0,45 \\
$\sigma_{\mathrm{e}}\left(10^{-20} \mathrm{~cm}^{2}\right)$ & $0,5-5$ & 41 & 4 & 4 & 65 \\
$\sigma(\mu \mathrm{s})$ & 270 & 3,2 & 67 & 330 & 230 \\
$\mathrm{n}$ & 1,74 & 1,76 & 1,41 & 1,54 & 1,82 \\
$\varepsilon\left(\mathrm{cm}^{-1}\right)$ & 0 & 0 & 0,002 & 0 & 0,002 \\
\hline
\end{tabular}


O laser de alexandrita possui um amplo potencial para aplicações científicas e atualmente diversos trabalhos tem sido apresentados na literatura $[49,51,52,53]$, como por exemplo, o de IMAI e ITO [47], que mostram a obtenção de um laser de alexandrita com pulso longo na região do ultravioleta. No sistema descrito por esses autores o laser é bombeado com uma lâmpada "flash" e atinge pulsos longos e sintonizáveis no UV com a utilização de um dobrador de freqüência (cristal de BBO). O laser de alexandrita tem também excelentes aplicações na área médica, como por exemplo, na remoção de tatuagens e pêlos e na eliminação de veias varicosas, etc $[54,55]$.

Os espectros ópticos de cristais dopados com $\mathrm{Cr}^{3+}$, que tem configuração eletrônica do Argônio mais três elétrons de valência na sub-camada $3 \mathrm{~d}$, tem sido extensivamente estudados, sendo os níveis de energia do $\mathrm{Cr}^{3+}$ bem conhecidos, tanto para o íon livre como para o íon submetido a um campo cristalino de simetria octaédrica [56,57]. As características dos espectros possibilitam importantes informações na compreensão das interações fundamentais entre os íons opticamente ativos e a rede hospedeira. Os dados sobre características espectroscópicas de alexandritas apresentados na literatura até 1978 são obtidos usualmente com cristais naturais e portanto, podem ser distorcidos pela presença de outras impurezas nessas amostras [43].

As propriedades espectroscópicas do $\mathrm{Cr}^{3+} \mathrm{em}$ alexandrita são similares as do $\mathrm{Cr}^{3+}$ em outros óxidos hospedeiros com simetria octaédrica, como $\mathrm{Al}_{2} \mathrm{O}_{3}$ e $\mathrm{YAlO}_{3}$. Todos eles tem duas linhas bem definidas ${ }^{4} \mathrm{~A} \leftrightarrow{ }^{2} \mathrm{E}$ (linhas $\mathrm{R}$ ) e duas bandas de absorção largas ${ }^{4} \mathrm{~T}_{1},{ }^{4} \mathrm{~T}_{2}$. Entretanto, a intensidade e posição relativa dessas 
transições variam de hospedeiro para hospedeiro. Em geral, se $\mathrm{orr}^{3+}$ está num sítio que possui simetria de centro de inversão, as transições por dipolo elétrico entre estados na configuração $3 \mathrm{~d}$ são proibidas. Como conseqüência , o ín $\mathrm{Cr}^{3+}$ que reside numa simetria de centro de inversão, como $\mathrm{YAlO}_{3}$, tem uma transição de dipolo magnético de zero-fônon fraca. As transições assistidas por fônons ou vibrônicas tendem também a ser mais fracas no sítio com simetria de centro de inversão do que no sítio sem simetria de inversão como em $\mathrm{Al}_{2} \mathrm{O}_{3}$. No caso da alexandrita, os espectros de absorção e luminescência mostram sinais relacionados ao $\mathrm{Cr}^{3+}$ nos sítios localizados num plano de reflexão, sendo que somente esses íons são caracterizados por altas probabilidades de transições por dipolo elétrico, ao passo que $\mathrm{Cr}^{3+}$ no sítio com simetria de centro de inversão suporta transições por dipolo magnético [58,59].

Os espectros de absorção óptica da alexandrita obtidos na literatura, são mostrados na Figura 3, e $\mathrm{o}$ espectro de emissão é mostrado na Figura 4. Na Figura 5 é apresentado o diagrama de níveis de energia do $\mathrm{Cr}^{3+}$. De acordo com a literatura, as características qualitativas dos espectros ópticos, como o número de linhas e suas intensidades relativas, dependem das diferentes polarizações em que são obtidos os espectros, ou seja, $E\|\mathrm{a}, \mathrm{E}\| \mathrm{b}$ ou $\mathrm{E} \| \mathrm{c}$, onde $\mathrm{a}, \mathrm{b}$ e c são os eixos principais do cristal . 


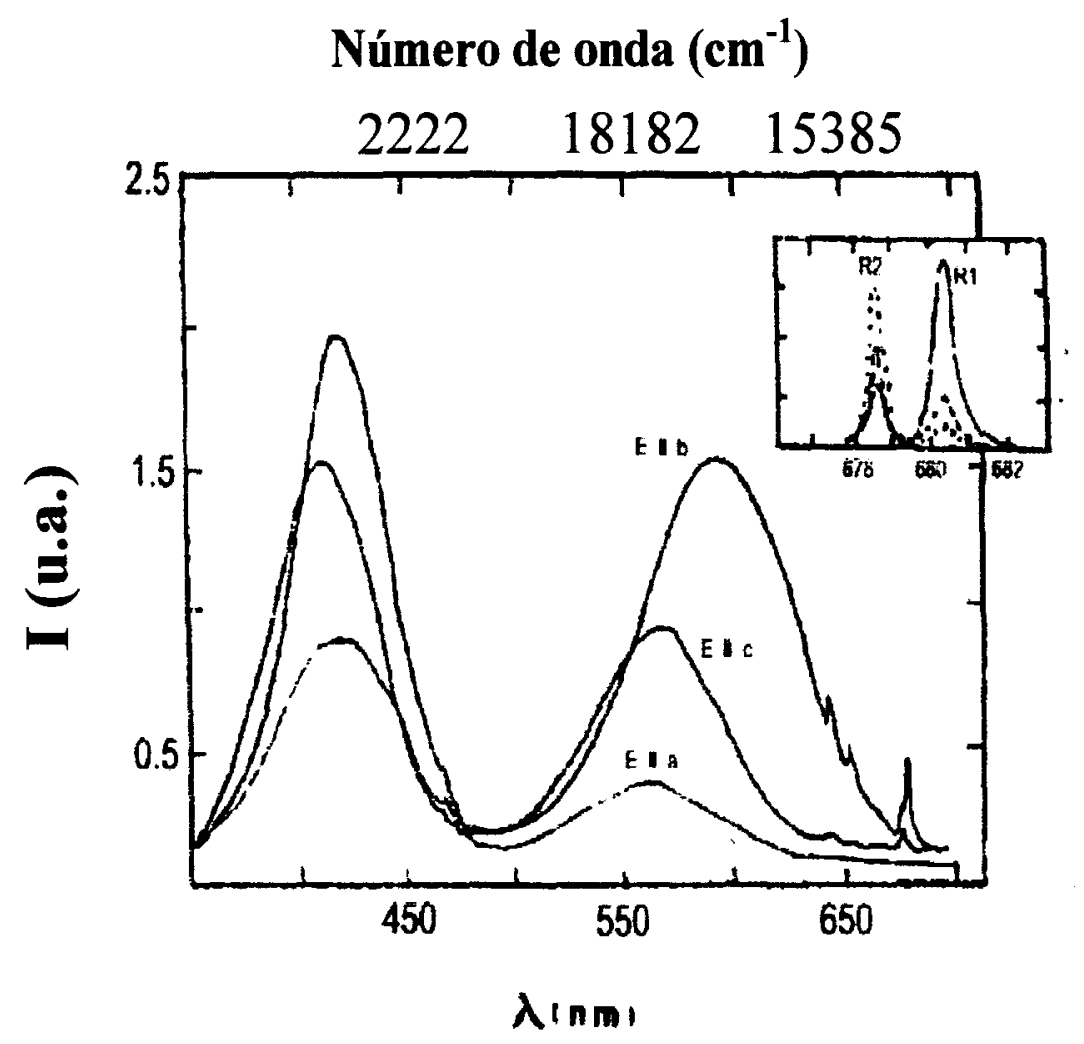

Figura 3- Espectro de absorção de alexandrita à temperatura ambiente. O gráfico menor mostra as linhas $\mathrm{R}$, com a linha sólida preta para $\mathrm{E} \| \mathrm{b}$, linha azul para $\mathrm{E} \| \mathrm{c}$ e linha vermelha para E \|a. Adaptado da referência [27].

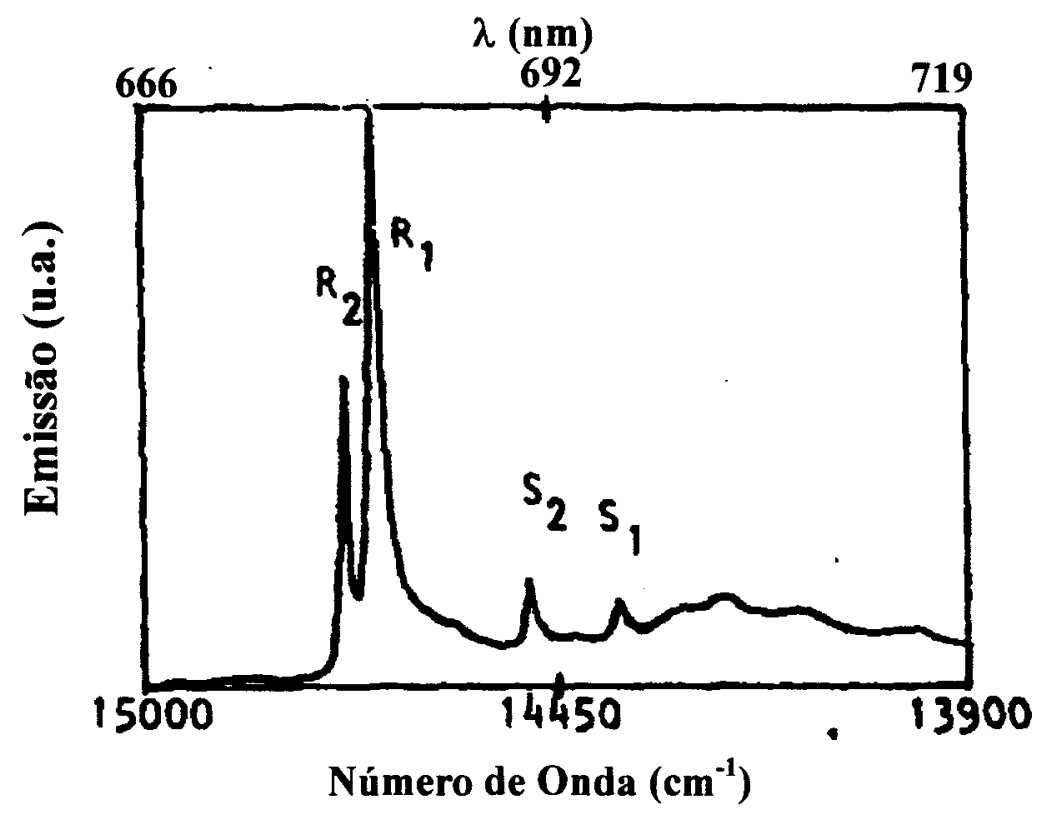

Figura 4- Espectro de luminescência da alexandrita à temperatura ambiente mostrando as linhas do $\mathrm{Cr}^{3+}$ nos sítios localizados sobre um centro de inversão $\left(\mathrm{S}_{1}\right.$ e $\left.\mathrm{S}_{2}\right)$ e sobre um plano de reflexão $\left(\mathrm{R}_{1}\right.$ e $\left.\mathrm{R}_{2}\right)$. Adaptado da referência [28]. 


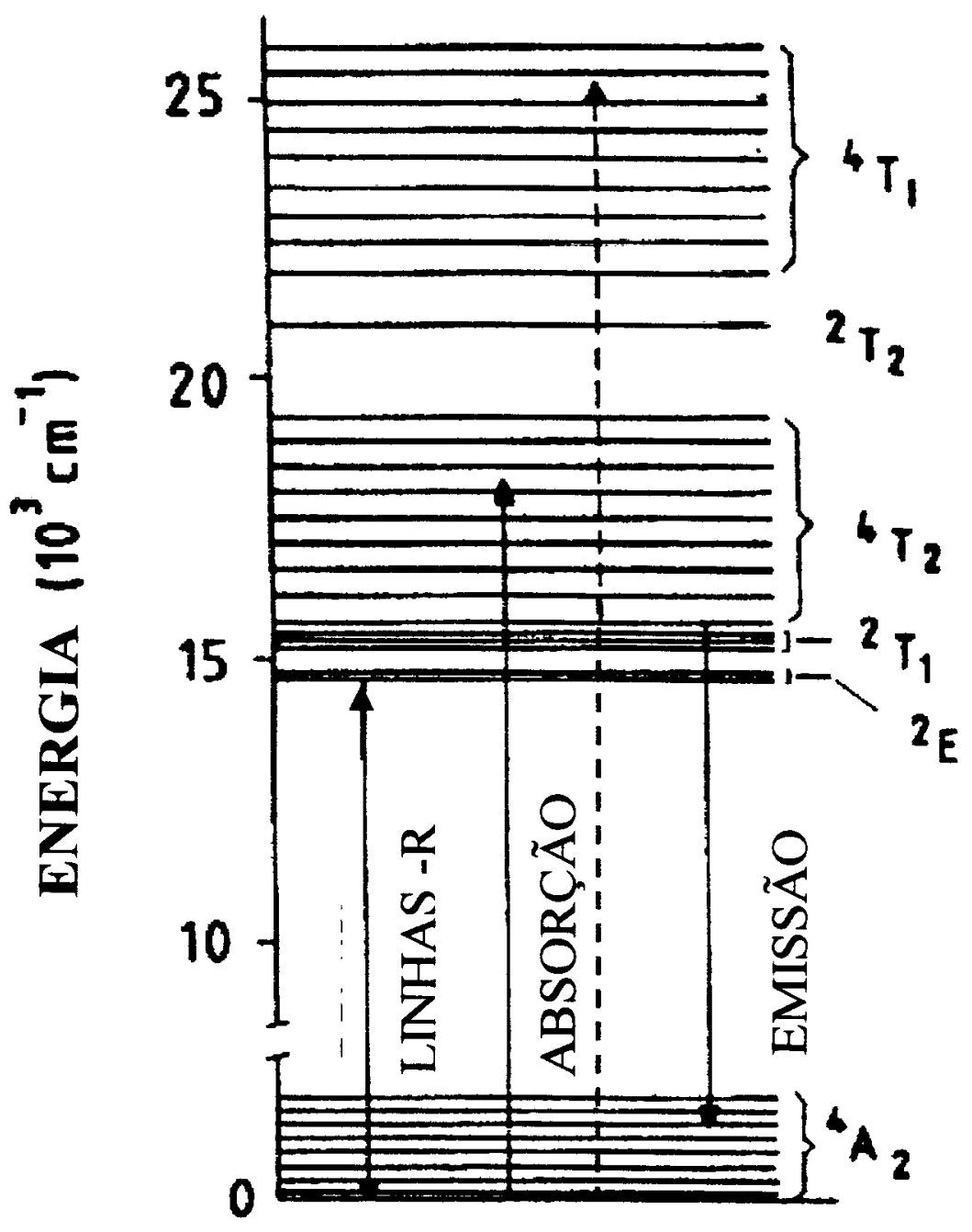

Figura 5 - Diagrama de níveis de energia para íons $\mathrm{Cr}^{3+}$ localizados sobre um plano de reflexão de alexandrita. Adaptado da referência [5].

No espectro de absorção as bandas largas são associadas com transições a partir do estado fundamental ${ }^{4} \mathrm{~A}_{2}$ para os estados excitados ${ }^{4} \mathrm{~T}_{2}$ (banda em torno de $590 \mathrm{~nm}$ ) e ${ }^{4} T_{1}$ (banda em torno de $420 \mathrm{~nm}$ ). Essas transições envolvem mudanças nos orbitais do campo cristalino dos elétrons e são portanto, altamente sensíveis ao campo cristalino em torno do íon.

As linhas do $\mathrm{Cr}^{3+}$ nos sítios localizados em um plano de reflexão, linhas $\mathrm{R}_{1} \mathrm{e}$ $\mathrm{R}_{2}$, aparecem precisamente no mesmo comprimento de onda, 680,4 e $678,5 \mathrm{~nm}$ 
respectivamente, em ambos os espectros, absorção e emissão, à temperatura ambiente. As linhas $\mathrm{R}$ são associadas com transições à partir do estado fundamental para o nível ${ }^{2} \mathrm{E}$, e envolvem pequenas mudanças nas funções de onda do elétron devido ao spin, sem mudanças nos estados do campo cristalino e portanto, aparecem como linhas estreitas [27].

No espectro de emissão as linhas $S_{1}$ e $S_{2}$, em torno de 695,8 e 689,9 nm são as transições de zero-fonon ${ }^{2} \mathrm{~T}_{1} \leftrightarrow{ }^{4} \mathrm{~A}_{2} \quad$ e aparecem como linhas estreitas em 655,7, 649,3 e 645,2 nm, respectivamente, no espectro de absorção óptica.

As linhas estreitas aqui descritas tem suas intensidades bastante diferentes para diferentes polarizações e à baixa temperaturas [43]. SUCHOCKI et al [60] apresentam o espectro de absorção da alexandrita à temperatura de $12 \mathrm{~K}$ e também os detalhes estruturais na região de 640 a 660 nm com variação de temperatura de 4 à 206K. Devido à simetria ortorrômbica da alexandrita, o cristal é opticamente biaxial [1]. No diagrama de níveis de energia a intensidade do campo cristalino regula a posição do nível ${ }^{2} \mathrm{E}$ (a qual gera a emissão da linha $\mathrm{R}$ estreita) com respeito à posição da banda de energia ${ }^{4} \mathrm{~T}_{2}$ ( a qual gera a emissão larga). Para intensidades de campo menores a banda ${ }^{4} T_{2}$ é abaixada, modificando as posições da banda de emissão. Os níveis largos são as bandas laterais vibrônicas fortes das transições ${ }^{4} \mathrm{~A}_{2} \rightarrow{ }^{4} \mathrm{~T}_{2} \mathrm{e}^{4} \mathrm{~A}_{2} \rightarrow$ ${ }^{4} \mathrm{~T}_{1}$. O parâmetro que mede a força do campo cristalino é $\mathrm{Dq} / \mathrm{B}$, onde $\mathrm{Dq}$ é o acoplamento entre o campo cristalino eletrostático e o campo Coulombiano, e B é o parâmetro de Racah o qual leva em conta a interação elétron-elétron [5]. A partir da posição média do pico das bandas de absorção, os valores Dq e B podem ser calculados [61] e para alexandritas tem-se que $10 \mathrm{Dq}=1739 \mathrm{~cm}^{-1}$ e $\mathrm{B}=650 \mathrm{~cm}^{-1}$. 
$\mathrm{Na}$ literatura são encontrados também, outros trabalhos investigando as propriedades ópticas da alexandrita, atribuídas principalmente aos ions de $\mathrm{Cr}^{3+}$ localizados nos planos de reflexão $\left(\mathrm{Al}_{2}\right)$. Por exemplo, no trabalho apresentado por SUN et al [62], é feita uma análise do decaimento da fluorescência da emissão de alexandrita com alta dopagem de $\mathrm{Cr}^{3+}$, com propósitos de aplicação para sensores ópticos. De acordo com os autores, um decaimento de exponencial dupla da emissão foi observado, diferindo da exponencial simples que ocorre para concentrações mais baixas do íon ativo $\mathrm{Cr}^{3+}$, e a origem do fenômeno foi investigada tanto experimentalmente como teoricamente, encontrando-se que o fenômeno vêm do $\mathrm{Cr}^{3+}$ tanto nos sítios $\mathrm{Al}_{1}$ como $\mathrm{Al}_{2}$. Assim, em relação às propriedades ópticas da alexandrita, a bibliografia é bastante ampla e muitos trabalhos tem sido reportados nas últimas décadas e, no presente trabalho, tais propriedades também foram identificadas a fim de, principalmente, auxiliar na compreensão da caracterização elétrica, através de medidas de Corrente de Despolarização Termicamente Estimulada, as quais são feitas pela primeira vez em alexandritas. 


\section{MÉTODOS EXPERIMENTAIS}

Nosso trabalho é centrado na investigação de alexandrita, através das medidas de Corrente de Despolarização Termicamente Estimulada (CDTE). No entanto, foi necessário a utilização de outras técnicas experimentais auxiliares com o intuito de fornecer subsídios necessários à interpretação dos resultados obtidos a partir de CDTE, conforme mencionado anteriormente. Assim, as três etapas descritas no início deste trabalho, preparação das amostras, no sentido de adaptá-las as diversas técnicas experimentais utilizadas, com posterior identificação dos elementos presentes e obtenção de informações cristalográficas de interesse (i), caracterização óptica das amostras com a determinação de parâmetros espectroscópicos (ii), e caracterização elétrica das amostras com a determinação dos parâmetros de relaxação dipolar elétrica desse material (iii) são correlacionadas e com isso obtemos um modelo que explica o comportamento de relaxação dipolar elétrica de alexandritas.

Neste capítulo é feita uma breve descrição das amostras utilizadas neste trabalho e a seguir são apresentadas as técnicas experimentais utilizadas na identificação da composição química das amostras (Espectroscopia por Dispersão de Energia de Raios X -EDX e Espectroscopia por Dispersão de Comprimentos de Onda de Raios-X - WDX), na análise estrutural (Difração de Raios-X), na caracterização óptica (Absorção e Emissão Óptica) e na caracterização elétrica (Corrente de Despolarização Termicamente Estimulada-CDTE). É dado maior destaque à técnica de CDTE por se tratar da principal ferramenta por nós utilizada na caracterização de alexandritas. As características que envolvem o estudo de dipolos elétricos também são apresentados neste capítulo. 


\section{1 - PREPARAÇÃO DAS AMOSTRAS, MICROANÁIISE E ANÁIISE ESTRUTURAL}

Nessa seção é feita uma abordagem dos procedimentos seguidos na preparação das amostras e também de alguns critérios adotados na escolha de quais amostras serão utilizadas em cada uma das técnicas experimentais que são apresentadas ao longo desse capítulo. As técnicas de EDX/WDX e difração de raios $\mathrm{X}$ são brevemente descritas, sendo que os principais objetivos na utilização dessas técnicas foram a determinação dos elementos presentes nas amostras e suas concentrações, através das microanálises elementares por EDX/WDX e a verificação dos parâmetros de rede das amostras naturais e de sua estrutura cristalina, através da técnica de difração de raios $\mathrm{X}$, utilizando o método do pó $[46,63]$.

\subsection{1 - PREPARAÇÃO DAS AMOSTRAS}

As amostras de alexandritas naturais são provenientes do Estado de Minas Gerais, sendo sua forma original bastante irregular, apresentando-se como pequenas pedras de aproximadamente $1 \mathrm{~cm}^{2}$ e espessura em torno de $5 \mathrm{~mm}$, de cor verde escura, passando ao vermelho claro quando expostas a luz de lâmpada incandescente, sendo esse um forte indício da qualidade de nossas amostras naturais que apresentaram mais de $50 \%$ de mudança de cor em seu volume, quando iluminadas com uma lanterna de lâmpada de tungstênio. As pedras apresentam incrustações que, em alguns casos, originam uma cor esbranquiçada e aspecto leitoso, deixando bastante evidente não serem um material puro, como era de se esperar de um cristal natural. 
Uma das características desse material é o fato de possuir alta resistência mecânica, com 8,5 de dureza na escala de Mohs [6] e módulo de Young em torno de $0,469 \times 10^{12} \mathrm{~Pa}[4,10]$, e portanto dificil de ser cortado. Assim, para obtermos amostras com faces planas e paralelas recorremos ao uso de um disco diamantado para cortarmos as pedras, originando amostras de espessuras que variavam de 1,17 à $2,86 \mathrm{~mm}$.

Uma das amostras foi lapidada manualmente com lixas finas \# 400 e \# 600, movimentando-se a amostra de forma a descrever um oito e alternando-se, periodicamente, a face lapidada e, no final do processo, foi feita a limpeza da amostra com acetona. Depois de lapidada a amostra foi polida utilizando-se uma politriz não comercial, em nosso próprio laboratório. A amostra foi fixada através de uma camada de cera de abelha previamente derretida, em uma peça cilíndrica de aço inox. Aplicando-se uma pequena pressão sobre a amostra, inicia-se o polimento, utilizandose nujol e carburundum 2000 entre a amostra e a base da politriz, que faz a amostra girar com frequeência regulável. Por se tratar de um material bastante duro e resistente, o tempo destinado à lapidação e polimento foi relativamente grande, em torno de 24 horas e, uma das dificuldades encontrada ao se trabalhar com esse material é que ele tende a se esfarelar quando polido, o que provavelmente seja devido a existência de diversas outras impurezas presentes nas amostras, formando inclusões sólidas, cuja existência foi depois verificada. A tentativa de se lapidar e polir esse material advém da necessidade de termos amostras livres de rugosidade e imperfeições superficiais em, basicamente, todas as técnicas que planejamos utilizar. Por não dispormos de muitas amostras naturais, pois as pedras são relativamente pequenas e ainda, durante o corte com disco diamantado ocorrer um fator de perda relevante, as amostras foram 
divididas de forma a serem utilizadas de acordo com suas características macroscópicas (tamanho, regularidade das faces e transparência) nas diferentes técnicas experimentais, conforme é apresentado na Tabela 5, onde as amostras naturais são designadas pela sigla "AN" .

No caso da alexandrita sintética foi utilizada uma única amostra, crescida nos E.U.A., por H.P. Jenssen e R.Morris (Allied Signal Inc.), pelo método de Czochralsky e gentilmente cedida pelo prof. Dr. Tomaz Catunda, do DFI-USP-São Carlos. A área dessa amostra é de aproximadamente $35 \mathrm{~mm}^{2}$ e espessura de $2,32 \mathrm{~mm}$ e apresenta faces perfeitamente paralelas e brilho não metálico, de aparência translúcida ${ }^{3}$ esverdeada mudando para o vermelho quando exposta a luz de lâmpada incandescente. Na Tabela 5 a amostra sintética é designada "AS1".

Tabela 5- Características macroscópicas das amostras utilizadas e técnicas experimentais a que foram submetidas. "AN" refere-se as amostras naturais e "AS" a amostra sintética.

\begin{tabular}{|c|c|c|c|c|}
\hline Amostra & origem & cor & $\begin{array}{l}\text { Espessura } \\
\text { (mm) }\end{array}$ & Técnicas \\
\hline AN1 & pedra 1 & Verde opaca & 1,92 & Absorção /CDTE/ EDX \\
\hline AN2 & pedra 2 & Verde opaca & 2,86 & Absorção/CDTE \\
\hline AN3 & pedra 3 & $\begin{array}{c}\text { Verde } \\
\text { translúcida }\end{array}$ & 2,03 & $\begin{array}{c}\text { CDTE/Absorção/Luminescência/ } \\
\text { EDX }\end{array}$ \\
\hline AN4 & pedra 3 & Verde opaca & Irregular & EDX/WDX/Raios X \\
\hline AN5 & pedra 4 & $\begin{array}{c}\text { Verde } \\
\text { translúcida }\end{array}$ & 1,17 & $\begin{array}{c}\text { CDTE/Absorção/ } \\
\text { Luminescência/EDX }\end{array}$ \\
\hline AS1 & - & $\begin{array}{c}\text { Verde } \\
\text { translúcida }\end{array}$ & 2,32 & $\begin{array}{c}\text { CDTE/Absorção/luminescência/ } \\
\text { EDX/WDX/Raios-X }\end{array}$ \\
\hline
\end{tabular}

\footnotetext{
${ }^{3}$ Em Mineralogia é utilizado o termo "brilho vitreo", para descrever a aparência de minerais com brilho não metálico (minerais que são claros e transmitem luz através de suas bordas delgadas) [46]
} 
O conjunto de amostras escolhidas e apresentadas na Tabela 5, juntamente com as diversas técnicas experimentais citadas na última coluna, a que foram submetidas cada uma delas, foi determinado levando-se em conta que nas medidas de CDTE é necessário a utilização de amostras possuindo superficies planas e paralelas, sendo as melhores amostras a AN3 e AN5. Estas amostras foram também utilizadas nas medidas de absorção óptica nas regiões do ultravioleta, visível e infravermelho por serem também, as mais transparentes. A fim de otimizarmos o uso das amostras disponíveis, a parte restante da pedra que originou a amostra AN3, foi chamada de AN4, com formato irregular, e portanto a única a ser utilizada em uma técnica destrutiva, como no caso da técnica de Difração de Raios $\mathrm{X}$ pelo método do pó.

As amostras AN1 e AN2, obtidas a partir de pedras diferentes, também foram utilizadas nas medidas iniciais de CDTE e absorção óptica na região UV-VIS, entretanto, por serem muito espessas e opacas, foram abandonadas após ter se tentado a lapidação de $\mathrm{AN} 1$, como mencionado anteriormente. A amostra sintética, sendo única, foi submetida a todas as medidas de interesse, tomando-se o cuidado de não utilizá-la em análises destrutivas.

\subsection{2 - MICROANÁIISE POR EDX/WDX}

A microanálise através da técnica de Espectroscopia por Dispersão de Energia de Raios $\mathrm{X}$ (EDX) foi realizada para todas as amostras utilizadas, com exceção apenas da amostra AN2 (muito opaca e espessa). Achamos conveniente realizar essa análise de forma abrangente, por estarmos trabalhando com amostras 
naturais e portanto, com possibilidades de apresentarem características microscópicas diferentes, o que poderia acarretar resultados não reprodutíveis de uma amostra para outra. Além da técnica de EDX, foi realizada também a microanálise através da técnica de Espectroscopia por Dispersão de Comprimentos de Onda de Raios X (WDX), na tentativa de se conseguir uma determinação mais completa da composição química de nossas amostras.

O termo microanálise origina-se da capacidade de realização de análises químicas elementares em volumes muito pequenos, da ordem de um micrômetro cúbico. A técnica de EDX é baseada na medição da energia do fóton emitido e possui resolução geralmente da ordem de $138 \mathrm{eV}$. A técnica de WDX identifica os elementos com base no comprimento de onda da luz emitida, sendo o comprimento de onda inversamente proporcional ao número atômico e tem resolução da ordem de 5 à 20 eV. A diferença básica entre as duas técnicas está nos detetores utilizados para a medida de intensidade de raios-X. Nos EDX os detetores são materiais semicondutores e possuem softwares bastante sofisticados para processamento dos sinais de intensidade dos raios-X. entretanto, mesmo que tal sistema produza análises bastante rápidas ele não possui a mesma resolução e precisão do WDX que, em geral, utiliza dois tipos de detetores em um mesmo dispositivo, denominados contador de fluxo proporcional (FPC) e contador proporcional vedado (SPC), sendo que cada detetor atua em uma faixa específica de emissão de raios $\mathrm{X}$, e constituem sistemas mecânicos de alta precisão. Os detetores de EDX e WDX podem ser ajustados para permitir a passagem de sinais correspondentes a apenas um pico espectral, característico de determinado elemento. A análise pode ser qualitativa e quantitativa para elementos com número atômico, $Z$, maior do que 10 , com limite de deteç̧ão a 
partir de $100 \mathrm{ppm}$ e apenas qualitativa para $Z$ entre 5 e 10 . A técnica de WDX tem sensibilidade até $100 \mathrm{ppm}$ e a EDX de 1000ppm. A sensibilidade é baixa para elementos leves em uma matriz pesada e a análise quantitativa é limitada a superficies planas e polidas $[64,65]$.

As análises de EDX foram realizadas no Laboratório de Microscopia do DFCM-IFSC/USP e WDX no Laboratório de Análise Microestrutural do CCDM/UFSCar-UNESP. A desvantagem no uso dessas técnicas foi a impossibilidade de uma análise quantitativa de linhas de elementos leves, como o berílio $(Z=4)$ e, no caso do oxigênio $(Z=8)$, embora tenha sido detectado por WDX, o erro associado a medida é considerado grande comparado aos elementos com $Z>10$. A amostra sintética por ser perfeitamente plana e polida não necessitou de nenhuma preparação especial , além das necessárias às medidas de WDX/EDX, e a amostra natural AN4, por apresentar superficies não planas foi embutida em uma resina e polida antes de ser submetida a análise de WDX. As análises de EDX/WDX são apresentadas no capítulo 4.

\section{1 .3 - DIFRAÇÃo DE RAIOS-X}

O objetivo da utilização da técnica de Difração de Raios X, foi comprovar a estrutura cristalina ortorrômbica das amostras naturais assim como confirmar seus parâmetros de rede.

A difração de raios $\mathrm{X}$ pelos cristais resulta de um processo em que os raios $\mathrm{X}$ são dispersos pelos elétrons dos átomos sem mudança de comprimento de onda (dispersão coerente ou de Bragg). Um feixe difratado é produzido por dispersão só 
quando algumas condições geométricas, expressas pela lei de Bragg ( $\mathrm{n} \lambda=2 \mathrm{~d} \operatorname{sen} \theta)$, são satisfeitas. A difração resultante de um cristal, compreendendo posições e intensidades das linhas de difração, é uma propriedade fisica fundamental da substância, servindo não só à identificação como também ao estudo de sua estrutura [63]. Portanto, a caracterização de minerais (ou fases) pode ser efetuada com o auxílio da difração de raios $\mathrm{X}$ sendo que, os espaçamentos interplanares (valores de d) constituem características fisicas de um material, a exemplo da densidade, do índice de refração e etc.

Essas medidas foram realizadas no CCDM-UFSCar-UNESP, no Laboratório de Difração de Raios X. As condições de ensaio foram: intervalo $2 \theta$ de $5^{\circ}$ à $80^{\circ}$, fenda de divergência e fenda de antiespalhamento igual a $3^{\circ}$, passo de $0,033^{\circ}$, tempo de exposição de 1s, porta amostra giratório com velocidade de $120 \mathrm{rpm}$ e monocromador secundário de grafite. $\mathrm{O}$ equipamento utilizado foi um Difratômetro Siemens D500 operando com a linha $\mathrm{K}_{\alpha}$ de emissão do $\mathrm{Cu}$ e comprimento de onda $1,5406 \AA$ e os difratogramas resultantes foram processados pelo programa original do equipamento, sendo então realizada a indexação dos planos cristalográficos segundo a tabela do crisoberilo para a obtenção dos índices de Miller. Os difratogramas de raios X obtidos são apresentados no capítulo 4 .

\section{2 - TÉCNICAS EXPERIMENTAIS UTILIZADAS NA DETERMINAÇÃO DOS PARÂMETROS ESPECTROSCÓPICOS.}

A realização de medidas ópticas nesse trabalho, conforme descrevemos a seguir, visam explorar, de forma conveniente, algumas propriedades ópticas já 
conhecidas na literatura. Com isso, obtemos informações auxiliares para a interpretação dos resultados de CDTE.

\subsection{1 - ABSORÇÃo ÓPTICA}

A utilização desta técnica nos permite estudar propriedades ópticas de materiais, que são influenciadas pela presença de impurezas na rede hospedeira. A técnica de absorção óptica se refere à absorção, por uma amostra, de radiação eletromagnética com comprimentos de onda na faixa do infravermelho até o ultravioleta. A energia absorvida acusa transições entre os níveis de energia eletrônico dos átomos, centros de cor, etc, ou transições da banda de valência para a banda de condução. Através dessa técnica podemos obter a concentração de impurezas, N, utilizando a fórmula de SMÁKULA [66,67]:

$$
N=0,87 \times 10^{17} \frac{n}{\left(n^{2}+2\right)^{2}} 1240\left(\frac{1}{\lambda_{1}}-\frac{1}{\lambda_{2}}\right) 2,303 \frac{D . O .}{f e}
$$

Nessa equação, $n$ e $f$, índice de refração para o pico da banda e força do oscilador, respectivamente, podem ser obtidos na literatura para diversos materiais; $\lambda_{1}$ e $\lambda_{2}$ (ambos em nm), comprimentos de onda que definem a largura a meia altura da banda, $D . O$, densidade óptica, são obtidos a partir do espectro de absorção e $e$ (cm) é a espessura da amostra. A constante $0,87 \times 10^{17}\left(\mathrm{~cm}^{-1}\right)$ é utilizada considerandose que a forma da curva obtida seja uma Gaussiana. 
Sendo densidade óptica, $D . O$, ou absorbância definida como:

$$
\text { D.O. }=\log _{10}\left(\frac{I_{0}}{I}\right)
$$

onde $I_{0}$ é a intensidade de luz transmitida por um cristal não dopado e $I$ é a intensidade de luz de um cristal dopado.

A partir de resultados experimentais temos:

$$
N=2,303 \sigma \frac{D . O}{e}
$$

onde $\sigma\left(\mathrm{cm}^{-2}\right)$ é o inverso da seção de choque.

O coeficiente de absorção óptica ( $\alpha$ ) pode ser calculado como:

$$
\alpha=2,303 \frac{D . O}{e}
$$

É interessante observar que, conforme descrito por BURNS [39], várias constantes têm sido utilizadas para expressar a absorção sendo que todas elas são baseadas na equação geral:

$$
\log _{10}\left(\frac{I_{0}}{I}\right)=a b
$$

onde $I_{0}$ é a intensidade da luz incidente, $I$ é a intensidade da luz emergente, $a$ é a constante de absorção e $b$ é uma constante que depende das condições da medida.

As numerosas constantes de absorção encontradas na literatura têm origem a partir da escolha de quantidades incorporadas na constante $b$. Alguns dos termos mais comuns usados para expressar absorção em minerais são resumidos na Tabela 6. 
Tabela 6- Vários termos usados para absorção. ${ }^{*} e$ é a espessura do material; $C$ é a concentração das espécies absorvedoras [39].

\begin{tabular}{ccc}
\hline Termo & Símbolo & Equação $^{*}$ \\
\hline Transmissão & T & $T=I / I_{0}$ \\
Absorção & A & $A=I-T=I / I_{0}$ \\
Densidade óptica ou absorbância & D.O. & $D . O .=\log _{10}\left(I_{0} / I\right)$ \\
Coeficiente de absorção ou coeficiente de extinção & $\alpha$ & $\alpha=\log _{10}\left(I / I_{0}\right) / e$ \\
Coeficiente de extinção molar & & $\varepsilon=\log _{10}\left(I_{0} / I\right) C e$ \\
\hline
\end{tabular}

Os espectros de absorção óptica foram obtidos utilizando-se um espectrofotômetro Cary 17, possuindo intervalo espectral de varredura de 185 a 2500 nm. As medidas de absorção na região UV-VIS foram realizadas à $300 \mathrm{~K}$ (TA) e 77 $\mathrm{K}$ (TNL). Nas medidas à temperatura de nitrogênio líquido utilizamos um dos criostatos não comerciais existente em nosso laboratório, que permite o resfriamento da amostra à temperatura de $77 \mathrm{~K}$, num curto espaço de tempo, da ordem de 5 à 15 minutos.

Também foram obtidos os espectros de absorção óptica na região do infravermelho (IV), utilizando-se um espectrofotômetro BOMEM DA8, no intervalo espectral de 2500 a $22222 \mathrm{~nm}\left(4000\right.$ à $\left.450 \mathrm{~cm}^{-1}\right)$, à temperatura ambiente. As medidas na região do infravermelho servem, por exemplo, para o estudo de grupos moleculares que podem estar presentes em nossas amostras, como por exemplo $\mathrm{H}_{2} \mathrm{O}$.

Desde que eventuais processos térmicos possam alterar as características do material, como a formação de agregados, processos de difusão ou desagregação, utilizamos a técnica de absorção óptica no UV-VIS e IR , paralelamente às medidas 
de CDTE como ferramenta auxiliar na interpretação dos resultados obtidos com essas medidas. Nos espectros de absorção óptica na região do ultravioleta (UV) e visível (VIS) a resolução foi sempre igual à $0,5 \mathrm{~nm}$ e nos espectros de absorção óptica na região do infravermelho (IV) a resolução foi de $1,0 \mathrm{~cm}^{-1}$.

\section{2 .2 - LUMINESCÊNCIA}

Os espectros de emissão óptica de alexandritas, tanto natural quanto sintética, são também bastante conhecidos [27]. Em vista disso, foram obtidos os espectros de luminescência para nossas amostras em primeiro lugar, com o objetivo de verificar o seu comportamento e então compará-lo com os espectros apresentados na literatura, certificando assim mais uma vez, a qualidade de nossas amostras, principalmente as naturais. Pudemos também realizar uma comparação das posições e intensidade das linhas de emissão entre os dois tipos de amostras utilizadas, natural e sintética, o que pode fornecer informações auxiliares importantes na interpretação das medidas de CDTE.

$O$ arranjo experimental utilizado nas medidas de luminescência [68] foi montado em nosso próprio laboratório pelos alunos de pós-graduação Antônio Carlos de Castro e Fábio Simões de Vicente e, o diagrama esquemático simplificado [69] é mostrado na Figura 6. Foi utilizado como fonte de excitação um laser

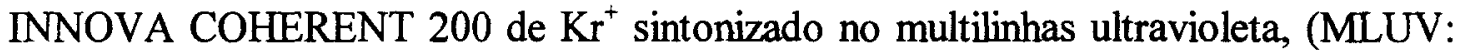
$337,5 \mathrm{~nm}, 350,7 \mathrm{~nm}$ e $356,4 \mathrm{~nm}$ ), o qual provoca uma mudança de $100 \%$ na cor da

amostra, excitando uma das bandas de absorção do $\mathrm{Cr}^{3+}$. $\mathrm{O}$ feixe do laser 
sintonizado no MLUV, utilizado nas medidas de luminescência, corresponde às linhas de energia mais alta disponíveis em nosso laboratório.

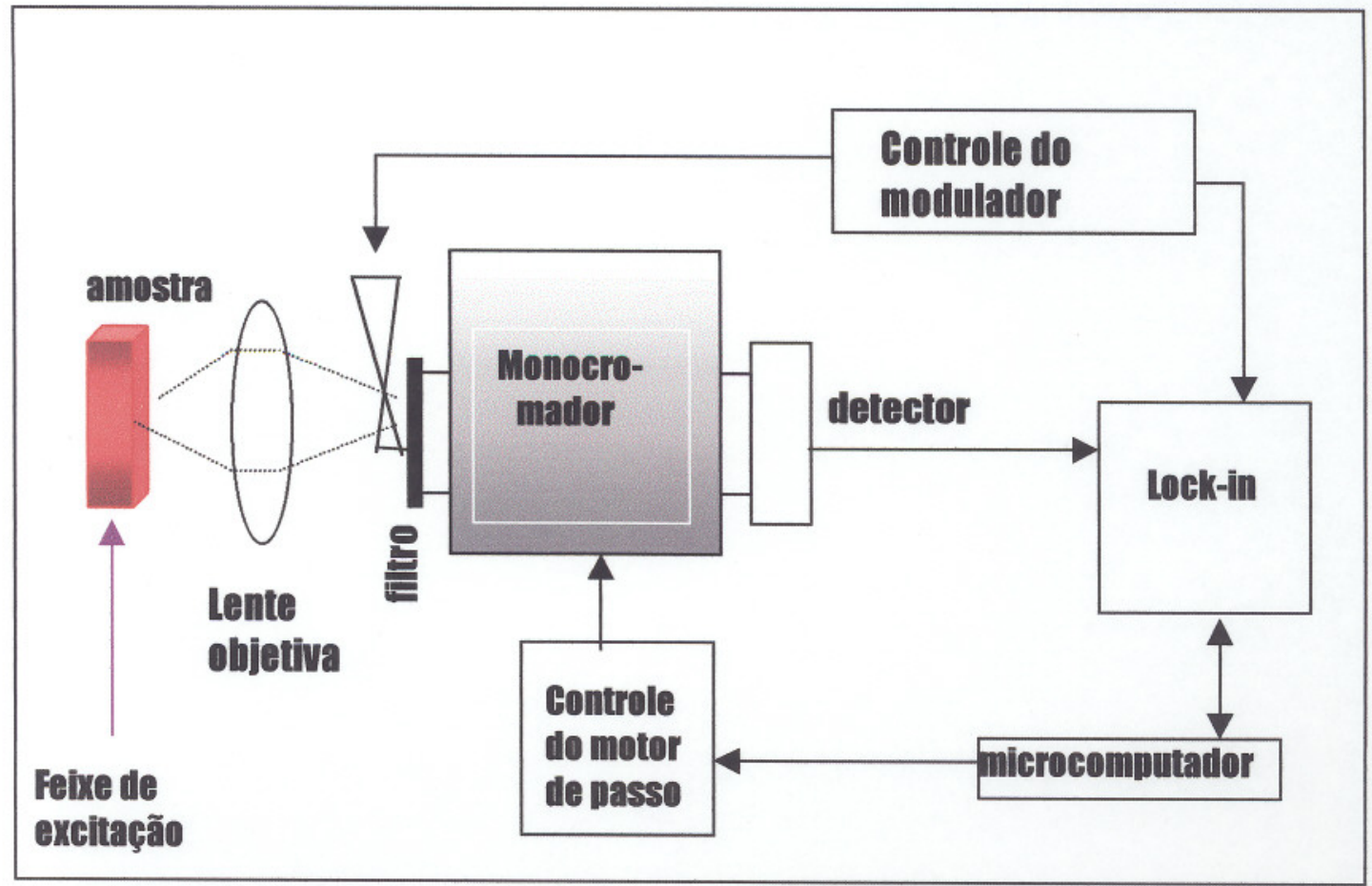

Figura 6- Diagrama esquemático do sistema de medidas de luminescência. Extraído da referência [69].

O feixe do laser é direcionado por espelhos e focalizado na amostra por meio de uma lente e um outro espelho desvia o feixe, bombeando a amostra de modo que a geometria da luminescência fique paralela à fenda de entrada do monocromador, conforme é mostrado na Figura 6 . A luz emitida é focalizada por uma lente objetiva e modulada por um "chopper" e a dispersão da luminescência é feita por um monocromador Thermo Jarrell Ash, com rede de difração de $1200 \mathrm{~g} / \mathrm{mm}$ e blaze de 500nm, medindo no intervalo de 380 à $900 \mathrm{~nm}$, e detectado com uma fotomultiplicadora HAMAMATSU R446. O sinal é enviado para um lock-in ligado a um microcomputador que faz a aquisição do sinal gerado e também monitora o 
posicionamento do motor de passo do monocromador. A luz do laser é filtrada conforme indicado no esquema da Figura 6, garantindo que o sinal detectado pelo monocromador é proveniente apenas da luminescência da amostra.

\section{3 - CORRENTE DE DESPOLARIZAÇÃO TERMICAMENTE ESTIMULADA - CDTE}

O objetivo principal que deu origem a este trabalho consiste na utilização de técnicas experimentais que proporcionem a caracterização elétrica de cristais de alexandrita. $\mathrm{Na}$ literatura, as propriedades elétricas desse material não são discutidas ou apresentadas, embora muitas questões a respeito de suas características, comportamento e utilização continuem sendo levantadas e investigadas. Nesse contexto, consideramos ser bastante interessante a aplicação em alexandritas da técnica de Corrente de Despolarização Termicamente Estimulada, CDTE, a qual tem sido largamente empregada no estudo de diversos materiais como por exemplo, sólidos iônicos (por exemplo, filmes e cristais de haletos alcalinos da família $\mathrm{KCl}$, dopados com impurezas metálicas [70,71] ), polímeros [72,73], óxidos [74] e até mesmo em semicondutores [75].

Assim, nesta seção, é dado ênfase à técnica de medidas de CDTE, a qual constitui a principal técnica utilizada neste trabalho e é feita uma descrição mais detalhada dos princípios básicos envolvidos e do procedimento experimental utilizado. 


\subsection{1 - PRINCÍPIOS BÁSICOS}

Medidas de CDTE datam de 1936 quando FREI e GROETZINGER [25] propuseram incrementar a mobilidade de cargas congeladas pelo aquecimento suave de eletretos colocados entre dois eletrodos conectados a um medidor de corrente para detectar a corrente de descarga. A técnica foi depois amplamente utilizada por outros autores e todos eles faziam uso de um aumento de temperatura arbitrário e muitos estudos foram feitos com materiais complexos, como cera, resinas, cerâmicas e plásticos. Entretanto, as primeiras bases teóricas do fenômeno de corrente de despolarização estimulada termicamente foram introduzidas somente em 1964, por BUCCI e FIESCHI [21] com seus trabalhos sobre defeitos dipolares em cristais iônicos, sendo que, até então, os efeitos de polarização devido ao movimento iônico eram essencialmente estudados através de dois métodos: considerando-se a variação, no tempo, da corrente elétrica na amostra sujeita a um campo externo dc, ou, por medidas de perdas dielétricas em função da temperatura. Essa técnica foi chamada inicialmente de "Termocondutividade Iônica" ou "Termocorrente Iônica" (ITC) e desde então, muitos autores se dedicaram a investigar o fenômeno de relaxação dipolar usando procedimentos muitos similares entre si e muitos nomes diferentes foram dados ao mesmo tipo de medida ${ }^{4}$. A técnica de CDTE mostrou ser um método bastante sensivel e preciso na determinação de parâmetros fisicos, como o tempo de relaxação $(\tau)$ associado aos defeitos, a energia de ativação $\left(E_{a}\right)$ com que os defeitos se reorientam dentro do material hospedeiro e o tamanho do dipolo (p) responsável pela relaxação dipolar, em materiais sólidos, por meio de uma única medida. Um dos pré

\footnotetext{
4 Alguns termos encontrados na literatura são : "electret thermal analysis", "thermally stimulated discharge"; "thermal current spectra": "thermally stimulated depolarization"; "thermally activated depolarization", [25].
} 
requisitos para detectar o comportamento de defeitos em sólidos, através dessa técnica, é que possuam comportamento clássico e apresentem características de dipolo elétrico [76,77].

Assim, considerando um sistema de $\mathrm{N}$ dipolos $/ \mathrm{cm}^{3}$, sendo cada dipolo de magnitude $\mathrm{p}$, livres no espaço submetido a um campo elétrico $\mathrm{E}$, a energia potencial U do dipolo p será:

$$
\mathrm{U}=-\mathbf{p} \cdot \mathbf{E}=-\mathrm{pE} \cos \theta
$$

onde $\theta$ é o ângulo entre a direção do dipolo e a direção do campo. A polarização total do sistema vem a ser:

$$
\mathrm{P}=\mathrm{Np}\langle\cos \theta\rangle
$$

$\langle\cos \theta\rangle$ representa o valor médio de uma distribuição em equilibrio térmico, e pode ser determinada através da distribuição de Boltzmann. A lei de distribuição de Boltzmann que diz respeito à probabilidade relativa de encontrar um dipolo num elemento de ângulo sólido $\mathrm{d} \Omega$ é proporcional a $\mathrm{e}^{-\mathrm{U} / \mathrm{kT}}$, onde $\mathrm{k}$ é a constante de Boltzmann, e:

$$
\langle\cos \theta\rangle=\frac{\int e^{-U / k T} \cos \theta d \Omega}{\int e^{-U / k T} d \Omega}
$$

integrando sobre o ângulo sólido, teremos:

$$
\langle\cos \theta\rangle=\frac{\int_{0}^{\pi} 2 \pi \operatorname{sen} \theta \cos \theta e^{p E \cos \theta / k T} d \theta}{\int_{0}^{\pi} 2 \pi \operatorname{sen} \theta e^{p E \cos \theta / k T} d \theta}
$$


para simplificar o cálculo definimos $s=\cos \theta$ e $x \equiv p E / k T$, de modo que:

$$
\langle\cos \theta\rangle=\frac{\int_{-1}^{1} e^{s c} s d s}{\int_{-1}^{1} e^{s x} d s}=\operatorname{coth} x-\frac{1}{x}
$$

Este resultado define a função de Langevin $\mathrm{L}(\mathrm{x})$ [76], cujo gráfico está representado na Figura 7.

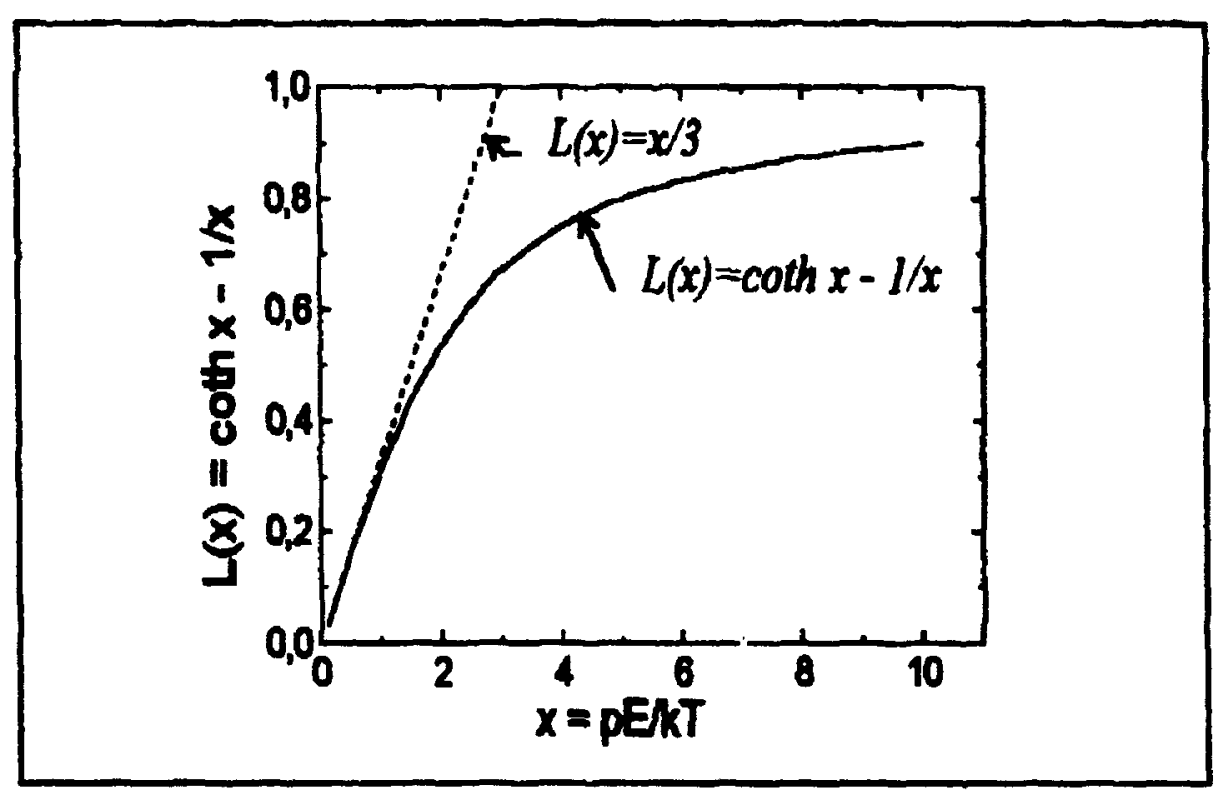

Figura 7 - Gráfico da função de Langevin $\mathrm{L}(\mathrm{x})$

É possivel, então, observar que para valores $\mathrm{E} \gg>\mathrm{kT}$, o gráfico apresenta saturação, e para o caso contrário de $\mathrm{E}<<\mathrm{kT}$ a curva se ajusta a uma reta, isto é:

$$
L(x)=\operatorname{coth} x-\frac{1}{x} \approx \frac{x}{3}=\frac{p E}{3 k T}
$$


A polarização do sistema de dipolos será então [78]:

$$
P=n p\langle\cos \theta\rangle=\frac{N p^{2} E}{3 k T}
$$

Para o caso em que o sistema de dipolos está dentro de um sólido, por exemplo monocristalino, é esperado que os dipolos se encontrem orientados aleatoriamente em direções preferenciais cristalográficas de equilíbrio, uma vez que o campo cristalino deve, de certa forma, interferir na reorientação dos dipolos. Considerando que cada dipolo possua $\mathrm{g}$ posições reorientáveis equivalentes de equilibrio cristalográficos, teremos que a polarização pode ser reescrita da seguinte maneira:

$$
P=N p\langle\cos \theta\rangle=\frac{N p \sum_{i=1}^{g} \cos \theta_{i} e^{-U_{i} / k T}}{\sum_{i=1}^{g} e^{-U_{i} / k T}}
$$

o sub-índice $i$ representa a i-ésima posição de equilíbrio do dipolo.

O esquema do processo fisico de CDTE é mostrado na Figura 8 e o método das medidas pode ser descrito da seguinte forma:

1) A amostra é primeiramente, polarizada em um campo elétrico $E_{p}$ por um tempo $t_{p}$, à uma temperatura de polarização $T_{p}$. Essa temperatura deve ser tal que os dipolos ainda possam ser orientados estatisticamente com o campo elétrico aplicado no instante $t_{1}$, e não pode ser muito alta, de forma a impedir fortes contribuições de 
carga espacial. Para assegurar uma boa polarização, devemos polarizar por um tempo $t_{p}>\tau\left(T_{p}\right)$

2) Em seguida, a temperatura na amostra é abaixada a $T_{0} \ll T_{p}$, de forma que o tempo de relaxação dos dipolos é bastante longo, impossibilitando sua reorientação a baixa temperatura. Dependendo da situação que se queira estudar, $\mathrm{T}_{0}$ pode ser temperatura de nitrogênio líquido ou temperatura de hélio líquido. Neste estágio podemos dizer que os dipolos encontram-se congelados e estatisticamente alinhados com o campo aplicado.

3) Após atingir a temperatura de hélio líquido (THL) ou a temperatura de nitrogênio líquido (TNL), o campo é retirado e um eletrômetro é ligado à amostra. Após esperar um certo tempo para que ocorra a descarga capacitiva inicial da amostra, esta é aquecida com uma taxa constante $b=d T / d t$, e a corrente é registrada como uma função da temperatura. O tempo de relaxação fica cada vez mais curto e uma corrente de despolarização $\mathrm{i}(\mathrm{T})$ será detectada quando os dipolos perdem sua orientação de polarização preferencial. Durante o tempo em que este processo ocorre, a corrente primeiro aumenta exponencialmente até atingir um valor máximo e então cai rapidamente, chamamos esta corrente de despolarização termicamente estimulada ou termo-estimulada CDTE (ou ITC). 


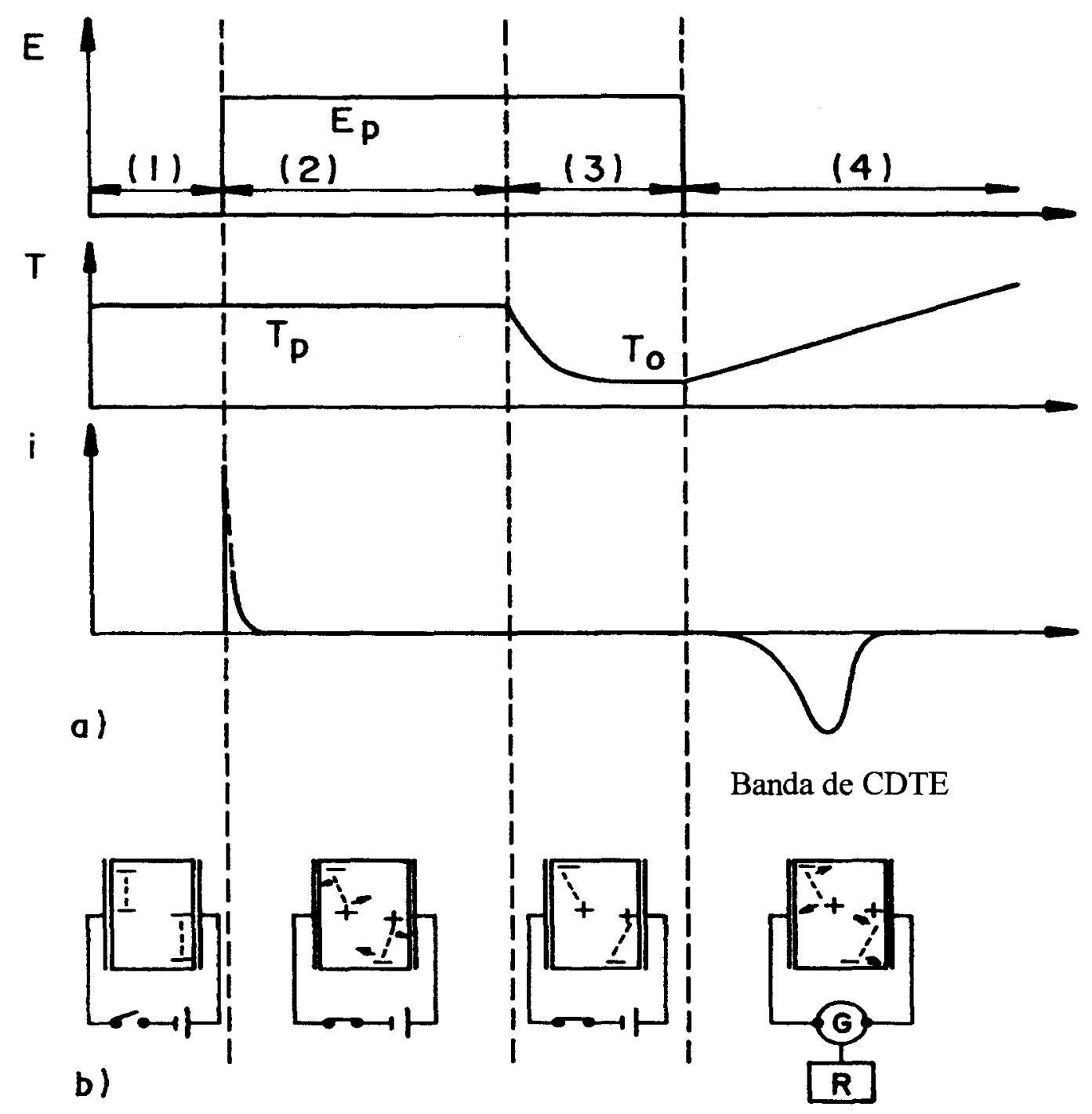

Figura 1- (a) representação esquemática do experimento de CDTE, mostrando os parâmetros campo elétrico (E), temperatura (T) e corrente (i), em função do tempo. Antes de aplicar o campo, a polarização é zero (0). Depois de aplicar o campo à $T_{p}$ (1), um rápido aumento de I é detectado, seguido de um decaimento exponencial enquanto a polarização é feita. $\grave{A} \mathrm{~T}_{0}$ o campo é removido (3). Sob aquecimento (4) um pico de corrente aparece. (b) esquema do movimento dos dipolos na amostra, correspondendo a situação fisica descrita em (a). Figura adaptada da referência [78]. 
Em nossas medidas foi utilizado um criostato óptico (Janis) modificado [71], onde a amostra é mantida em vácuo melhor do que $10^{-5}$ Torr. O campo elétrico de polarização teve seu valor definido de acordo com a espessura da amostra e o tempo de polarização foi de $5 \min$ e, após esse tempo, as amostras foram resfriadas até TNL. Para detectar a corrente utilizamos um eletrômetro Keithley 6517A, acoplado a um microcomputador que registra os dados de temperatura, tempo e corrente. A taxa de aquecimento foi mantida em torno de $0,10 \mathrm{Ks}^{-1}$. O aquecimento na amostra foi feito através de uma resistência de $250 \mathrm{~W}$, controlada manualmente e a temperatura é medida por meio de um termistor diodo de silício acoplado a um medidor digital OMEGA CYD201, colocado diretamente no dedo frio que suporta a amostra dentro do criostato. Os eletrodos nas amostras foram feitos pintando-se as faces maiores do cristal com tinta prata. A reprodutibilidade das medidas sobre diferentes amostras do mesmo cristal depende não somente da homogeneidade do cristal (sob o ponto de vista das impurezas) mas, também da qualidade dos eletrodos pintados.

A densidade de corrente $\mathrm{j}(\mathrm{T})$ que ocorre durante o processo de aquecimento, com taxa constante b, num experimento de CDTE é dada por:

$$
j(T)=\frac{P_{0}}{\tau} \sigma_{0} \exp \left(-\frac{E_{a}}{k_{B} T}\right) \exp \left[-\frac{1}{b \tau_{0}} \int_{T_{0}}^{T} \exp \left(-\frac{E_{a}}{k_{B} T^{\prime}}\right) d T \cdot\right]
$$

onde $E_{a}(\mathrm{eV})$ é a energia da barreira de potencial que os dipolos precisam vencer para reorientar-se noutra direção durante a relaxação, ou seja, é a energia de ativação; $k_{B}$ é constante de Boltzmann; $\tau_{0}$ é o fator pré-exponencial para o tempo de relaxação de Arrhenius e $b$ é a taxa de aquecimento. 
No processo clássico de relaxação por ativação térmica, a dependência do tempo de relaxação com a temperatura é representada pela equação de Arrhenius:

$$
\tau=\tau_{0} \exp \left(E_{a} / k T\right)
$$

onde $1 / \tau_{0}$ é a frequência vibracional do íon em torno de sua posição de equilíbrio e $\exp \left(E_{a} / k_{B} T\right)$ é o fator estatístico de Boltzmann. Nesse caso o íon se desloca de uma posição de equilíbrio para outra, ou seja, se desloca entre dois poços de potencial $i$ e $j$, ao adquirir energia térmica suficiente para vencer a barreira de potencial.

Assim, analisando um pico de CDTE podemos obter as seguintes informações:

(1) a área delimitada pela função $\mathrm{i}(\mathrm{T})$ é proporcional ao número de dipolos de uma dada espécie presente na amostra. A área sob a curva de $\mathrm{i}[\mathrm{A}]$ versus $\mathrm{t}[\mathrm{s}]$ nos permite calcular a carga total da polarização (Q) [79]. Assim, desde que saibamos a concentração de dipolos $\mathrm{N}$ podemos obter o valor do momento de dipolo, a partir da equação 13 , resultando em:

$$
p=\left(\frac{3 Q k_{B} T_{p} e}{N E_{p} A_{e}}\right)^{1 / 2}
$$

onde $A_{e}\left(\mathrm{~cm}^{2}\right)$ é a área dos eletrodos e $e(\mathrm{~cm})$ é a espessura da amostra.

(2) o gráfico de

$$
\ln \tau(T)=\ln \tau_{0}+\frac{E_{a}}{k_{B}} \frac{1}{T}=\ln \left[\int_{t(T)}^{\infty} i\left(t^{\prime}\right) d t^{\prime}\right]-\ln i(T)
$$

em função de $1 / T$ nos permite obter o valor da energia de ativação $E_{a} e$, consequentemente da constante de tempo $\tau_{0}$. 
Cálculos de $E_{a}$ e $\tau_{0}$ a partir de picos de CDTE podem ser feitos por diversos métodos dos quais, muitos, são similares aos métodos utilizados em termoluminêscencia [78]. Medidas de CDTE obedecendo um tratamento clássico de Debye, com um único tempo de relaxação, são raras e são encontradas por exemplo em alguns haletos alcalinos dopados com íons divalentes, onde cada dipolo impurezavacância pode ser esperado para relaxar independentemente quando a concentração de impurezas é baixa. Inúmeros trabalhos sobre cristais iônicos, tipo $\mathrm{NaCl}$, usando a técnica de CDTE existem na literatura e geralmente confirmam o comportamento de Debye.

O método proposto por BUCCI et al [23] é baseado em cálculos sucessivos de áreas parciais dos picos de CDTE, dando resultados com erros de $\pm 10 \%$ nos valores de $E_{a}$. Esse método exige que se tenha um pico bem resolvido e uma boa estimativa da corrente de fundo. PRAKASH [80] em 1986, propôs um novo método o qual eliminava automaticamente a corrente de fundo e são obtidos valores de $E_{a}$ com erros menores que $\pm 1 \%$. A integral aparecendo na equação (15) não pode ser resolvida analiticamente, entretanto, através de integrações sucessivas por partes, uma expansão em série pode ser obtida. Assim, o método de Prakash baseia-se em levar em conta somente o primeiro termo dessa expansão, que pode serfeito se E/kT é grande. Nesse método a equação (15) é reduzida à:

$$
i(T)=\frac{P_{0}}{\tau_{0}} \exp \left(-\frac{E_{a}}{k_{B} T}\right) \exp \left[-\frac{k_{B} T^{2}}{b E_{a} \tau_{0}} \exp \left(-\frac{E_{a}}{k_{B} T}\right)\right]
$$

O método de Prakash foi então melhorado [81] levando-se em conta termos até $2^{\mathrm{a}}$. ordem na expansão da equação (15). Nesse caso, o pico de CDTE será dado por: 


$$
i(T)=\frac{P_{0}}{\tau_{0}} \exp \left(-\frac{E_{a}}{k_{B} T}\right) \exp \left[-\frac{k_{B} T^{2}}{b \tau_{0} E_{a}}\left(1-\frac{2 k_{B} T}{E_{a}}\right) \exp \left(-\frac{E_{a}}{k_{B} T}\right)\right]
$$

e a intensidade de corrente máxima será:

$$
i_{m}=\frac{P_{0}}{\tau_{0}} \exp \left(-\frac{E_{a}}{k_{B} T_{m}}\right) \exp \left(-1+\frac{2 k_{B} T_{m}}{E_{a}}\right)
$$

E assim, a função C(T) usada por Prakash é agora:

$$
C(T)=\frac{i(T)}{i_{m}}=\exp \left\{1+\frac{E_{a}}{k_{B}}\left(\frac{1}{T_{m}}-\frac{1}{T}\right)-\frac{T^{2}}{T_{m}^{2}}\left(1-\frac{2 k_{B} T}{E_{a}}\right) \exp \left(\frac{E_{a}}{k_{B}}\left(\frac{1}{T_{m}}-\frac{1}{T}\right)\right)-\frac{2 k_{B} T_{m}}{E_{a}}\right\}
$$

onde $i_{m}$ é a corrente máxima de despolarização e $T_{m}$ é a temperatura máxima correspondente.

O modelo de Bucci et al descrito acima assume processos de relaxação discreta, cada um tendo energia de ativação e fator pré-exponencial bem definidos. Tal processo é muitas vezes chamado de "uma relaxação de Debye simples". De acordo com esse modelo, obtida a energia de ativação, pode-se calcular o tempo de relaxação $\tau_{0}$ através da seguinte expressão:

$$
\tau_{0}=\frac{k_{B} T_{m}^{2}}{b E_{a}} \exp \left(-\frac{E_{a}}{k_{B} T_{m}}\right)
$$

a qual é obtida derivando a expressão 15 em relação à temperatura e em seguida, maximiza-se tal expressão.

Entretanto, conforme já mencionado, uma curva de CDTE geralmente é complexa e muitas vezes é composta por uma série de picos caracterizando uma sucessão de relaxações na amostra estudada e dois tipos principais de problemas podem ser encontrados em sua análise: o primeiro é que podem existir dois picos 
sucessivos que se superpõem parcialmente e então as duas relaxações não podem ser separadas de uma maneira muito simples e o outro é que um pico individual pode ser constituído por um grupo contínuo de relaxações e este não pode ser descrito por um único tempo de relaxação e sim por uma distribuição de tempos de relaxação.

No caso de uma distribuição contínua de energia de ativação, a corrente de despolarização é dada por:

$$
j(T)=P_{0} s \int_{0}^{\infty} F(E) \exp \left[-\frac{E}{k T}-\frac{s}{b} \int_{T_{0}}^{T} \exp \left(-\frac{E}{k T^{\prime}}\right) d T^{\prime}\right] d E
$$

E, no caso de uma distribuição contínua do fator pré-exponencial:

$$
j(T)=P_{0} \exp \left(-\frac{E}{k T}\right)_{0}^{\infty} s \bar{F}(s) \exp \left[-\frac{s}{b} \int_{T_{0}}^{T} \exp \left(-\frac{E}{k T^{\prime}}\right) d T^{\prime}\right] d s
$$

onde $s=1 / \tau_{0}$, e $F(E)$ e $F(S)$ são as funções distribuições das energias de ativação e fatores pré-exponencial.

Através dos resultados obtidos nesse trabalho foi verificada a necessidade de um método de ajuste das curvas teóricas e experimentais considerando-se uma distribuição contínua de tempo de relaxação e energia de ativação e então utilizamos o método de Havriliak-Negami [30]. Nesse caso, a densidade de corrente é dada por:

$$
J(T)=\frac{Q}{\tau_{0}} \int_{-\infty}^{\infty} f(u) \exp \left\{\left[\left(u+\frac{E_{a}}{k_{B} T}\right)+\frac{k_{B} T^{2}}{\tau_{0} b E_{a}} \exp \left[-\left(u+\frac{E_{a}}{k_{B} T}\right)\right]\right]\right\} d u
$$

sendo: 


$$
f(u)=\operatorname{sen} \frac{\beta \theta}{\pi}\{1+2 \cos \pi(1-\alpha) \exp [-u(1-\alpha)]+\exp [-2 u(1-\alpha)]\}^{-x / 2}
$$

onde:

$$
\theta=\operatorname{arctg}\left(\frac{\operatorname{sen}(1-\alpha)}{\exp [u(1-\alpha)]+\cos \pi(1-\alpha)}\right)
$$

Dependendo do tipo de distribuição envolvida $\left(\tau_{0}\right.$ ou $\left.\mathrm{E}_{\mathrm{a}}\right), u$ será igual à:

$$
\ln \frac{\tau_{0}}{\tau_{0 m}} \quad \quad \text { ou } \quad u=\frac{E-E_{m}}{k_{B} T}
$$

sendo $\tau_{0 \mathrm{~m}}$ e $E_{\mathrm{m}}$ os valores mais prováveis de $\tau_{0}$ e $E_{a}$, respectivamente. $O$ ajuste é feito variando $\alpha, \beta, E_{\mathrm{a}}$ e $\tau_{0}$.

$\mathrm{Na}$ literatura podemos encontrar inúmeros trabalhos descrevendo a interpretação das curvas de CDTE aplicadas à diversos materiais [82,83]. Os métodos utilizados na análise de curvas complexas de CDTE podem ser tanto experimentais, como o método de aquecimento parcial ou polarização fracional $[84,85,86]$ quanto os baseados em cálculos numéricos para a decomposição da curva experimental de CDTE [87]. De acordo com a literatura [78] é encontrado que interações dipolodipolo dão origem a um processo de relaxação com uma distribuição de energias de ativação. Picos largos de CDTE, atribuídos a distribuições contínuas de energias de ativação ou fatores pré-exponencial, são comuns em polímeros, por exemplo. No caso de uma polarização distribuída, a forma e a temperatura do pico dependem fortemente da temperatura de polarização $T_{p}$ e sobre o tempo que a amostra permanece polarizada antes de seu aquecimento. 
De forma geral, os mais importantes parâmetros que podem ser conhecidos a partir de um processo de relaxação dipolar são: I) a energia de ativação $\mathrm{E}_{\mathrm{a}}$, a qual está normalmente entre 1 e $100 \mathrm{kcal} / \mathrm{mol}, \mathrm{II})$ o fator pré-exponencial $\tau_{0}$, que é tipicamente da ordem de $10^{+13} \mathrm{~s}^{-1}$, III) a polarização de equilíbrio $\mathrm{P}_{\mathrm{e}}$, a qual, via a função de Langevin, pode conduzir ao conhecimento da concentração de dipolos, $\mathrm{N}_{\mathrm{d}}$, ou o momento de dipolo, p, se uma ou outra quantidade é conhecida, e IV) eventualmente, a função de distribuição $f(\tau)$.

\section{3 .2 - CDTE FOTOINDUZIDA}

A alexandrita possui bandas de absorção bastante conhecidas que ocorrem na região visível do espectro (em torno de 590 e 420 nm,) e na região do ultravioleta (em torno de $265 \mathrm{~nm}$ ) e são atribuídas aos íons de $\mathrm{Cr}^{3+}$ substituindo os íons $\mathrm{Al}^{3+}$ em dois sítios diferentes na estrutura cristalina. Supondo que a origem do fenômeno de relaxação dipolar nesse material tenha a participação dos íons de $\mathrm{Cr}^{3+}$, podemos esperar que exista uma influência da fotoexcitação desses íons presentes nas amostras, sobre o comportamento do processo de relaxação dipolar observado através da técnica de CDTE.

Assim, além das medidas de CDTE na sua forma convencional, conforme descrito anteriormente, foram realizadas também medidas de CDTE de uma forma modificada, onde é utilizado mais de um tipo de excitação das amostras, a fim de observar sua influência sobre o fenômeno de relaxação dipolar previamente identificado com as medidas usuais de CDTE. Este método consiste na fotoexcitação das amostras em uma temperatura na qual o sistema de dipolos já se encontre 
plenamente congelado quer numa condição de polarização ou de despolarização. $O$ método é chamado de CDTE Fotoinduzida (CDTEFI).

Uma representação esquemática do experimento de CDTEFI utilizado neste trabalho é apresentada na Figura 9. Em ambos os casos mostrados nessa figura temos a amostra sob as mesmas condições iniciais, ou seja, no estágio (1) a amostra se encontra no escuro, sem nenhum campo elétrico aplicado e mantida à temperatura ambiente. A diferença entre os dois processos, (i) e (ii) da Figura 9, tem origem no estágio (2) onde as condições iniciais antes de aplicar a fotoexcitação são diferentes para cada caso obedecendo os seguintes procedimentos:

\section{(i) $O$ sistema de dipolos é previamente polarizado, orientado e congelado:}

Nesse caso, no estágio (2) a amostra é polarizada a uma temperatura $T_{p}$, onde os dipolos se encontram relaxando, por aplicação de um campo elétrico $E_{p}$, ou seja, o mesmo procedimento utilizado nas medidas usuais de CDTE. Em (3) a temperatura é abaixada rapidamente até $77 \mathrm{~K}$ com o campo elétrico ainda aplicado. Após desligar o campo elétrico e esperar a corrente de descarga capacitiva, a amostra é irradiada com luz por 5 a 15 minutos (etapa 4). Em seguida, a amostra é retornada ao escuro e a temperatura é aumentada a uma taxa fixa (5). Neste processo a única modificação em relação a CDTE normal é a fotoexcitação da amostra a baixa temperatura, quando os dipolos já se encontram plenamente congelados numa condição de polarização. 
(ii) $O$ sistema de dipolos previamente não polarizado e congelado orientado aleatoriamente:

Em (2) a amostra é levada, rapidamente, a partir da temperatura ambiente até 77K sem a aplicação do campo elétrico. Nessa temperatura, em (3), é aplicado o campo elétrico de polarização que, nesse caso, não poderia mudar a distribuição aleatória original dos dipolos que se encontram congelados, mas, junto com o campo elétrico se incide luz na amostra por 2 a 15 minutos. Em seguida, na etapa (4) a amostra é retornada ao escuro e o campo elétrico é desligado, quando então se inicia o aquecimento da amostra a uma taxa fixa (5). Portanto, nesse caso a foto excitação é feita numa situação em que os dipolos se encontrem congelados e orientados aleatoriamente.

Podemos dizer que com o processo (i) pretendemos observar a ocorrência ou não de uma "destruição" das bandas de CDTE com a foto excitação da amostra e, com o processo (ii) observar a ocorrência ou não da "formação" das bandas de CDTE com a fotoexcitação. O arranjo experimental nas medidas de CDTEFI é exatamente o mesmo descrito na seção anterior com a única alteração de que agora, uma das janelas do criostato é de fluorita de modo a permitir a passagem do feixe de luz que irá incidir sobre a amostra da forma esquematizada na Figura 10. 

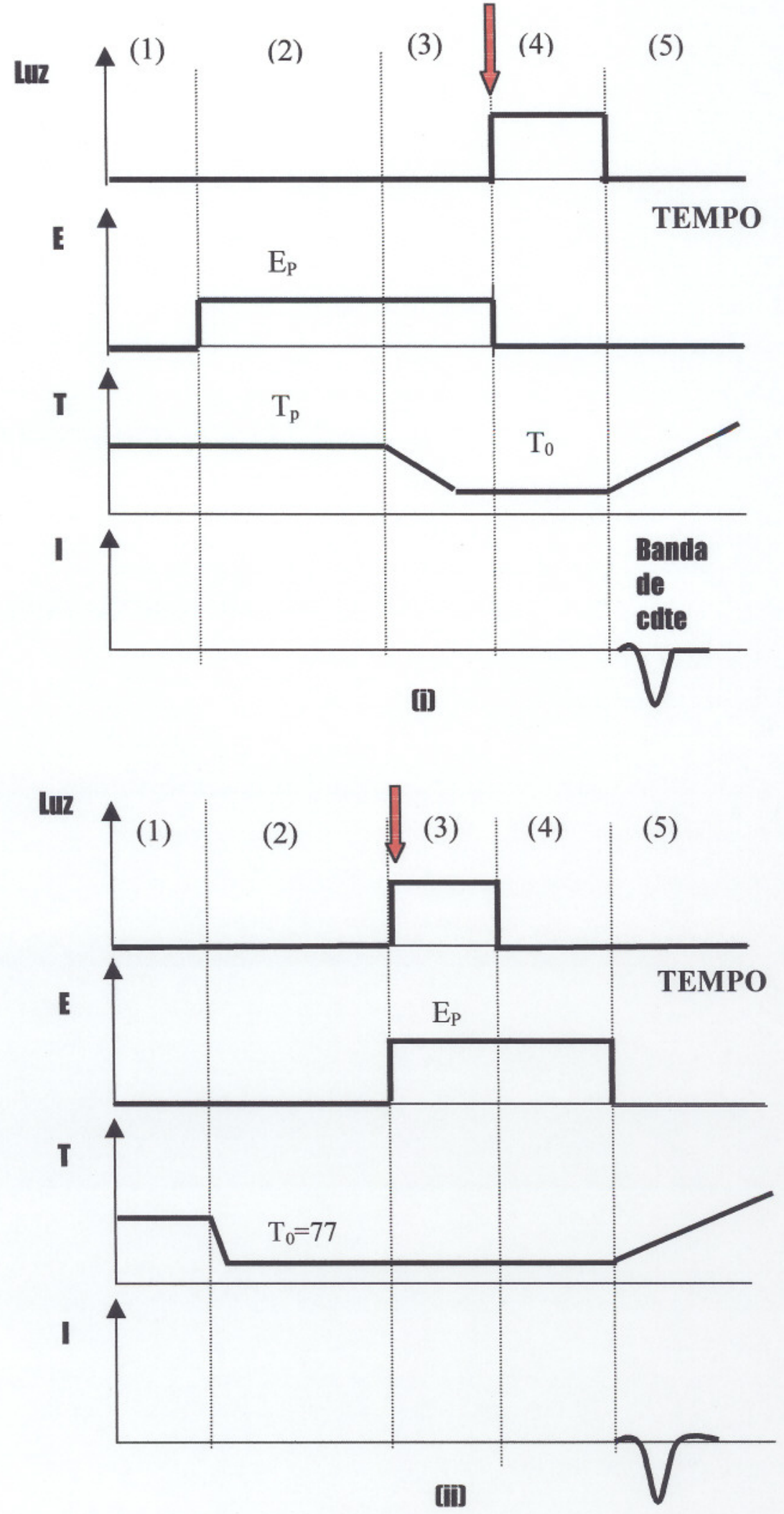

Figura 9- esquema de medidas de CDTEFI. (i) incidência de luz quando o sistema de dipolos está previamente polarizado $\left(\mathrm{T}_{\mathrm{p}}=300 \mathrm{~K}\right)$ e congelado, (ii) incidência de luz quando o sistema de dipolos está previamente não polarizado e congelado $\left(\mathrm{T}_{\mathrm{p}}=77 \mathrm{~K}\right)$. 


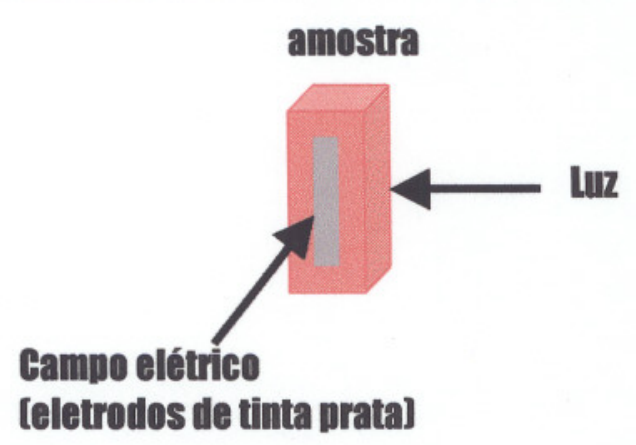

Figura 10 - Esquema indicando as direções da incidência de luz e aplicação do campo elétrico na amostra.

O estudo do efeito da fotoexcitação envolveu a utilização de várias linhas de emissão de um laser de $\mathrm{Kr}^{+}$, permitindo com isso, realizar uma investigação sistemática da dependência do comprimento de onda da excitação. As linhas de emissão foram: multilinhas ultravioleta (MLUV: 337,5; 350,7 e 356,4 nm), multilinhas violeta (MLVI:406,7; 413,1 e 415,4 nm), multilinhas verde-azul (MLBG:468,0; 476,2; 482,5; 520,8 e 530,9 nm) e multilinhas vermelho (MLRD:647,1 e 676,4nm).

O feixe é direcionado por espelhos e a intensidade da luz que chega na amostra é avaliada por um medidor de potência OPHIR OPTRONICS modelo DGX. Os comprimentos de onda acima foram escolhidos à partir do espectro de absorção óptica da alexandrita sintética, de forma a irradiar a amostra em comprimentos de onda sobre as bandas de absorção. Ambos os processo descritos são observados em função do comprimento de onda utilizado e da potência do laser e, o processo (ii) foi realizado também em função do tempo de incidência de luz na amostra. Os resultados das medidas de CDTEFI são apresentados no capítulo 4. 


\section{4 - TRATAMENTOS TÉRMICOS.}

Embora os tratamentos térmicos não estejam citados no início desse capítulo, quando foi descrita a metodologia experimental utilizada nesse trabalho, consideramos conveniente abordar esse assunto, ainda dentro do capítulo de procedimentos experimentais, uma vez que os resultados obtidos são apresentados para as amostras de alexandrita naturais em função de tratamentos térmicos realizados. Nosso objetivo, ao optarmos pela realização de tratamentos térmicos variando-se a temperatura e tempo de tratamento, foi observar sua influência sobre o comportamento de relaxação dipolar das amostras naturais, pois foi verificado com as microanálises de EDX e WDX, a presença de diversas outras impurezas nessas amostras, com inclusões de quartzo e mica, que poderiam interferir nas medidas de CDTE. Também as medidas de Difração de Raios-X, apresentadas no capítulo 4, indicam a presença dessas inclusões. Além disso, os espectros de absorção óptica na região do infravermelho apontaram a presença de $\mathrm{H}_{2} \mathrm{O}$ e O-H .

Assim, as amostras AN3, AN4 e AN5 foram submetidas a tratamentos térmicos em uma mufla modelo CON3P-1800 da EDG, em atmosfera ambiente, variando-se o tempo de tratamento e temperatura. Para a amostra AN3 os tratamentos térmicos realizados foram de $700{ }^{\circ} \mathrm{C}$ por 15 minutos, $800{ }^{\circ} \mathrm{C}$ por 15 minutos, $900{ }^{\circ} \mathrm{C}$ por 15 minutos e $1000{ }^{\circ} \mathrm{C}$ por 5 horas, sendo o resfriamento feito imediatamente após atingir o patamar desejado, retirando a amostra do forno e colocando-a, no ar, sobre uma placa de vidro à temperatura ambiente esfriando-a rapidamente, de forma a tentar impedir que possíveis aglomerados de outras 
impurezas uma vez dissociados com os tratamentos térmicos pudessem novamente serem formados. Entretanto, esse procedimento provocou fraturas na amostra que se partiu em duas após o $2^{\circ}$ tratamento térmico.

Para a amostra AN5 os tratamentos térmicos foram feitos à 700, 800, $900 \mathrm{e}$ $1000{ }^{\circ} \mathrm{C}$ por 5 minutos, respectivamente, e à $1000{ }^{\circ} \mathrm{C}$ por 5 horas. $\mathrm{O}$ resfriamento foi feito retirando a amostra do forno sempre na temperatura de $700{ }^{\circ} \mathrm{C}$ e colocando-a sobre uma folha de papel alumínio, que por sua vez estava situada sobre uma placa de vidro mantida à temperatura ambiente, para que atingisse essa temperatura mais lentamente, evitando-se assim choques térmicos que pudessem fragilizar muito a amostra, como ocorreu com AN3. Para AN5, optamos por um tempo mais curto de tratamento ( 5 minutos) a fim também de se tentar evitar a ocorrência de fraturas na amostra. Com isso, essa amostra se manteve mais resistente e transparente após os tratamentos térmicos em relação a amostra AN3, com sua aparência mudando apenas após o primeiro tratamento térmico $\left(700{ }^{\circ} \mathrm{C}\right.$ por 5 minutos), ficando mais opaca e apresentado menos fraturas, e sem alterações após os outros tratamentos.

A amostra AN4 foi cortada em três partes e uma delas foi submetida a um tratamento térmico à $700{ }^{\circ} \mathrm{C}$ por 5 minutos e outra parte a um tratamento térmico à $1000{ }^{\circ} \mathrm{C}$ por 5 horas, a fim de, posteriormente, realizar medidas de Difração de Raios $\mathrm{X}$. Embora tenha se tentado formas diferentes de resfriamento, como descritas acima, com os tratamentos térmicos verificamos que, de forma geral, as amostras se tornam "quebradiças" resultando num cristal visivelmente fraturado. Este comportamento pode ser atribuído a um rompimento das paredes de inclusões fluidas existentes, que ocorre por volta de $500{ }^{\circ} \mathrm{C}$, conforme foi recentemente verificado em cristais naturais de alexandrita com ocorrência na região de Minaçu, Goiás [33]. 
O fato da amostra sintética não ter apresentado as inclusões observadas nas amostras naturais, com análises de EDX/WDX, não achamos necessários submetê-la à tratamentos térmicos. Entretanto, a presença de outras fases não foi também descartada com análise de difração de raios $X$ uma vez, que essa amostra não foi submetida à essa técnica de caracterização mas, em contrapartida, foi observado que o espectro de CDTE tem um aparência muito mais regular do que no caso das amostras naturais, conforme é apresentado no capítulo seguinte e portanto, mais uma vez achamos desnecessário a realização de tratamentos térmicos na amostra sintética. 


\section{RESULTADOS EXPERIMENTAIS}

Neste capítulo são apresentados os resultados das microanálises por EDX e WDX com as quais foi possível verificar parcialmente a composição de nossas amostras e são apresentados os resultados obtidos com a técnica de difração de raios $\mathrm{X}$, que permitiu confirmar a estrutura ortorrômbica e os parâmetros de rede das amostras naturais. Em seguida são apresentados os resultados obtidos na segunda etapa da metodologia experimental, ou seja, medidas de absorção e emissão óptica, realizadas paralelamente às medidas de $\mathrm{CDTE}$, completando a terceira etapa experimental. Todas as medidas citadas acima foram feitas também em função de tratamentos térmicos realizados nas amostras naturais.

Uma etapa bastante interessante e desenvolvida neste trabalho, foram as medidas de CDTE fotoinduzidas, que nos permitiram obter informações a respeito do comportamento das bandas de relaxação dipolar, para a amostra sintética, que podem ser "criadas" ou "destruídas" com a fotoexcitação, na região espectral UV-VIS, da amostra.

\section{1 - MICROANÁLISE POR EDX/WDX}

Através das análises de EDX e WDX das amostras naturais foram observadas ocorrências de fases diferentes nesses cristais, mostradas na Figura 11, a qual apresenta uma micrografia típica obtida por Microscopia Eletrônica de Varredura para uma das amostras naturais (AN4). 


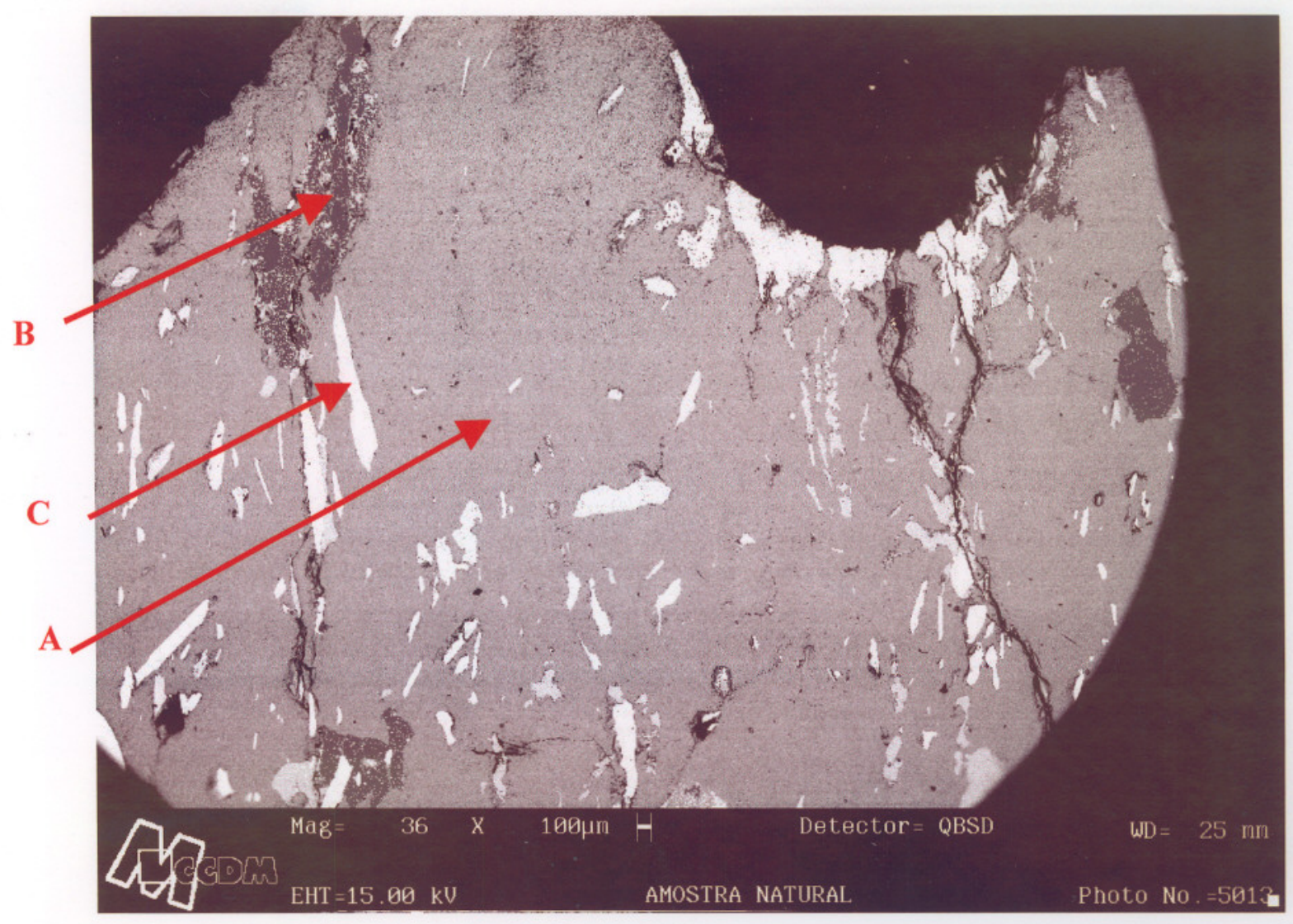

Figura 11 - Micrografia da amostra de alexandrita natural (AN4) mostrando fases distintas: (A) matriz, (B) quartzo e (C) mica

Esse resultado é bastante coerente, pois sendo cristais naturais, o ambiente, a temperatura e outros importantes parâmetros do processo de formação não são controlados e diversos tipos de outras impurezas podem ser incorporadas. Essas espécies minerais estranhas ao mineral hospedeiro são chamadas inclusões e são um dos fatores preponderantes na classificação gemológica dos minerais, sendo que, quase sempre o valor da gema varia inversamente com a quantidade de inclusões. Algumas inclusões cristalinas em crisoberilo e alexandrita de diversas ocorrências são apresentadas na literatura, assim como alguns trabalhos descrevendo a substituição dos elementos $\mathrm{Al}$ e $\mathrm{Be}$ por outros elementos com raios iônicos semelhantes, comprovados espectroscopicamente em amostras de crisoberilo e alexandrita [33]. 
A análise por EDX forneceu as concentrações parciais das amostras de alexandrita, uma vez que o equipamento utilizado nessa técnica não permitiu a detecção dos elementos oxigênio e berilio, por possuírem número atômico menor do que 10. Na tentativa de se obter uma composição química mais completa das amostras analisadas foram realizadas as medidas de WDX, que possui uma resolução melhor do que EDX, e com isso foi possível detectar também o oxigênio $(Z=8)$ embora ainda não tenha sido possível detectar o berílio $(Z=4)$. Na Tabela 7 , os resultados das medidas de EDX para as amostras naturais são apresentados de forma quantitativa somente quando presentes na matriz, indicada pela letra A na Figura 11. Nessa tabela também são apresentados os resultados obtidos por WDX para a amostra natural AN4.

Nas amostras naturais utilizadas em nosso trabalho pode-se afirmar que prevalece nas regiões mais escuras (região A da Figura 11) os elementos $\mathrm{Al}, \mathrm{Fe}, \mathrm{Cr}$ e em algumas amostras, apresenta-se também os elementos $\mathrm{Mg}, \mathrm{Ti}, \mathrm{Ca}, \mathrm{K}$ e $\mathrm{Si}$. As inclusões mostradas na Figura 11 (regiões B e C) apresentam além dos elementos Al, Fe e $\mathrm{Cr}$ também os outros elementos listados na Tabela 7 , com concentrações superiores a dos elementos da matriz (região A). Essas inclusões foram identificadas como quartzo (região B) e mica (região C), de acordo com PETERSEN [33] e, posteriormente, confirmadas neste trabalho e apresentadas na seção seguinte através de medidas de difração de raios $\mathrm{X}$.

A amostra sintética mostrou ser bastante homogênea e não foram detectadas inclusões avaliáveis. Entretanto, o espectro de EDX apresentou uma linha extra, pouco intensa em todas as regiões analisadas da amostra, correspondendo ao Ir, que pode ser devido ao cadinho utilizado no crescimento [6]. Para essa amostra, as 
medidas de WDX indicaram também, uma pequena concentração de Fe em apenas numa das cinco regiões analisadas. Os resultados de EDX e WDX para a amostra sintética são apresentados na Tabela 7.

Tabela 7 - Composição química parcial das amostras de alexandritas naturais e sintética obtida através das microanálises por EDX e WDX. As medidas de EDX estão em preto e as medidas de WDX em vermelho. Os resultados representam o valor médio obtido a partir de 5 áreas diferentes da matriz de alexandrita (região A na Figura 11). A concentração dos elementos foi medida em porcentagem de átomos (at.\%).

\begin{tabular}{|c|c|c|c|c|c|c|c|c|c|}
\hline \multirow{2}{*}{$\begin{array}{c}\text { Amostra } \\
\text { E } \\
\text { Técnica }\end{array}$} & \multirow[t]{2}{*}{$\begin{array}{c}\mathbf{A l} \\
\text { (atom\%) }\end{array}$} & \multirow[t]{2}{*}{$\underset{\text { (ato\%) }}{\mathbf{0}}$} & \multirow[t]{2}{*}{$\begin{array}{c}\mathbf{C r} \\
\text { (atom.\%) }\end{array}$} & \multirow[t]{2}{*}{$\begin{array}{c}\mathbf{F e} \\
\text { (atom.\%) }\end{array}$} & \multicolumn{5}{|c|}{$\begin{array}{l}\text { Outras impurezas } \\
\text { (atom.\%) }\end{array}$} \\
\hline & & & & & $\mathrm{Ti}$ & $\mathrm{K}$ & $\mathrm{Si}$ & $\mathrm{Mg}$ & $\mathrm{Ca}$ \\
\hline $\begin{array}{c}\text { AN1 } \\
\text { (EDX) }\end{array}$ & 97,22 & - & 0,46 & 0,77 & - & - & - & 1,35 & - \\
\hline $\begin{array}{c}\text { AN3 } \\
\text { (EDX) }\end{array}$ & 97,04 & - & 0,22 & 0,46 & 0,33 & 0,03 & 0,20 & 1,58 & 0,15 \\
\hline $\begin{array}{c}\text { AN4 } \\
\text { (EDX) } \\
\text { (WDX) }\end{array}$ & $\begin{array}{l}99,34 \\
31,50\end{array}$ & $\begin{array}{c}- \\
68,26\end{array}$ & $\begin{array}{c}0,13 \\
0,073\end{array}$ & $\begin{array}{l}0,53 \\
0,13\end{array}$ & - & - & $\begin{array}{l}- \\
-\end{array}$ & $\begin{array}{l}- \\
-\end{array}$ & $\begin{array}{l}- \\
-\end{array}$ \\
\hline $\begin{array}{c}\text { AN5 } \\
\text { (EDX) }\end{array}$ & 99,11 & - & 0,21 & 0,51 & 0,17 & - & - & - & - \\
\hline $\begin{array}{c}\text { AS1 } \\
\text { (EDX) } \\
\text { (WDX) }\end{array}$ & $\begin{array}{l}99,77 \\
32,40\end{array}$ & 67,55 & $\begin{array}{l}0,21 \\
0,05\end{array}$ & $\overline{-}, \overline{002}$ & $\begin{array}{l}- \\
-\end{array}$ & - & $\begin{array}{l}- \\
-\end{array}$ & - & $\begin{array}{l}- \\
-\end{array}$ \\
\hline
\end{tabular}

$\mathrm{Na}$ Tabela 7, pode ser observado que o elemento $\mathrm{Fe}$ é detectado nas amostras naturais com uma concentração maior do que o elemento $\mathrm{Cr}$ na matriz hospedeira. Também foi observado nessas medidas que, em relação aos resultados de EDX, as concentrações das impurezas estranhas $(\mathrm{K}, \mathrm{Ti}, \mathrm{Si}, \mathrm{Mg}, \mathrm{Ca})$ apresentam uma variação muito maior em cada uma das regiões analisadas das amostras, enquanto 
que, para os elementos $\mathrm{Fe}$ e $\mathrm{Al}$ (e oxigênio no caso de WDX) essa variação é muito pequena e, no caso do $\mathrm{Cr}$, a variação também é mais notável. A ocorrência de outras impurezas estranhas à composição química das alexandrita naturais pode ser justificada, uma vez que, os elementos presentes, considerados "estranhos", estão entre os mais abundantes na formação das rochas [46]. Também com as microanálises de EDX e WDX é possível verificar que há uma excelente concordância entre as quantidades relativas de $\mathrm{Al}, \mathrm{O}$ e $\mathrm{Cr}$ entre as amostras naturais e sintética.

Também podemos observar que, de acordo com os resultados de WDX, apresentados em vermelho na Tabela 7, a taxa relativa entre os elementos $\mathrm{Al}$ e $\mathrm{O}$ para a amostra natural AN4 $(\mathrm{Al} / \mathrm{O}=0,46)$ e para a amostra sintética $(\mathrm{Al} / \mathrm{O}=0,48)$ são bastante próximas, indicando uma deficiência de alumínio em torno de $2 \%$. No caso da taxa relativa entre os íons cromo e oxigênio para a amostra natural $(\mathrm{Cr} / \mathrm{O}=$ $\left.1 \times 10^{-3}\right)$ e para a amostra sintética $\left(\mathrm{Cr} / \mathrm{O}=0,7 \times 10^{-3}\right)$ essa diferença é maior, indicando uma deficiência maior de $\mathrm{Cr}$ na amostra natural. Esses resultados nos dão indícios de que a existência de vacâncias de oxigênio na amostra natural deve ser mais acentuada.

Os resultados de EDX/WDX para a amostra AS1 indicam ser um material sintético de excelente qualidade sendo reforçado pelo fato de que medidas de Ressonância Paramagnética Eletrônica (EPR) realizadas com uma amostra sintética de mesma procedência de nossa amostra não apresentam linhas atribuídas ao $\mathrm{Fe}$ conforme reportado por RAGER et al [12].

As medidas complementares realizadas com a técnica de Difração de Raios $\mathrm{X}$ fortalecem a opção de utilizar a amostra sintética como referência, conforme é mostrado a seguir. 


\section{2 - DIFRAÇÃO DE RAIOS-X}

A técnica de difração de raios $\mathrm{X}$ foi utilizada com o objetivo de obter a estrutura cristalina das amostras naturais e, consequentemente, identificá-las como alexandritas verdadeiras e de boa qualidade. Por dispormos de poucas amostras naturais o seu uso foi limitado em métodos de análises consideradas destrutivas, como é o caso da difração de raios $\mathrm{X}$ pelo método do pó e portanto, somente a amostra AN4 foi submetida a essas medidas. Devido à raridade de se encontrar cristais naturais bem formados, como é o caso da alexandrita, a utilização de medidas de Difração de Raios X pelo método do pó são mais indicadas nesses casos do que métodos que exigem uma orientação precisa da amostra, como o de Laue e o da rotação do cristal, por exemplo [46].

Para as medidas de difração de raios $\mathrm{X}$, foi utilizada a amostra natural (AN4) obtida a partir da mesma pedra que a amostra $\mathrm{AN} 3$, utilizada nas medidas de CDTE. A amostra foi cortada em três partes de tamanhos iguais (AN4a, AN4b e AN4c) e as partes AN4b e AN4c foram submetidas à tratamentos térmicos, cujos resultados são apresentados e discutidos nesse mesmo capítulo. As três partes foram então moídas separadamente em almofariz de ágata e passadas por malha 325 e os pós obtidos foram adicionado a álcool isopropílico e depositados entre lâminas de vidro a fim de proceder a análise.

A Figura 12(a) mostra o difratrograma de raios $\mathrm{X}$ obtido para AN4a com os valores de intensidade normalizados. Além da própria estrutura do crisoberilo, foram identificadas duas outras estruturas como sendo quartzo e mica reforçando os resultados obtidos através da microanálise por EDX e WDX. 

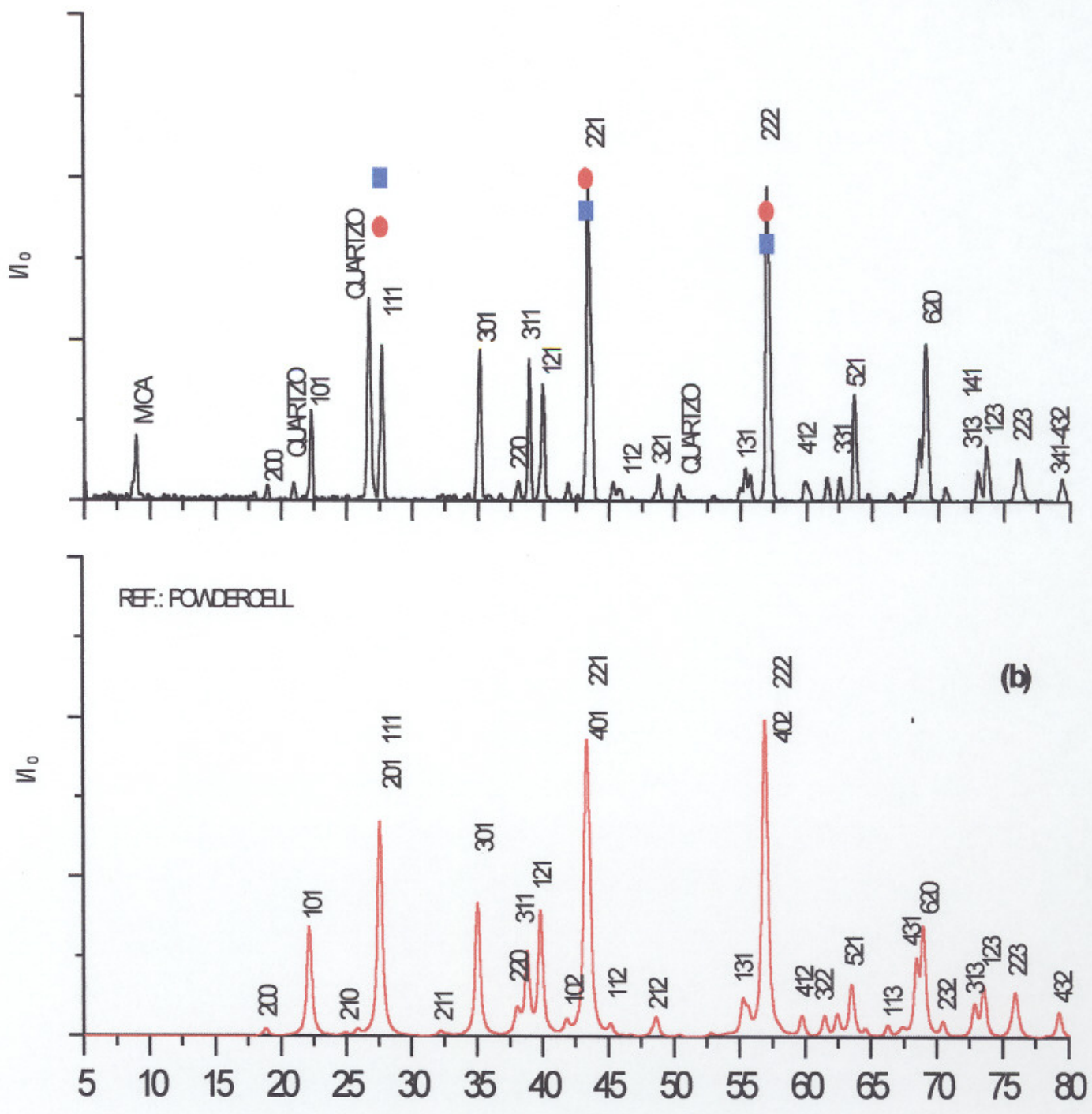

Figura 12 - (a) Difratograma de Raios-X para a amostra natural AN4 e representação das três linhas mais intensas para uma amostra natural $(\lambda)$ e uma amostra sintética $(v)$ obtidas nos fichários JCPDS [88]. (b) Difratograma de raios X para uma amostra sintética obtido a partir do programa "Powder Cell" . 
Também na Figura 12(a) estão representadas as posições e intensidades das três linhas de difração mais intensas obtidas para uma amostra sintética de alexandrita (em azul) e para uma amostra natural (em vermelho) encontradas nos fichários de difração de raios X preparados pela "American Society for Testing Materials" [88]. $\mathrm{Na}$ Figura $12(\mathrm{~b})$ é apresentado um difratograma de raios $\mathrm{X}$ obtido através do programa "Powder Cell" [89] que se refere a medidas de difração de raios X pelo método do pó para uma amostra sintética.

A partir do difratograma de raios $\mathrm{X}$ da amostra AN4a (sem tratamento térmico) e utilizando um programa de análise chamado "DICVOL91" foram obtidos os parâmetros de rede $a=9,405 \AA, b=5,471 \AA$ e $c=4,409 \AA$. Outros autores obtiveram, para as amostras cujo padrão de difração também está representado na Figura 12(a), $a=9,404 \AA, b=5,476 \AA$ e $c=4,427 \AA$ para a amostra sintética (azul) e $a=9,423 \AA$, $\mathrm{b}=5,488 \AA$ e $\mathrm{c}=4,433 \AA$ para a amostra natural (vermelho). Na Figura 12(a) também pode ser observado que existem diferenças significativas entre as intensidades relativas das linhas de difração de nossa amostra AN4 e as amostras dos fichários JCPDS [88].

Com os resultados obtidos nas medidas de difração de raios $\mathrm{X}$ também foi verificado que as distâncias interplanares (d) concordam plenamente com a referência [33], a qual apresenta o espectro de difração de raios $\mathrm{X}$ de uma amostra de alexandrita natural, oriunda da região de Minaçu, Goiás, cujos parâmetros de rede são $a=9,409 \AA, b=5,483 \AA$ e $c=4,432 \AA$. Entretanto, novamente foram constatadas algumas discrepâncias em relação às intensidades relativas das linhas do difratograma. Na referência [33] a linha mais intensa corresponde aos índices de Miller (111), que corresponde a $3^{a}$ linha mais intensa de AN4. Finalmente, 
comparando os espectros de difração de AN4 e o espectro de difração mostrado na Figura 12(b) notamos uma maior concordância entre as intensidades relativas das linhas.

Em síntese, as medidas de difração de raios $\mathrm{X}$ mostram uma excelente concordância entre os parâmetros de rede obtidos para a amostra natural AN4 e os parâmetros de rede obtidos para amostras de alexandrita na literatura. Também foi possível comprovar a estrutura ortorrômbica das alexandritas naturais. Em relação às intensidades das linhas dos vários espectros citados verifica-se que sempre ocorrem algumas diferenças que podem ser atribuídas a diversos fatores como diferentes concentrações de impurezas presentes na matriz das amostras de alexandritas naturais, diferentes orientações que podem ocorrer nessas amostras e ainda pequenas variações na realização das medidas.

\section{3 - ABSORÇÃO ÓPTICA NA REGIÃO UV-VIS}

Os espectros de absorção óptica da alexandrita têm sido amplamente apresentados na literatura desde temperatura ambiente à hélio líquido. Diversos trabalhos apresentam os espectros sob efeito de luz polarizada nos eixos cristalinos a, b e c das amostras $[1,2,11,27,48,90]$. Esses espectros mostram duas linhas estreitas próximas de $680 \mathrm{~nm}$, chamadas geralmente de linhas $\mathrm{R}$, que são identificadas como linhas do $\mathrm{Cr}^{3+}$ associadas com íons nos sítios localizados sobre um plano de reflexão (sítio $\mathrm{Al}_{2}$ ) na alexandrita. Os espectros apresentam ainda duas bandas largas em torno de $580 \mathrm{~nm}$ e $420 \mathrm{~nm}$ associadas com transições à partir do estado fundamental ${ }^{4} \mathrm{~A}_{2}$ para os estados excitados ${ }^{4} \mathrm{~T}_{2} \quad \mathrm{e}^{4} \mathrm{~T}_{1}$, respectivamente, mostradas no diagrama de 
níveis de energia na Figura 5, do capítulo 2. As posições em que essas bandas largas estão centralizadas, assim como suas intensidades (coeficiente de absorção) apresentam variações de acordo com o eixo de polarização e também varia de amostra para amostra.

Neste trabalho as medidas de absorção óptica na região do ultravioleta e visível do espectro, de 190 à $700 \mathrm{~nm}$, foram realizadas com um espectrofotômetro Cary 17 , à temperatura ambiente e a $77 \mathrm{~K}$ e sem levar em conta efeitos de polarização da luz. Na Figura 13 são apresentados os espectros de absorção óptica para as amostras sintética (AS1) e natural (AN3) juntamente com o espectro de absorção de uma amostra sintética de alexandrita, com $0,0897 \%$ em átomos de $\mathrm{Cr}$, obtido na literatura [27] e anteriormente apresentado na Figura 3. As concentrações de $\mathrm{Cr}$ e $\mathrm{Fe}$, para as amostras AS1 e AN3, são aquelas apresentadas na Tabela 7, obtidas por EDX. Os resultados de absorção óptica obtidos para as amostras sintética e natural a 77K também são apresentados na Figura 13.

Para a amostra sintética, AS1, observamos a presença das duas bandas largas, neste caso, centralizadas em torno de 576,5 e $424,5 \mathrm{~nm}$, chamadas bandas A e B respectivamente, e as duas linhas do $\mathrm{Cr}^{3+}$ nos sítios localizados num plano de reflexão, em 678,5 e $680,5 \mathrm{~nm}$ e também a presença de uma banda menos intensa em torno de $265 \mathrm{~nm}$ (banda C). As linhas vibrônicas laterais, em torno de 650 e $470 \mathrm{~nm}$ respectivamente, podem ser fracamente identificadas no espectro à temperatura ambiente. A 77K (TNL) se torna evidente a presença das linhas vibrônicas em 635 , $644,644,5,647$ e $653,5 \mathrm{~nm}$ e em 468 e $472 \mathrm{~nm}$ que são atribuídas aos ions $\mathrm{Cr}^{3+}$ localizados num plano de reflexão, conforme é reportado por SUCHOCKI [60]. 


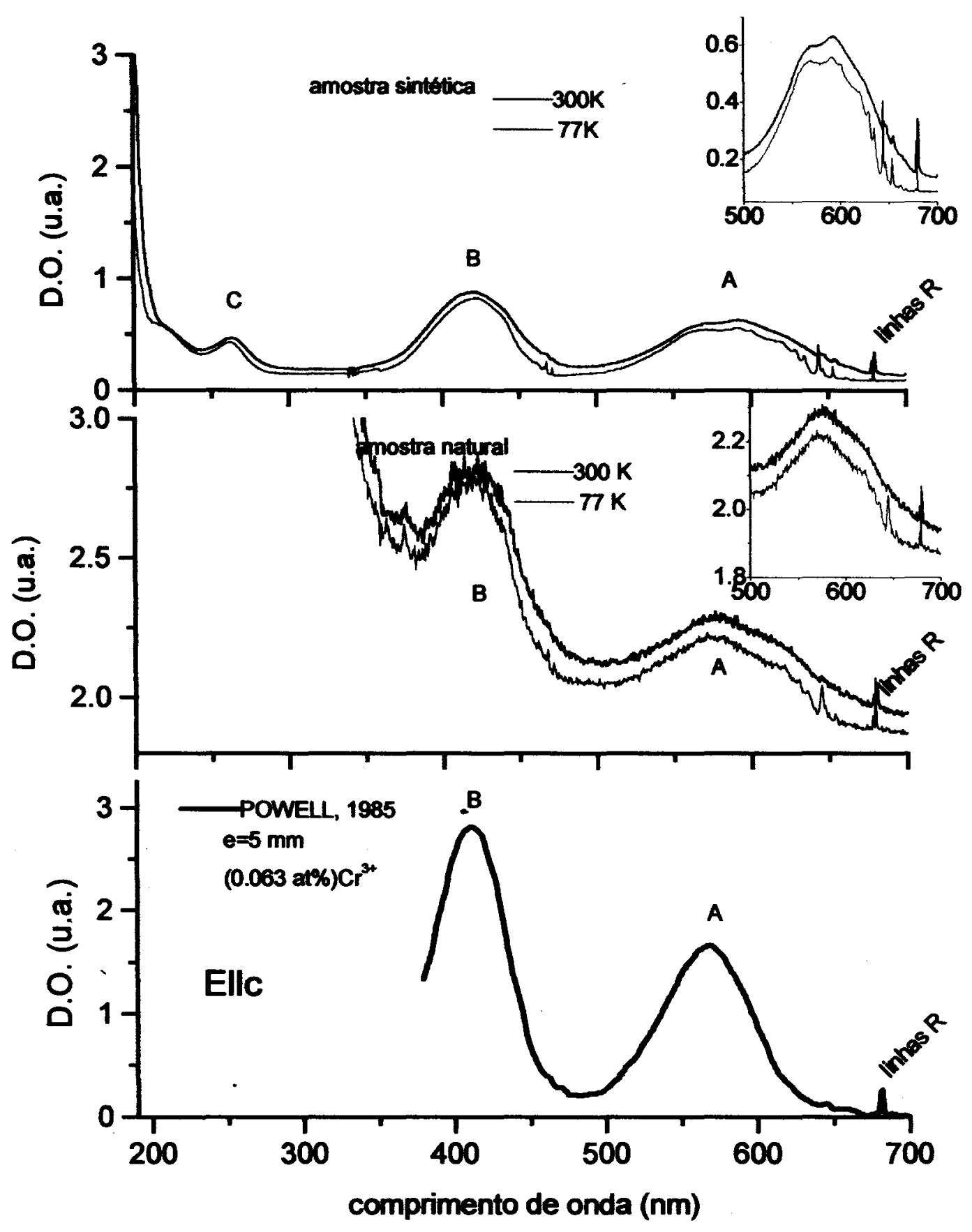

Figura 13 - Espectros de absorção óptica das amostras sintéticas (AS1), natural (AN3) e da referência [27]. Os espectros em vermelho representam as medidas de absorção a 77K e as inserçøes mostram as linhas vibrônicas laterais da banda $\mathrm{A}$ de forma ampliada 
As amostras naturais apresentam o mesmo comportamento em relação as linhas $R$, próximas de $680 \mathrm{~nm}$, e as bandas largas estão centralizadas entre 570 e 587nm ( banda A) e 416-425 nm (banda B), dependendo da amostra natural analisada. Nesse caso, o espectro de absorção não é tão suave (com ruído), e a 77K é possível observar apenas uma das linhas vibrônicas, em torno de $645 \mathrm{~nm}$.

As bandas A e B são atribuídas a primeira $\left(v_{1}\right)$ e segunda $\left(v_{2}\right)$ transições eletrônicas permitidas por spin na camada $3 \mathrm{~d}$ parcialmente preenchida do ín $\mathrm{Cr}^{3+}$, sendo que, a primeira transição permitida por spin $\left(v_{1}\right)$ é exatamente $\Delta(=10 \mathrm{Dq})$ [2,91]. Assim, para a amostra sintética temos $\mathrm{Dq}=1734 \mathrm{~cm}^{-1}$ para $\mathrm{Cr}^{3+}$ rodeado por 6 oxigênios na estrutura e, para as amostras naturais temos Dq entre $1754 \mathrm{~cm}^{-1}$ e 1705 $\mathrm{cm}^{-1}$. De acordo com HASSAN [36], cujo trabalho se refere a uma amostra sintética de alexandrita, uma terceira transição permitida por $\operatorname{spin}\left(v_{3}\right){ }^{4} \mathrm{~A}_{2 \mathrm{~g}} \rightarrow{ }^{4} \mathrm{~T}_{\mathrm{lg}}(\mathrm{P})$ pode ser esperada e calculada usando-se a fórmula [91,92]:

$$
340 \mathrm{Dq}^{2}-18\left(v_{2}+v_{3}\right) \mathrm{Dq}+v_{2} v_{3}=0
$$

e deve ocorrer na região do ultravioleta.

De acordo com a literatura existe sempre uma considerável dificuldade em se obter o espectro do íon $\mathrm{Cr}^{3+}$ na região do UV pois, essa região é geralmente influenciada por traços de $\mathrm{Fe}^{3+}$ [36]. Para a amostra sintética, com concentração de Fe praticamente desprezivel, é possível observar no espectro de absorção óptica a banda $\mathrm{C}$ em torno de $265 \mathrm{~nm}$, enquanto que, para as amostras naturais com concentração de $\mathrm{Fe}$ maior do que $\mathrm{Cr}$, a banda $\mathrm{C}$ do $\mathrm{Cr}^{3+}$ na região do UV não é observada no espectro. A posição dessa banda calculada através da equação (30) seria em aproximadamente $267 \mathrm{~nm}$, ou seja, praticamente coincidente com o valor 
obtido experimentalmente no espectro de absorção de AS1. Em medidas reportadas por SUCHOCKI [60], o espectro de absorção da alexandrita obtido a $12 \mathrm{~K}$ apresenta em sua estrutura um "ombro" em torno de $245 \mathrm{~nm}$, enquanto que todos os outros autores citados em nosso trabalho, não apresentam o espectro de absorção na região do ultravioleta.

A presença do $\mathrm{Fe}$ nas amostras naturais, também pode ser considerada quando se observa a banda B (em torno de $420 \mathrm{~nm}$ ) nos espectros de ambas as amostras, natural e sintética, na Figura 13, os quais são visivelmente distintos na região do UV. As bandas do $\mathrm{Fe}^{3+}$ ocorrem em torno de 440,5 e 377,4 nm [2] e , nos espectros de absorção óptica das amostras naturais, principalmente AN3 por ser mais fina e transparente, é possível verificar uma estrutura como um "ombro" em torno de $380 \mathrm{~nm}$, que torna a banda B bem mais assimétrica em comparação com a banda B da amostra sintética e isso pode ser atribuído a influência da presença do íon $\mathrm{Fe}^{3+}$ em nossas amostras naturais. As amostras naturais apresentam também inclusões de mica e quartzo cujo espectro de absorção óptica na região do visível apresenta uma absorção bastante intensa [93]. Entretanto, devemos também considerar que a subida abrupta no lado de maior energia da banda B do espectro de absorção das amostras naturais seja devido a efeitos de dispersão da luz nessa região, uma vez que essas amostras são bastante opacas e rugosas em comparação com a amostra sintética. Na Tabela 8 os resultados dos cálculos da largura a meia altura, intensidade (coeficiente de absorção) e posição das bandas de absorção são apresentados tanto para as amostras sintética e natural AN3, quanto para as outras amostras naturais, AN1 e AN5, cujos espectros têm sido aqui citados. 
Tabela 8- Resultados das medidas de absorção óptica, no visível, obtidos à temperatura ambiente. $\lambda$ indica as posições de máximos de absorção, $\alpha$ é o coeficiente de absorção calculado a partir da equação (5) e $\Delta \lambda$ é a largura a meia altura da banda de absorção.

\begin{tabular}{|c|c|c|c|c|c|c|c|}
\hline \multicolumn{7}{|c|}{ Bandas de Absorção } & \multirow{3}{*}{$\begin{array}{c}\text { Linhas de } \\
\text { Absorção } \\
\text { do } \mathrm{Cr}^{3+} \\
\left(\mathrm{Al}_{2}\right) \\
\lambda(\mathrm{nm})\end{array}$} \\
\hline \multicolumn{4}{|c|}{ Banda $A\left(\mathrm{Cr}^{3+}\right)$} & \multicolumn{3}{|c|}{ Banda $\mathrm{B}\left(\mathrm{Cr}^{3+}, \mathrm{Fe}^{3+}\right)$} & \\
\hline Amostra & $\lambda(\mathrm{nm})$ & $\alpha\left(\mathrm{cm}^{-1}\right)$ & $\Delta \lambda(\mathbf{n m})$ & $\lambda(\mathbf{n m})$ & $\alpha\left(\mathrm{cm}^{-1}\right)$ & $\begin{array}{c}\Delta \lambda \\
(\mathbf{n m})\end{array}$ & \\
\hline AS1 & 576,5 & 3,55 & 99,50 & 424,5 & 8,54 & 62,50 & $\begin{array}{l}678,5 \\
680,5\end{array}$ \\
\hline AN1 & 570,1 & 10,42 & 62,16 & - & - & - & $\begin{array}{l}678,6 \\
680,7\end{array}$ \\
\hline AN3 & 576,5 & 4,25 & 92,30 & 416,0 & 7,25 & 51,28 & $\begin{array}{l}678,5 \\
680,6\end{array}$ \\
\hline AN5 & 576,5 & 6,12 & 98,39 & 418,0 & 7,39 & 51,61 & $\begin{array}{l}678,0 \\
679,5\end{array}$ \\
\hline
\end{tabular}

Em relação a banda $\mathrm{A}$, de acordo com a literatura [2], o espectro de absorção obtido para os cristais de alexandrita consiste da superposição dos espectros de absorção dos íons $\mathrm{Cr}^{3+}$ situados num centro de inversão (em $\mathrm{Al}_{1}$ ) e $\mathrm{Cr}^{3+}$ localizados num plano de reflexão $\left(\mathrm{em}^{\mathrm{Al}} \mathrm{l}_{2}\right.$ ) coexistindo e a largura das bandas de absorção, na região da banda A, favorece essa visão apresentando bandas superpostas. Na Figura 13, mesmo sem levar em conta efeitos de polarização da luz, 
observamos que a largura da banda A não é relacionada com uma banda simples mas, sim a duas bandas superpostas. A decomposição da banda complexa A pode então, dar informações a respeito da relação entre os íons $\mathrm{Cr}^{3+}$ nos dois sítios, com a absorção localizada no comprimento de onda maior atribuída aos centros $\mathrm{Cr}^{3+}(2)$ dos sítios mais populados $\mathrm{Al}_{2}$ (maiores) e a absorção localizada para energias mais altas é atribuída aos centros de $\mathrm{Cr}^{3+}(1)$ nos sítios menos populados $\mathrm{Al}_{1}$ (menores) [2,36]. Comparando as medidas da largura a meia altura da banda A da amostra sintética com as amostras naturais, se verifica que a maior diferença é de $7,2 \mathrm{~nm}$, em relação a amostra AN3, e para AN5 praticamente são coincidentes, com a pequena variação associada a erros de medições. Entretanto, a intensidade da banda A para a amostra sintética é razoavelmente menor do que para as amostras AN3 e AN5, o que pode significar comportamentos diferentes das bandas superpostas para amostras sintética e natural, indicando taxas de ocupação relativa diferentes nos sítios $\mathrm{Al}_{1}$ e $\mathrm{Al}_{2}$ para ambos os tipos de amostras.

Outra consideração a respeito dos espectros de absorção das amostras sintética e naturais é a relação existente entre as intensidades das bandas $\mathrm{A}\left(\mathrm{Cr}^{3+}\right)$ e $\mathrm{B}\left(\mathrm{Cr}^{3+}, \mathrm{Fe}^{3+}\right)$. A partir da Tabela 8 podemos verificar que a intensidade relativa entre essas bandas, $\left(I_{B} / I_{A}\right)$, é em torno de $41 \%$ maior para AS1 do que AN3 e quase $100 \%$ maior para AS1 do que AN5. Isso pode significar que o $\mathrm{Cr}^{3+}$ está mais localizado nos sítios menores $\left(\mathrm{Al}_{1}\right)$ na amostra sintética do que nas amostras naturais [2]. Analisando a região espectral onde são detectadas as linhas R, em torno de 580 nm, na Figura 13 observamos a intensidade da linha do $\mathrm{Cr}^{3+}$ localizada em torno de $680,5 \mathrm{~nm}$ (linha $\mathrm{R}_{1}$ ) é maior do que a linha localizada em torno $678,5 \mathrm{~nm}$ (linha $\mathrm{R} 2$ ) para ambos os tipos de amostras, natural e sintética. A distância entre as linhas $R_{1}$ e $R_{2}$ para amostra 
sintética é de $2 \mathrm{~nm}\left(43,3 \mathrm{~cm}^{-1}\right)$, para AN3 é de $2,1 \mathrm{~nm}\left(45,5 \mathrm{~cm}^{-1}\right)$ e para AN7 é 1,5 $\mathrm{nm}\left(32,56 \mathrm{~cm}^{-1}\right)$, à temperatura ambiente. Na literatura a separação entre as linhas $\mathrm{R}$, isto é, a separação do nível ${ }^{2} \mathrm{E}$, é medida como sendo $34,1 \mathrm{~cm}^{-1}(1,6 \mathrm{~nm})$ à $12 \mathrm{~K}$ e aumenta para $40 \mathrm{~cm}^{-1}(1,8 \mathrm{~nm})$ para temperaturas mais altas, obtida para uma amostra sintética contendo 0,0325 at $\% \mathrm{Cr}^{3+}$ com $78 \%$ desses íons ocupando os sítios $\mathrm{Al}_{2}$ e $22 \%$ ocupando os sítios $\mathrm{Al}_{1}[60]$.

Portanto, podemos garantir que nossas amostras são de excelente qualidade com os espectros de absorção plenamente coincidentes com a literatura em relação as bandas largas A e B e em relação as linhas $\mathrm{R}$ e, novamente pudemos nos certificar de que a amostra sintética pode ser utilizada como uma referência em nosso trabalho, uma vez que não há influência do Fe em seu comportamento, inclusive possibilitando a observação da banda $\mathrm{C}$, a qual não é apresentada na literatura.

\section{4 - ABSORÇÃO ÓPTICA NO INFRAVERMELHO}

Também foram obtidos os espectros de absorção na região do infravermelho, utilizando o espectrofotômetro BOMEM DA8, no intervalo espectral de 4000 à 1000 $\mathrm{cm}^{-1}(2,5-10 \mu \mathrm{m})$, para as amostras naturais e sintética. Nessa região, se observa o aparecimento de bandas em torno de $1600 \mathrm{~cm}^{-1}(6250 \mathrm{~nm})$ e $1720 \mathrm{~cm}^{-1}(5814 \mathrm{~nm})$ e somente no caso da amostra natural observamos uma banda larga entre 2850-2990 $\mathrm{cm}^{-1}$ (3508 e $3344 \mathrm{~nm}$ ), além de evidências de outras bandas entre 3500 e $3620 \mathrm{~cm}^{-1}$, observadas melhor quando mudamos a escala de absorbância para o intervalo de 1 a 2 u.a.. Os espectros no infravermelho, na região de 1000 à $4000 \mathrm{~cm}^{-1}$, à temperatura 
ambiente, são apresentados na Figura 14, para a amostra sintética AS1 e para uma dẹ amostras naturais.

Especificamente para alexandritas, não temos conhecimento de nenhuma referência na literatura mas, de acordo com um trabalho publicado para a sodalita [94], um alumino-silicato de sódio e cloro, cuja fórmula química é $\mathrm{Na}_{4}\left(\mathrm{AlSiO}_{4}\right)_{3} \mathrm{Cl}$, o espectro no infravermelho apresenta uma banda em $3640 \mathrm{~cm}^{-1}$ atribuida a um modo vibracional de $\mathrm{O}-\mathrm{H}$, bandas em $3486 \mathrm{~cm}^{-1}$ e $1660 \mathrm{~cm}^{-1}$ atribuídas a $\mathrm{H}_{2} \mathrm{O}$. Ainda para sodalita a regiåo de 992 à $410 \mathrm{~cm}^{-1}$ é caracterizada com a presença de bandas atribuídas a modos vibracionais de $\mathrm{Si}-\mathrm{O}$, Si-O-Al e $\mathrm{Al}-\mathrm{O}$, principalmente.

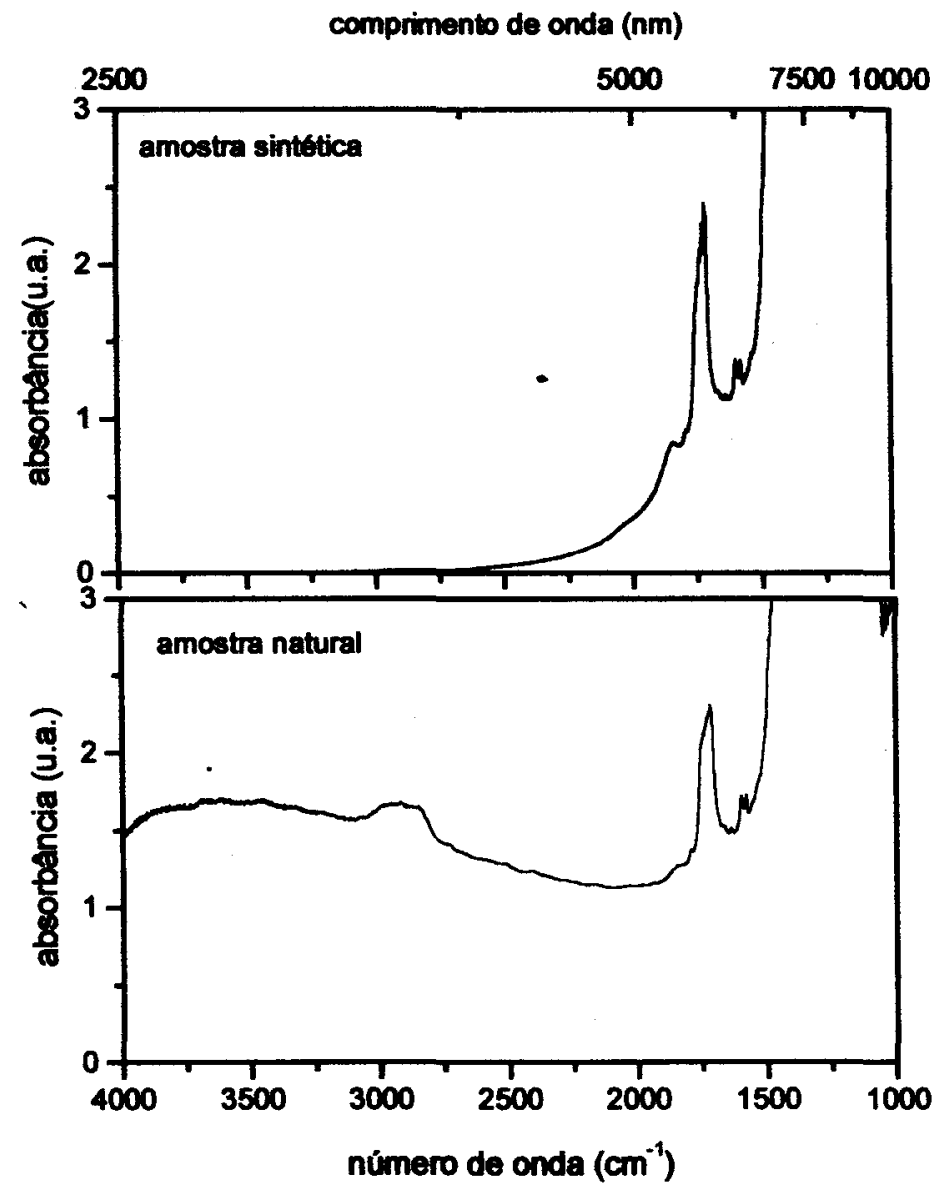

Figura 14 - Espectros de absorção óptica no infravermelho para AS1 e AN5, à temperatura ambiente. 
Assim, baseados nas medidas para sodalita e também em trabalhos realizado para outras matrizes, como por exemplo niobato de litio e haletos alcalinos, atribuímos as bandas largas, na região de 2800 à $4200 \mathrm{~cm}^{-1}$, observadas apenas nas amostras naturais, à vibrações moleculares de $\mathrm{O}-\mathrm{H}$ e $\mathrm{H}_{2} \mathrm{O}$. As bandas que aparecem para ambas as amostras aproximadamente entre 1500 à $2000 \mathrm{~cm}^{-1}$ não foram identificadas nesse trabalho mas, uma possibilidade é que sejam atribuídas a vibrações moleculares de Al-O.

Embora não tenha sido possível uma análise mais detalhada dos espectros de absorção na região do infravermelho, essas medidas parecem reforçar a indicação de que nas amostras naturais existe realmente a presença de inclusões fluidas, como podemos supor ocorrer nesse tipo de amostra. Para a amostra sintética, podemos pensar que não ocorre esse tipo de inclusão uma vez que, na região do espectro entre 2000 à $4000 \mathrm{~cm}^{-1}$ não detectamos nenhuma banda.

\section{5 - LUMINESCÊNCIA}

Conforme mencionado no capítulo 3 , quando foram descritas as técnicas experimentais utilizadas nesse trabalho, as medidas de luminescência tem por objetivo principal auxiliar na interpretação dos resultados de CDTE e também, podemos considerá-las como complementares às medidas de absorção, possibilitando melhores condições de análise sobre o comportamento dos íons de $\mathrm{Cr}^{3+}$ nos dois sítios diferentes da alexandrita. Os resultados obtidos nessas medidas estão apresentados na Figura 15, para a amostra natural AN3 $(e=2,03 \mathrm{~mm})$ e sintética AS1 
$(\mathrm{e}=2,32 \mathrm{~mm})$ à temperatura ambiente, excitadas com um laser de $\mathrm{Kr}^{+}$sintonizado no MLUV com potência de saída de $0,43 \mathrm{~W}$.

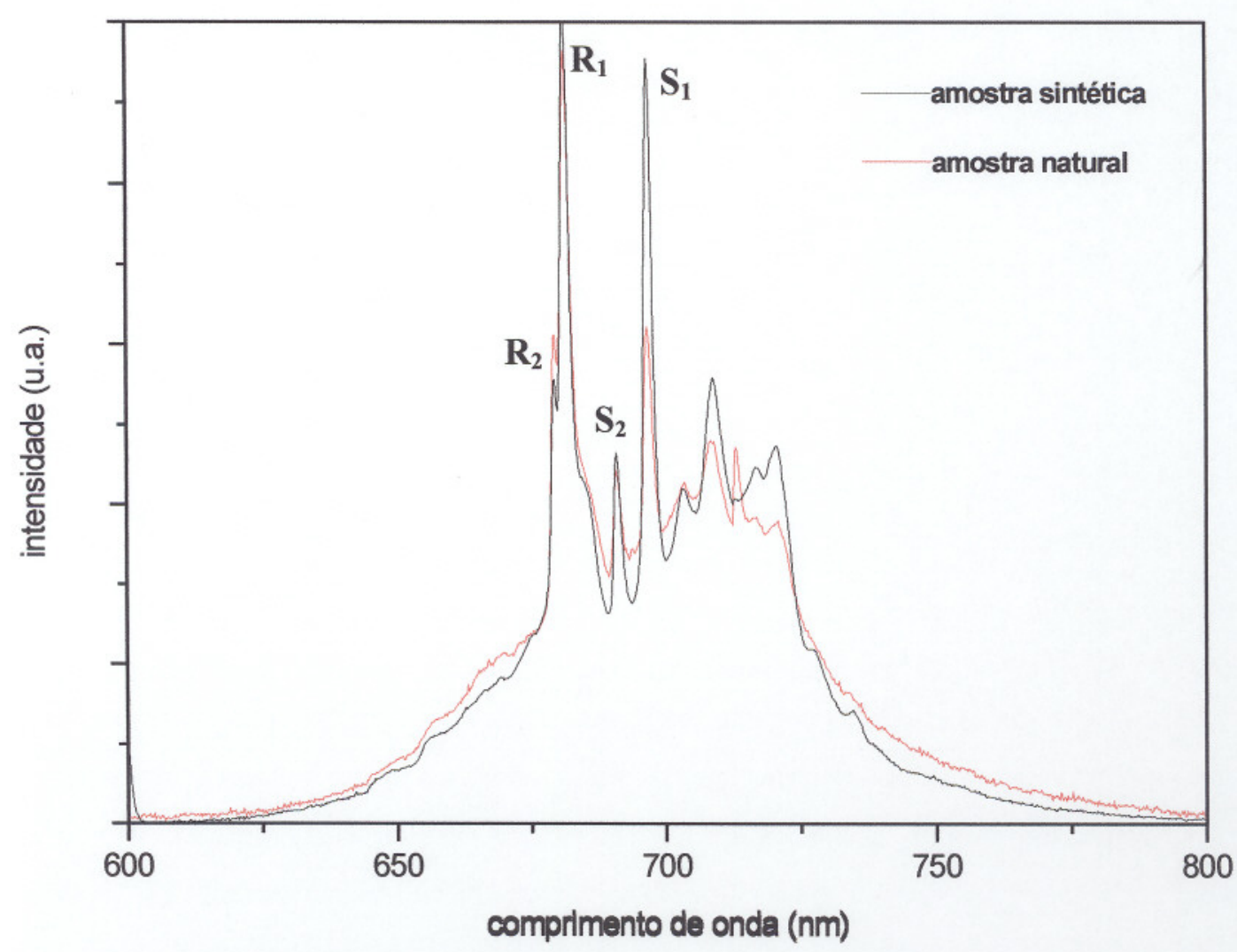

Figura 15 - Espectros de emissão das amostras de alexandrita natural (AN3) e sintética (AS1), obtidos à temperatura ambiente, através de excitação com MLUV do laser de $\mathrm{Kr}^{+}$.

Na Figura 15 se observa as linhas do $\mathrm{Cr}^{3+}$ nos sítios em um plano de reflexão (linhas $\mathrm{R}$ ) e as linhas do $\mathrm{Cr}^{3+}$ nos sítios situados num centro de inversão (linhas $\mathrm{S}$ ), que podem ser comparados com a literatura [28], de acordo com a Figura 4 do capítulo 2. Os espectros de emissão também foram obtidos para outras amostras naturais, inclusive AN5, e as posições e intensidades das linhas de emissão são coincidentes com a amostra AN3. 
O sistema de aquisição do sinal de luminescência foi ajustado com sensibilidade de $200 \mathrm{mV}$ e abertura de fenda de $10 \mu \mathrm{m}$, dando uma resolução de 0,20 nm. A tensão na fotomultiplicadora foi de $900 \mathrm{~V}$. A partir da Figura 15, pode ser verificado que as amostras sintética e naturais utilizadas nesse trabalho, possuem um comportamento muito semelhante ao apresentado na literatura (Figura 4), com a presença das linhas $R\left(R_{1}\right.$ e $\left.R_{2}\right)$ e $S\left(S_{1}\right.$ e $\left.S_{2}\right)$ bem definidas. As posições das linhas de emissão mostradas na Figura 4 e na Figura 15 estão apresentadas na Tabela 9.

Tabela 9 - Posições das linhas $R$ nos sítios localizados num plano de reflexão $\left(R_{1} e\right.$ $R_{2}$ ) e das linhas $S$ nos sítios localizados no centro de inversão $\left(S_{1}\right.$ e $\left.S_{2}\right)$ para as amostras AS1, AN3 e da referência [28].

\begin{tabular}{ccccc}
\hline amostra & $\begin{array}{c}\text { Linha } \mathbf{R}_{1} \\
(\mathrm{~nm})\end{array}$ & $\begin{array}{c}\text { Linha } \mathbf{R}_{2} \\
(\mathrm{~nm})\end{array}$ & $\begin{array}{c}\text { Linha } \mathbf{S}_{1} \\
(\mathrm{~nm})\end{array}$ & $\begin{array}{c}\text { Linha } \mathbf{S}_{2} \\
(\mathrm{~nm})\end{array}$ \\
\hline AS1 & 681,2 & 679,4 & 696,6 & 690,8 \\
AN3 & 681,2 & 679,4 & 696,6 & 690,8 \\
{$[28]$} & 680,3 & 678,5 & 695,8 & 690,0 \\
\hline
\end{tabular}

Nos espectros apresentados na Figura 15, as intensidades relativas das linhas do $\mathrm{Cr}^{3+}$ no sítios $\mathrm{Al}_{2}, \mathrm{R}_{1}$ e $\mathrm{R}_{2}$, apresentam o mesmo comportamento, com $\mathrm{R}_{1}>\mathrm{R}_{2}$; como também foi verificado nos espectros de absorção óptica dessas amostras. Entretanto, para as linhas do $\mathrm{Cr}^{3+}$ referentes ao sítio $\mathrm{Al}_{1}, \mathrm{~S}_{1}$ e $\mathrm{S}_{2}$, vemos que para nossas amostras sintética e natural, a linha $S_{1}$ é mais intensa do que a linha $S_{2}$, com maior evidência para a amostra sintética, enquanto que na literatura [28,58], $S_{2}>S_{1}$. Uma das causas dessa diferença pode estar na utilização de comprimento de onda de 
excitação diferentes nos dois casos sendo que, na literatura o bombeio foi feito com um laser de argônio operando em $488 \mathrm{~nm}$ enquanto que nesse trabalho foi utilizado laser de $\mathrm{Kr}^{+}$sintonizado no MLUV (337,5-356,4nm). SCHEPLER [95] apresenta os espectros de emissão de uma amostra de alexandrita sintética em função do comprimento de onda do bombeio, onde as variações que ocorrem nas intensidades das linhas, são explicadas como sendo um indicativo de que mais de um tipo de mecanismo de relaxação está presente. Em relação às diferenças das intensidades das linhas $S_{1}$ e $S_{2}$ também é possível que esteja relacionado com uma variação entre a taxa de população dos dois sítios de simetrias diferentes para ambas as amostras, o qual também foi verificado com as medidas de absorção óptica, cuja largura a meia altura e intensidade diferem ligeiramente para as amostras AN3 e AS1, conforme foi apresentado na Tabela 8.

De acordo com SUCHOCKI et al [60], existe uma mudança nas intensidades relativas das linhas $S_{1}$ e $S_{2}$ (chamadas $R_{1 i}$ e $R_{2 i}$ no trabalho de SUCHOKI) para diferentes direções de polarização do campo elétrico e magnético, consistentes com uma transição de dipolo magnético. Também de acordo com esses autores, a separação em energia entre as linhas $\mathrm{S}$ é em torno de três vezes maior do que a separação das linhas $\mathrm{R}$, o que indica uma componente de baixa simetria mais forte do campo cristalino para os íons nos sítios localizados em um centro de inversão. Este resultado concorda plenamente com as medidas apresentadas na Tabela 9 para nossas amostras sintética e natural, sendo a separação entre as linhas $S_{1}$ e $S_{2}$ igual à $120 \mathrm{~cm}^{-1}$, enquanto que para as linhas $R_{1}$ e $R_{2}$, a separação entre as linhas é em torno de $39 \mathrm{~cm}^{-1}$. 
Portanto, os espectros de emissão óptica, assim como os espectros de absorção óptica, puderem nos fornecer informações importantes a respeito dos íons $\mathrm{Cr}^{3+}$ nos dois sítios de simetrias diferentes da alexandrita, as quais são plenamente coincidentes com a literatura, demonstrando, mais uma vez, a excelente qualidade de nossas amostras.

\section{6 - CORREMTE DE DESPOLARIZAÇÃO THRMICAMENTE ESTIMUTADA}

A técnica de Corrente de Despolarização Termicamente Estimulada, CDTE, constitui a ferramenta mais importante neste trabalho, sendo utilizada pela primeira vez, no estudo das propriedades elétricas de alexandritas e assim, os mecanismos envolvidos nos processos de relaxação dipolar elétrica são aqui investigados, através dessas medidas.

Foram utilizadas a amostra sintética, AS1, e as amostras naturais AN1, AN2, AN3 e AN5, sendo que, a amostra AS1 pode ser considerada uma referência na análise do comportamento das bandas de CDTE, em primeiro lugar, conforme verificado através das técnicas de EDX e WDX, por não possuir quantidades significativas de outras impurezas além do $\mathrm{Cr}^{3+}$ e depois pela sua procedência (crescida por H.P. Jenssen e R.Morris, autores de inúmeros trabalhos publicados, com cristais sintéticos de alexandritas). As amostras AN1 e AN2 podem ser consideradas como elementos de testes iniciais na investigação das propriedades elétricas através dessa técnica e, as amostras AN3 e AN5 os elementos principais de 
análise neste trabalho, com as quais realizamos medidas de CDTE, CDTEFI e CDTE em função de tratamentos térmicos.

As possibilidades de formação de dipolos em alexandritas pode ser visualizada com base em sua estrutura cristalina representada na Figura 2. Na estrutura temos os íns $\mathrm{Al}^{3+}$ localizados num centro de inversão $\left(\mathrm{Al}_{1}\right)$ e $\mathrm{Al}^{3+}$ situados num plano de reflexão $\left(\mathrm{Al}_{2}\right)$ ligados, cada um deles, a seis íons de oxigênio, sendo que apenas 3 são simetricamente independentes e designados $\mathrm{O}_{1}, \mathrm{O}_{2}$ e $\mathrm{O}_{3}$. A Figura 16 mostra um sítio $\mathrm{Al}_{1}$ e um sítio $\mathrm{Al}_{2}$ em detalhes. As distâncias interatômicas entre os íons de $\mathrm{Al}$ e os íons de oxigênio são diferentes. Em alexandrita os íons $\mathrm{Al}^{3+}$ são substituídos pelos íons $\mathrm{Cr}^{3+}$ com uma distribuição em torno de $75 \%$ de $\mathrm{Cr}^{3+}$ em $\mathrm{Al}_{2}$ e o restante de $\mathrm{Cr}^{3+}$ em $\mathrm{Al}_{1}$.

A simples substituição de um íon trivalente por outro de mesma valência não causaria a formação de dipolos. Entretanto, a presença de vacâncias de oxigênio, intrínsecas à estrutura, distribuídas aleatoriamente para cada $\mathrm{Cr}^{3+}$ coordenado octaedricamente com oxigênio, pode dar origem a presença de dipolos do tipo impureza-vacância, I-V. Nesse caso, se a vacância está próxima à impureza $\mathrm{Cr}^{3+}$ ocupando posições aleatórias 1, 2 ou 3, como mostrado também na Figura 16, e essas distâncias são diferentes, forma-se então um momento de dipolo entre $\mathrm{o} \mathrm{Cr}^{3+} \mathrm{e} \mathrm{V}$. Por outro lado, a origem da formação de dipolos pode ser atribuída às deformações que ocorrem na rede devido ao ín substituído, $\mathrm{Al}^{3+}$, possuir raio iônico $(0,535 \AA)$ menor do que o íon $\mathrm{Cr}^{3+}(0,615 \AA)$. No caso de ocorrer uma deformação local na estrutura, a formação de dipolos não envolve necessariamente a presença de vacâncias, como ilustrado no lado esquerdo Figura 16 onde o íon $\mathrm{Cr}^{3+}$ está indicado na cor lilás substituindo o íon $\mathrm{Al}^{3+}$ 

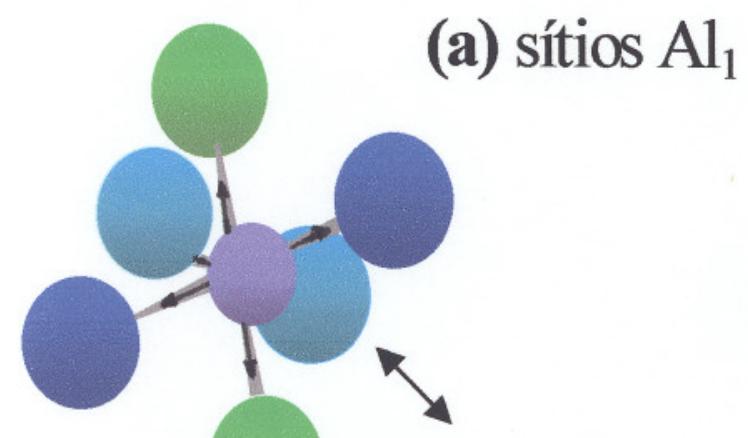

Dipolo formados por deformação local da rede
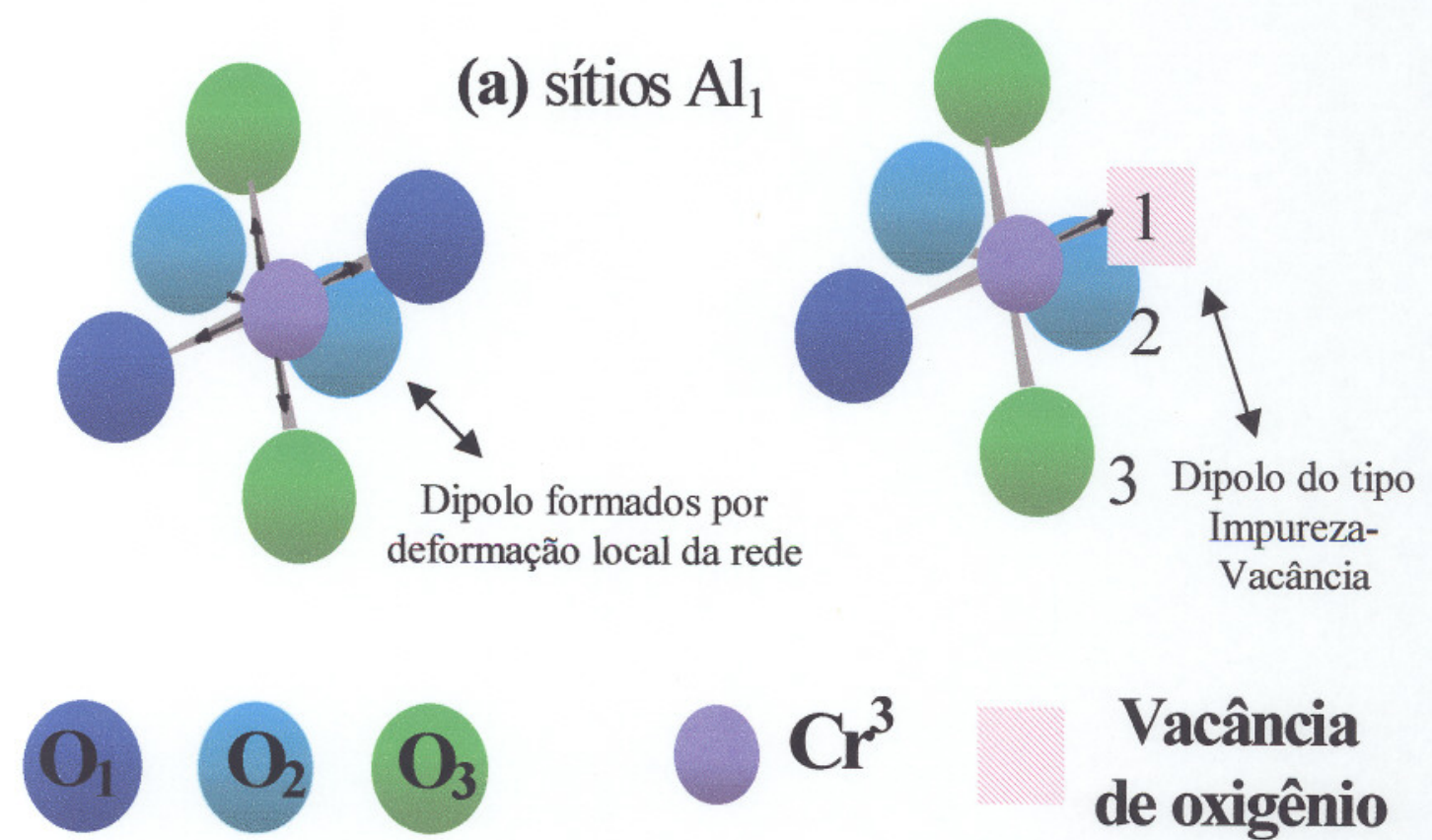

\section{Vacância de oxigênio}

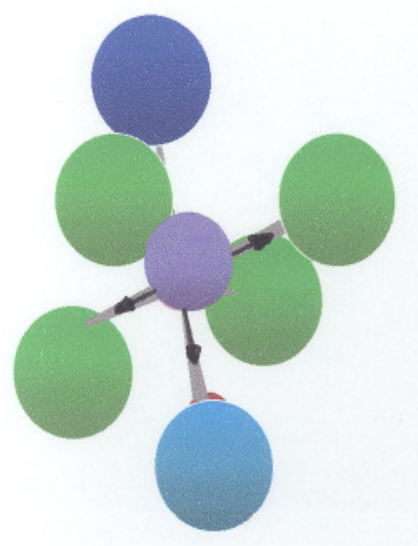

(b) sítios $\mathrm{Al}_{2}$

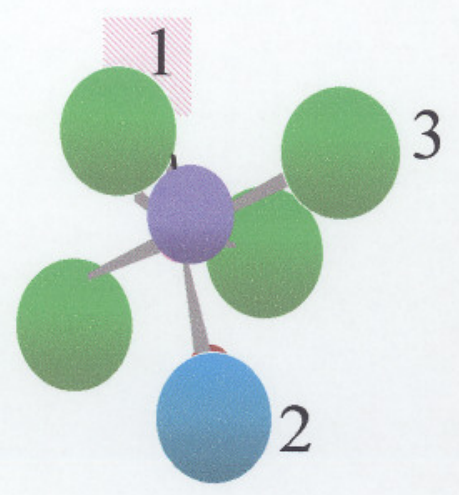

Figura 16 - Esquema da formação de dipolos na alexandrita: (a) detalhes de um sítio $\mathrm{Al}_{1}$ (localizado sobre um centro de inversão) Adaptado da referência [8]. (b) sítio $\mathrm{Al}_{2}$ (localizado num plano de reflexão). Adaptado da referência [96]. 
Uma forma de comprovar essa possibilidade seria realizar as medidas de CDTE em uma amostra não dopada com $\mathrm{Cr}^{3+}$, ou seja, crisoberilo, verificando se ocorre ou não a presença de dipolos devido a deformação local sofrida pela substituição de $\mathrm{Al}^{3+}$ por $\mathrm{Cr}^{3+}$.

A presença de tais dipolos, tanto impureza-vacância quanto os originados por deformação local devido a diferença de raio iônico são detectados de forma sensível e precisa através das medidas de CDTE. Outras possibilidades que devem ser levadas em consideração é a presença de outros defeitos intrínsecos à estrutura, principalmente no caso das amostras naturais que possuem inclusões de quartzo e mica. Em quartzo é típica a presença de longos canais ao longo do eixo cristalográfico $c$ o que permite a vários íons alcalinos $\mathrm{e}$ íons $\mathrm{H}^{+}$, moverem-se na direção do eixo $c$, dando origem a condutividade iônica e modificações no balanço de cargas de sítios de defeitos quando um cristal de quartzo é submetido a um campo elétrico [97].

\subsection{1 - COMPORTAMENTO DAS BANDAS DE CDTE PARA AS AMOSTRAS NATURAIS}

As primeiras medidas de CDTE em alexandritas foram realizadas para a amostra AN1, de espessura igual a 2,17 mm (na região central da amostra), sem nos preocuparmos muito com suas características aparentes, como espessura, cor e uniformidade de suas faces, através das quais é aplicado o campo elétrico de polarização, $\mathrm{E}_{\mathrm{p}}$. 
Como resultado das primeiras medidas, foi observado o aparecimento de uma banda localizada em torno de $179 \mathrm{~K}$, com intensidade de $34 \times 10^{-14}$ A. Nessas medidas foram utilizados eletrodos de tinta prata $3 \times 4 \mathrm{~mm}^{2}$ e a amostra foi polarizada próximo à temperatura ambiente com campo elétrico igual a $2,3 \mathrm{kV} / \mathrm{cm}$. Os resultados obtidos para essa amostra foram bastante reprodutiveis para condições de medidas idênticas. Para um campo elétrico de polarização igual a 4,6 kV/cm foi observada essa mesma banda, com o pico de corrente máximo localizado na mesma temperatura e com intensidade de $41 \times 10^{-14} \mathrm{~A}$. Essas medidas também apontaram um acentuado aumento da corrente para temperaturas acima de $200 \mathrm{~K}$, que pode ser atribuída à presença de água na amostra natural, previamente detectada nas medidas de absorção óptica na região do infravermelho, conforme apresentado na Figura 14 neste mesmo capítulo e/ou também a presença das inclusões sólidas, como quartzo e mica. A observação da banda descrita acima é facilitada com leituras de CDTE efetuadas após polarização com $T_{p}$ bastante próxima da temperatura de intensidade máxima da banda e portanto, foram realizadas também medidas com temperatura de polarização em torno de $170 \mathrm{~K}$, próximo do pico, com $E_{p}=4,6 \mathrm{kV} / \mathrm{cm}$ e foi observada uma banda centralizada em torno $180 \mathrm{~K}$, eliminando o aumento de corrente acima de 200K. Esses resultados estão representados na Figura 17.

Como a amostra apresentava espessura bastante irregular, com faces maiores não paralelas, foi realizado um polimento conforme processo descrito no capítulo 4, resultando em uma espessura final de $1,95 \mathrm{~mm}$. Após o polimento as medidas de CDTE foram realizadas, com $T_{p}=300 \mathrm{~K}$ e campo elétrico de polarização igual a 10,2 $\mathrm{kV} / \mathrm{cm}$ e $12,3 \mathrm{kV} / \mathrm{cm}$, respectivamente. Novamente foi possivel observar a presença de uma banda em torno de 194K para ambos campos de polarização aplicados, com 
a intensidade do pico aumentando para campos elétricos mais altos. O deslocamento da banda de CDTE para temperatura mais alta pode ser justificado pelas variações nas taxas de aquecimento, a qual não foi possível manter fixa, com variação de 0,02 à $0,08 \mathrm{~K} / \mathrm{s}$ em cada uma das medidas.

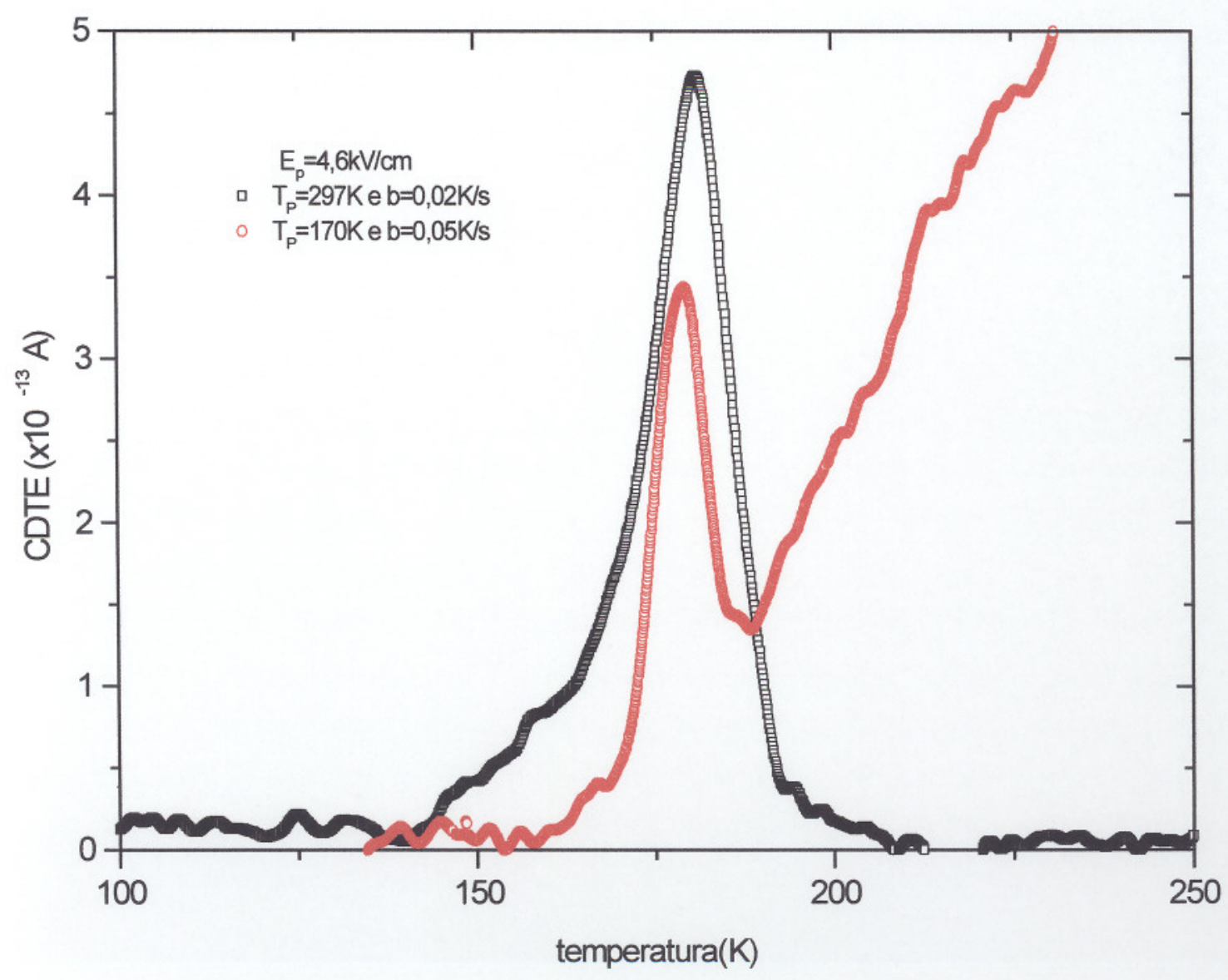

Figura 17- Medidas de CDTE para amostra AN1 $(\mathrm{e}=2,17 \mathrm{~mm})$. Para curva em vermelho, $T_{p}=297 \mathrm{~K}$ e $b=0,02 \mathrm{~K} / \mathrm{s}$ e para curva em preto, $T_{p}=170 \mathrm{~K}$ e $b=0,05 \mathrm{~K} / \mathrm{s}$. $\mathrm{E}_{\mathrm{p}}=4,6 \mathrm{kV} / \mathrm{cm}$ para ambas as curvas. 
A fim de verificar a reprodutibilidade dos resultados para diferentes amostras de alexandritas, uma segunda amostra natural, AN2, com espessura de 2,86 mm, obtida a partir de uma pedra diferente da amostra AN1, foi também submetida a medidas de CDTE. Essas medidas foram realizadas nas mesmas condições descritas para a amostra AN1, para $T_{p}$ (temperatura de polarização), $E_{p}$ (campo elétrico de polarização) e b (taxa de aquecimento), e foi verificado que, dentro da margem de erro esperada para medidas de CDTE (em torno de 10\%), os resultados são perfeitamente reprodutiveis, com a presença de uma banda com as mesmas características das observadas anteriormente com AN1.

Com as amostras AN1 e AN2 também foi verificado que, dado um conjunto de parâmetros fixos, como amostra, temperatura de polarização e área dos eletrodos, o comportamento da área sob a banda é bastante regular com a tensão de polarização, com a área crescendo linearmente com a tensão aplicada, de acordo com a equação17. Este resultado é uma indicação de um comportamento típico de uma entidade dipolar e está representado na Figura 18 para a amostra AN2, onde temos também representada as variações associadas aos parâmetros envolvidos, ou seja, $T_{p}$ e $E_{p}$, estimadas, através do cálculo de propagação de erros, em torno de $8 \%$. 


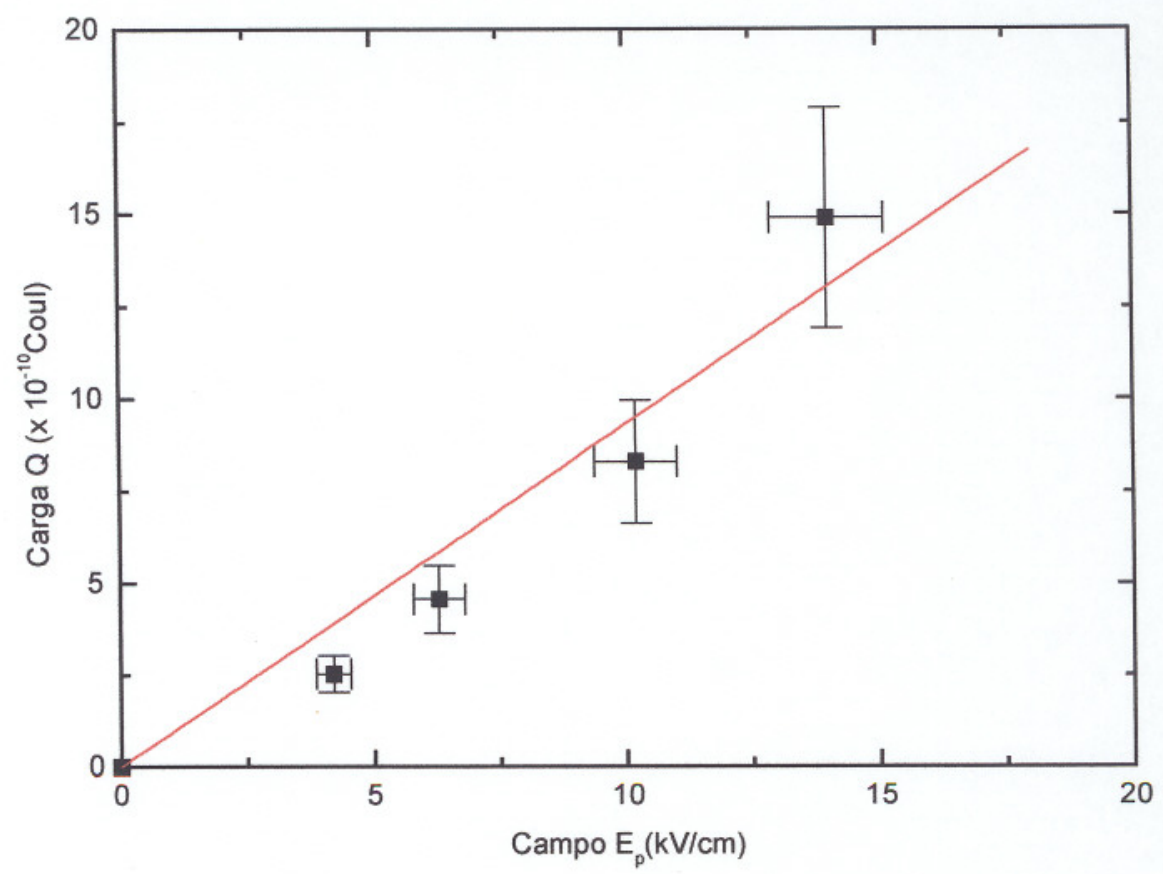

Figura 18 - Comportamento da área sob a banda de CDTE em função do campo elétrico de polarização para a amostra natural AN2 $(\mathrm{e}=2,86 \mathrm{~mm})$.

A partir de uma $3^{\mathrm{a}}$ pedra de alexandrita foram obtidas as amostras AN3 e AN4, sendo que a amostra AN4, de forma irregular, foi submetida a medidas de EDX e WDX e a amostra AN3, de espessura 2,03mm, foi utilizada nas medidas de CDTE. Essas amostras apresentam uma coloração verde bem mais homogênea e mais translúcida do que as anteriores AN1 e AN2.

As medidas de CDTE para AN3 foram realizadas sem nenhum polimento da amostra, com eletrodos de tinta prata $3 \times 6 \mathrm{~mm}^{2} \mathrm{e}$, para temperatura de polarização próxima à temperatura ambiente, com $\mathrm{E}_{\mathrm{p}}=6,9 \mathrm{kV} / \mathrm{cm}$ e b=0,09K/s, foi observada uma banda de CDTE centralizada em torno de $195 \mathrm{~K}$, com intensidade de $90 \times 10^{-14} \mathrm{~A}$. Nessa amostra também foi observado um comportamento da corrente aumentando intensamente para temperaturas acima de $220 \mathrm{~K}$. Para $\mathrm{T}_{\mathrm{p}}$ em torno de $189 \mathrm{~K}$, próximo do pico, com $\mathrm{E}_{\mathrm{p}}=6,9 \mathrm{kV} / \mathrm{cm}$ e $\mathrm{b}=0,08 \mathrm{~K} / \mathrm{s}$, temos a mesma banda sem o efeito do aumento de corrente para $\mathrm{T}>220 \mathrm{~K}$. Esses resultados são apresentados na Figura 19. 

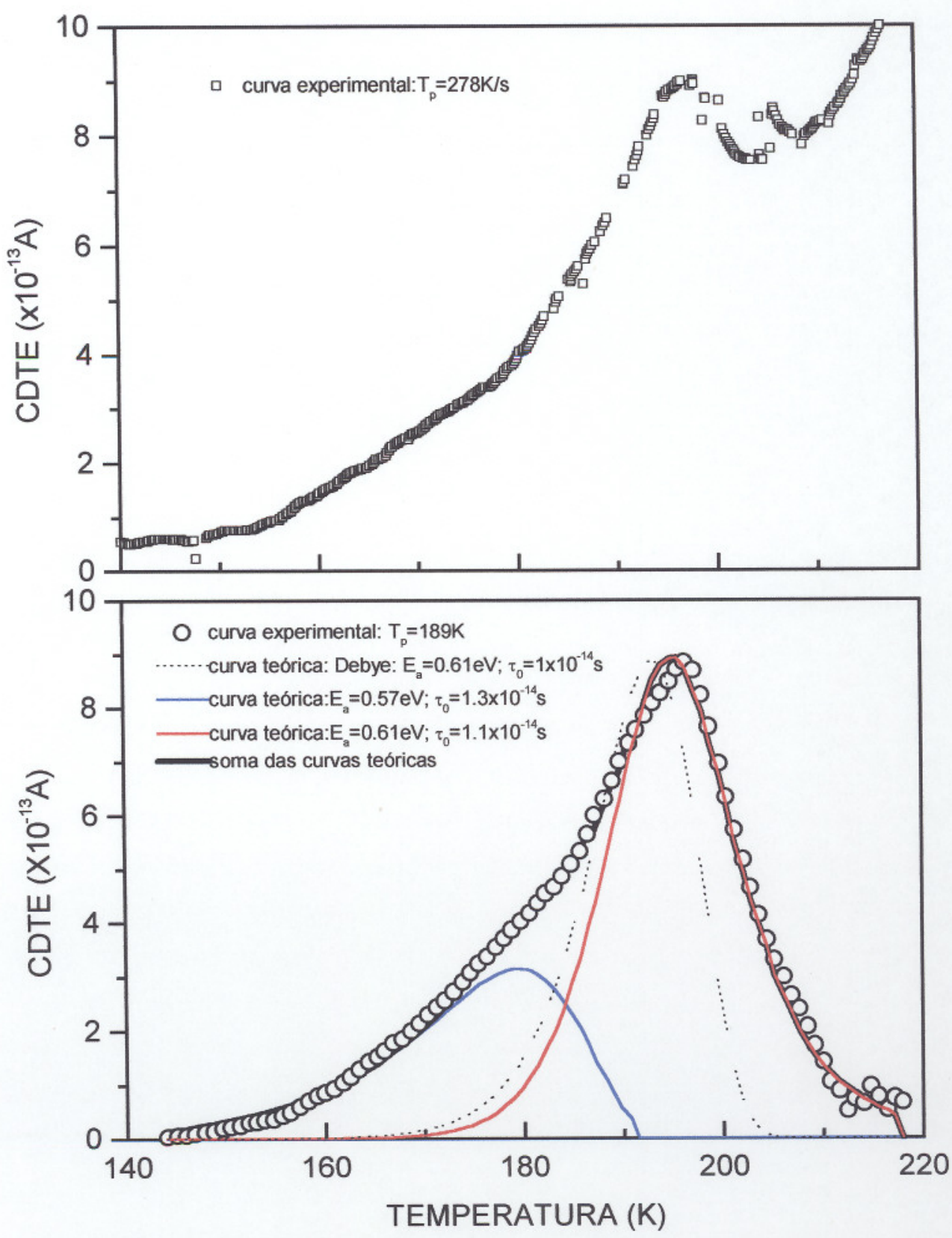

Figura 19 - Medidas de CDTE para a amostra AN3 (e=2,03mm). (a) curva experimental para $T_{p}=278 \mathrm{~K}$ e $b=0,09 \mathrm{~K} / \mathrm{s}$. (b) curva experimental para $T_{p}=189 \mathrm{~K}$ e $\mathrm{b}=0,08 \mathrm{~K} / \mathrm{s}$. As curvas em vermelho e azul representam o ajuste teórico pelo método de Havriliak-Negami. 
Os principais parâmetros que definem as relaxações térmicas estudadas por CDTE são a energia de ativação $\left(\mathrm{E}_{\mathrm{a}}\right)$ e a frequência natural de relaxação ou o seu inverso que é o tempo de relaxação $(\tau)$. Essas grandezas se relacionam com a densidade de corrente de despolarização medida experimentalmente. As hipóteses básicas que permitem determinar a energia de ativação das relaxações térmicas relacionadas com as bandas de CDTE empregadas neste trabalho são baseadas nas equações apresentadas no capítulo 3, onde foram descritos os princípios básicos dessas medidas.

Assim, iniciamos a análise das curvas experimentais obtidas para alexandritas utilizando um modelo simples, conhecido como modelo de Debye, o qual leva em conta um único tempo de relaxação e uma única energia de ativação, e obtivemos a curva pontilhada apresentada na Figura 19b. Diante da discrepância entre as curvas experimental e teórica obtidas, tentamos utilizar o método melhorado de Prakash [81], representado na equação 21 do capítulo 3, para ajustar as curvas experimentais, o qual considera uma distribuição discreta dos parâmetros de relaxação envolvidos. Esse método mostrou ser relativamente bem aplicado quando utilizamos duas curvas teóricas para descrever a curva experimental obtida. Contudo, a escolha de uma, duas ou mais curvas para realizar tal ajuste é bastante arbitrária e além disso, os resultados obtidos para o tempo de relaxação através da equação 23 , utilizando parâmetros das curvas calculadas pelo método melhorado de Prakash, apontaram uma discrepância muito grande em seus valores em comparação à valores usualmente esperados em medidas de CDTE, com $\tau_{0}=1,2 \times 10^{-8} \mathrm{~S}$ a partir de uma das curvas teóricas ajustadas para a amostra AN3 e $\tau_{0}=1,3 \times 10^{-6} \mathrm{~s}$ a partir da outra. Este comportamento também foi 
encontrado quando o ajuste de curvas foi feito para as amostras AN1 e AN2, cujos valores para o tempo de relaxação mostraram ser bastante dispersivos e incoerentes.

Diante disso, foi utilizado então um método de ajuste das curvas experimentais que considera uma distribuição contínua dos parâmetros de relaxação envolvidos no processo, conforme proposto por HAVRILIAK e NEGAMI [30]. Além disso, uma distribuição contínua parece ser mais adequada às bandas de CDTE obtidas para alexandrita pois, conforme pode ser observado Figura 16, podemos esperar uma distribuição de dipolos que podem inclusive, interagir entre si, dando origem a bandas de CDTE mais complexas do que previstas por uma distribuição discreta. Os ajustes de curvas experimentais e curvas calculadas pelo método de Havriliak-Negami estão representados na Figura 19 para a amostra AN3

Na Figura 19 podemos observar um excelente ajuste das curvas teóricas e experimentais quando são consideradas duas distribuições envolvendo os parâmetros de relaxação. Nesse caso, tanto os valores obtidos para as energias de ativação $(0,57$ eV e $0,61 \mathrm{eV})$ quanto os valores obtidos para os tempos de relaxação $\left(\tau_{0}=1,3 \times 10^{-14} \mathrm{~s}\right.$ e $\tau_{0}=1,1 \times 10^{-14} \mathrm{~s}$ ) para cada uma das distribuições, centralizadas em $180 \mathrm{~K}$ (curva azul) e 195K (curva vermelha), respectivamente, são bastante coerentes, em relação a valores obtidos à partir de medidas de CDTE em cristais iônicos, por exemplo.

A fim de verificar se o abrupto aumento de corrente para temperaturas superiores a 220K, apresentado na Figura 19(a) poderia ser devido às condições experimentais, uma vez que poderiam estar ocorrendo efeitos de superficie devido a tinta prata, que poderia estar muito diluída, com a presença de água e não a um comportamento próprio da amostra, foram realizadas medidas de CDTE utilizando-se eletrodos de ouro, de dimensões 3,7 x 2,4 mm² obtidos por evaporação resistiva [70]. 
$O$ resultado obtido com essas medidas, para $T_{p}=189 \mathrm{~K}, E_{p}=6,9 \mathrm{kV} / \mathrm{cm}$ e $b=0,09 \mathrm{~K} / \mathrm{s}$ está representado na Figura 20.

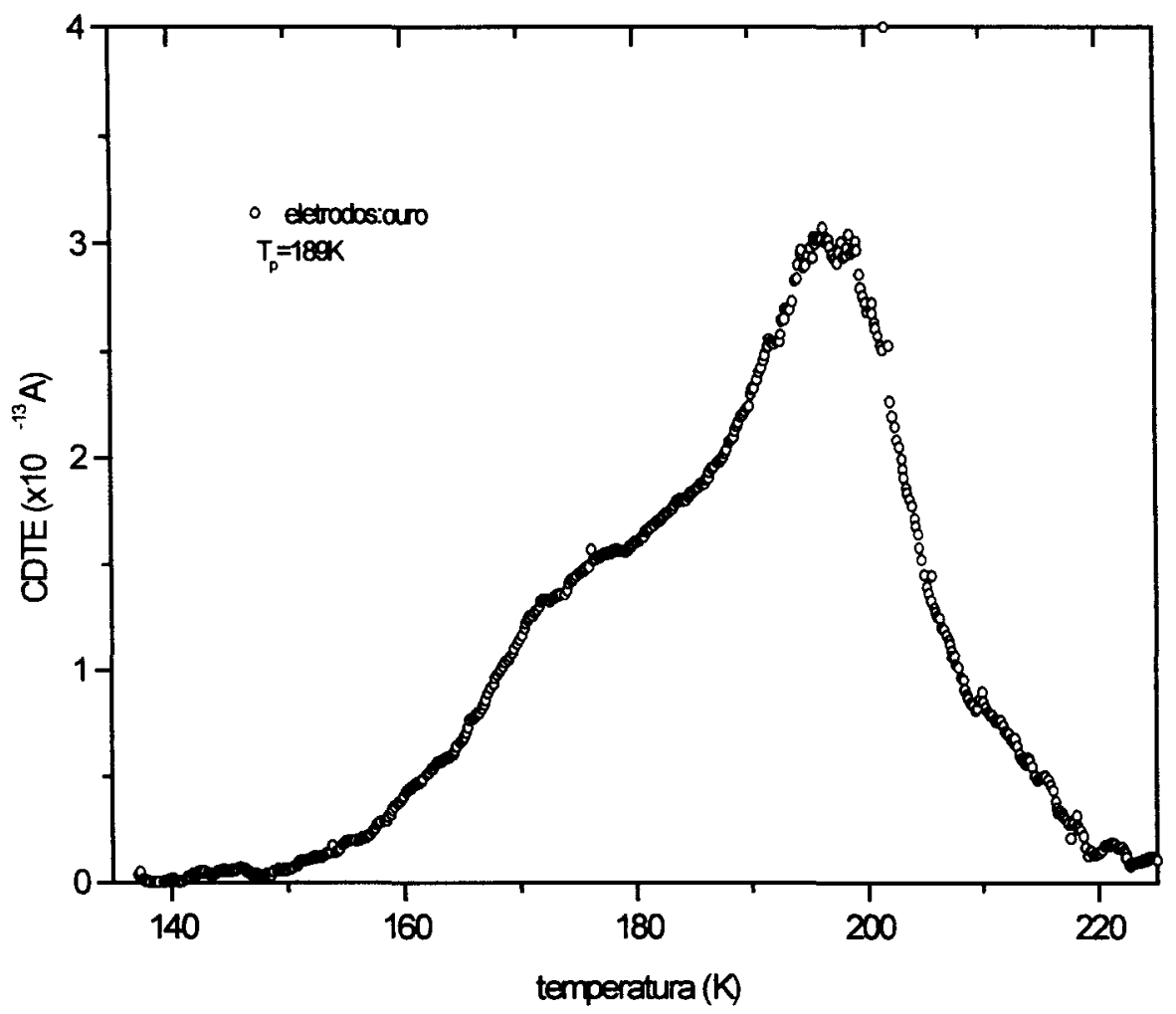

Figura 20 - CDTE para a amostra $\operatorname{AN} 3(\mathrm{e}=2,03 \mathrm{~mm})$ com $T_{p}=189 \mathrm{~K}, E_{p}=6,9 k V / c m ~ e$ eletrodos de ouro.

Comparando a curva experimental dessa figura com a curva experimental mostrada na Figura 19(b), podemos verificar que a utilização de eletrodos de ouro dá origem ao aparecimento da banda de CDTE praticamente na mesma posição de quando se utiliza eletrodos de tinta prata, como era esperado, uma vez que o fenômeno de relaxação dipolar se deve a fatores volumétricos e não superficiais. As diferentes intensidades das bandas nas duas condições para eletrodos utilizados, ouro e tinta prata, são explicadas pelo fato de ter se utilizado área dos eletrodos diferentes, 
mantendo-se então coerente a proporcionalidade entre as intensidades máximas e área dos eletrodos (tinta prata $=18,0 \mathrm{~mm}^{2}$ e ouro $=8,9 \mathrm{~mm}^{2}$ ).

Uma característica interessante a respeito da forma das bandas mostradas na Figura 20 é uma melhor visualização da banda em torno de 177K, superposta a banda observada em torno de $196 \mathrm{~K}$ quando utilizamos eletrodos de ouro. E, conforme queria se verificar, realmente ocorre um comportamento mais regular para correntes acima de $225 \mathrm{~K}$, mesmo quando utilizamos temperatura de polarização próxima da temperatura ambiente, indicando que o aumento acentuado da corrente nessas temperaturas pode ser atribuído também a qualidade dos eletrodos utilizados. Entretanto, como não houve nenhum alteração brusca na forma, posição e intensidade da banda de CDTE não consideramos essencial a utilização de eletrodos de ouro pois embora apresente algumas vantagens, como acabamos de ver, o seu uso sistemático tornaria as medidas de CDTE ainda mais demoradas (o processo de evaporação resistiva leva em torno de 2 horas, nesse caso), além do custo mais alto desses eletrodos.

Motivados pelo fato de trabalharmos com amostras naturais com características um pouco diferentes umas das outras, entendemos ser de fundamental importância realizar as medidas de CDTE com o maior número possível de amostras a fim de, principalmente, confirmar, com segurança, o efeito dipolar de forma reprodutível. Portanto, foram realizadas medidas de CDTE utilizando a amostra natural AN5 e, desde que foi verificado que a banda de CDTE, na qual estamos interessados, ocorre para temperaturas abaixo de $200 \mathrm{~K}$, foi possível nessas medidas utilizar sempre temperaturas de polarização menores do que esse valor, ou seja, temperaturas de polarização apenas próximas da temperatura máxima das bandas de 
CDTE. Os resultados obtidos para a amostra AN5 são perfeitamente coerentes com aqueles obtidos para AN1, AN2 e AN3 e serão apresentados futuramente, ainda nesse capítulo.

\subsection{2 - MEDIDAS DE CDTE PARA A AMOSTRA SINTÉTICA.}

Para a amostra sintética de alexandrita, AS1 as medidas de CDTE indicaram a presença de uma banda em torno de $174 \mathrm{~K}$ quando polarizadas à temperatura ambiente com eletrodos de tinta prata, $4,10 \times 6,60 \mathrm{~mm}^{2}, \mathrm{E}_{\mathrm{p}}=6,9 \mathrm{kV} / \mathrm{cm}$ e taxa de aquecimento $b=0,08 \mathrm{~K} / \mathrm{s}$. Na Figura 21 são apresentados os resultados obtidos para essa amostra.

Para essa amostra não foi observado o efeito do aumento de corrente para temperaturas acima de $220 \mathrm{~K}$, conforme pode ser visto na Figura 21(a). Isto pode indicar que nas amostras naturais o comportamento da banda acima dessa temperatura corresponde, realmente, a outra origem que não seja a de relaxação dipolar em alexandritas. Na Figura 21(b) são apresentadas a curva experimental obtida para a amostra sintética para temperatura de polarização próxima do pico e a soma das curvas teóricas ajustadas pelo método de Havriliak-Negami.

A Tabela 10 mostra os parâmetros de relaxação obtidos a partir dos ajustes mostrados na Figura 19 e na Figura 21, onde também consta o cálculo da área sob a curva de corrente em função do tempo, a qual é proporcional ao número de dipolos de uma dada espécie presente na amostra e chamada carga total de polarização $Q$, citada no capítulo 3. Nessa tabela são apresentados também os parâmetros $\alpha$ e $\beta$ utilizados no ajuste de curvas através desse método. 


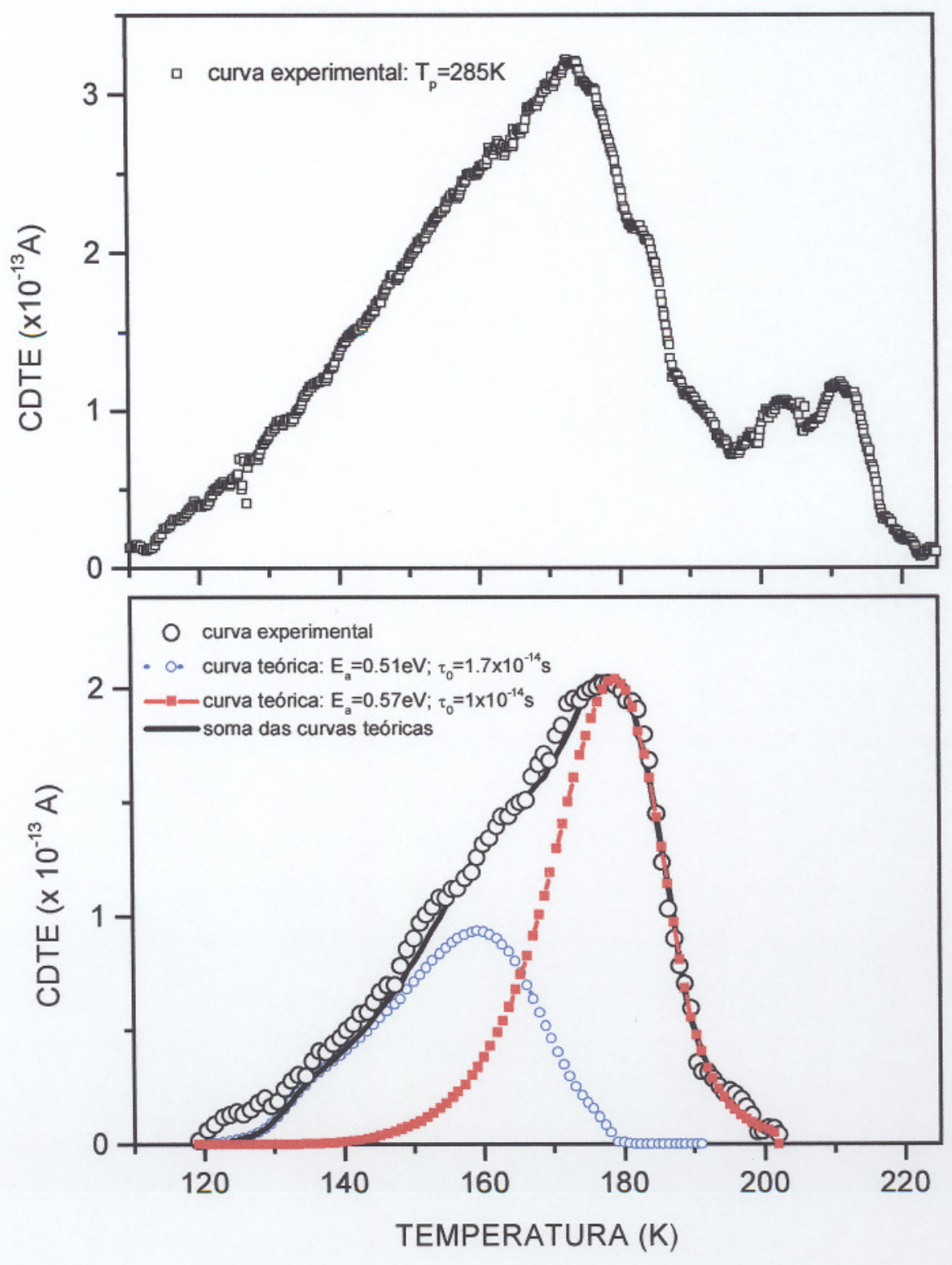

Figura 21- CDTE para a amostra AS1 $(\mathrm{e}=2,32 \mathrm{~mm})$.(a) curva experimental para $T_{p}=285 K$. (b)curva experimental para $T_{p}=167 \mathrm{~K}$. Para ambas $b=0,08 K / s$ e $\mathrm{E}_{\mathrm{p}}=6,9 \mathrm{kV} / \mathrm{cm}$. As curvas vermelha e azul representam o ajuste teórico pelo método de Havriliak-Negami. 
Tabela 10- Parâmetros de relaxação obtidos para AS1 e AN3 através do ajuste por $H N$. $T_{m}$ é a temperatura máxima de cada uma das distribuições em $[K] ; E_{a}$ é a energia de ativação em [eV]; $\tau_{0}$ é o tempo de relaxação $\left(\times 10^{-14}\right)$ em [s] e Q é a carga total de polarização $\left(\times 10^{-10}\right) \mathrm{em}\left[\mathrm{C}^{-1}\right] \cdot \mathrm{b}=0,08 \mathrm{~K} / \mathrm{s}$ em todas as medidas.

\begin{tabular}{|c|c|c|c|c|c|c|c|c|c|c|c|c|c|}
\hline & \multicolumn{4}{|c|}{ Curva 1} & \multicolumn{4}{|c|}{ Curva 2} & \multicolumn{4}{|c|}{ Curva3 } & \multirow[t]{2}{*}{$Q$} \\
\hline & $\overline{\mathbf{E}_{\mathbf{a}}}$ & $\tau_{0}$ & $T_{m}$ & $\alpha$ e $\beta$ & $\overline{\mathbf{E}_{\mathbf{a}}}$ & $\tau_{0}$ & $T_{m}$ & $\alpha$ e $\beta$ & $\mathbf{E}_{\mathbf{a}}$ & $\overline{\tau_{0}}$ & $T_{m}$ & $\alpha \mathbf{e} \beta$ & \\
\hline AN3 & - & - & - & - & 0.57 & 1.3 & 180 & $\begin{array}{l}0.045 \\
0.410\end{array}$ & 0.61 & 1.1 & 195 & $\begin{array}{c}0.263 \\
0.7\end{array}$ & 2.64 \\
\hline AS1 & 0.51 & 1.7 & 159 & $\begin{array}{c}0.30 \\
0.365\end{array}$ & 0.57 & 1.0 & 179 & $\begin{array}{l}0.20 \\
0.69\end{array}$ & - & - & - & - & 0.96 \\
\hline
\end{tabular}

Conforme pode se verificar com os resultados sintetizados na Tabela 10, um fato bastante interessante é que a curva representando a distribuição dos parâmetros de relaxação das medidas de CDTE com intensidade mais baixas da amostra natural AN3 se localiza praticamente na mesma temperatura da curva de intensidade mais alta para a amostra sintética ( 180 e $179 \mathrm{~K}$, respectivamente). Este comportamento das bandas de CDTE deve ser considerado uma evidência de que ambos os tipos de amostra, natural e sintética, possuem um mesmo tipo de entidade dipolar e que esses dipolos estejam associados às impurezas de $\mathrm{Cr}^{3+}$ na matriz hospedeira uma vez que, de acordo com resultados de EDX/WDX, a amostra sintética não possui quantidades significativas de inclusões (apenas traços de Ir) e a concentração de Fe também é desprezível. No caso das amostras naturais, as análises de EDX (e WDX para uma das amostras), conforme foi visto na seção 4.1 , indicaram a presença de outras 
impurezas na matriz de crisoberilo ( $\mathrm{Mg}, \mathrm{Si}, \mathrm{Ti}, \mathrm{K}$ e Ca no caso da amostra AN3), além dos elementos $\mathrm{Cr}$ e $\mathrm{Fe}$, com uma concentração de $\mathrm{Fe}$ bem maior do que $\mathrm{Cr}$.

Assim, devemos considerar que as bandas de relaxação dipolar observadas nas amostras naturais sofram a influência da presença do $\mathrm{Fe}^{3+}$, o qual foi verificado influenciar também nos espectros de absorção óptica dessas amostras, e tambẻm das inclusões de quartzo e mica, que podem possuir dipolos em suas estruturas. Esta pode ser a causa da grande diferença entre as cargas de polarização calculadas para ambas as amostras (última coluna da Tabela 10), mesmo quando consideramos a diferença entre as áreas dos eletrodos, e do deslocamento das bandas de CDTE centralizadas em temperaturas mais altas no caso das amostras naturais.

\section{7 - EFEITO DOS TRATAMENTOS TÉRMICOS}

Embora tenha sido verificado com as medidas de CDTE que a região de interesse, onde ocorre o fenômeno de relaxação dipolar, seja abaixo da região influenciada pela presença de água nas amostras, foram realizados tratamentos térmicos nas amostras naturais a fim de verificar, principalmente, o efeito que as outras impurezas podem ter sobre as bandas de CDTE.

Nesta seção são apresentados os resultados obtidos nas medidas de CDTE, Absorção Óptica no UV-VIS e Infravermelho e Luminescência para a amostra AN5 cujos tratamentos foram feitos num intervalo de tempo mais curto (5 minutos) e não provocaram a quebra da amostra, como ocorreu com AN3. Para a amostra AN5 os tratamentos térmicos foram: $\quad$ TT $1=700{ }^{\circ} \mathrm{C}$ por 5 minutos, TT2 $=800{ }^{\circ} \mathrm{C}$ por 5 
minutos, TT3 $=900{ }^{\circ} \mathrm{C}$ por 5 minutos, TT $4=1000{ }^{\circ} \mathrm{C}$ por 5 minutos e TT $5=1000$ ${ }^{0} \mathrm{C}$ por 5 horas.

\subsection{1 - CDTE APÓS OS TRATAMENTOS TÉRMicos.}

Nas medidas de CDTE foram utilizados os mesmos valores para campo elétrico de polarização $\left(E_{p}=7,0 \mathrm{kV} / \mathrm{cm}\right)$, taxa de aquecimento $(b=0,08-0,09 \mathrm{~K} / \mathrm{s})$, temperatura de polarização próxima do pico $\left(\mathrm{T}_{\mathrm{p}}=183-185 \mathrm{~K}\right)$, tempo de polarização $\left(t_{p}=5\right.$ minutos) e eletrodos de tinta prata de área igual $12,06 \mathrm{~mm}^{2}$. Para obtermos eletrodos sempre iguais nas diferentes medidas utilizamos uma "máscara" de papel alumínio com estas dimensões. Os resultados das medidas de CDTE em função dos tratamentos térmicos, sob as condições descritas, são apresentados em um único gráfico na Figura 22. Nessa figura temos também representado o resultado das medidas de CDTE para essa amostra antes de ser submetida aos tratamentos térmicos.

Para a amostra AN5, após TT1, uma única banda foi observada em torno de $186 \mathrm{~K}$ com intensidade aproximada de $70 \times 10^{-14} \mathrm{~A}$ (banda 1), ou seja, bem mais intensa do que a banda sem tratamento térmico e ligeiramente deslocada para temperatura mais baixa, em relação a essa.

Após TT2, as medidas de CDTE, apresentam a banda 1 bem mais intensa em relação as anteriores (sem tratamento e com TT1) e começa também a apresentar evidências da presença da banda em torno de $175 \mathrm{~K}$.

Conforme pode ser verificado na Figura 22 após TT3, a banda de CDTE apresenta realmente um outro pico do lado de temperatura mais baixa (em torno de 
175K) e portanto, foram realizadas também medidas de CDTE nas mesmas condições descritas anteriormente em relação ao campo elétrico de polarização, tempo de polarização, taxa de aquecimento e área dos eletrodos de tinta prata porém, com temperatura de polarização próximo desse novo pico, ou seja, em torno de $175 \mathrm{~K}$. O resultado obtido para essa condição de $T_{p}$ é apresentados na Figura 23. Nessa figura podemos notar que a banda localizada na temperatura mais baixa é fortemente favorecida sobrepondo a banda 1, quando $T_{p}=175 \mathrm{~K}$.

Com o $4^{\circ}$ tratamento térmico, TT 4 , as bandas 1 e 2 têm praticamente a mesma intensidade quando $T_{p}=185 \mathrm{~K} e$, para $T_{p}=175 \mathrm{~K}$ novamente a banda 2 superpõe a banda 1, conforme é mostrado na Figura 22 e na Figura 23.

O último tratamento térmico para AN5 $\left(1000{ }^{\circ} \mathrm{C}-5\right.$ horas $)$ mostra que a banda 2 , tanto para $T_{p}=185 \mathrm{~K}$ quanto para $T_{p}=175 K$, parece sobrepor completamente a banda 1.

As posições e intensidades das bandas apresentadas na Figura 22 e na Figura 23 são apresentadas na Tabela 11 , assim como a carga total de polarização $Q$, a qual é calculada mantendo-se constante a área dos eletrodos. 


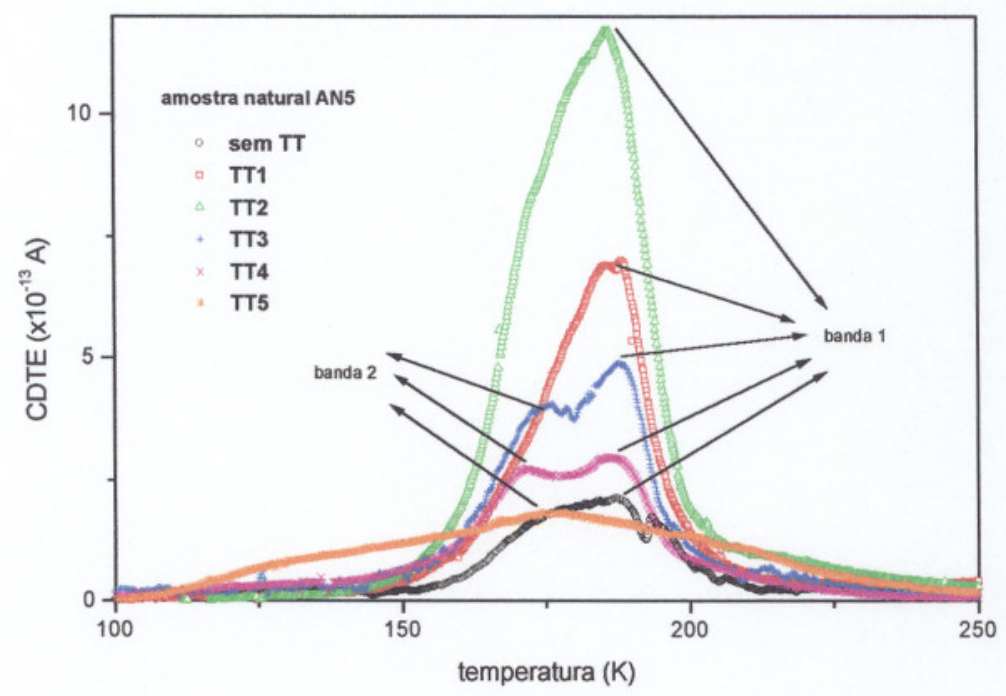

Figura 22 - Medidas de CDTE para a amostra AN5 sem tratamento térmico e após TT1 $\left(700{ }^{\circ} \mathrm{C}-5 \mathrm{~min}\right)$, TT2 $\left(800{ }^{\circ} \mathrm{C}-5 \mathrm{~min}\right)$, TT3 $\left(900{ }^{\circ} \mathrm{C}-5 \mathrm{~min}\right)$, TT4 $\left(1000{ }^{\circ} \mathrm{C}-\right.$ $5 \mathrm{~min})$ e TT5 $\left(1000{ }^{\circ} \mathrm{C}\right.$ - 5 horas). Em todas as medidas $\mathrm{T}_{\mathrm{p}} \cong 185 \mathrm{~K} \mathrm{e} \mathrm{b}=0,08 \mathrm{~K} / \mathrm{s}-$ $0,09 \mathrm{~K} / \mathrm{s}$

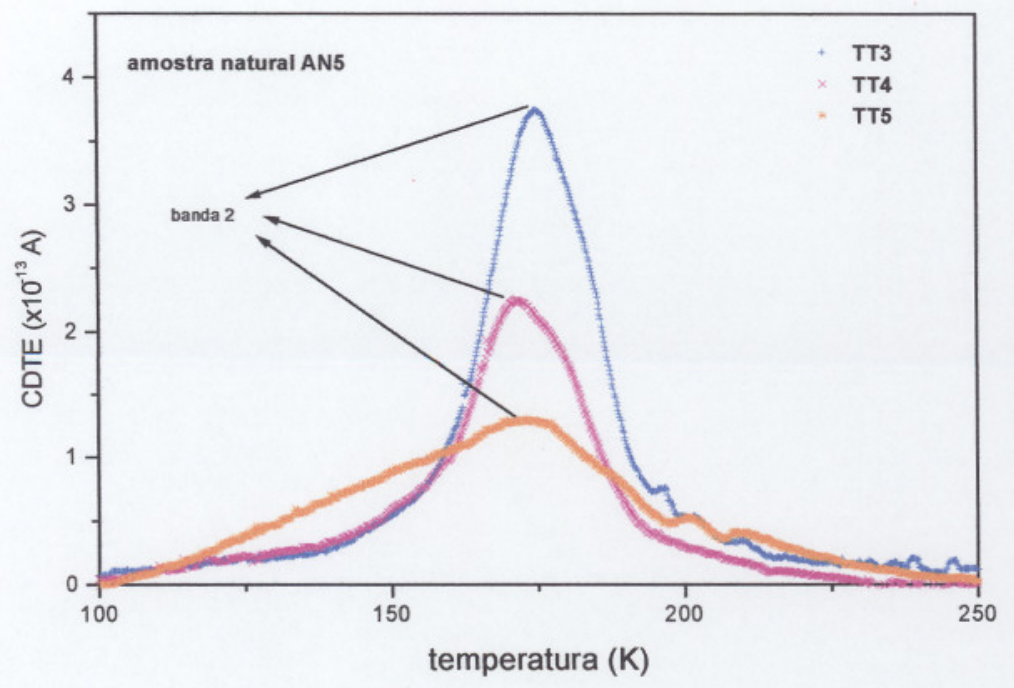

Figura 23 - Medidas de CDTE para a amostra AN5 após TT3 (900 $\left.{ }^{\circ} \mathrm{C}-5 \mathrm{~min}\right)$, TT4 $\left(1000{ }^{\circ} \mathrm{C}-5 \mathrm{~min}\right)$ e TT5 $\left(1000{ }^{\circ} \mathrm{C}-5\right.$ horas $)$. Em todas as medidas $\mathrm{T}_{\mathrm{p}} \cong 175 \mathrm{~K}$ e $\mathrm{b}=0,08 \mathrm{~K} / \mathrm{s}-0,09 \mathrm{~K} / \mathrm{s}$ 
Tabela 11 - Resultados obtidos a partir das medidas de CDTE para a amostra AN5 antes e após os tratamentos térmicos.

\begin{tabular}{|c|c|c|c|c|c|c|}
\hline & & \multicolumn{2}{|c|}{ Banda 1} & \multicolumn{2}{|c|}{ Banda 2} & \multirow[b]{2}{*}{$\mathrm{Q}\left(\mathrm{C}^{-1}\right)$} \\
\hline Condiçã & $T_{p}(K)$ & $\mathrm{T}_{\mathrm{ml}}(\mathrm{K})$ & $\mathrm{I}_{\mathrm{ml}}(\mathrm{A})$ & $\mathrm{T}_{\mathrm{m} 2}(\mathrm{~K})$ & $\mathrm{I}_{\mathrm{m} 2}(\mathrm{~K})$ & \\
\hline \multicolumn{7}{|l|}{0} \\
\hline $\mathrm{S} / \mathrm{TT}$ & 186 & 187 & $25 \times 10^{-14}$ & - & - & $0,78 \times 10^{-10}$ \\
\hline TT1 & 183 & 186 & $68 \times 10^{-14}$ & - & - & $2,5 \times 10^{-10}$ \\
\hline TT2 & 183,5 & 186 & $116 \times 10^{-14}$ & 173 & $70 \times 10^{-14}$ & $4,3 \times 10^{-10}$ \\
\hline \multirow[t]{2}{*}{ TT3 } & 175 & - & - & 175 & $40 \times 10^{-14}$ & $1,1 \times 10^{-10}$ \\
\hline & 185 & 187 & $45 \times 10^{-14}$ & 175 & $42 \times 10^{-14}$ & $1,7 \times 10^{-10}$ \\
\hline \multirow[t]{2}{*}{ TT4 } & 175 & - & - & 172 & $25 \times 10^{-14}$ & $1,0 \times 10^{-10}$ \\
\hline & 185 & 187 & $26 \times 10^{-14}$ & 172 & $25 \times 10^{-14}$ & $1,4 \times 10^{-10}$ \\
\hline \multirow[t]{2}{*}{ TT5 } & 175 & - & - & 175 & $15 \times 10^{-14}$ & $1,0 \times 10^{-10}$ \\
\hline & 185 & - & - & 176 & $17 \times 10^{-14}$ & $1,6 \times 10^{-10}$ \\
\hline
\end{tabular}

De acordo com a Tabela 11, após os tratamentos térmicos para a amostra AN5, a banda principal observada antes dos tratamentos, em torno de $187 \mathrm{~K}$, é ligeiramente deslocada para uma temperatura mais baixa e sofre um acentuado aumento em sua intensidade com os tratamentos térmicos 1 e 2, desaparecendo após o tratamento térmico por um tempo mais longo (TT5). Este mesmo comportamento foi também observado para a amostra natural AN3, cuja banda principal antes dos tratamentos térmicos localiza-se em torno de 196K, conforme mostrado na Figura 19(b). Após os tratamentos térmicos por um tempo de 5 minutos, a amostra AN3 teve sua banda principal deslocada para temperaturas próximas de $188 \mathrm{~K}$ e após o 
tratamento térmico por um tempo mais longo (5horas) somente uma banda larga, em torno de 176K, foi observada. Em relação à área sob a curva da corrente em função do tempo, o comportamento observado na Tabela 11 mostra que após o terceiro tratamento térmico, a carga total de polarização se torna bem mais estável, com um valor em torno de $1 \times 10^{-10} \mathrm{C}^{-1}$ para $\mathrm{T}_{\mathrm{p}}=175 \mathrm{~K}$.

As medidas de CDTE em função dos tratamentos térmicos para a amostra AN5 foram ajustadas através do método de Havriliak-Negami [30], após ter sido tentado também o método melhorado de Prakash [81]. Os ajustes das curvas experimentais são apresentados na Figura 24 para AN5 sem tratamento, a qual foi somente citada na seção 4.6.1, na Figura 25 após TT1, na Figura 26 após TT3, na Figura 27 após TT4 e Figura 28 após TT5.

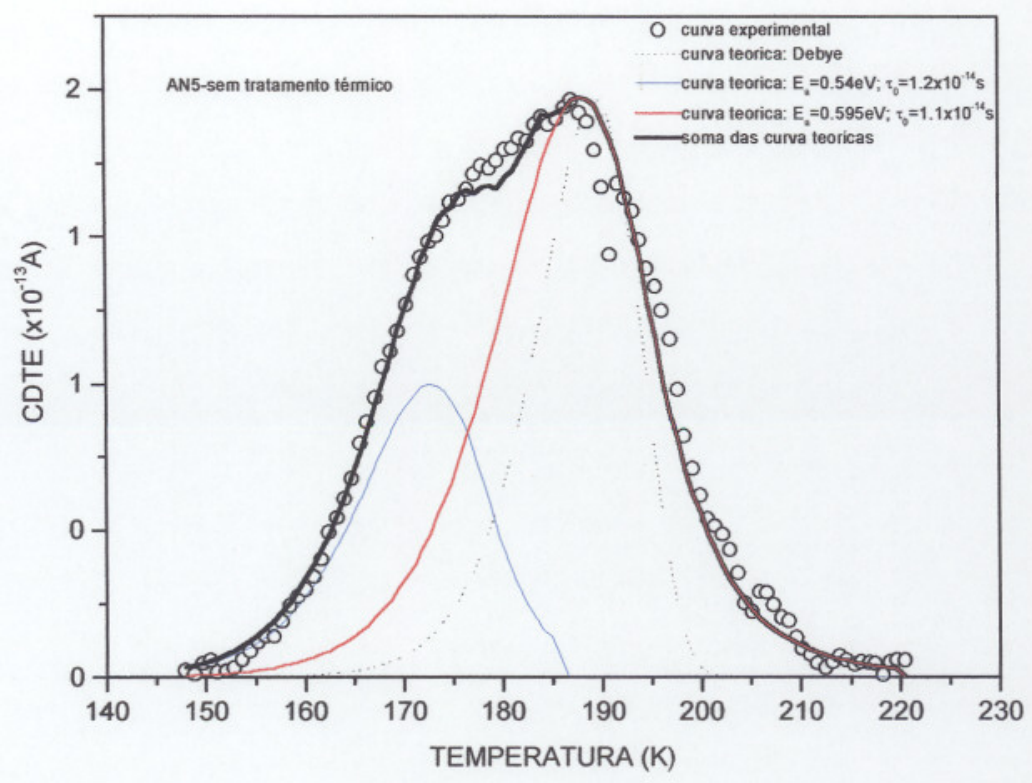

Figura 24 - Medidas de CDTE para AN5 sem tratamento térmico. As curvas em vermelho e azul representam as distribuições dos parâmetros de relaxação obtidas a partir do método de Navriliak-negami. 


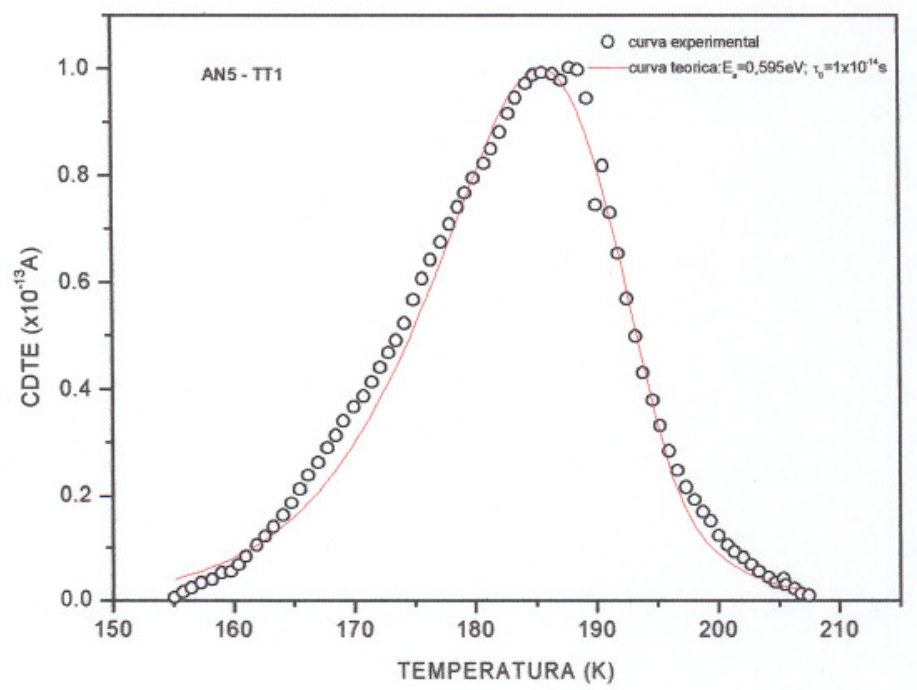

Figura 25 - CDTE para a amostra AN5 após TT1 (700 $\left.{ }^{\circ} \mathrm{C}-5 \mathrm{~min}\right)$. A curva em vermelho representa a distribuição obtida através do método de Havriliak-Negami.

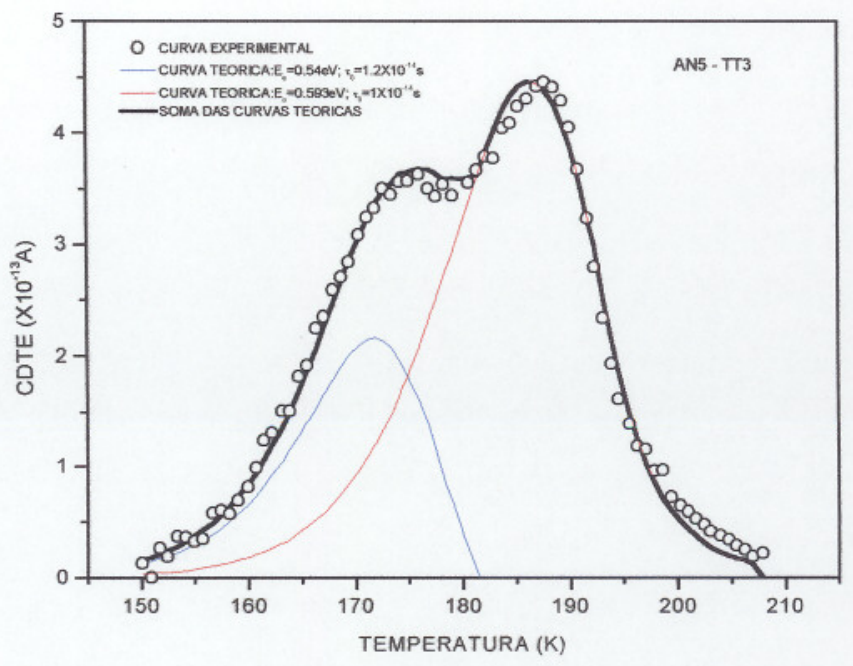

Figura 26 - CDTE para a amostra AN5 após TT3 (900 $\left.{ }^{\circ} \mathrm{C}-5 \mathrm{~min}\right)$. As curvas em vermelho e azul representam a distribuição obtida através do método de HavriliakNegami. 


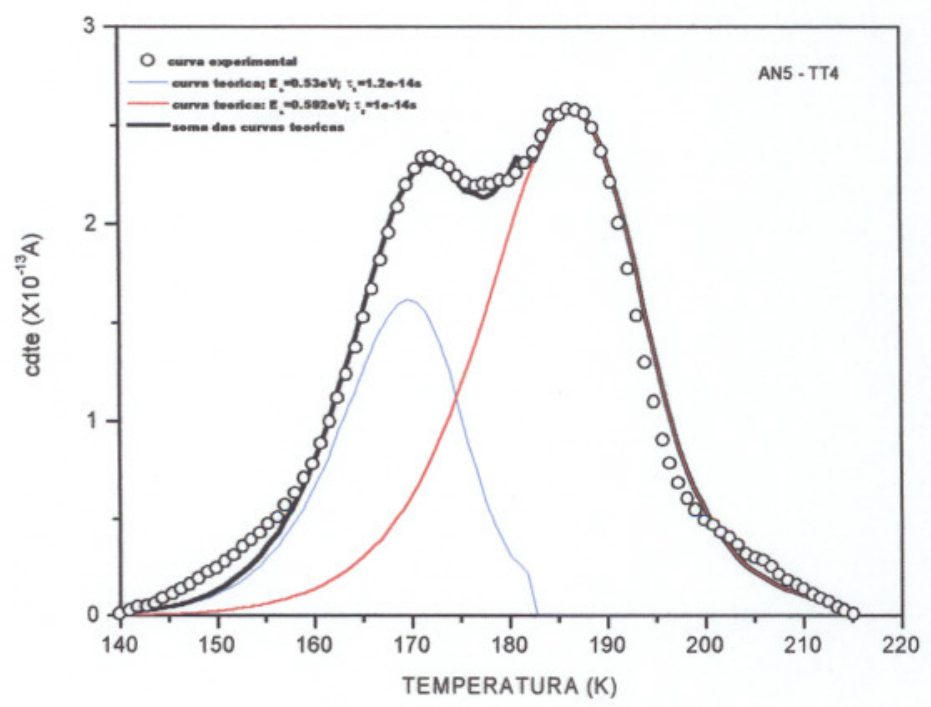

Figura 27 - CDTE para a amostra AN5 após TT4 (1000 $\left.{ }^{0} \mathrm{C}-5 \mathrm{~min}\right)$. As curvas em vermelho e azul representam a distribuição obtida através do método de HavriliakNegami.

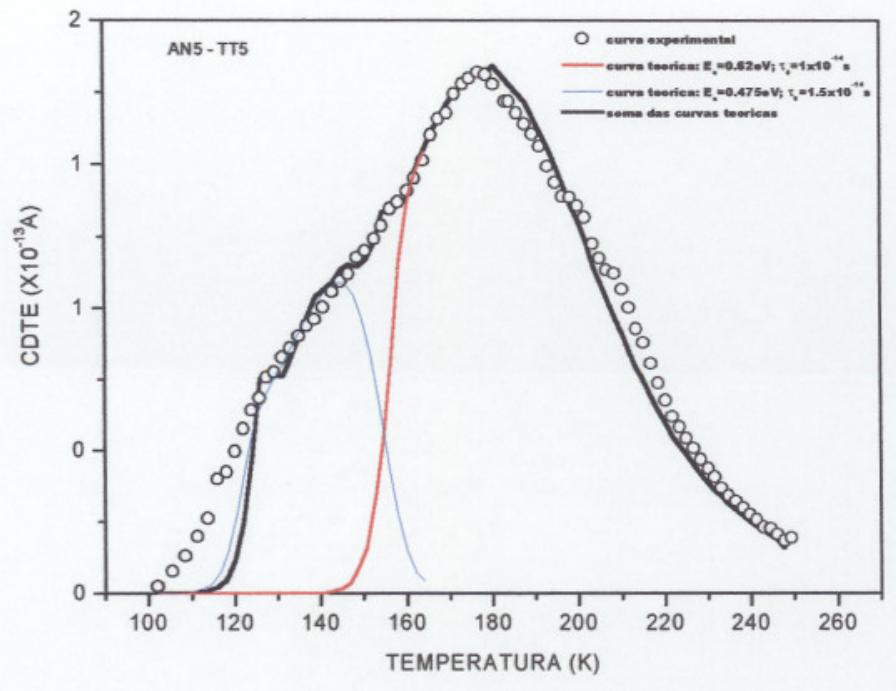

Figura 28 - CDTE para a amostra AN5 após TT5 (1000 $\left.{ }^{\circ} \mathrm{C}-5 \mathrm{~h}\right)$. As curvas em vermelho e azul representam a distribuição obtida através do método de HavriliakNegami. 
Os parâmetros de relaxação obtidos a partir dos ajustes de curvas das medidas de CDTE para a amostra natural AN5 antes e após os tratamentos térmicos apresentados nas Figuras 24 à 28 são apresentados na Tabela 12.

Comparando os resultados obtidos para AN5 sem tratamento com aqueles anteriormente apresentados para AN3 na Tabela 10, verificamos que as posições das duas distribuições com as quais ambas foram ajustadas (curva 2 e curva 3 nas Tabelas 10 e 12) estão em temperaturas um pouco diferentes, defasadas em menos de $10 \mathrm{~K}$, para ambas as curvas, ou seja, a diferença entre as posições das bandas é de aproximadamente $6 \%$, portanto, dentro do limite de reprodutibilidade de $8 \%$ citado anteriormente.

Tabela 12 - Parâmetros de relaxação obtidos para AN5, antes e após os tratamentos térmicos, através do ajuste por $\mathrm{HN}$. $\mathrm{T}_{\mathrm{m}}$ é a temperatura máxima de cada uma das distribuições em $[\mathrm{K}] ; \mathrm{E}_{\mathrm{a}}$ é a energia de ativação em $[\mathrm{eV}] ; \tau_{0}$ é o tempo de relaxação $\left(\mathrm{x} 10^{-14}\right) \mathrm{em}[\mathrm{s}]$.

\begin{tabular}{lccccccccccccc}
\hline & \multicolumn{3}{c}{ Curva 1 } & \multicolumn{1}{c}{ Curva 2 } & \multicolumn{1}{c}{ Curva3 } \\
\cline { 2 - 4 } & $\mathrm{E}_{\mathrm{a}}$ & $\tau_{0}$ & $\mathrm{~T}_{\mathrm{m}}$ & $\alpha \mathrm{e} \beta$ & $\mathrm{E}_{\mathrm{a}}$ & $\tau_{0}$ & $\mathrm{~T}_{\mathrm{m}}$ & $\alpha \mathrm{e} \beta$ & $\mathrm{E}_{\mathrm{a}}$ & $\tau_{0}$ & $\mathrm{~T}_{\mathrm{m}}$ & $\alpha \mathrm{e} \beta$ \\
& & & & & & & & & & & & \\
STT & - & - & - & - & 0.54 & 1.4 & 172 & 0.205 & 0.60 & 1.1 & 188 & 0.263 \\
& & & & & & & & 0.941 & & & & 0.969 \\
TT1 & - & - & - & - & - & - & - & - & 0.60 & 1.0 & 186 & 0.15 \\
& & & & & & & & & & & & 0.64 \\
TT3 & - & - & - & - & 0.54 & 1.2 & 172 & 0.08 & 0.59 & 1.0 & 187 & 0.181 \\
& & & & & & & & 0.73 & & & & 0.82 \\
TT4 & - & - & - & - & 0.53 & 1.2 & 169 & 0.20 & 0.59 & 1.0 & 186 & 0.25 \\
& & & & & & & & 0.973 & & & & 0.847 \\
& & & & & & & & & & & & \\
TT5 & 0.48 & 1.5 & 146 & 0.15 & 0.62 & 1.0 & 178 & 0.70 & - & - & - & - \\
\end{tabular}


As amostras AN3 e AN5, de acordo com as medidas de EDX apresentadas na Tabela 7, apresentam diferenças acentuadas nas concentrações de impurezas estranhas à matriz hospedeira, como $\mathrm{Ti}, \mathrm{K}, \mathrm{Si}, \mathrm{Mg}$ e $\mathrm{Ca}$, que estão presentes principalmente na amostra AN3, enquanto que AN5 apresenta apenas o elemento Ti na matriz hospedeira ( área A, da Figura 11). Assim, a possibilidade de que a banda mais intensa para a amostra AN3, em 195K, seja devido a dipolos relacionados com as outras impurezas é reforçada, uma vez que na amostra AN5 a banda mais intensa se localiza numa temperatura mais baixa, $188 \mathrm{~K}$. 


\subsection{2 - ABSORÇÃO ÓPTICA APÓS TRATAMENTOS TÉRMICOS}

Na Figura 29 são apresentados os espectros de absorção óptica na região do ultravioleta e visível para a amostra AN5 sem tratamento térmico e após os tratamentos térmicos TT1, TT2, TT3, TT4 e TT5. Os parâmetros obtidos a partir dessas medidas são apresentados na Tabela 13.

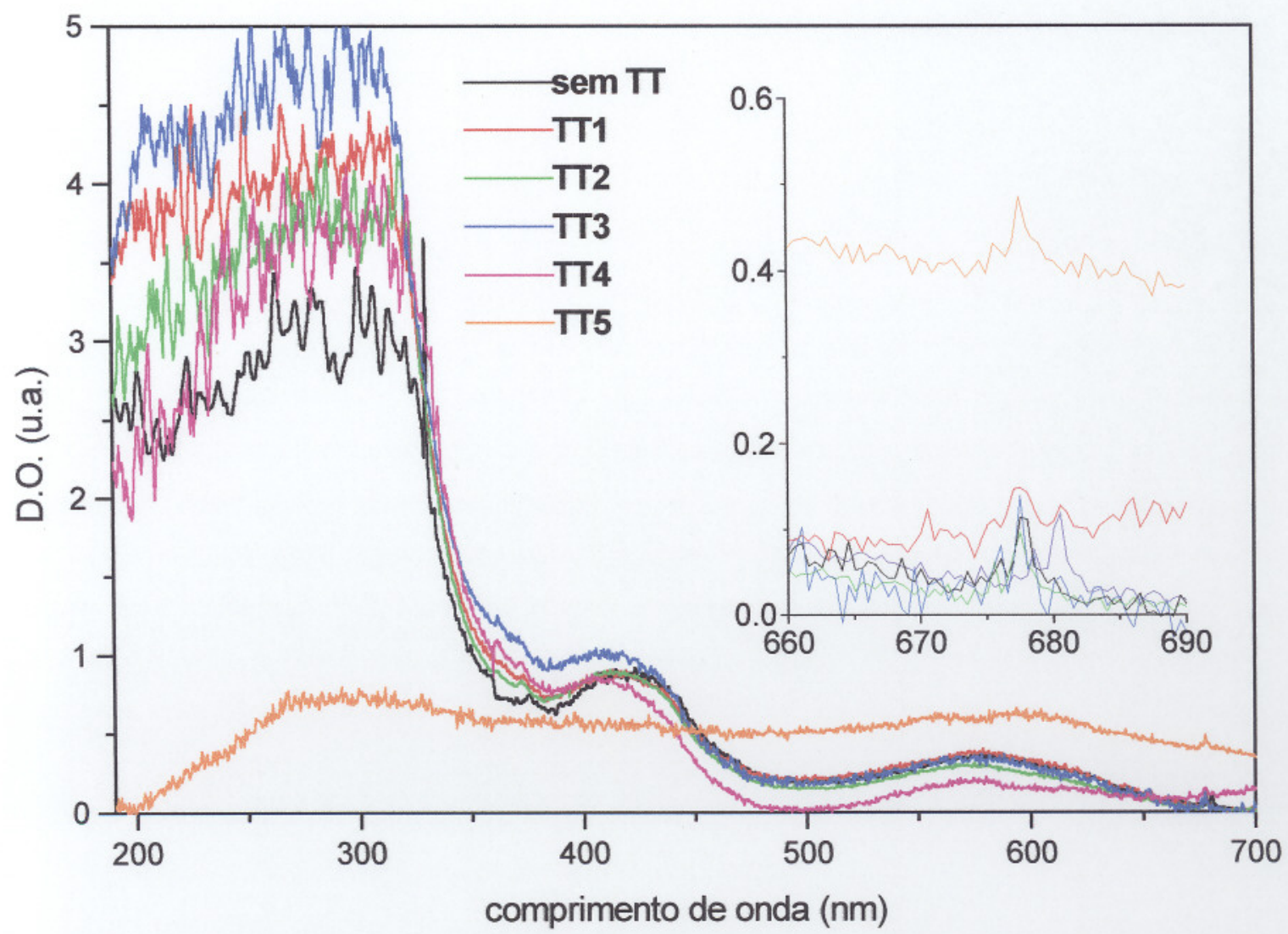

Figura 29 - Espectros de absorção óptica no UV-VIS para AN5 sem tratamento térmico e após TT1, TT2, TT3, TT4 e TT5. 
Tabela 13 - Resultados das medidas de absorção óptica (UV-VIS) obtidos à temperatura ambiente, após os tratamentos térmicos de AN5. $\lambda$ significa as posições de máximos de absorção, $\alpha$ o coeficiente de absorção óptica e $\Delta \lambda$ é a largura a meia altura da banda de absorção

\begin{tabular}{|c|c|c|c|c|c|c|c|}
\hline \multicolumn{7}{|c|}{$\begin{array}{c}\text { Bandas de Absorção } \\
\text { Amostra AN5 }\end{array}$} & \multirow{3}{*}{\begin{tabular}{|c|}
$\begin{array}{c}\text { Linhas } \\
\text { de } \\
\text { Absorção } \\
\mathrm{Cr}^{3+}\end{array}$ \\
$\lambda(\mathrm{nm})$ \\
\end{tabular}} \\
\hline \multicolumn{4}{|c|}{ Banda $\mathrm{A}\left(\mathrm{Cr}^{3+}\right)$} & \multicolumn{3}{|c|}{ Banda $\mathrm{B}\left(\mathrm{Cr}^{3+}, \mathrm{Fe}^{3+}\right)$} & \\
\hline TT & $\lambda(\mathrm{nm})$ & $\alpha\left(\mathrm{cm}^{-1}\right)$ & $\Delta \lambda(\mathrm{nm})$ & $\lambda(\mathrm{nm})$ & $\alpha\left(\mathrm{cm}^{-1}\right)$ & $\Delta \lambda(\mathrm{nm})$ & \\
\hline $700^{\circ} \mathrm{C}$ & & & & & & & 677,5 \\
\hline $5 \mathrm{~min}$ & 577 & 6,06 & 98,14 & 415 & 7,80 & 53,70 & - \\
\hline $800^{\circ} \mathrm{C}$ & & & & & & & 677,5 \\
\hline $5 \min$ & 575 & 5,09 & 103,53 & 413 & 8,61 & 54,12 & - \\
\hline $900^{\circ} \mathrm{C}$ & & & & & & & 677,5 \\
\hline $5 \min$ & 578 & 3,11 & 103,70 & 410 & 3,82 & 44,44 & 680,5 \\
\hline $1000^{\circ} \mathrm{C}$ & & & & & & & 677,5 \\
\hline $5 \mathrm{~min}$ & 575 & 3,79 & 92,59 & 411 & 6,95 & 38,89 & 680,5 \\
\hline $1000^{\circ} \mathrm{C}$ & & & & & & & 677,5 \\
\hline 5horas & 593 & 4,79 & 130,10 & - & - & - & - \\
\hline
\end{tabular}

A partir da Tabela 13 notamos que a banda $\mathrm{A}\left(\mathrm{Cr}^{3+}\right)$ tem sua posição central média levemente alterada com os tratamentos térmicos que foram realizados por um tempo curto (5 minutos) e, uma alteração mais sensivel ocorre para essa banda após o tratamento térmico por 5 horas quando então, a banda $\mathrm{A}$ é deslocada de 
aproximadamente $16,5 \mathrm{~nm}$ para o lado de energia mais baixa, em relação a posição dessa banda antes dos tratamentos térmicos, apresentada na Tabela 8 .

A intensidade dessa banda diminui a partir de TT1, ficando reduzida quase que à metade após TT3, para então, voltar a aumentar com TT4 e TT5. Entretanto, observamos que há uma certa dificuldade em se definir a posição central da banda $\mathrm{A}$ uma vez que, com os tratamentos térmicos, sua meia largura aumenta ligeiramente com a condição de tempos curtos (5 minutos) para então, aumentar significativamente com o tratamento por 5 horas. Esse resultados indicam que os tratamentos térmicos afetam as posições relativas dos íons $\mathrm{Cr}^{3+}$ nos dois sítios diferentes, principalmente no caso do tratamento por 5 horas.

A banda $\mathrm{B}$ que, de acordo com a literatura $[2,36]$, é atribuída à presença das impurezas $\mathrm{Cr}^{3+} \mathrm{e} \mathrm{Fe}^{3+}$ na matriz de crisoberilo, tem sua posição um pouco deslocada para o lado de energias mais altas, em direção à região do ultravioleta, após cada um dos tratamentos térmicos, sendo que, com o tratamento térmico por 5 horas não é mais possível observá-la com nitidez. Essa banda parece também, primeiro, se alargar com os tratamentos térmicos à 700 e $800{ }^{\circ} \mathrm{C}$ e se estreitar com os tratamentos seguintes por 5 minutos e, sua intensidade obedece esse mesmo comportamento, ou seja, aumenta para TT1 e TT2 e diminui para TT3 e TT4. Uma hipótese que explique o comportamento da banda B é que, com os tratamentos térmicos, ocorra uma variação relativa da concentração de $\mathrm{Cr}^{3+} / \mathrm{Fe}^{3+}$ nesses sítios, com os íons migrando para outros sítios da rede hospedeira.

As linhas do $\mathrm{Cr}^{3+}$ nos sítios localizados no plano de reflexão parecem também sofrer alguma alteração em seu comportamento após os tratamentos térmicos. Com TT1 e TT2, essas linhas, que antes eram duas, tornam-se uma única linha mais larga 
em torno de $677,5 \mathrm{~nm}$; com TT3 e TT4 o espectro volta a apresentar duas linhas em torno de 677,5 e $680,5 \mathrm{~nm}$. Com o tratamento de $1000{ }^{\circ} \mathrm{C}$ por 5 minutos torna-se dificil distinguir as duas linhas do $\mathrm{Cr}^{3+}$ que agora parecem se alargar e se tornar uma única linha em torno de $677,5 \mathrm{~nm}$.

Assim, os tratamentos térmicos parecem influenciar muito mais a banda

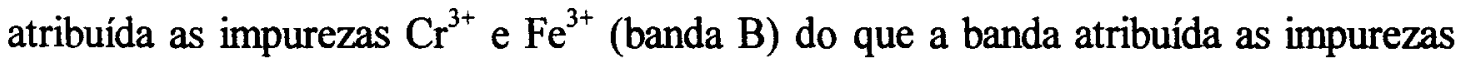
$\mathrm{Cr}^{3+}$ nos dois sítios distintos da alexandrita (banda A). Portanto, podemos pensar que, se os tratamentos térmicos favorecem o prevalecimento da banda de CDTE em torno de $175 \mathrm{~K}$, que anteriormente parecia estar encoberta, e fazem com que a banda B do espectro de absorção desapareça quase que totalmente, após TT5, a banda de CDTE em $175 \mathrm{~K}$ pode realmente ser atribuída as impurezas de $\mathrm{Cr}^{3+}$ formando dipolos com vacâncias de oxigênio na estrutura da alexandrita. Também é possível supor que o efeito dos íons $\mathrm{Fe}^{3+}$ (e talvez as outras impurezas) seja o de deslocar as bandas de CDTE das amostras naturais para temperaturas mais altas e dar origem a uma banda muito mais intensa que encobre a banda em $175 \mathrm{~K}$ antes dos tratamentos térmicos.

Após cada um dos tratamentos térmicos para a amostra AN5, foram obtidos também os espectros de absorção óptica na região do infravermelho, à temperatura ambiente, a fim de observar os efeitos desses tratamentos principalmente sobre a banda atribuída a água. Os resultados são mostrados na Figura 30. 


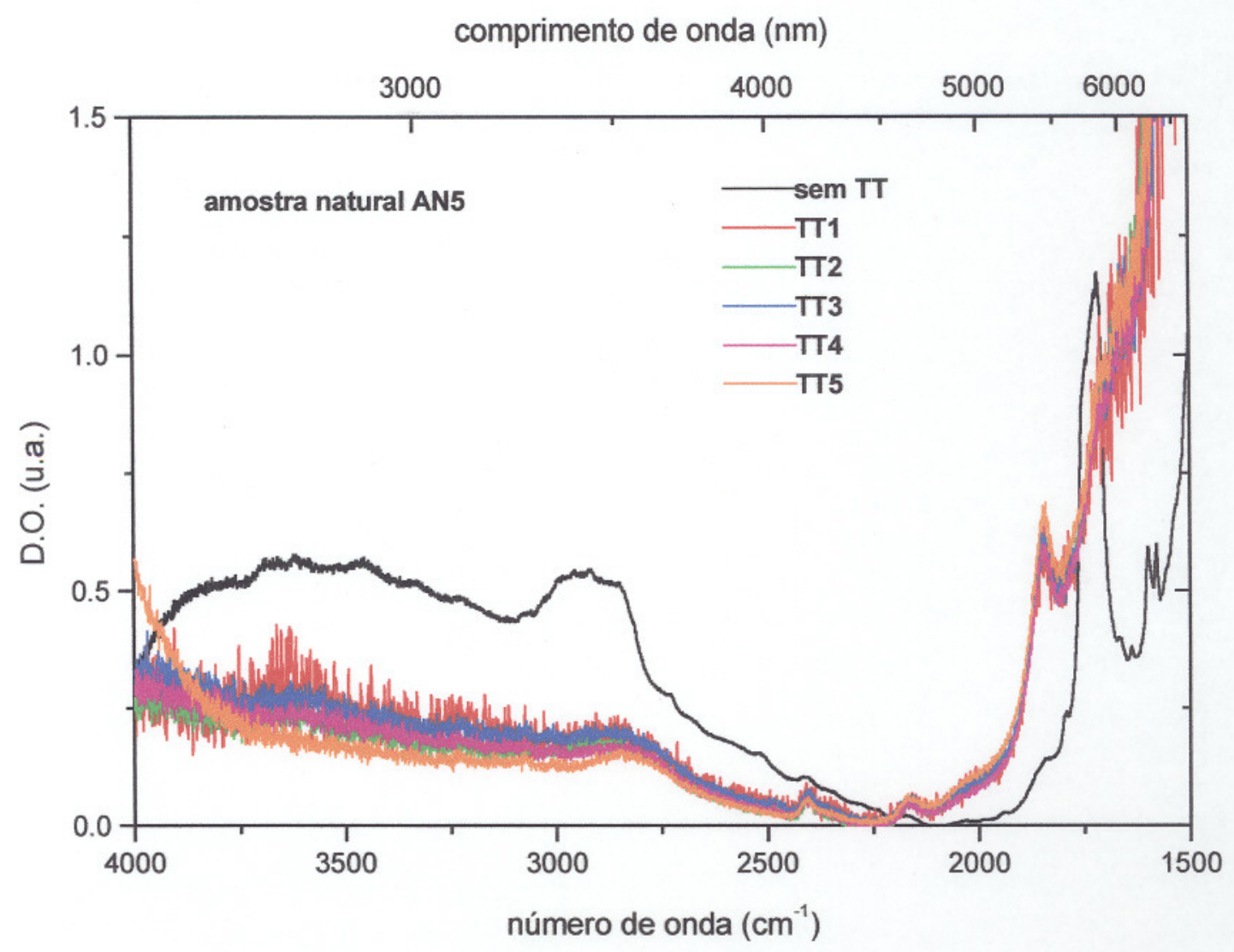

Figura 30 - Espectros de absorção óptica, à temperatura ambiente, para a amostra natural AN5 após os tratamentos térmicos TT1, TT2, TT3, TT4 e TT5 e sem tratamento térmico

Com os tratamentos térmicos a banda larga centralizada em torno de $2900 \mathrm{~cm}^{-1}$ torna-se bem menos intensa. A banda de absorção em torno de $1700 \mathrm{~cm}^{-1}$ também desaparece com os tratamentos térmicos o que, provavelmente, pode ser atribuído a ocorrência de migração das impurezas presentes nas amostras naturais para as outras fases da estrutura (como a mica e o quartzo). 


\subsection{3 - LUMINESCÊNCIA APÓS TRATAMENTOS TÉRMICOS}

Os espectros de luminescência em função dos tratamentos térmicos foram obtidos todos com as mesmas condições de medida, sendo a tensão na fotomultiplicadora igual a $900 \mathrm{~V}$, sensibilidade no lock-in de $200 \mu \mathrm{V}$, abertura da fenda do monocromador de $10 \mu \mathrm{m}$ e excitação da amostra no MLUV do laser de $\mathrm{Kr}^{+}$, de acordo com o processo esquematizado na Figura 6 do capítulo 3. Os resultados obtidos são apresentados na Figura 31.

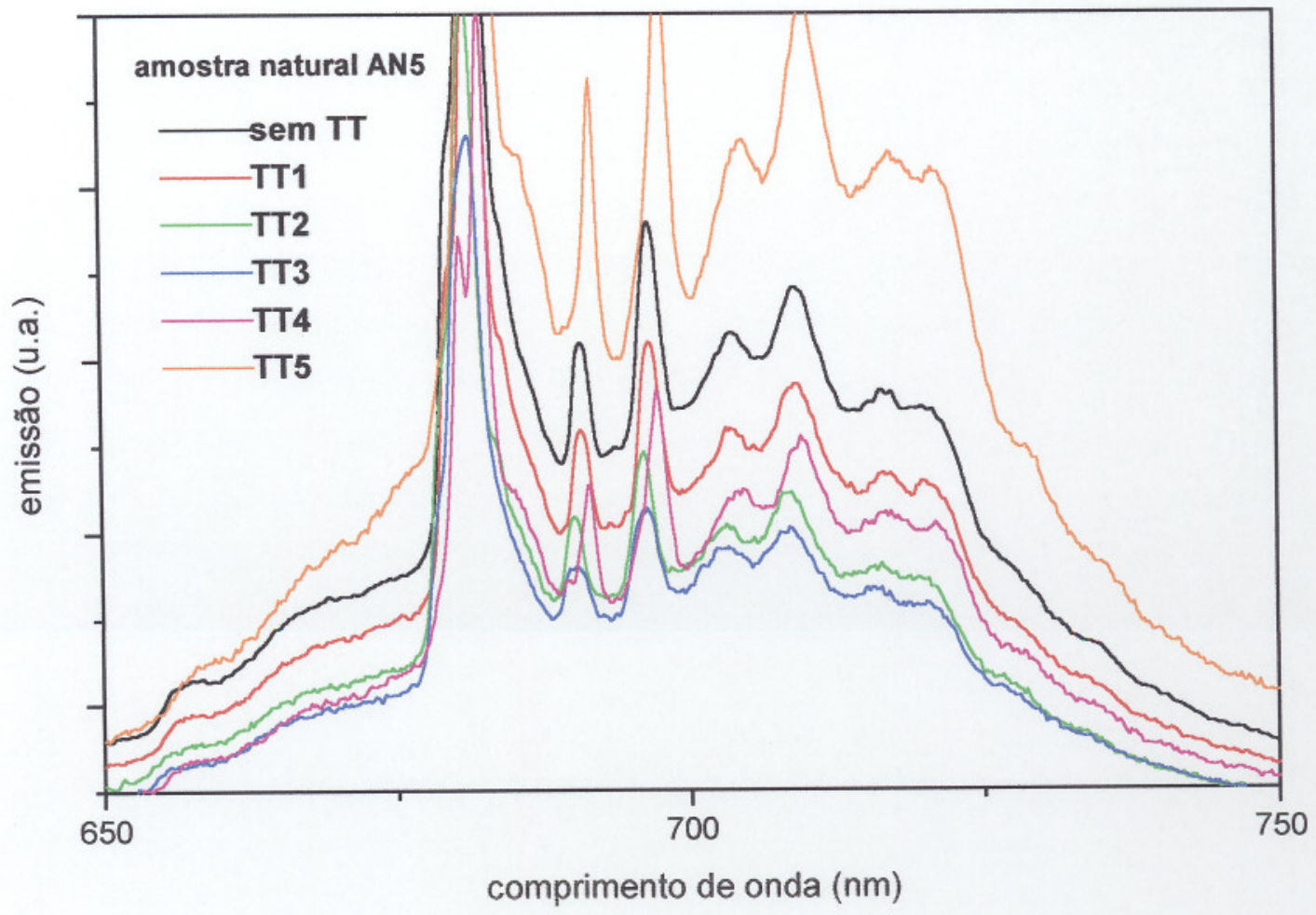

Figura 31 - Espectros de luminescência, à temperatura ambiente, para AN5 submetida aos tratamentos térmicos TT1, TT2, TT3, TT4, TT5 e sem tratamento térmico. 
Através dessas medidas verificamos que as linhas $\mathrm{S}_{1}$ e $\mathrm{S}_{2}\left(\mathrm{Cr}^{3+}\right.$ localizados no centro de inversão), no lado de energia mais baixa, também se comportam de modo diferente em relação às intensidades para a amostra natural e sintética mesmo quando a primeira é submetida a tratamentos térmicos. Uma hipótese inicial é que as diferenças nas intensidades dessas linhas entre as amostras natural e sintética seja devido a presença do Fe no centro de inversão, na amostra natural, que pode estar influenciando diferentemente no campo cristalino de ambas.

Com as medidas de luminescência em função dos tratamentos térmicos foi possível verificar que as propriedades ópticas desse material parecem não sofrer grandes alterações pois, as linhas $R_{s}\left(R_{1}\right.$ e $\left.R_{2}\right)$, atribuídas aos íons de $\mathrm{Cr}^{3+}$ localizados nos sítios em um plano de reflexão e responsáveis por essas propriedades, continuam sendo identificadas no espectro nas mesmas posições, conforme mostrado na Figura 31, assim como foi verificado para as linhas $\mathrm{R}$ no espectro de absorção, embora se torne mais dificil distinguir as duas linhas $\mathrm{R}$ separadamente em ambos os espectros, absorção e emissão, após os tratamentos térmicos.

\subsection{4 - DIFRAÇÃO DE RAIOS $X$ EM FUNÇÃO DE TRATAMENTOS TÉRMICOS.}

As medidas de difração de raios $\mathrm{X}$ em função dos tratamentos térmicos foram realizadas para outra amostra, AN4, obtida a partir da mesma pedra que AN3, conforme descrito na seção 3.4. Os difratogramas de raio X para a amostra AN4 sem tratamento térmico e após os tratamentos térmicos à $700{ }^{\circ} \mathrm{C}$ por 15 minutos $(\mathrm{TT} 1$ ') e $1000{ }^{\circ} \mathrm{C}$ por 5 horas (TT5 ) são mostrados na Figura 32. 

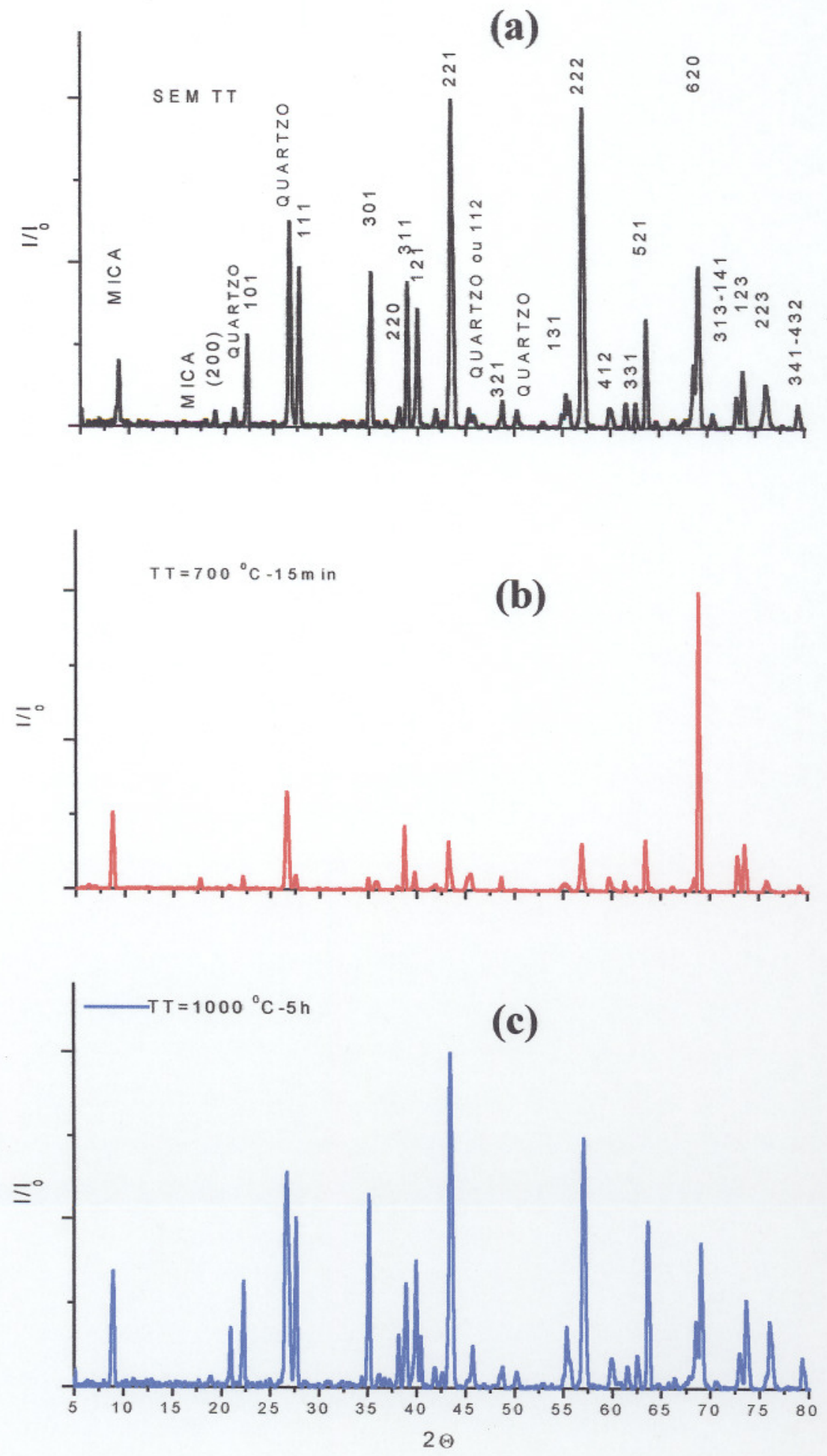

Figura 32 - Difratogramas de raios X para a amostra natural AN4. (a) antes dos tratamentos térmico, (b) após TT1 $1^{\prime}=700^{\circ} \mathrm{C}$ por 15 minutos e (c) após TT5 $=1000^{\circ} \mathrm{C}$ por 5 horas. 
Os parâmetros de rede para a amostra AN4, foram determinados através do programa "DICVOL91" a partir dos difratogramas mostrados na Figura 32. No caso da amostra sem ser submetida à tratamentos térmicos esses parâmetros já foram apresentados anteriormente na seção 4.2 como sendo $a=9,405 \AA, b=5,471 \AA$ e

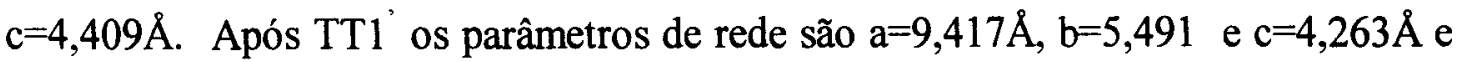
após TT5' temos $\mathrm{a}=9,409 \AA, \mathrm{b}=5,483 \AA$ e $\mathrm{c}=4,432 \AA$. Os resultados obtidos indicam que não ocorre uma mudança estrutural na amostra após os tratamentos térmicos, ocorrendo apenas um aumento de menos de $1 \%$ nos parâmetros de rede com o tratamento de $700{ }^{\circ} \mathrm{C}$ por 15 minutos e uma diminuição de $1,2 \%$ à $6,7 \%$ desses parâmetros para o tratamento a $1000{ }^{\circ} \mathrm{C}$ por 5 horas.

Nos difratogramas de raios $\mathrm{X}$ é possivel notar também um pequeno deslocamento das linhas de difração após TT1' para o lado de $2 \theta$ menores e um novo deslocamento, após TT5', praticamente para as mesmas posições antes dos tratamentos. Embora pequenas, as variações nos parâmetros de rede possam ser interpretadas como uma mudança na composição química do material que implicam a substituição por átomos em geral de tamanho um pouco diferente dos que ocorrem normalmente em alguns lugares do retículo. Como resultado se alteram levemente as dimensões da cela e como conseqüência, ocorre o deslocamento das posições das linhas correspondentes ao espaçamento observado nos difratogramas de raios $\mathrm{X}$. Estes resultados podem então indicar uma migração dos elementos presentes na amostra, entre as fases diferentes identificadas na Figura 11, reforçando a hipótese levantada com as medidas de absorção e emissão óptica. Os valores das intensidades das linhas de difração estão normalizados para os três gráficos apresentados. 


\section{8 - CDTE FOTOINDUZIDA}

De acordo com o que foi mencionado no início desse trabalho uma das mais interessantes propriedades da alexandrita é sua sensibilidade à incidência de luz, que faz com que passe de uma coloração verde para o vermelho. Assim, um primeiro teste de identificação de nossas amostras naturais, foi observá-las em luz ambiente (luz do sol) e em seguida sob luz incandescente (lâmpada de filamento de tungstênio). Esse primeiro teste mostrou ser muito eficiente para a amostra sintética pois, é bem visível sua mudança de cor, passando do verde para o vermelho, entretanto, com as amostras naturais a mudança de cor sob luz incandescente foi um pouco mais fraca, com a cor das pedras passando de verde, bastante opaco, para uma coloração vermelho rosada, com algumas delas em uma área quase total e outras apenas em algumas regiões. As amostras AN3 e AN5, utilizadas principalmente nas medidas de CDTE, foram as que mais apresentaram essa mudança de cor a qual foi observada em mais de $50 \%$ de seu volume.

Um outro teste foi colocar nossas amostras em frente ao laser $\mathrm{Kr}^{+}$, sintonizado no multilinhas ultravioleta (MLUV) e verificarmos que a mudança de cor é muito evidente, tanto nas amostras naturais quanto na sintética mas, para as naturais o feixe do laser não consegue atravessá-las, como ocorre para a amostra sintética. Esse comportamento é ilustrado na Figura 33. 

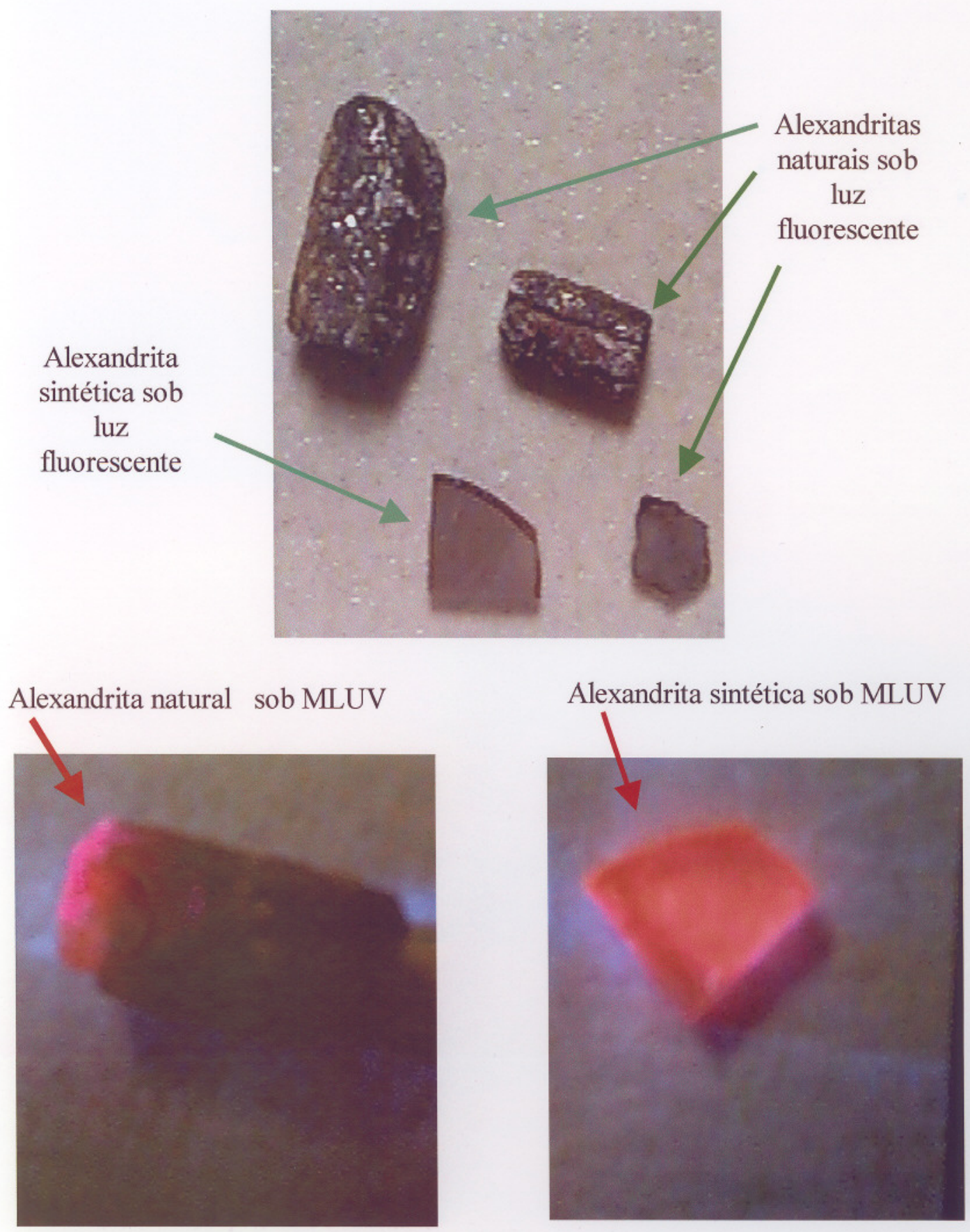

Figura 33 - Fotografias das amostras de alexandrita natural e sintética iluminadas com luz de lâmpada fluorescente e com laser de $\mathrm{Kr}$ sintonizado no multilinhas ultravioleta 
Assim, desde que a presença de dipolos foi evidenciada com as medidas de CDTE para as amostras de alexandritas, apresentadas nas seções anteriores, e que esses dipolos devem estar relacionados principalmente com as impurezas de $\mathrm{Cr}^{3+}$ nos dois sítios de simetrias diferentes na rede hospedeira, pode-se pensar em investigar tal fenômeno através de um experimento de CDTE modificado, no qual usamos como fonte de excitação além do campo elétrico aplicado também a luz de um feixe do laser. Este processo foi chamado no capítulo 3 de CDTE fotoinduzida (CDTEFI) e nessa seção são apresentados os resultados das medidas realizadas a fim de investigar a participação dos íons $\mathrm{Cr}^{3+}$ nas bandas observadas.

Nas medidas de CDTEFI foi utilizado um laser de $\mathrm{Kr}^{+}$COHERENT INNOVA 200 sintonizado em comprimentos de onda localizados sobre as bandas de absorção, conforme é mostrado na Figura 34, onde o MLUV (multilinhas ultravioleta) corresponde a três linhas sintonizadas em 337,5; 350,7 e 356,4 nm, MLVI (multilinhas violeta) às linhas 406,7; 423,1 e 415,4 nm, MLBG (multilinhas azul-verde) corresponde às linhas 468,$0 ; 476,2 ; 482,5 ; 520,8$ e 530,9 nm e MLRD (multilinhas vermelho) corresponde às linhas 647,1 e $676,4 \mathrm{~nm}$. As medidas de CDTEFI foram realizadas com a amostra sintética, AS1 e com as amostras naturais AN3 e AN5. 


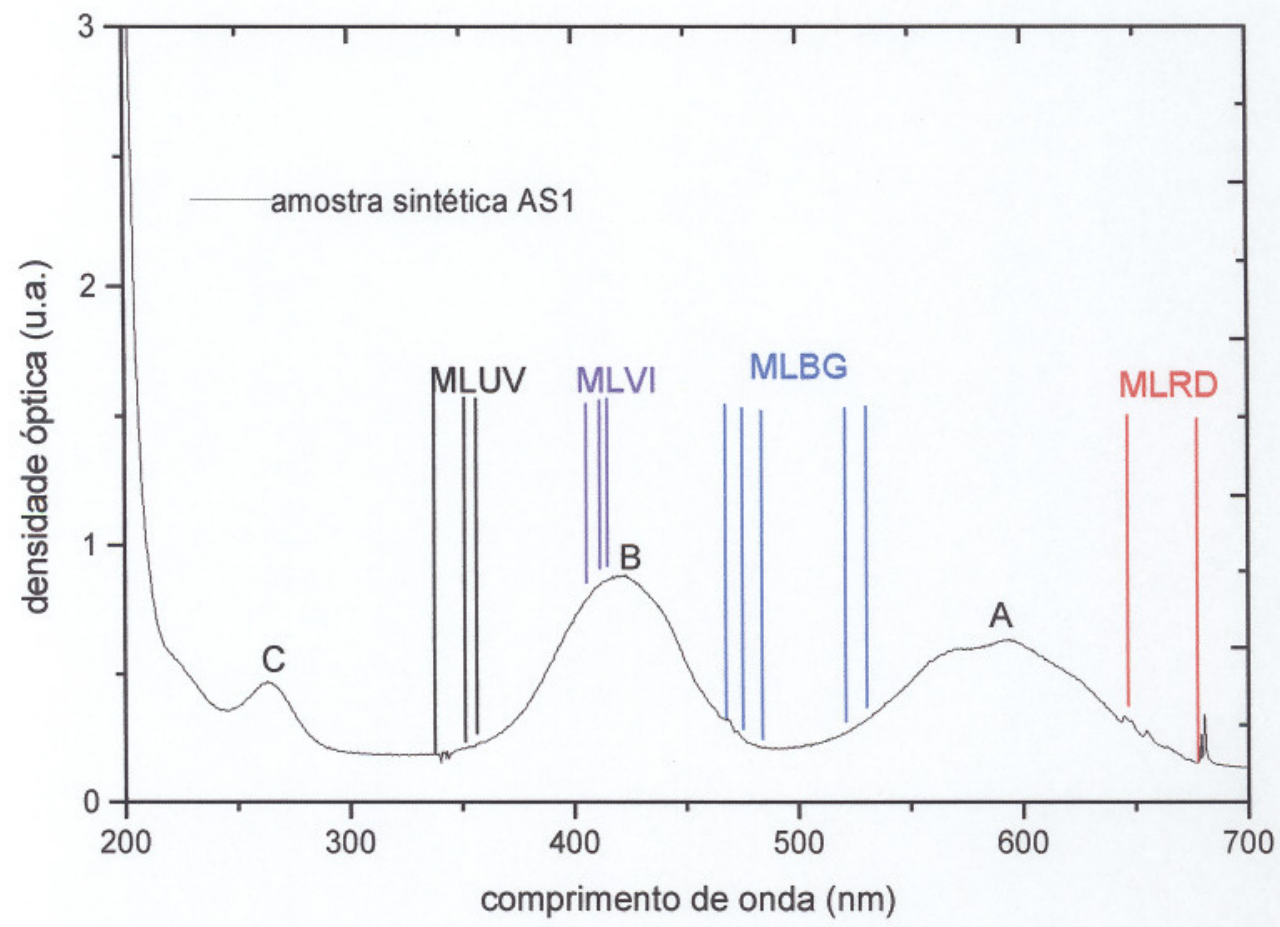

Figura 34 - Espectro de absorção óptica da amostra sintética de alexandrita mostrando as faixas de comprimentos de onda utilizados nas medidas de CDTEFI.

Conforme descrito anteriormente, as medidas de CDTE fotoinduzidas foram realizadas em duas etapas diferentes, a primeira com uma condição de polarização dos dipolos à temperatura ambiente, cujo processo pode ser entendido como uma "destruição" das bandas de CDTE previamente identificadas, com incidência de luz e, numa segunda etapa temos a condição de polarização dos dipolos à temperatura de nitrogênio líquido através da incidência de luz nas amostras juntamente com o campo elétrico aplicado e pode ser entendido como um processo de "formação" das bandas de CDTE. Ambos os processos são mostrados na Figura 9 do capítulo 3 nos esquemas (i) e (ii) respectivamente. 
Através do procedimento (i), ou seja, com a condição de polarização da amostra à temperatura ambiente, podemos verificar a influência da luz sobre os dipolos formados que poderiam estar recebendo energia suficiente para relaxar para suas distribuições aleatórias ainda a baixa temperatura; e com o segundo procedimento (ii), sem a condição de polarização à temperatura ambiente, pode-se verificar a possibilidade de ocorrer o processo inverso, ou seja, fornecer energia suficiente através da foto-excitação das amostras para que os dipolos possam ser orientados com o campo elétrico aplicado a baixa temperatura.

\subsection{1 - CDTEFI PARA A AMOSTRA SINTÉTICA}

Incidindo o feixe do laser sintonizado no MLUV, com potência de saída igual a $0,53 \mathrm{~W}$ por 10 minutos na amostra sintética, de acordo com o $1^{\circ}$ processo de CDTEFI (i), com $E_{p}=7,0 \mathrm{kV} / \mathrm{cm}$, foi verificado que a banda de CDTE observada anteriormente, mostrada na Figura 21, é completamente destruída. Isso ocorre também quando se incide luz do laser sintonizado no MLUV com $0,37 \mathrm{~W}$ de potência. Entretanto, se verifica que a destruição das bandas de CDTE nessa amostra depende da potência do laser, pois para potências mais baixas, em torno de $0,038 \mathrm{e}$ $0,089 \mathrm{~W}$, esse efeito não ocorre, aparecendo um pico com intensidade aproximada de $20 \times 10^{-14}$ A, localizado em torno de $180 \mathrm{~K}$. Esses resultados são mostrados na

Figura 35. O mesmo procedimento foi realizado aumentando-se o tempo de incidência de luz na amostra e os resultados obtidos foram os mesmos, ou seja, ocorre uma destruição total da banda de CDTE original com a aplicação de luz mas, que depende da potência da luz aplicada . 


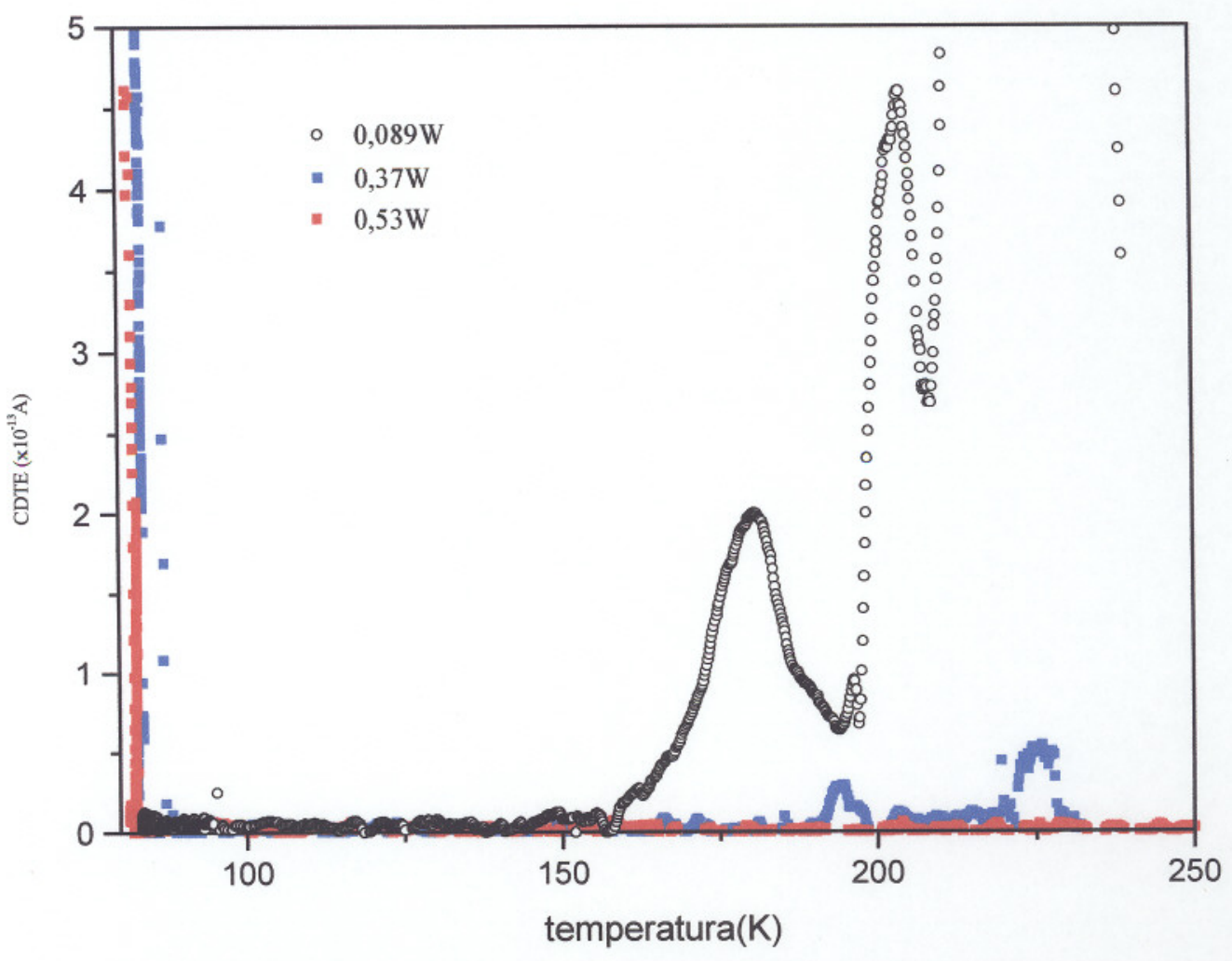

Figura 35 - CDTEFI para a amostra AS1 $(\mathrm{e}=2,32 \mathrm{~mm})$ com $\mathrm{T}_{\mathrm{p}}=297 \mathrm{~K}, \mathrm{E}_{\mathrm{p}}=7,0 \mathrm{kV} / \mathrm{cm}$ e $b=0,08 \mathrm{~K} / \mathrm{s}$, incidindo luz MLUV à TNL.

Foram realizadas outras medidas de CDTEFI utilizando potências intermediárias as apresentadas na Figura 35 e verificamos que para potências maiores de $0,30 \mathrm{~W}$, ocorre a destruição total da banda original de CDTE, ou seja, com energias entre 3,5 e 3,7 eV (MLUV) os dipolos podem relaxar livremente para suas orientações aleatórias iniciais com o processo de foto-excitação sem necessitarem de um processo térmico.

Também foi verificado nessas medidas que, ao incidir luz na amostra, isto gera um pico de corrente bastante intenso, da ordem de $10^{-12} \mathrm{~A}$, e provoca um aumento de temperatura em torno de $1 \mathrm{~K}$ na amostra, para qualquer potência utilizada. Essa 
corrente caí rapidamente quando a luz é retirada, retornando a zero, com a temperatura também voltando à inicial. Esse efeito de transiente de corrente e efeito térmico de luz na amostra não serão considerados nesse trabalho, ficando como uma sugestão para investigações futuras.

Com o $2^{\circ}$ processo (ii), ou seja, com a incidência de luz MLUV, com potência de $0,37 \mathrm{~W}$ (mesma potência com que os dipolos são desorientados por foto excitação), e campo elétrico de $7,0 \mathrm{kV} / \mathrm{cm}$, ambos aplicados em $77 \mathrm{~K}$ se verifica que é possivel, para esse comprimento de onda da luz, orientar os dipolos e com isso formar a banda de CDTE quando a temperatura é aumentada a uma taxa fixa.

Os resultados dessas medidas são mostrados na Figura 36 com excitação no MLUV e os resultados obtidos a partir de ambos os processos, (i) e (ii), em função dos comprimentos de onda utilizados são mostrados na Figura 37 para MLVI, na Figura 38 para MLBG e na Figura 39 para MLRD. Em todos os casos foi utilizado em torno de $0,30 \mathrm{~W}$ de potência do laser, campo elétrico de polarização de 7,0 $\mathrm{kV} / \mathrm{cm}$, taxa de aquecimento entre 0,06 a $0,12 \mathrm{~K} / \mathrm{s}$, temperatura de polarização próxima de $300 \mathrm{~K}$ no processo de destruição das bandas e $77 \mathrm{~K}$ no processo de formação das bandas. 


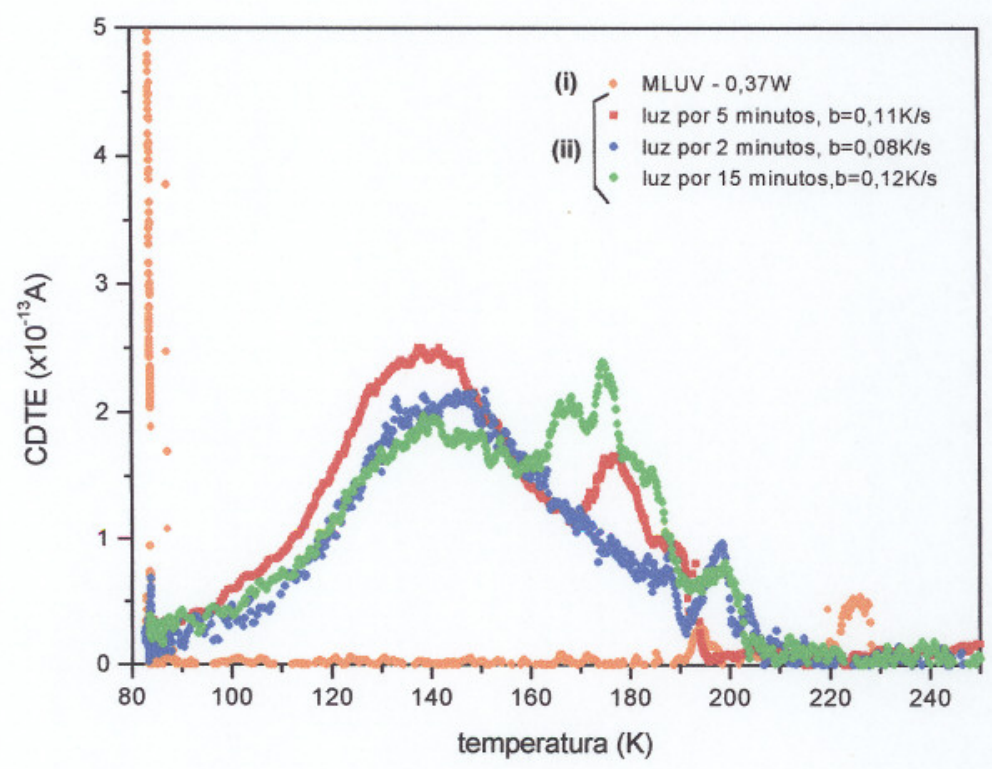

Figura 36 - CDTEFI para a amostra AS1, com $\mathrm{E}_{\mathrm{p}}=7,0 \mathrm{kV} / \mathrm{cm}$ e luz MLUV por 2, $5 \mathrm{e}$ 10 minutos em $\mathrm{T}_{\mathrm{p}}=77 \mathrm{~K}, \mathrm{~b}=0,08-0,12 \mathrm{~K} / \mathrm{s}$.

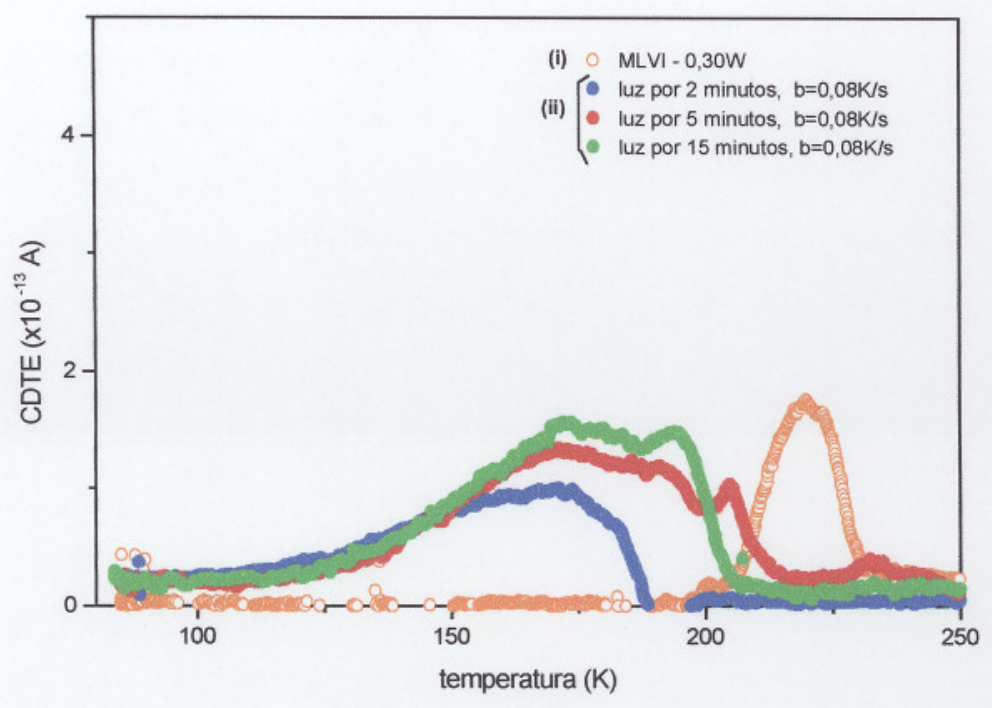

Figura 37- CDTEFI para a amostra AS1, com $\mathrm{E}_{\mathrm{p}}=7,0 \mathrm{kV} / \mathrm{cm}$ e luz MLVI por 2, 5 e 15 minutos em $T_{p}=77 \mathrm{~K}, b=0,08 \mathrm{~K} / \mathrm{s}$. 


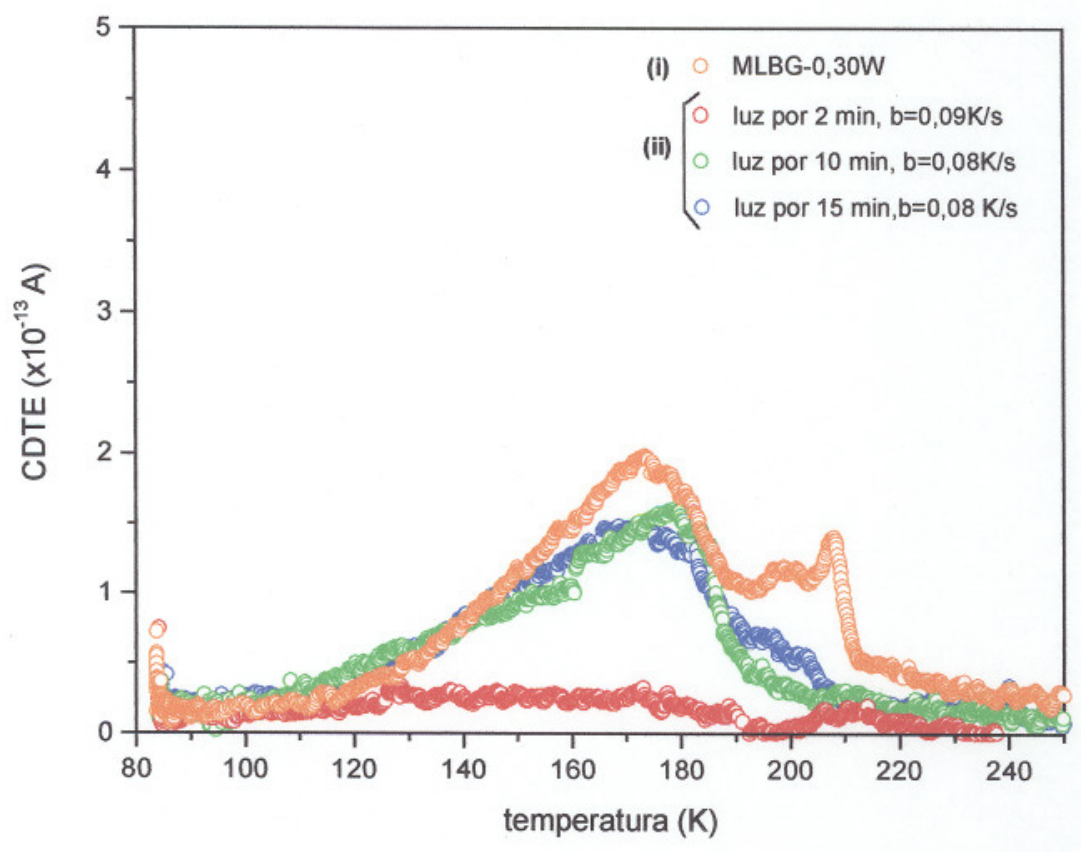

Figura 38 - CDTEFI para a amostra AS1, com $\mathrm{E}_{\mathrm{p}}=7,0 \mathrm{kV} / \mathrm{cm}$ e MLBG por 2,10 e 15 minutos em $\mathrm{T}_{\mathrm{p}}=77 \mathrm{~K}, \mathrm{~b}=0,08-0,09 \mathrm{~K} / \mathrm{s}$.

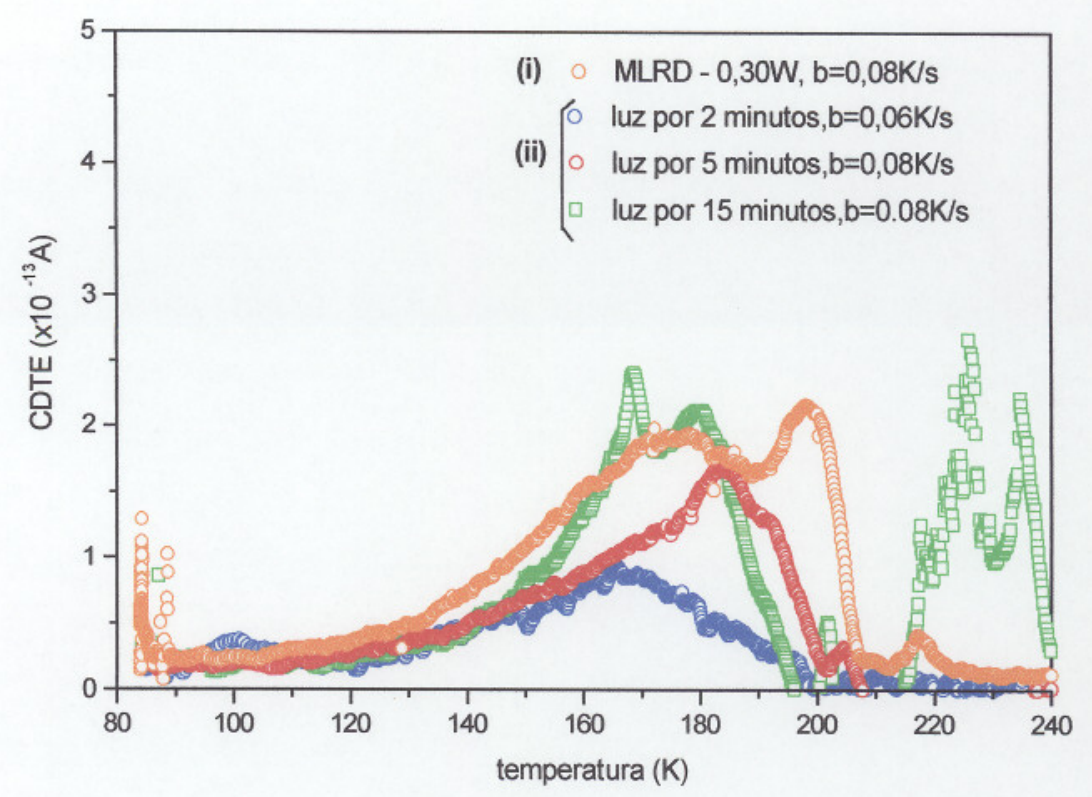

Figura 39 - CDTEFI para a amostra AS1, com $\mathrm{E}_{\mathrm{p}}=7,0 \mathrm{kV} / \mathrm{cm}$ e MLRD por 2, 5 e 15 minutos em $\mathrm{T}_{\mathrm{p}}=77 \mathrm{~K}, \mathrm{~b}=0,06-0,08 \mathrm{~K} / \mathrm{s}$. 
Nos resultados mostrados na Figura 36, para o MLUV, se verifica que a banda criada com o auxilio da foto-excitação está deslocada para temperaturas mais baixas em relação as medidas de CDTE usuais para a amostra AS1, conforme mostrado anteriormente na Figura 21. No caso da excitação no MLUV, a temperatura máxima do pico fica em torno de $140 \mathrm{~K}$, ou seja, mais próxima da temperatura da banda de CDTE menos intensa para essa amostra quando é feito o ajuste teórico das curvas pelo método melhorado de Havriliak-Negami. É possível observar ainda que os picos laterais que ocorrem na banda de CDTE da amostra sintética, mostrados na Figura 21 são favorecidos com o aumento do tempo de incidência de luz enquanto que, a banda em torno de $140 \mathrm{~K}$ observada nas medidas de CDTEFI parecem apresentar uma saturação em sua intensidade independente do tempo de aplicação de luz.

Na irradiação da amostra com MLVI (406,7-415,4 nm), Figura 37, observa-se que ocorre a destruição da banda de CDTE na posição original mas há o aparecimento de um pico, de mesma ordem de grandeza da banda, em torno de $220 \mathrm{~K}$. Para esse comprimento de onda a excitação da amostra ocorre exatamente sobre a banda $\mathrm{B}$ do espectro de absorção atribuída aos íons $\mathrm{Cr}^{3+}$ e $\mathrm{Fe}^{3+}$, sendo que , no caso da amostra sintética, a concentração de Fe é desprezível. No caso do processo de formação das bandas utilizando o MLVI, a saturação na intensidade da banda de CDTE é mais evidente independendo se o tempo utilizado de incidência de luz foi de 5 ou 15 minutos.

Quando a amostra é excitada com MLBG (468-530,9 nm), Figura 38, se verifica que a banda de CDTE não é destruída mas sim, deslocada para temperaturas mais altas, em torno de $178 \mathrm{~K}$, ou seja, para posições mais próximas da banda de 
CDTE mostrada na Figura 21, e o mesmo ocorre para o MLRD (647,1-676,4 nm), Figura 39, que também desloca um pouco mais a banda para temperaturas mais altas. Nos dois últimos casos também se observa que ocorre uma saturação na intensidade da banda para tempos de irradiação da amostra maiores, 5,10 ou 15 minutos. $\mathrm{Na}$ Figura 40 são apresentadas as posições médias das bandas de CDTE mostradas na Figura 36, na Figura 37, na Figura 38 e na Figura 39.

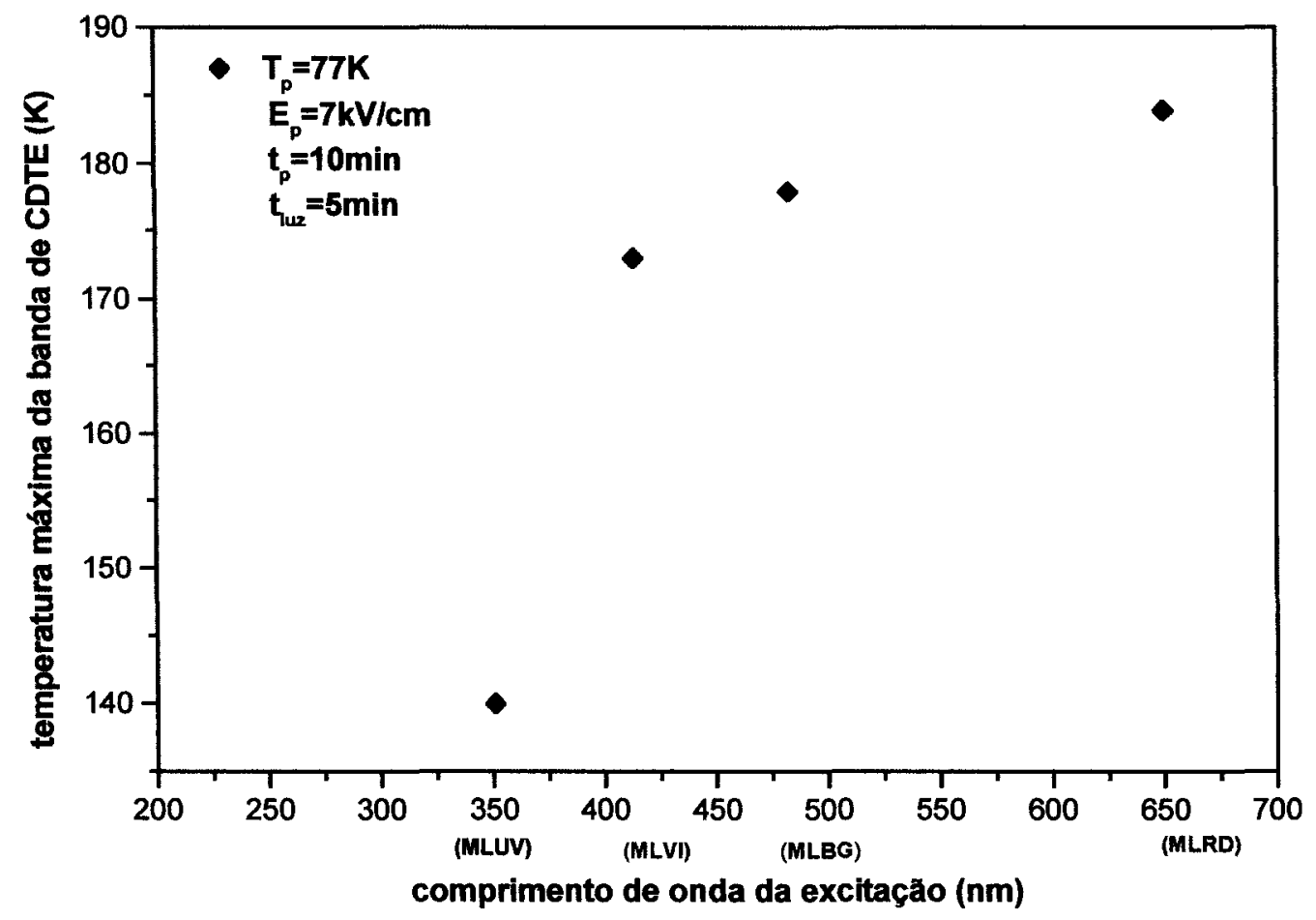

Figura 40 - Posições das bandas de CDTE referentes ao processo de formação das bandas com a condição de tempo de irradiação de 5 minutos, no MLUV, MLVI, MLBG e MLRD.

Na Figura 40 observa-se que a posição da banda de CDTE é deslocada para temperaturas mais altas quando se irradia a amostra com comprimentos de onda mais altos, indicando haver realmente uma distribuição de dipolos necessitando de tempos 
de relaxação diferentes para se desorientarem. Esse resultados reforçam a necessidade da análise das bandas de CDTE atribuídas a um processo de relaxação com uma distribuição contínua de energias de ativação, como o de Havriliak-Negami utilizado neste trabalho.

A respeito das medidas de CDTEFI para a amostra sintética podemos concluir que deve existir uma contribuição significativa dos $\mathrm{Cr}^{3+}$ localizados nos sítios localizados sobre o plano de reflexão $\left(\mathrm{Al}_{2}\right)$ pois, como já foi citado, esses são os íns que colaboram para com as propriedades ópticas nesse material e portanto são fortemente influenciados pela luz incidente na amostra. Entretanto, os mecanismos que descrevem a relaxação dipolar observadas nas medidas de CDTEFI não são os mesmos que descrevem a relaxação dipolar elétrica observada com medidas usuais de CDTE. No caso das bandas obtidas com a aplicação simultânea do campo elétrico de polarização e irradiação das amostras à baixa temperatura, as bandas observadas não puderam ser ajustadas com o método de Havriliak-Negami, considerando-se uma ou duas distribuições dos parâmetros de relaxação. Nas medidas fotoinduzidas os valores de energia de ativação e tempo de relaxação diferem muito dos valores apresentados na Tabela 10.

\subsection{2 - CDTEFI PARA AS AMOSTRAS NATURAIS}

Para a amostra AN3, com faces laterais bastante irregulares e sem nenhum polimento, a incidência de luz torna-se mais dificil pois, ocorre um espalhamento da luz nas faces da amostra, que embora fique quase que completamente vermelha, a luz não consegue atravessá-la. Esse efeito pode ser observado na Figura 33, onde a 
alexandrita natural não apresenta uma mudança total em sua cor quando irradiada, dependendo da direção de incidência de luz.

Entretanto, mesmo assim, foram realizadas medidas de CDTE polarizando a amostra em $280 \mathrm{~K}$, com $\mathrm{E}_{\mathrm{p}}=6,9 \mathrm{kV} / \mathrm{cm}$ e eletrodos de tinta prata, conforme procedimento já descrito, e incidiu-se luz MLUV à $77 \mathrm{~K}$, com potência de $0,37 \mathrm{~W}$ e 0,42 W. A incidência de luz gera um pico de corrente tal como foi verificado para a amostra sintética. Entretanto, o comportamento das bandas de CDTE é bastante diferente em relação a amostra sintética: a incidência de luz não provoca a destruição completa das bandas, ocorrendo um pico em torno de $192 \mathrm{~K}$, cuja intensidade é em torno da metade comparada as medidas obtidas na forma usual, mostrada na Figura 20 e outro menos intenso em $200 \mathrm{~K}$, os quais podem ser vistos na Figura 41 , quando utilizamos a mesma escala para a corrente dos gráficos referentes à amostra sintética.

No processo inverso, ou seja, de formação de bandas com a incidência de luz à TNL por 2 minutos juntamente com $\mathrm{E}_{\mathrm{p}}$, a amostra natural comporta-se como a sintética com a banda de CDTE sendo criada mas, com intensidade bem maior do que a banda de CDTE sem luz, comportamento esse contrário ao da sintética. Esse resultado é mostrado na Figura 42. 


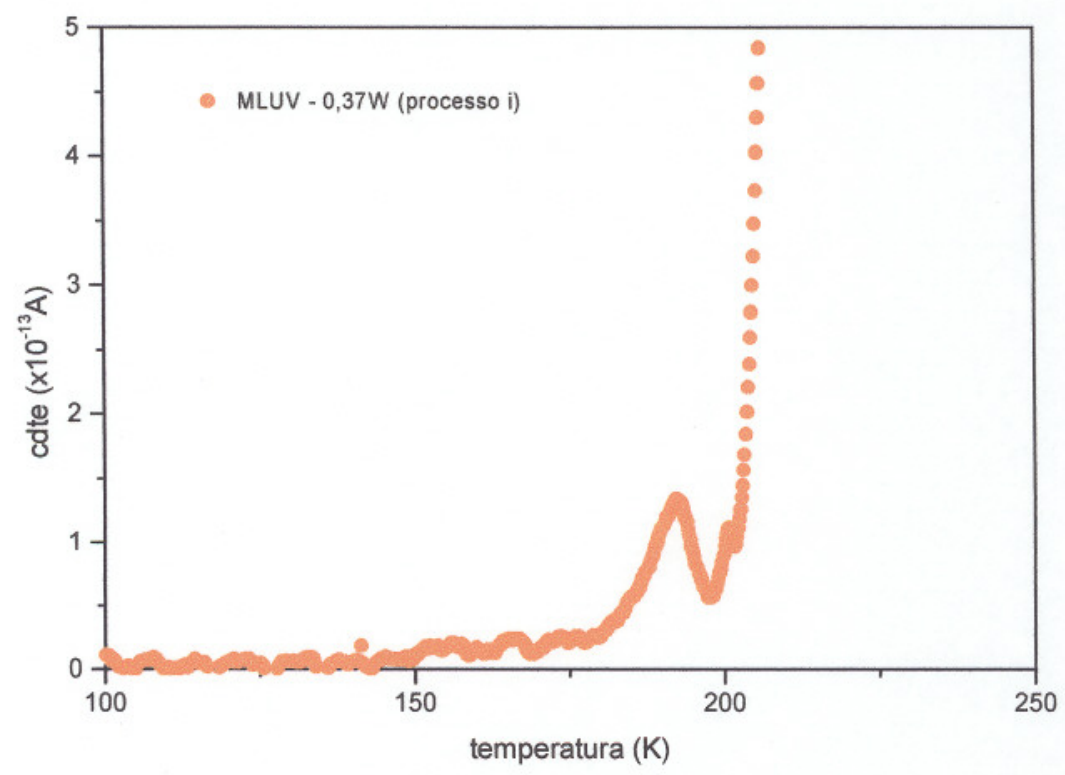

Figura 41 - CDTEFI para amostra AN3 $(e=2,03 \mathrm{~mm})$ com $T_{p}=280 \mathrm{~K}, E_{\mathrm{p}}=6,9 \mathrm{kV} / \mathrm{cm} \mathrm{e}$ $\mathrm{b}=0,08 \mathrm{~K} / \mathrm{s}$, com luz MLUV (processo i).

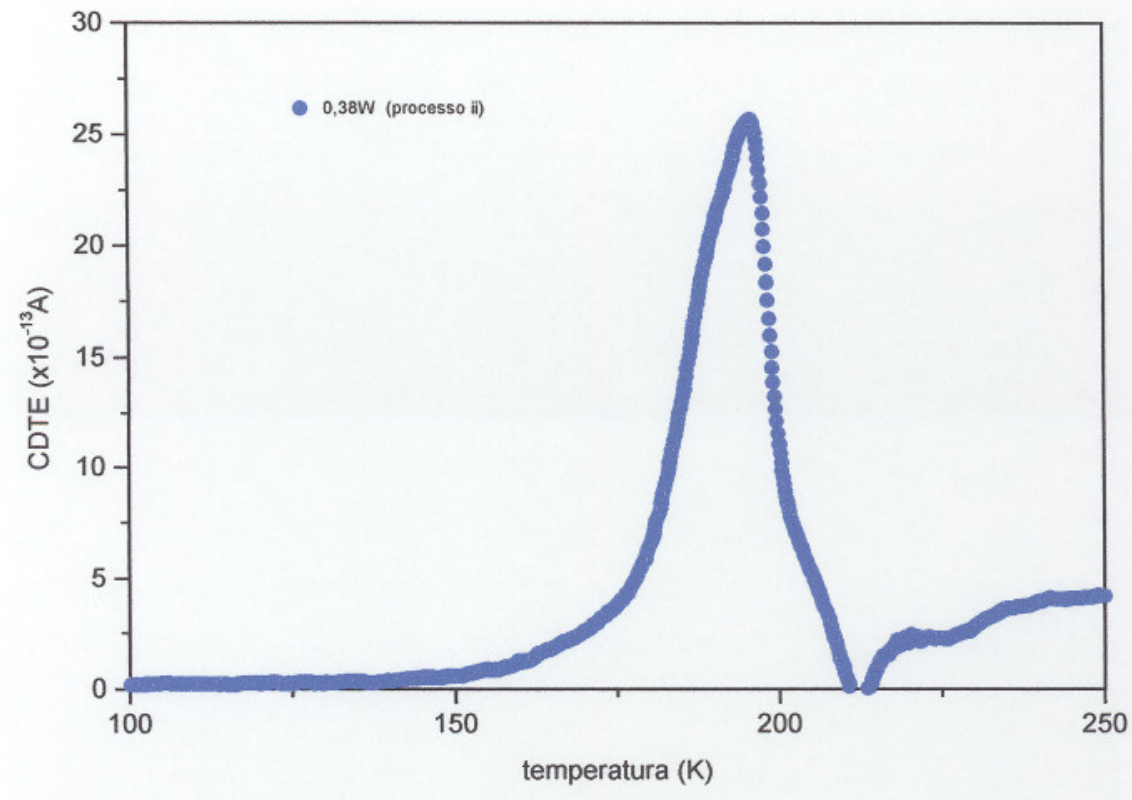

Figura 42 - CDTEFI para a amostra AN3 com $T_{p}=83 \mathrm{~K}, E_{p}=6,9 \mathrm{kV} / \mathrm{cm}$ e b=0,08K/s (processo ii). 
Foram realizadas também medidas de CDTE fotoinduzidas com a amostra AN3 com eletrodos de ouro, na tentativa de verificar se não ocorre alguma influência dos eletrodos de tinta prata que, conforme foi visto anteriormente, poderiam estar também interferindo no comportamento da corrente para temperaturas acima de 220K. Entretanto, novamente não ocorre a destruição da banda de CDTE. Mas, com $\mathrm{T}_{\mathrm{p}}=189 \mathrm{~K}, \mathrm{E}_{\mathrm{p}}=6,9 \mathrm{kV} / \mathrm{cm}$ e $\mathrm{b}=0,10 \mathrm{~K} / \mathrm{s}$, incidindo luz com $0,50 \mathrm{~W}$ (processo i), as bandas de CDTE aparecem em 172 e 193K, com intensidades mais baixas. Esse resultado é mostrado na Figura 43, juntamente com a medida sem luz utilizando eletrodos de ouro.

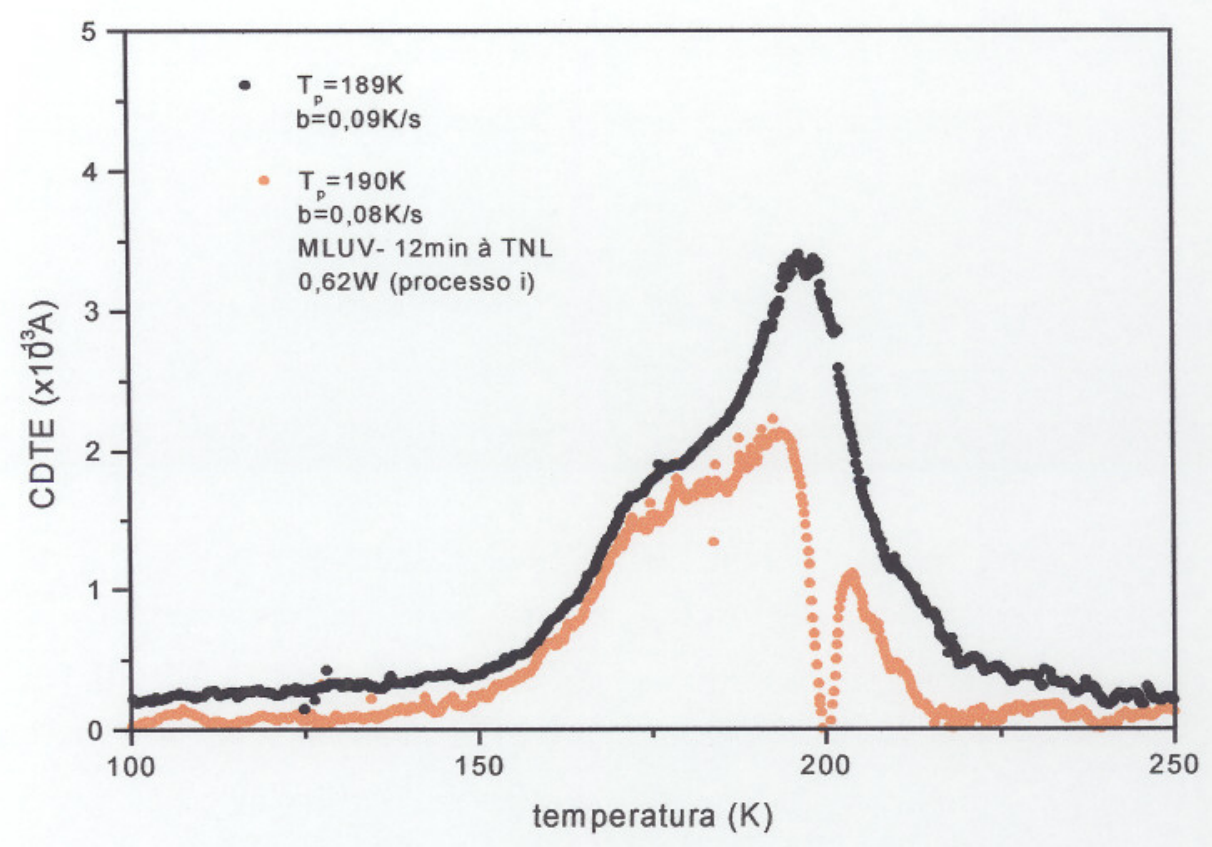

Figura 43 - CDTE fotoinduzida para AN3 com eletrodos de ouro, com $T_{p}=190 \mathrm{~K}$, $\mathrm{E}_{\mathrm{p}}=6,9 \mathrm{kV} / \mathrm{cm}$ e $\mathrm{b}=0,09 \mathrm{~K} / \mathrm{s}$ (processo i) 
No processo de formação de bandas com luz e campo elétrico aplicado na amostra, não foram obtidos bons resultados para a amostra com eletrodos de ouro. Um dos melhores resultados é mostrado na Figura 44 mas, não foi reprodutível. Para essa amostra foi possível somente observar que há uma forte tendência à formação das bandas mas, com o espalhamento de luz pela amostra, esta não é observada claramente como ocorre para AS1. Também foram realizadas medidas com potências do laser mais altas mas, com o alargamento do feixe o espalhamento de luz na amostra é ainda maior. Para essa amostra foram realizadas apenas medidas com excitação da amostra no MLUV.

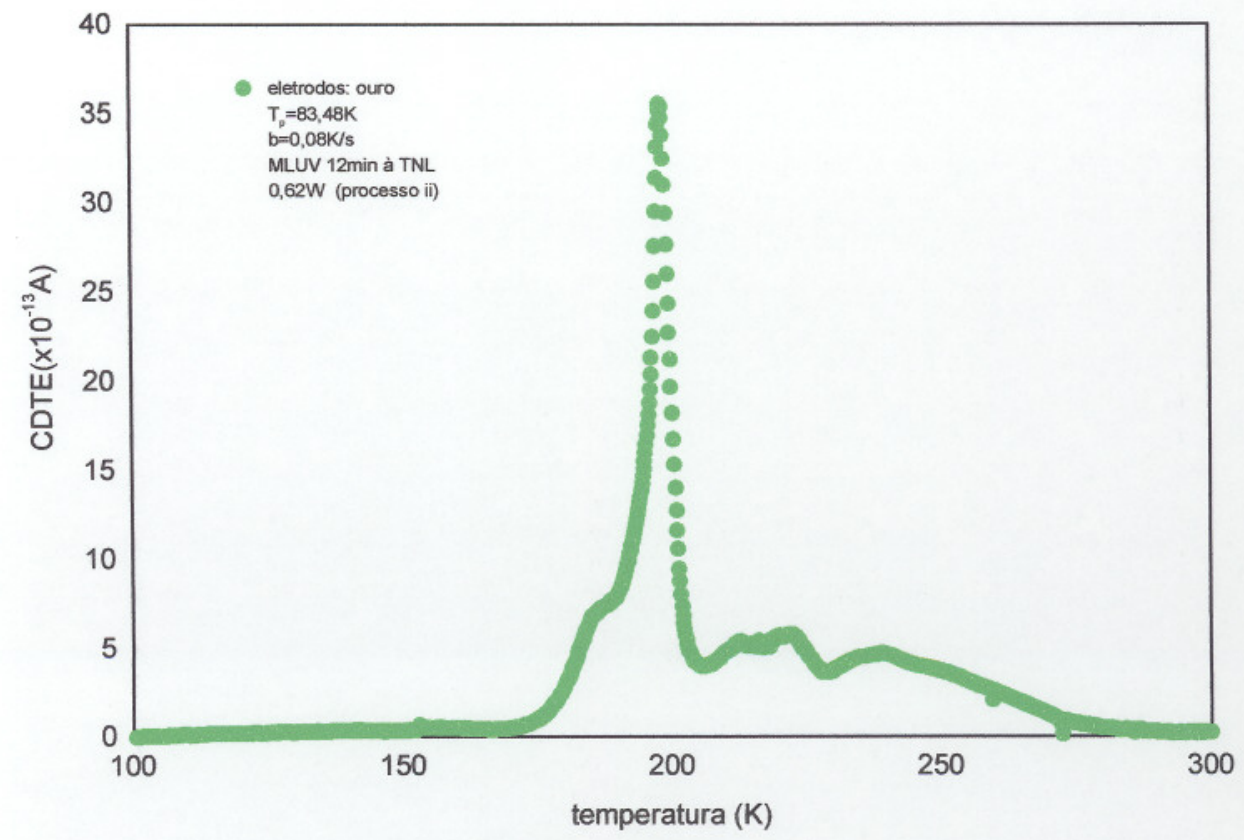

Figura $44-$ CDTE fotoinduzida para AN3 com eletrodos de ouro, com $T_{p}=83 \mathrm{~K}$, $\mathrm{E}_{\mathrm{p}}=6,9 \mathrm{kV} / \mathrm{cm}$ e $\mathrm{b}=0,08 \mathrm{~K} / \mathrm{s}$ (processo ii) 
Também foram realizadas medidas de CDTEFI com a amostra AN5, cuja face lateral possui o melhor polimento possível, sem apresentar tendência a esfarelar-se, e com aspecto mais translúcido. Com incidência de luz do laser sintonizado no MLUV, com potência de $0,62 \mathrm{~W}$, por 10 minutos, após polarizar em $186 \mathrm{~K}$ e esperar a corrente de descarga, e com o aumento da temperatura com $b=0,08 \mathrm{~K} / \mathrm{s}$ se verifica que as bandas não são destruídas e aparecem nas mesmas posições sem a aplicação da luz porém, com intensidades um pouco menores, ou seja, pode haver apenas uma tendência de ocorrer a destruição das bandas. Esse resultado é apresentado na Figura 45. No processo de obtenção das bandas por luz, não foi obtido nenhum resultado satisfatório para essa amostra.

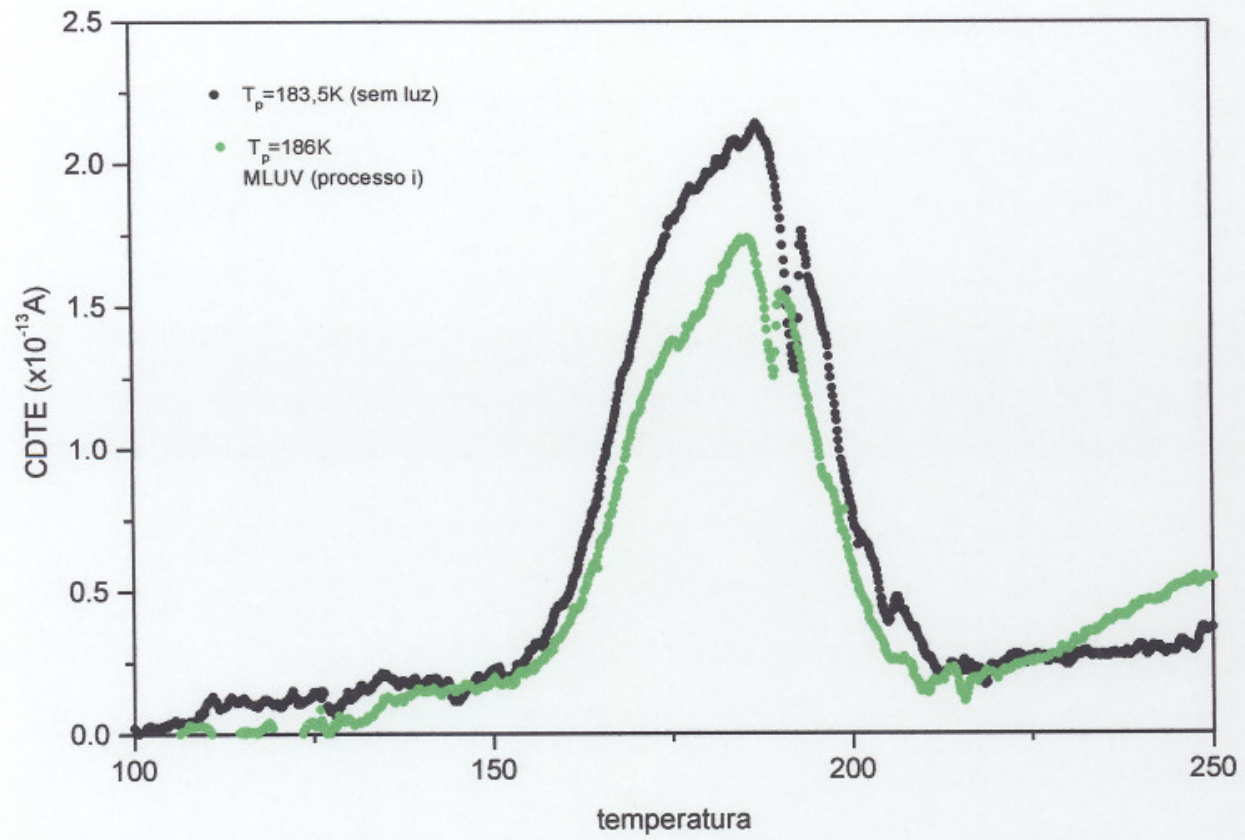

Figura 45 - CDTE fotoinduzida para AN5 $(\mathrm{e}=1,14 \mathrm{~mm})$ com eletrodos de tinta prata, $\mathrm{T}_{\mathrm{p}}=186 \mathrm{~K}$ e $\mathrm{b}=0,08 \mathrm{~K} / \mathrm{s}$ (processo i) 
Portanto, com as medidas de CDTEFI é possível dizer que o processo de formação das bandas sempre é mais eficiente, e ocorre tanto para a amostra sintética, nesse caso em função dos comprimento de onda de excitação, quanto para as amostras naturais AN3 e AN5, medidas somente para MLUV. Por outro lado, o processo de destruição não é facilmente observado, dependendo fortemente da potência do laser e do comprimento de onda da luz para a amostra sintética e, não ocorre para as amostras naturais, as quais possuem faces laterais irregulares causando um espalhamento da luz que nela incide. Além disso, deve-se levar em conta que as amostras naturais não são monocristalinas e podem ter dipolos associados a outros tipos de impurezas que não seja o $\mathrm{Cr}^{3+}$. 


\section{CONCLUSÕES:}

\section{1 - IDENTIFICAÇÃO DAS AMOSTRAS}

A identificação das amostras de alexandrita naturais, confirmando serem realmente verdadeiras, uma vez que esse material é bastante raro, foi realizada através das técnicas de EDX, WDX, Difração de Raios X, Absorção Óptica e Luminescência. As conclusões a partir dos resultados obtidos são as seguintes:

\section{1 .1 - COMPOSIÇÃO QUÍMICA E CARACTERIZAÇÃO ESTRUTURAI}

Através das microanálises por EDX e WDX, foi detectada a existência de inclusões sólidas, como quartzo e mica, nas amostras naturais, e também a presença de outras impurezas na matriz hospedeira tais como: $\mathrm{Mg}, \mathrm{Ti}, \mathrm{Si}, \mathrm{Ca}, \mathrm{K}$. Com essas medidas foi também verificado que a concentração de Fe nas amostras naturais é bem maior do que a concentração de Cr. Enquanto que, para a amostra sintética foram detectadas apenas concentração desprezível de Fe em uma das regiões analisadas, assim como, apenas traços de Ir . Com isso pudemos concluir que é possível utilizar a amostra sintética, possuindo apenas impurezas $\mathrm{Cr}^{3+}$, como uma referência nas medidas de CDTE. Este fato pode ser reforçado também pelo crescimento e procedência da amostra sintética. 
A presença de outras impurezas e formação de inclusões sólidas nas amostras naturais foram confirmadas com medidas de Difração de Raios X, as quais permitiram também confirmar os parâmetros de rede, $a=9,504 \AA ; b=5,471 \AA$ e c $=4,409 \AA$ e a estrutura cristalina ortorrômbica desse material. Esses resultados são plenamente coincidentes com a literatura.

\section{1 .2 - CARACTERIZAÇÃO ÓPTICA}

Para ambos os tipos de amostras as medidas de absorção óptica apresentaram as duas bandas largas em torno de 576,6 e $416-424,5 \mathrm{~nm}$, chamadas bandas A e B e atribuídas as transições a partir do estado fundamental ${ }^{4} \mathrm{~A}_{2}$ para os estados excitados ${ }^{4} \mathrm{~T}_{2}$ e ${ }^{4} \mathrm{~T}_{1}$, respectivamente. As duas linhas do $\mathrm{Cr}^{3+}$ localizados nos sítios sobre um plano de reflexão, característicos da alexandrita, em torno 678,5 e $680,5 \mathrm{~nm}$ também foram facilmente detectadas. No caso da amostra sintética uma terceira banda de absorção do $\mathrm{Cr}^{3+}$, na região do ultravioleta, em torno de $265 \mathrm{~nm}$ (banda C), pode ser detectada. Essa banda raramente é citada na literatura e concluímos que sua presença nos espectros de absorção obtidos neste trabalho se deve a ausência de Fe nessa amostra, uma vez que, essa região é bastante influenciada por íons de $\mathrm{Fe}^{3+}$.

No caso das amostras naturais a influência do $\mathrm{Fe}^{3+}$ é bastante evidenciada nas medidas de absorção óptica, as quais não apresentam a banda $\mathrm{C}$ e a banda $\mathrm{B}$ ( em torno de 416-420nm, dependendo da amostra analisada) é bastante assimétrica, com absorção muito alta a partir de $400 \mathrm{~nm}$. Essas características apontam também uma 
influência das inclusões de quartzo e mica, cujos espectros de absorção apresentam o mesmo comportamento nessa região do espectro.

Com as medidas de luminescência foi possível verificar que as posições das linhas $\mathrm{R}$ atribuídas ao $\mathrm{Cr}^{3+}$ nos sítios localizados num plano de reflexão $\left(\mathrm{R}_{1}=681,2 \mathrm{~nm}\right.$ e $\mathrm{R}_{2}=679,4 \mathrm{~nm}$ ) e das linhas $\mathrm{S}$ atribuídas ao $\mathrm{Cr}^{3+}$ localizados sobre um centro de inversão $\left(S_{1}=696,6 \mathrm{~nm}\right.$ e $\left.S_{2}=690,8 \mathrm{~nm}\right)$ para as amostras sintética e natural são bastante coincidentes com a literatura, o que pode mais uma vez confirmar a qualidade das amostras utilizadas.

\section{2 - CORRENTE DE DESPOLARIZAÇÃO TERMICAMENTE ESTIMULADA}

Neste trabalho foi observado pela primeira vez a presença do fenômeno de relaxação dipolar elétrica em alexandrita sob as formas natural e sintética, através de medidas de Corrente de Despolarização Termicamente Estimulada. As bandas de CDTE observadas são típicas dos mecanismos de relaxação por ativação térmica característicos da presença de entidades dipolares, ou seja, a temperatura máxima, $T_{m}$, da banda depende da taxa de aquecimento, b, utilizada; e apresentam um comportamento linear regular da área sob a banda com a tensão de polarização aplicada, $E_{p}$. Dadas as mesmas condições de medidas, para $E_{p}, b, t_{p}$ e área dos eletrodos os resultados são plenamente reprodutíveis na região abaixo da temperatura ambiente.

As medidas de CDTE indicaram a presença de uma banda larga centralizada em torno de 188 à $195 \mathrm{~K}$ para as amostras naturais enquanto que, para a amostra sintética, essa banda está centralizada em torno de $177 \mathrm{~K}$. A própria estrutura da 
alexandrita, mostrada na Figura 2, nos leva a considerar como hipótese principal, que a forma com que as curvas características da relaxação dipolar se apresenta deve ser atribuída a uma distribuição contínua dos parâmetros de relaxação envolvidos, $\mathrm{E}_{\mathrm{a}} \mathrm{e}$ $\tau_{0}$

A conclusão em relação a forma das bandas é obtida levando-se em consideração que a origem da formação de dipolos nesse material é atribuída a presença de vacâncias de oxigênio associadas com impurezas $\mathrm{Cr}^{3+}$ (dipolo tipo I-V) ou dipolos formados pelo deslocamento local dos vizinhos mais próximos devido a substituição do íon $\mathrm{Al}^{3+}$ da rede pelos íons $\mathrm{Cr}^{3+}$ que possuem raio iônico maior. Conforme o modelo apresentado na Figura 16, as vacâncias de oxigênio podem estar distribuídas aleatoriamente nas posições 1,2 e 3 nos dois sítios de simetrias diferentes, $\mathrm{Al}_{1}$ e $\mathrm{Al}_{2}$, encontrados na estrutura cristalina. Os dipolos formados devem interagir entre si durante o processo térmico dando origem ao aparecimento das bandas largas observadas.

A participação do $\mathrm{Cr}^{3+}$ na formação de dipolos pode ser considerada quando realizamos também a caracterização óptica através das técnicas de absorção e luminescência, e verificamos que o espectro para a amostra sintética possuem somente as bandas de absorção do $\mathrm{Cr}^{3+}$, como descrito anteriormente

Portanto, analisando as curvas experimentais de CDTE utilizando o método de Havriliak-Negami, que considera uma distribuição contínua dos parâmetros de relaxação, temos que os resultados obtidos mostram que realmente as curvas podem ser ajustadas com duas distribuições continuas desses parâmetros. Os valores de energia de ativação e tempo de relaxação obtidos e apresentados na Tabela 10 para as amostras AS1 e AN3 são bastante coerentes e, o mais importante, é que 
observamos que uma das distribuições, chamada nessa tabela de curva 2, é praticamente coincidente para ambas as amostras, ou seja, essa distribuição deve ser originada pelo participação dos íons $\mathrm{Cr}^{3+}$ na formação dos dipolos.

O fato da banda de CDTE para a amostra natural estar deslocado para temperaturas mais altas deve ser atribuído a presença das outras impurezas detectadas nas amostras naturais. Isso é reforçado pelos resultados obtidos com a amostra natural AN5, cuja concentração de outras impurezas e a presença de inclusões de quartzo e mica é bem menor do que em AN3 e, por isso, a banda de CDTE está localizada numa temperatura um pouco mais baixa (em torno de $188 \mathrm{~K}$ ) em relação a amostra AN3. Os íons de $\mathrm{Fe}^{3+}$ também podem entrar na estrutura da alexandrita substituindo os íons $\mathrm{Al}^{3+}$ e então podem também dar origem a formação de dipolos do tipo I-V. As distribuições e os parâmetros de relaxação obtidos para as amostras naturais e apresentados na Tabela 10 e na Tabela 12 , indicados na coluna referente a Curva 3, podem ser atribuídos a esses dipolos ou ainda, a outros dipolos formados com a participação de outras impurezas.

\section{3 - EFEITOS DOS TRATAMENTOS TÉRMICOS}

Tratamentos térmicos consecutivos realizados para as amostras naturais reforçam as conclusões anteriores, eliminando a distribuição centralizada em temperaturas mais altas e evidenciando a presença da Curva 2 de distribuição, com os parâmetros de relaxação coerentes com a Curva 2 da amostra sintética, conforme apresentado na Tabela 10 e na Tabela 12. 
A comprovação de que os tratamentos térmicos não alteram a estrutura cristalina da alexandrita, e portanto mantém a formação de dipolos com a participação do $\mathrm{Cr}^{3+}$, foi feita através das medidas de Difração de Raios $\mathrm{X}$ e medidas de absorção óptica e luminescência em função dos tratamentos térmicos realizados. Em relação a absorção os tratamentos térmicos influenciam apenas na banda atribuída ao $\mathrm{Fe}^{3+} / \mathrm{Cr}^{3+}$ (banda B em torno de $420 \mathrm{~nm}$ ) e principalmente, a região do ultravioleta, caracterizada pela mica e quartzo.

\section{4 - MEDIDAS DE CDTEFI}

Neste trabalho também foram realizadas medidas de CDTE fotoinduzidas que apontaram uma forte sensibilidade das bandas de CDTE com a incidência de luz nas amostras. Os resultados obtidos com as medidas de CDTEFI confirmam um comportamento das bandas de CDTE com uma distribuição contínua dos parâmetros de relaxação.

No caso da amostra sintética, as bandas de CDTE podem ser formadas a partir de uma situação de não polarização a temperatura de $77 \mathrm{~K}$, quando a amostra é foto excitada nessa temperatura juntamente com o campo elétrico aplicado, para qualquer um dos comprimentos de onda utilizados (MLUV, MLVI, MLBG e MLRD). As bandas assim obtidas estão deslocadas para temperaturas mais baixas, em torno de 140K, quando a amostra é excitada pelo MLUV e voltam a deslocar-se para temperaturas mais altas quando irradiadas com comprimentos de onda maiores, na região do visível. 
O processo de destruição das banda de CDTE, previamente alcançada numa situação de polarização a temperatura ambiente, é obtido apenas no caso da utilização da luz laser sintonizado no MLUV e depende da potência do laser.

No caso das amostras naturais foi possivel somente verificar que há uma tendência à formação das bandas com a incidência de luz e que não ocorre a destruição dessas como no caso da amostra sintética. Entretanto, esses resultados não podem ser considerados conclusivos uma vez que existe um grande espalhamento de luz pelas amostra naturais que possuem faces laterais, por onde incide a luz, bastante irregulares e além disso, essas amostras não são monocristalinas, como é o caso da amostra sintética.

De forma geral, podemos concluir que os resultado inéditos de medidas de CDTE em alexandritas mostram que esse material possui propriedades elétricas bastante interessantes e que são fortemente influenciadas pela incidência de luz. Com isso novas perspectivas em estudar alexandritas são abertas e, futuramente, medidas e análises suplementares na caracterização elétrica podem proporcionar um completo entendimento do fenômeno de relaxação dipolar e, outras aplicações para esse material podem surgir baseadas nesses resultados. 


\section{TRABALHOS FUTUROS}

Para complementar a caracterização elétrica dos cristais de alexandrita através da técnica de CDTE, ainda é conveniente a realização de alguns experimentos citados a seguir:

1. Em primeiro lugar é sugerida a obtenção de cristais não dopados $\operatorname{com} \mathrm{Cr}^{3+}$, ou seja, de crisoberilo na forma sintética natural ou, preferencialmente, em ambas. As medidas de CDTE para o crisoberilo poderiam nos dar informações conclusivas se realmente os dipolos detectados nas medidas com alexandrita podem ser atribuídos a impureza-vacância ou mesmo a deformação local sofrida pela rede devido as diferenças de raios iônicos entre $\mathrm{o}^{3+} \mathrm{e} \mathrm{Al}^{3+}$, conforme é sugerido neste trabalho.

2. Realizar medidas de CDTE fotoinduzidas com uma amostra natural lapidada ou com mínima presença de inclusões. Com isso poderia ser minimizado o efeito do espalhamento da luz incidente nas amostras naturais como ocorreu nas medidas com nossas amostras naturais disponíveis.

3. Realizar medidas de CDTE fotoinduzidas com outras linhas do laser além das quatro linhas utilizadas neste trabalho, por exemplo, no infravermelho, e com linhas exatamente sobre as bandas de absorção, em torno de 420 e $570 \mathrm{~nm}$. Este experimento poderia ampliar a investigação da dependência da posição das bandas de CDTE em função do comprimento de onda utilizado.

4. Dar continuidade as medidas de CDTE em amostras naturais provenientes de outras regiões que podem apresentar diferentes características em sua composição quimica e estrutura. Sugerimos essas medidas baseados na possibilidade de que outras amostras possuam quantidades de Fe e outras 
impurezas bastante diferentes comparadas com as amostras estudadas nesse trabalho. Recentemente obtivemos algumas amostras de alexandrita natural oriundas da região de Minaçu, no Estado de Goiás e, medidas preliminares de CDTE proporcionaram resultados muito semelhantes aos obtidos com nossas amostras naturais oriundas de Minas Gerais, com uma banda de CDTE bastante intensa centralizada também em torno de 196K. Entretanto a composição química de ambas é bastante semelhante em relação ao $\mathrm{Cr}$ e Fe.

5. Possuindo outras amostras podemos realizar as medidas de CDTE em função de tratamentos térmicos feitos em atmosferas controladas, principalmente em atmosfera de oxigênio, e então investigar melhor a presença de vacâncias de oxigênio, analisando a concentração de dipolos através da área sob a curva de corrente em função do tempo nas medidas de CDTE. Esses tratamentos térmicos também podem ser realizados com uma variação maior de intervalos de tempos, por exemplo, de 30 em 30 minutos até completar as 5 horas proposta nesse trabalho.

6. Realizar medidas de EPR para as amostras naturais em função dos tratamentos térmicos consecutivos. Essas medidas poderiam nos fornecer informações relevantes sobre a taxa de concentrações de impurezas nos dois sítios diferentes, $\mathrm{Al}_{1}$ e $\mathrm{Al}_{2}$, e relacioná-las com as bandas de CDTE obtidas após os tratamentos térmicos. Observamos que medidas de EPR para alexandrita natural foram tentadas neste trabalho mas, verificamos que existe uma grande dificuldade em sua realização devido a alta concentração de $\mathrm{Fe}^{3+}$ que essas amostras possuem. 
7. A realização de medidas de Absorção Óptica com luz polarizada também é sugerida a fim de se obter informações adicionais a respeito dos parâmetros espectroscópicos.

8. Utilização de técnicas experimentais que possibilitem a determinação da composição química das amostras de forma mais abrangente e precisa do que as análises de EDX e WDX realizadas neste trabalho, com as quais não foi possível detectar principalmente o berilio e detectar o oxigênio, no caso de WDX, com erros grandes comparados aos outros elementos

9. Realizar medidas de Difração de Raios X em função da temperatura analisando sistematicamente prováveis alterações que possam ocorrer nas amostras de alexandritas .

10. Realizar medidas de tempo de vida em diferentes amostras, obtendo-se assim informações a respeito da concentração de $\mathrm{Cr}^{3+}$ nos dois tipos de sítios, $\mathrm{Al}_{1} \mathrm{e}$ $\mathrm{Al}_{2}$.

Para finalizar devemos lembrar do grande interesse que existe na obtenção do material em estudo de forma mais rápida e, principalmente, mais barato e portanto, uma continuidade para esse trabalho poderia se basear na dedicação em se obter alexandrita na forma de filmes através de evaporação via canhão de elétrons, por exemplo, disponível em nosso laboratório. 


\section{Referências:}

[1] Liu, Y.; Shigley, J.E., Fritsch, E. and Hemphill, S. - "Relationship between the crystallographic orientation and the effect alexandrite in synthetic alexandrite"Miner. Magazine, 59, 111-114, 1995.

[2] Schmetzer, K., Bank, H. and Gubelin, E. - "The alexandrite effect in minerals: Chrysoberyl, Garnet, Corundum, Fluorite”- N.Jb.Miner.Abh, 138(2), 147-164, 1980. [3] Liu, Y. , Shigley, J.; Fritsch, E. and Hemphill, S.- "The alexandrite effect in gemstones"- Color Res. Appl., 19(3), 186-191, 1994.

[4] Walling, J.C., Peterson, O.G.; Jenssen, H.P. , Morris, R.C. and O'Dell, E.W."Tunable alexandrite lasers"- IEEE J. Quantum Electron., QE-16(12), 1302-1314, 1980.

[5] Fabeni, P.; Pazzi, G.P. and Salvini, L. - "Impurity centers for tunable lasers in the ultraviolet and visible regions" - J. Phys. Chem. Solids, 52(1), 299-317, 1991.

[6] Cassedane, J. and Roditi, M. - "The location, geology, mineralogy and gem deposits of alexandrite, cat's eye and chrysoberyl in Brazil"- J. Gemm., 23(6), 333354, 1993.

[7] Elawar, K.K. - "Principais aspectos e a comercialização de crisoberilos"- Anais do XXVIII Congresso Brasileiro de Geologia, 219-222, 1985.

[8] Farrel, E.F.; Fang, J.H. and Newham, R.E. - "Refinement of the chrysoberyl structure"- Amer. Mineralogist, 48, 804-810, 1963.

[9] Shand, M.L.; Walling, J.C. and Jenssen, H.P. - "Ground state absorption in the lasing wavelength region of alexandrite: theory and experiment"- IEEE J. Quantum Electron., QE-18(2), 167-169, 1982.

[10] Jovanic, B.R.-"High pressure effects on the Rl line lifetime in alexandrite $\mathrm{BeAl}_{2} \mathrm{O}_{4}: \mathrm{Cr}^{3+}$ "- J. Lumin., 68, 43-48, 1996. 
[11] Iwata, S. A.; Schultz-Guttler; R. A. and Madureira Filho, J.B. - "Espectros de absorção (UV/VIS) de alexandritas brasileiras"- Anais do XXXIX Congresso Brasileiro de Geologia, 39, 72-75, 1996.

[12] Barry, W.R. and Troup, G.J. - "EPR of $\mathrm{Cr}^{3+}$ ions in alexandrite" - Phys. Stat. Sol., 35, 861-864, 1969.

[13] Rager, H.; Bakhshandh-Khiri, A. and Schmetzer,K. -“. Investigation of the intracrystalline $\mathrm{Cr}^{3+}$ distribution in natural and synthetic alexandrites"N.Jb.Miner.Mh, 2 , 545-557, 1998.

[14] Forbes, C.E. - "Analysis of the spin Hamiltonian parameters for $\mathrm{Cr}^{3+}$ in mirror and inversion symmetry sites of alexandrite $\left(\mathrm{Al}_{2-x} \mathrm{Cr}_{x} \mathrm{BeO}_{4}\right)$. Determination of the relative site occupancy by EPR"- J. Chem. Phys., 79(6), 2590-2599, 1983.

[15] Yeom, T.H.; Hong, K.S.; Yu, I.; Shin, H.W. and Choh, S.H. - "Spin lattice relaxations of ${ }^{9} \mathrm{Be}$ and ${ }^{27} \mathrm{Al}$ single crystalline alexandrite"- J. Appl. Phys., 82(5), 2472-2475, 1997.

[16] Reaves, H.L. and Gilmer, T.E. - "Quadrupole splitting of the magnetic resonance spectrum of ${ }^{9} \mathrm{Be}$ in chrysoberyl"- J. Chem. Phys., 42(12), 4138-4140, 1965.

[17] Yeom, T.H.; Lim, A.R.; Choh, S.H., Hong, K.S. and Yu, Y.M. "Temperature-dependent nuclear magnetic resonance study of ${ }^{9} \mathrm{Be}$ in an alexandrite single crystal"- J. Phys.: Condens. Matter, 7, 6117-6123, 1995.

[18] Yeom, T.H.; Choh, S.H.; Hong, K.S.; Yeom, H.Y.; Park, Y.H. and Yu, Y.M. "Nuclear Quadrupole Interactions of $A l^{27}$ in alexandrite single crystal"- $\mathrm{Z}$. Naturforsch, 53a, 568-572, 1998.

[19] Bukin, G. V.; Eliseev, A. V.; Matrosov, V. N.; Solntsev, V.P.; Kharchenko, E. I. \& Tsvetkov, E. G. - "The growth and examination of optical properties of gem 
alexandrite" - In: Inhomogeneity of Minerals and Crystals Growth. - Proceedings of the XI IMA Meeting, Novosibirsk, 317-328, 1980.

[20] Pestryakov, E. V.; Trunov, V. I.; Alimpiev, A. I. \& Solntsev, V. P. - “Induced emission from iron-group ions in crysoberyl"- Bull. Akad. Of Science USSR, Phys. Series, 52, 124-131, 1988.

[21] Bucci, C. and Fieschi, R. - "Ionic thermo conductivity method for the investigation of polarization in insulators"- Phys. Rev. Lett., 12(1), 16-19, 1964.

[22] Bucci, C.; Fieschi, R. and Guidi, G.- "Ionic thermocurrents in dielectrics", Phys. Rev., 148(2), 816-823, 1966.

[23] Bucci, C.; Cappelletti, R.; Fieschi, R.; Guidi, G. and Pirola, L. - "Ionic thermocurrents in dielectric solids"- Il Nuovo Cim., 4(3), 607-629, 1966.

[24] Radhakrishna, S. and Haridoss, S. - Thermo currents in ionic crystals"- Crystal Latt. Def., 7, 191-207, 1978.

[25] Bräunlich, P. - Topics in Applied Physics: Thermally Stimulated Relaxation in Solids, 37, cap.4, Springer-Verlag Berlin Heidelberg New York, 1979.

[26] Shannon, R.D. - "Revised effective ionic radii and systematic studies of interatomic distances in halides and chalcogenides"- Acta Cryst., A32, 751-767, 1976. [27] Powell, R.C.; Xi, L.; Gang, X. and Quarles, G.J.- "Spectroscopic properties of alexandrite crystals"'- Phys. Rev.B, 32(5), 2788-2797, 1985.

[28] Liu, J.; Tang, R.; Wang, Y.; Jia, W.; Shang, Y. and He, S. - "The fluorescence spectrum of chrysoberyl $\mathrm{BeAl}_{2} \mathrm{O}_{4}: \mathrm{Cr}^{3+}$ at high pressure and low temperature"- J. Lumin., 40\&41, 419-420, 1988.

[29] Rabadanov, M.K. and Dudka, A . P. - "Comparative structural study of $\mathrm{Al}_{2} \mathrm{BeO}_{4}$ and $\mathrm{Al}_{2} \mathrm{BeO}_{4}: \mathrm{Cr}^{3+}$ (0.3at.\%Cr) crystals"- Inorg. Mat., 33(1), 48-51, 1997. 
[30] Havriliak, S. and Negami, S.- "A complex plane representation of dielectric and mechanical relaxation processes in some polymers"- Polymer, 8(4), 161-224, 1967. [31] Cline, C.F.; Morris, R.C.; Dutoit, M. and Harget, P.J. - "Physical properties of $\mathrm{BeAl}_{2} \mathrm{O}_{4}$ single crystals"'- J. Mat. Sci., 14, 941-944, 1979.

[32] Leonardos, O.H. - "Ocorrências de crisoberilo no Brasil" - Mineração e Metalurgia, 9 (49), 29-30, 1945.

[33] Petersen Junior, K.J. - Dissertação de Mestrado: “Alexandrita no municipio de Minaçu, Goiás: Mineralogia, Geologia e considerações genéticas", Instituto de Geociências, USP- São Paulo, 1998.

[34] Lu, T.; Liu, Y.; Shigley, J.; Moses, T. and Reinitz, I.M. - Characterization of a notable historic gem diamond showing the alexandrite effect"- J. Cryst. Growth, 193, 577-584, 1998.

[35] Schumann, W. - Gemas do Mundo - Editora ao Livro Técnico, pág. 99, $8^{\text {a }}$. edição, 1995.

[36] Hassan, F. and El-Rakhawy, A . - "Chromium III centers in synthetic alexandrite"- Amer. Mineralogist, 59, 159-165, 1974.

[37] Phakey, P.P. - "Transmission Electron Microscope Study of anti-phase boundaries in alexandrite $\left(\mathrm{Al}_{2-x} \mathrm{Cr}_{x} \mathrm{BeO}_{4}\right)$ "- Phys. Stat. Sol., 32, 801-814, 1969.

[38] Rabadanov, M.K. and Dudka, A .P. - “On localization of impurity chromium ions in alexandrite", Crystal. Rep., 43(6), 991-994, (1998).

[39] Burns, R.G. - Mineralogical applications of crystal field theory, Cambridge University Press, cap.2, pág.18, 1970.

[40] Hazen, R. M. - "High-pressure crystal chemistry of chrysoberyl, $\mathrm{Al}_{2} \mathrm{BeO}_{4}$ :Insights on the origin of olivine elastic anisotropy" - Phys. Chem. Mineral, 14, 13-20, 1987. 
[41] Tarjan, I and Matrai, M. - Laboratory Manual on Crystal Growth - Akademiai Kiadó, Budapest, pág 200, 1972.

[42] Pan, S.K. and Wang, X.G. - "Growth of laser crystal alexandrite"- Cryst. Re. Technol., 29(2), k31-k35, 1994.

[43] Bukin, G.V.; Matrosov, V.N.; Orekhova, V.P. et al - "Growth of alexandrite crystals and investigation of their properties"- J. Cryst. Growth, 52, 537-541, 1981. [44] Zhang, Q.; Hu, B.; Deng, P. and Gan, F. - "X-ray topographic investigation of dislocations in Czochralski-grow alexandrite (BeAl $\mathrm{O}_{4}: \mathrm{Cr}$ ) single crystal"- J. Phys. D: Appl. Phys., 26, A92-A97, 1993.

[45] Pestryakov, E.V.; Petrov, V.V.; Zubrinov, I.I.; Semenov, V.I.; Trunov, V.I. and Kirpichnikov, A .V. - "Physical properties of $\mathrm{BeAl}_{6} \mathrm{O}_{10}$ single crystals"- J. Appl. Phys., 82(8), 3661-3666, 1997.

[46] Dana, J.D. - Manual de Mineralogia, vol 1, Tradução de Franco, R.R., Editora da Universidade de São Paulo, 1969.

[47] Imai, S. and Ito, H. - "Long-pulse ultraviolet-Laser sources based on tunable alexandrite lasers"- IEEE J. Quantum Electron. 34(3), 573-576, 1998.

[48] Walling, J.C.; Jenssen, H.P.; Morris, R.C.; O’Dell, E.W. and Peterson, O.G. "Tunable laser perfomance in $\mathrm{BeAl}_{2} \mathrm{O}_{4}: \mathrm{Cr}^{3+}$ "- Opt. Lett., 4(6), 182-183, 1979.

[49] Walling, J.C.; Heller, D.F.; Samelson, H.; Harter, D.J.; Pete, A.J.A. and Morris, R.C. - "Tunable Alexandrite Lasers: Development and Performance”- IEEE J. Quantum Electron., QE-21(10), 1568-1581, 1985.

[50] Payne, S.A. ; Chase, L.L.; Smith, L.K.; Kway, W.L. and Newkirk, H.W. "Laser performance of LiSrAlF $: \mathrm{Cr}^{3+}$ ”- J. Appl. Phys., 66(3), 1051-1056.

[51] Saha, S. and Mistry, B.P. - "Preparation of alexandrite by the Sol-Gel process and its characterization"'- Ceram. Int., 22, 329-334, 1996. 
[52] Ponsardin, P.; Higdon, N.S.; Grossmann, B.E. and Browell, E.V. - "Spectral control of na alexandrite laser for an airborne water-vapor differential absorption lidar system"- Appl. Opt., 33(27), 6439-6449.

[53] Torizuka, K.; Yamashita, M. and Yabiku, T. - "Thermal Effect in a lamppumped continuous-wave alexandrite laser"- Jpn. J. Appl. Phys., 33(4A), 1899-1904, 1994.

[54] Pearle, M.S. et al -"Safety and efficacy on the alexandrite laser for the treatment of renal and ureteral calculi"- Urology , 51(1), 33-38,1998.

[55] Ash,K, et al - "Hair removal using a long-pulsed alexandrite laser"- Dermatol. Clin., 17(2), 387, 1999.

[56] Weber, M.J. and Varitimos, T.E. - "Optical spectra and relaxation of $\mathrm{Cr}^{3+}$ ion in $\mathrm{YAlO}_{3}$ "- J. Appl. Phys., 45(2), 810-816, 1974.

[57] Marfunin, A. S. - Spectroscopy, Luminescence and Radiation Centers in Minerals, Springer Verlag, Cap.3, pág.83, 1979.

[58] Xu, J.; Shi, K.; Xiong, G. and Xu, X. - "The vibrational relaxation processes in $\mathrm{BeAl}_{2} \mathrm{O}_{4}: \mathrm{Cr}^{3+}$ "- J. Lumin., 40 \& 41, 611-612, 1988.

[59] Shand, M.L. and Jenssen, H.P. - "Temperature dependence of the excited state absorption of alexandrite"- IEEE J. Quantum Electron., QE-19(3), 480-483, 1983.

[60] Suchocki, A. B.; Gilliland, G. D., Powell, R.C. and Bowen, J.M. "Spectroscopic properties of alexandrite crystals II"- J. Lumin., 37, 29-37, 1987.

[61] Vergara, I.; Sole, J.G.; Hoyos, M.A. and Calderon, T. - "Fluorescence properties of $\mathrm{Cr}^{3+}$ in natural eosphorite crystals"- Solid St. Commun., 76(3), 289293, 1990. 
[62] Sun, T.; Zhang, Z.Y.; Grattan, K.T.V.; Palmer, A. W. and Collins,S.F."Analysis of the double exponential behavior in alexandrite for optical temperature sensing applications"- Rev. Sci. Instrumen., 68(9), 3442-3446, 1997

[63] Formoso, M.L.L.; Trescases, J.J.; Dutra, C.V. e Gomes, C.B. - Técnicas Analíticas instrumentais aplicadas à geologia, Editora Edgard Blucher Ltda, 1984.

[64] Chinaglia, C.R. - Apostila de Introdução à microscopia eletrônica de Varredura e microanálise, CCDM-UFSCar, capítulo 2, 1997.

[65] Nascente, P.A.P.; Bolfarini, C. e Corrêa, C.A . - Simpósio sobre a ciência e engenharia de materiais no Mercosul, Curso 1: caracterização microestrutural de materiais, UFSCar, 1998.

[66] Novailhat, A; Perrenoud, R.; Aegerter,M.A and Rossel, J. - J. Lumin., 6, 245, 1973.

[67] Hernandez, J.A.; Cory, W.K.and Rubio, J.O. - "A non-destructive method for determining the $E u^{2+}$ concentration in the alkali chlorides"- Japn. J. Appl. Phys., 18(3), 533-538, 1979.

[68] Lumb, M. S. - Luminescence Spectroscopy - Academic Press, London, cap.3, 1978.

[69] Castro, A. C.- Tese de Doutorado: Espectroscopia óptica de aglomerados $\mathrm{Yb}^{2+} / \mathrm{CN} / \mathrm{OCN}$ em halogenetos de potássio- IFSC/DFCM, São Carlos, 1998.

[70] Oliveira, L. - Tese de Doutorado: Produção e Caracterização de filmes de $\mathrm{KCl}$ e $\mathrm{KBr}$ impurificados com íons $\mathrm{Cu}^{+}$- IFSC, São Carlos, 1994.

[71] Siu Li, M.; Sousa, M. and Lutty, F. - "Off-center $\mathrm{Cu}^{+}$ions in Potassium Halides Studied with ionic Thermocurrents" - Phys. Rev. B, 7(10), 4677-4681, 1973. 
[72] Shimizu, H.; Kitano, K. And Nakayama, K. - "Thermally stimulated depolarization current study on the glass transition of a liquid crystalline copolyester"- Jpn. J. Appl. Phys., 35, L231-L233, 1996.

[73] Glowacki, I. and Ulanski, J. - "Simultaneous measurements of thermoluminescence and thermally, stimulated currents in poly $(N$ vinylcarbazole)/polycarbonate blends"- J. Appl. Phys., 78 (2), 1019-1025, 1995.

[74] Vianna, C. A.P.; Valério, M.E.G. and Blak, A. R. - "The role played by hydrogen in the ionic thermocurrents of beryl"- Rad. Eff. \& Def. Solids, 119-121, 603-608, 1991.

[75] Scalvi, L.V.A.; Oliveira, L. and Siu Li, M. - "Light-induced relaxing dipoles in n-type $A l_{x} G a_{l-x} A s$ "- Phys. Rev. B, 51 (19), 13864-13867, 1995.

[76] Lutty, F. - "Orientational defect relaxation by classical and tunneling processes"- J. Physique, 34 (11-12), C9-49-59, 1973.

[77] Kittel, C. - Introdução a fisica do Estado sólido, $5^{\mathrm{a}}$ edição, Editora Guanabara Dois, 1978.

[78] Chen, R and Kirsh, Y. - Analysis of thermally stimulated processes, Pergamon Press, Oxford, 1981.

[79] Unger, S. and Perlman, M.M. - "Dipole relaxation, aggregation, and X-Ray effects in $\mathrm{KCl}$ doped with $\mathrm{Eu}^{++}, \mathrm{Yb}^{++}$, or $\mathrm{Sm}^{++}$"- Phys. Rev. B, 6 (10), 3973-3981, 1972.

[80] Prakash, J.; Nishad, A; and Rahul, K. - "Apperance of Depolarization current in ITC measurements"- Japn. J. Appl. Phys., 25(5), 701-704, 1986.

[81] Vila, R.; Ibarra, A and Castro, M.J. - "Improvements of Prakash's method for analyzing ITC peaks"- Phys. Stat. Sol. (a), 105, 601-607, 1988. 
[82] Maeta, S. and Yoshida, F. - "On the determination of the trap depths from thermally stimulated currents II"- Japn. J. Appl. Phys., 28 (9), 1712-1717, 1989.

[83] Ferreira, G.F.L.; Figueiredo, M.T.; Fedosov, S.N. and Giacometti, J.A. "Thermally Stimulated polarization in dye doped polystyrene explained via the Williams- Watts $\alpha$ - $\beta$ relaxation model"- J. Phys. D.: Appl. Phys., 31, 2051-2056, 1998.

[84] Teyssèdre, G. and Lacabane, C. - "Some considerations about the analysis of thermostimulated depolarization peaks"- J. Phys. D: App. Phys., 28, 1478-1487, 1995.

[85] Halpern. V. - "The significance of temperature-dependent distributions of activation energies”- J. Phys.: Condens. Matter, 9, 5479-5485, 1997.

[86] Halpern, V. - "The interpretation of thermally stimulated currents obtained by the thermal slicing technique" - J. Phys. D: Appl. Phys., 30, 458-465, 1997.

[87] Faubert, F. and Sanchez, M. - "Numerical decomposition of a complex thermostimulated depolarization current spectrum in single time relaxation peaks"J. Appl. Phys., 84 (3), 1541-1545, 1998.

[88] JCPDS - International Centre for Diffraction Data, 81-1049, 1998.

[89] Obtido no endereço eletrônico: http://.bam.de.a/a_v/v_1/powder/e_cell.html [90] Zhang, Z.; Grattan, K.T.V. and Palmer, A.W. - "Thermal characteristics of alexandrite fluorescence decay at high temperatures, induced by a visible laser diode emission"- J. Appl. Phys., 73(7), 3493-3498, 1993.

[91] Underhill, A.E. and Billing, D.E. - "Calculation of the Racah parameter B for Nickel (II) and cobalt(II) compounds"- Nature, 210, 834-835, 1966.

[92] Balhaussen, C.J. - Introduction to ligand field theory, cap. 10, Mc Graw-Hill Book Company, 1962. 
[93] Index to data files on the mineral spectroscopy server - Endereço eletrônico: http://minerals.gps.caltech.edu/files/visible/mica/index.htm.

[94] Stroud, C.E.; Stencel, J.M. and Todd Jr, L.T. - "Infrared spectra of cathodochromic sodalite"- J. Phys. Chem., 83 (18), 2378-2382, 1979.

[95] Schepler, K.L. - "Fluorescence of inversion site $\mathrm{Cr}^{3+}$ ions in alexandrite"- J. Appl. Phys., 56(5), 1314-1318, 1984.

[96] Barry, W.R. and Troup, G.J.- "EPR of $\mathrm{Fe}^{3+}$ ions in chrysoberyl"- phys. stat. sol., 38, 229-234, 1970.

[97] Martini, M. and Meinardi, F. - "Thermally stimulated luminescence: new perspectives in the study of defects in solids"- La Rivista del Nuovo Cim. 2(8), 1-71, 1977. 